ADVANCED STEEL CONSTRUCTION

An International Journal

Volume 10 Number 1

March 2014

CONTENTS

Technical Papers

Investigation of the Behavior of Weakened and Strengthened Steel Column-Beam Connections under Seismic Effects

Ali Koken and E. Tuba Hatipoglu

Steady State Response and Stability of an Elastically Restrained Tapered Beam

M.S. Abdel-Jaber, A.A. Al-Qaisia, M. Abdel-Jaber and R.G. Beale

Ductility Requirements for the Design of Bolted Lap Shear Connections in Bearing J. Henriques, J-P. Jaspart and L. Simões da Silva

A Parametric Study on Seismic Characteristics of Cold-Formed Steel Shear Walls by Finite Element Modeling

S. Hatami, A. Rahmani, A. Parvaneh and H.R. Ronagh

Experimental Study on Fire Resistance of Square Hollow Section (SHS) Tubular T-Joint under Axial Compression

J. Yang, Y.B. Shao and C. Chen

Seismic Response of Straight Line Type and Broken Line Type Transmission Lines Subjected to Non-Uniform Seismic Excitations

L. Tian, R.S. Ma, H.N. Li and P. Zhang

Experimental Study of Concrete-Filled Steel Tubular Arches with Corrugated Steel Webs Jing Gao, Jiazhan Su, Yong Xia and Baochun Chen

Announcement for eurosteel2014

Announcement for ICASS'2015

Copyright $\odot 2014$ by :

The Hong Kong Institute of Steel Construction

Website: $h$ ttp://www.hkisc.org

ISSN 1816-112X

Science Citation Index Expanded, Materials Science Citation Index and ISI Alerting

Cover: Flower Dome Conservatories @Gardens by The Bay, Singapore

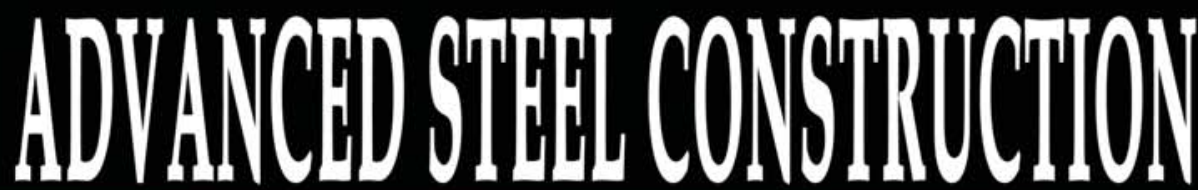

an International ]ounal ISSN 1816-112X

Volume 10 Number 1

March 2014

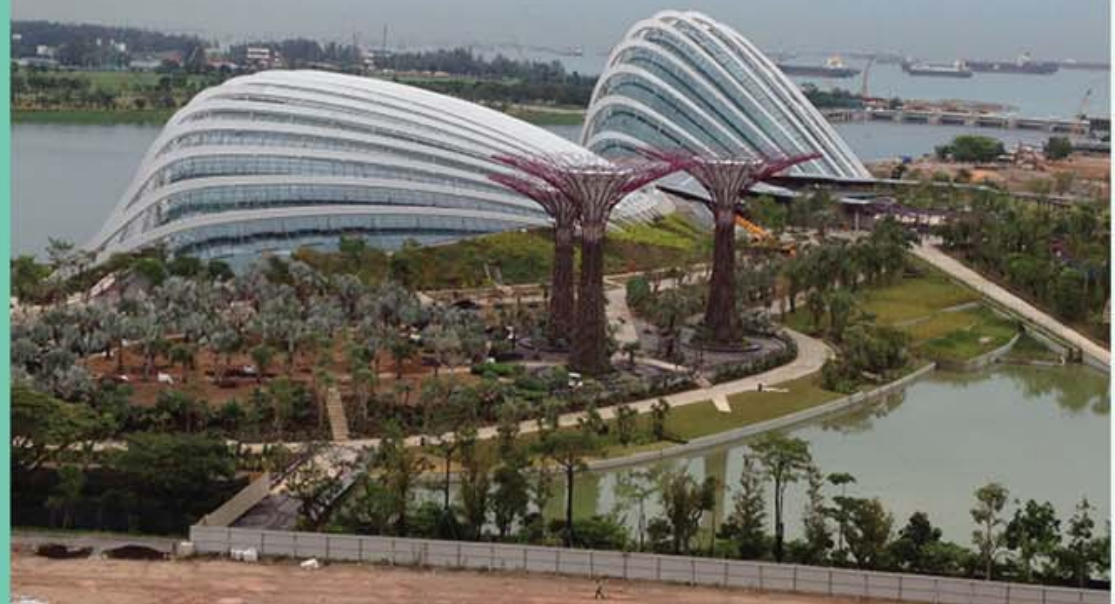

Editors-in-Chief

S.L. Chan, The Hong Kong Polytechnic University, Hong Kong

W.F. Chen, University of Hawaii at Manoa, USA

R. Zandonini, Trento University, Italy 


\section{Advanced Steel}

ISSN 1816-112X

Science Citation Index Expanded, Materials Science Citation Index and ISI Alerting

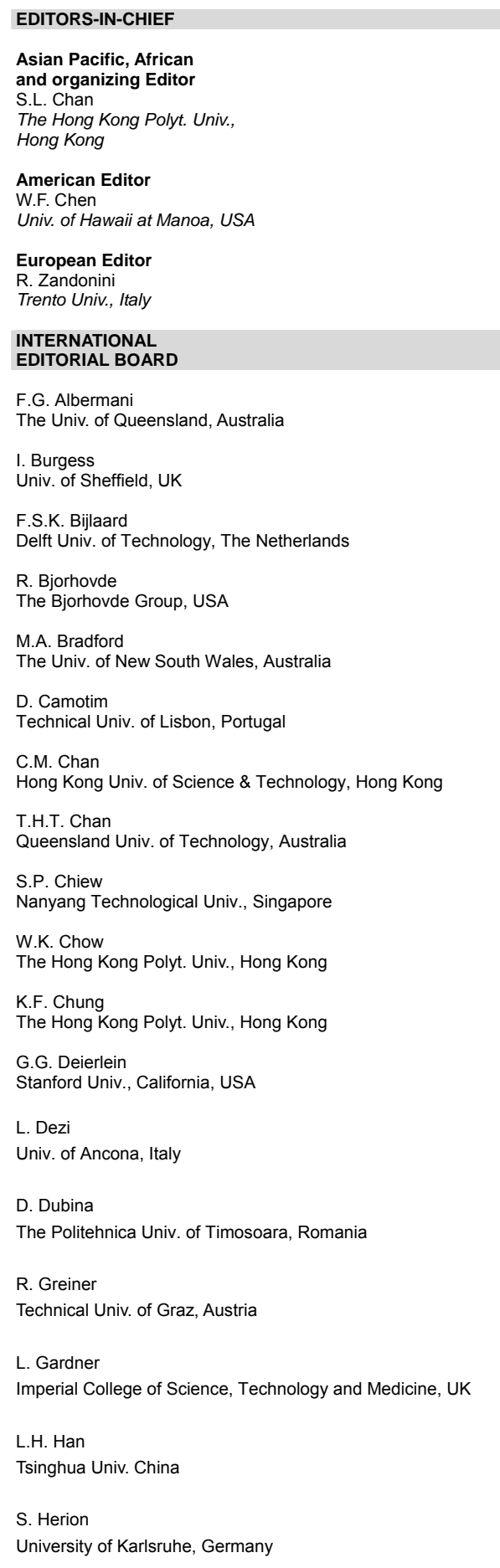

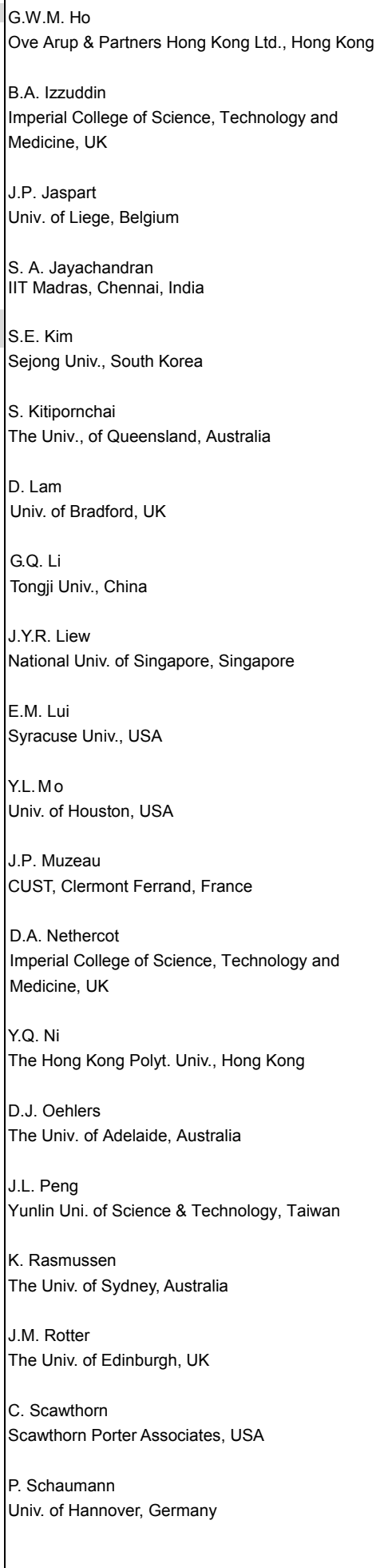

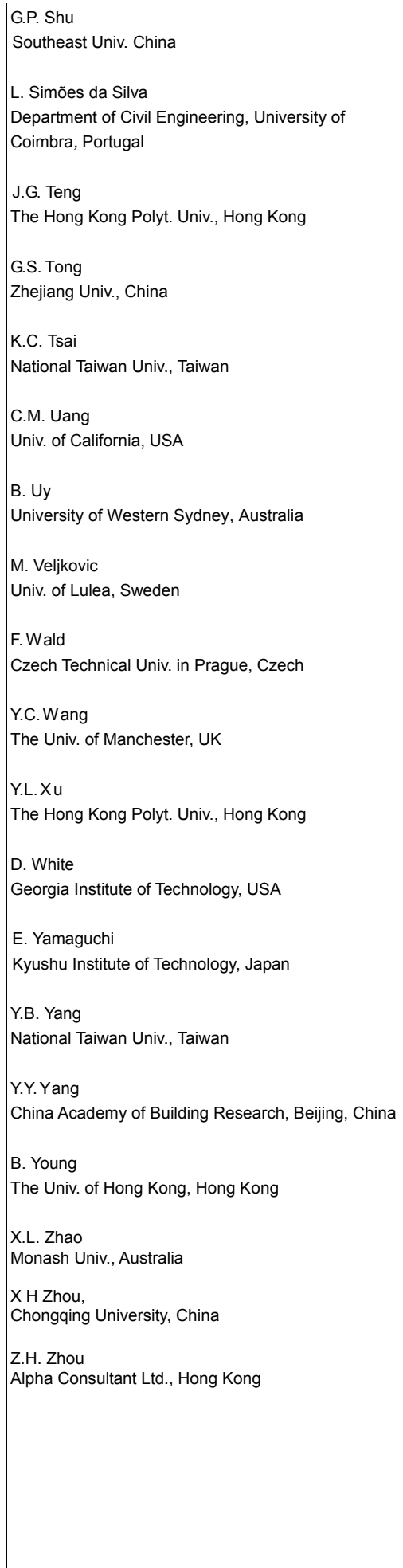

Cover: Flower Dome Conservatories @Gardens by The Bay, Singapore

The two arch structures behind the big trees. Grand Award of IStructE-UK/Structural Division-HKIE 2013. Stability design by second-order direct analysis without effective length, jointly by The National University of Singapore and The Hong Kong Polytechnic University 


\begin{tabular}{ll}
\hline \hline & General Information \\
& Advanced Steel Construction, an international journal \\
\hline \hline Aims and scope
\end{tabular}

\section{Aims and scope}

The International Journal of Advanced Steel Construction provides a platform for the publication and rapid dissemination of ori ginal and up-to-date research and tec hnological developments in steel c onstruction, design and anal ysis. Scope of research $p$ apers published in this journal includes but is not limite $d$ to theor etical and expe rimental research on elements, assemblages, sy stems, material, design philosophy and codification, standards, fabrication, projects of innov ative nature an d computer tech niques. The journal is specifically $t$ ailored to channel the e xchange of tec hnological know-ho $w$ bet ween $r$ esearchers an d practitioners. Contributions from all aspects related to the recent developments of advanced steel construction are welcome.

\section{Instructions to authors}

Submission of the manuscript. Authors may submit double-spaced manuscripts preferably in MS Word by emailing to one of the chief editors as follows for arrangement of review. Alternatively papers can be submitted on a diskette to one of the chief editors.

Asian Pacific, African and organizing editor: Professor S.L. Chan, Email: ceslchan@polyu.edu.hk

American editor :

European editor:

Professor S.L. Chan, Email: ceslchan@polyu.edu.

Professor R. Zandonini, Email: riccardo_zandonini@ing.unitn.it

All manuscripts submitted to the journal are recommended to accompany with a list of four potential reviewers suggested by the author(s). This list should include the complete name, add ress, telephone and fax num bers, em ail address, and at least five keywords that identify the expertise of each reviewer. This scheme will improve the process of review.

Style of manuscript

General. Author(s) should provide full postal and email addresses and fax number for correspondence. The manuscript including abstract, keywords, references, figures and tables should be in English with pages numbered and typed with double line spacing on single side of A4 or letter-sized paper. The front page of the article should contain:

a) a short title (reflecting the content of the paper);

b) all the name(s) and postal and email addresses of author(s) specifying the author to whom correspondence and proofs should be sent;

c) an abstract of $100-200$ words; and

d) 5 to 8 keywords.

The paper must contain an introduction and a conclusion. The length of paper should not exceed 25 journal pages (approximately 15,000 words equivalents).

Tables and figures. Tables and figures including photographs should be typed, numbered consecutively in Arabic numerals and with short titles. They should be referred in the text as Figure 1, Table 2, etc. Originally drawn figures and photographs should be provided in a form suitable for photographic reproduction and reduction in the journal.

Mathematical expressions and units. The Systeme Internationale (SI) should be followed whenever possible. The numbers identifying the displayed mathematical expression should be referred to in the text as Eq. (1), Eq. (2).

References. References to published literature should be referred in the text, in the order of citation with Arabic numerals, by the last name(s) of the author(s) (e.g. Zandonini and Zanon [3]) or if more than three authors (e.g. Zandonini et al. [4]). References should be in English $w$ ith occasional allow ance of 1-2 e xceptional referenc es in local lang uages and $r$ eflect the curren $t$ state-of-technology. Journal titles should be abbreviated in the style of the Word List of Scientific Periodicals. References should be cited in the following style $[1,2,3]$.

Journal: [1] Chen, W.F. and Kishi, N., "Semi- rigid Steel Beam-to-column Connections, Data Base and Modellin g", Journal of Structural Engineering, ASCE, 1989, Vol. 115, No. 1, pp. 105-119.

Book: [2] Chan, S.L. and Chui, P.P.T., "Non-linear Static and Cyclic Analysis of Semi-rigid Steel Frames", Elsevier Science, 2000.

Proceedings: [3] Zandonini, R. a nd Zanon, P., "Experimental Analy sis of S teel Beams with Semi -rigid Joint s", Proceedings of International Conference on Advances in Steel Structures, Hong Kong, 1996, Vol. 1, pp. 356-364.

Proofs. Proof will be sent to the $c$ orresponding author to correct any typesetting errors. Alternations to the original manuscript at this stage will not be accepted. Proofs should be returned within 48 hours of receipt by Express Mail, Fax or Email.

Copyright. Submission of an article to "Advanced Steel Construction" implies that it presents the original and unpublished work, and not under consideration for publication nor published elsewhere. On acceptance of a manuscript submitted, the copyright thereof is transferred to th e publisher b y the Transfer of $C$ opyright Ag reement and upon t he acceptance of publication for the $p$ apers, the corresponding author must sign the form for Transfer of Copyright.

Permission. Quoting from this journal is granted provided that the customary acknowledgement is given to the source.

Page charge and Reprints. There will be no page charges if the length of paper is within the limit of 25 journal pages. A total of 30 free offprints will be supplied free of charge to the corresponding author. Purchasing orders for additional offprints can be made on order forms which will be sent to the authors. These instructions can be obtained at the Hong Kong Institute of Steel Construction, Journal website: http://www.hkisc.org

The International Journal of Advanced Steel Construction is published quarterly by learnt society, The Hong Kong Ins titute of Steel Construction, c/o Department of Civil \& Environmental Engineering, The Hong Kong Polytechnic University, Hung Hom, Kowloon, Hong Kong.

Disclaimer. No responsibility is assumed for a ny injury and / or damage to per sons or property as a matter of products liability, negligence or otherwise, or from any use or operation of any methods, products, instructions or ideas contained in the material herein.

Subscription inquiries and change of address. Address all subscription inquiries and correspondence to Member Records, IJASC. Notify an address change as soon as possible. All communications should include both old and new addresses with zip codes and be accompanied by a mailing label from a recent issue. Allow six weeks for all changes to become effective.

The Hong Kong Institute of Steel Construction

HKISC

c/o Department of Civil and Environmental Engineering,

The Hong Kong Polytechnic University,

Hunghom, Kowloon, Hong Kong, China.

Tel: 852- 27666047 Fax: 852- 23346389

Email: ces/chan@polyu.edu.hk Website: http://www.hkisc.org/

ISSN 1816-112X

Science Citation Index Expanded, Materials Science Citation Index and ISI Alerting

Copyright $\odot 2014$ by:

The Hong Kong Institute of Steel Construction. 


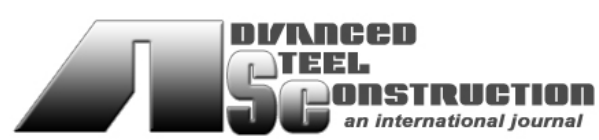

ISSN 1816-112X

Science Citation Index Expanded, Materials Science Citation Index and ISI Alerting

\section{EDITORS-IN-CHIEF}

Asian Pacific, African and organizing Editor

S.L. Chan

The Hong Kong Polyt. Univ., Hong Kong

Email: ceslchan@polyu.edu.hk

\section{American Editor}

W.F. Chen

Univ. of Hawaii at Manoa, USA

Email:waifah@hawaii.edu

\section{European Editor}

R. Zandonini

Trento Univ., Italy

Email: riccardo.zandonini@ing.unitn.it

\section{Advanced Steel Construction an international journal}

VOLUME 10 NUMBER 1

MARCH 2014

Technical Papers

Investigation of the Behavior of Weakened and Strengthened

1

Steel Column-Beam Connections under Seismic Effects

Ali Koken and E. Tuba Hatipoglu

Steady State Response and Stability of an Elastically Restrained Tapered Beam

M.S. Abdel-Jaber, A.A. Al-Qaisia, M. Abdel-Jaber and R.G. Beale

Ductility Requirements for the Design of Bolted Lap Shear

Connections in Bearing

J. Henriques, J-P. Jaspart and L. Simões da Silva

A Parametric Study on Seismic Characteristics of Cold-Formed

Steel Shear Walls by Finite Element Modeling

S. Hatami, A. Rahmani, A. Parvaneh and H.R. Ronagh

Experimental Study on Fire Resistance of Square Hollow Section 72

(SHS) Tubular T-Joint under Axial Compression

J. Yang, Y.B. Shao and C. Chen

Seismic Response of Straight Line Type and Broken Line Type

Transmission Lines Subjected to Non-Uniform Seismic

Excitations

L. Tian, R.S. Ma, H.N. Li and P. Zhang

Experimental Study of Concrete-Filled Steel Tubular Arches with 99 Corrugated Steel Webs

Jing Gao, Jiazhan Su, Yong Xia and Baochun Chen

Announcement for eurosteel2014

Announcement for ICASS’2015 


\title{
INVESTIGATION OF THE BEHAVIOR OF WEAKENED AND STRENGTHENED STEEL COLUMN-BEAM CONNECTIONS UNDER SEISMIC EFFECTS
}

\author{
Ali Koken ${ }^{1, *}$ and E. Tuba Hatipoglu ${ }^{2}$ \\ ${ }^{1}$ Assistant Professor, Department of Civil Engineering, Engineering Faculty, Selcuk University, Konya, Turkey \\ ${ }^{2}$ Civil Engineer, Konya Provincial Administration, Turkey \\ *(Corresponding author: E-mail: akoken@selcuk.edu.tr)
}

Received: 14 March 2012; Revised: 4 August 2012; Accepted: 3 January 2013

\begin{abstract}
Newly developed solution techniques were used for the beam to column connections of the steel structures after the 1994 Northridge and 1995 Kobe earthquakes. Two significant methods, the use of reduced beam sections and strengthened beam to column connections, are the methods most frequently studied in recent years.

In this study, an experimental procedure was performed to prevent the damages occurring at the beam to column connections of the buildings during an earthquake. For this purpose, four test specimens of beam to column connections were produced. While the first specimen was a strengthened beam to column connection, the second and third were weakened specimens with $40 \%$ and $45 \%$ ratios, respectively. Additionally, an extra reference specimen (the fourth) was produced to compare the test results. Additionally, a calculation of the analytical force and moment capacities of the test specimens, and the experimental and analytical results were evaluated. The use of reduced beam sections and strengthened beam to column connections favorably affected the behavior of the frame system in a manner that the failure formation occurred not at the connection members but at the end-sections of the beams.
\end{abstract}

Keywords: Steel frame, steel beam to column connection, seismic behavior of beam to column connections, weakened beam cross-section.

\section{INTRODUCTION}

Unexpected failures were observed at the beam to column connections of the buildings after the Northridge (1994) and Hyogo-ken Nanbu, Kobe (1995) earthquakes (Hatipoglu [1]).

Rigorous post-earthquake investigations have revealed many factors contributing to the failure. The high stress concentration at the welded web and flanges and the vulnerability of the connection to the large ductility demand are considered to be two critical factors causing such failures (Pachoumis et al. [2], FEMA 350 [3], Engelhardt et al. [4], Tsai et al. [5], Plumier [6]).

A number of improved beam-to-column connection design strategies have been proposed (FEMA 350 [3]), many of which have shown to exhibit satisfactory levels of ductility in numerous tests. Two key concepts have been developed to provide a highly ductile response and reliable performance, and strengthening the connection and/or weakening the beam framing into the connection to avoid damages to the respective column (Pachoumis et al. [7]).

Reduced beam section connections have been shown to exhibit satisfactory levels of ductility in numerous tests and has found broad acceptance (Bruneau et al. [9]; Chen et al. [10]; Plumier [11]; Zekioglu et al. [12]; Engelhardt et al. [13]; Jones et al. [14]; Uang et al. [15]; Lee et al. [16]). In reduced beam section connections, a portion of the beam flanges at a short distance from the column are strategically trimmed to remote stable yielding at the reduced section, and to effectively protect the more vulnerable beam-to-column groove welded joints (Lee et al. [8]). 
Some design parameters are recommended by FEMA 350 [3] and FEMA 351 [17] regarding the location and reduction rate of a reduced beam section, based on the local performance of tested beam-to-column assemblies. In Europe, also, following the spirit of the above-mentioned recommendations, in Eurocode 8, Part 3, the designs of such connections are presented. The values for the geometrical parameters recommended in Eurocode 8 are also recommended in FEMA 350 [3], due to the lack of experimental studies on European profiles. Thus, the effectiveness of these recommendations is questionable. Recent experimental research (Pachoumis et al. [2]) confirmed the need for readjustment of the geometrical characteristics for the design of a radius-cut reduced beam section.

Although the concept of weakening the beam to strengthen the steel frame can be thought as meaningless, experimental studies on this subject presented a high level of performance for this type of beam to column connection (Hatipoglu [1]).

In this study, three test specimens were produced and tested under reversed-cyclic loading to prevent the problems experienced at the beam to column connections of the typical forehead-panel beam to column connection. While the first specimen had beam strengthening (N4), the other two had $40 \%$ (N2) and 45\% (N3) circular weakening in accordance with FEMA 350 [3] and Eurocode 8, respectively. Additionally, a reference specimen (N1) was produced and tested to compare the results. At the end of the tests, the obtained values were evaluated and compared with each other (Hatipoglu [1]).

\section{EXPERIMENTAL PROGRAM}

\subsection{Method}

In this study, four beam to column connections with different connection characteristics were produced and tested under reversed-cyclic vertical loads applied at the beam ends. The required loading and displacement data were recorded during the tests using a computer-aided data acquisition system.

\section{$2.2 \quad$ The Material and Cross-section Characteristics}

In this study, four different test specimens produced in the laboratory were tested under reversed-cyclic vertical loading applied at the beam-ends. The columns (IPE400 profile) had 400 $\mathrm{mm}$ height and $180 \mathrm{~mm}$ width, while the column flange and web had the dimensions of $13.5 \mathrm{~mm}$ and $8.6 \mathrm{~mm}$, respectively. The beams (IPE270 profile) had a height of $270 \mathrm{~mm}$ and a width of 135 $\mathrm{mm}$, with a $10.2 \mathrm{~mm}$ beam flange and a $6.6 \mathrm{~mm}$ beam web.

The coupon specimens used for the tests, which were obtained by cutting the profiles to determine the mechanical properties of the profiles, were subjected to an axial tensile test. The mechanical properties obtained as a result of the tensile tests are given in Table 1 (Hatipoglu [1]). 
Table 1. Mechanical Characteristics of IPE Profiles Used for the Tests

\begin{tabular}{|lll|c|}
\hline \multicolumn{4}{|c|}{ Mechanical Characteristics } \\
\hline Yield stress & $\left(\mathrm{f}_{\mathrm{y}}\right)$ & $\left(\mathrm{N} / \mathrm{mm}^{2}\right)$ & 302 \\
\hline Ultimate stress & $\left(\mathrm{f}_{\mathrm{u}}\right)$ & $\left(\mathrm{N} / \mathrm{mm}^{2}\right)$ & 448 \\
\hline Young's modulus & $(\mathrm{E})$ & $\left(\mathrm{N} / \mathrm{mm}^{2}\right)$ & 203000 \\
\hline
\end{tabular}

\section{3}

The Characteristics of the Test Specimens

In this study, the aforementioned four specimens having different cross-sections and beam to column connections were tested under reversed-cyclic vertical loading. The first specimen was the reference specimen (N1), whose beam cross-section was not subjected to any weakening or strengthening process. The beam cross-sections of the second and third specimens were weakened circularly in accordance with FEMA 350 [3], Eurocode 8 [18], and the Turkish Earthquake Code [19], in a manner that the top and bottom flanges of the second specimen (N2) were subjected to $40 \%$ weakening, while the third (N3) had 45\% reduction. Finally, the fourth specimen (N4) was strengthened using a stiffness panel at the beam-end (Hatipoglu [1]). The properties of the test specimens and the beam to column connection photographs are presented in Figure 1.

Test specimens

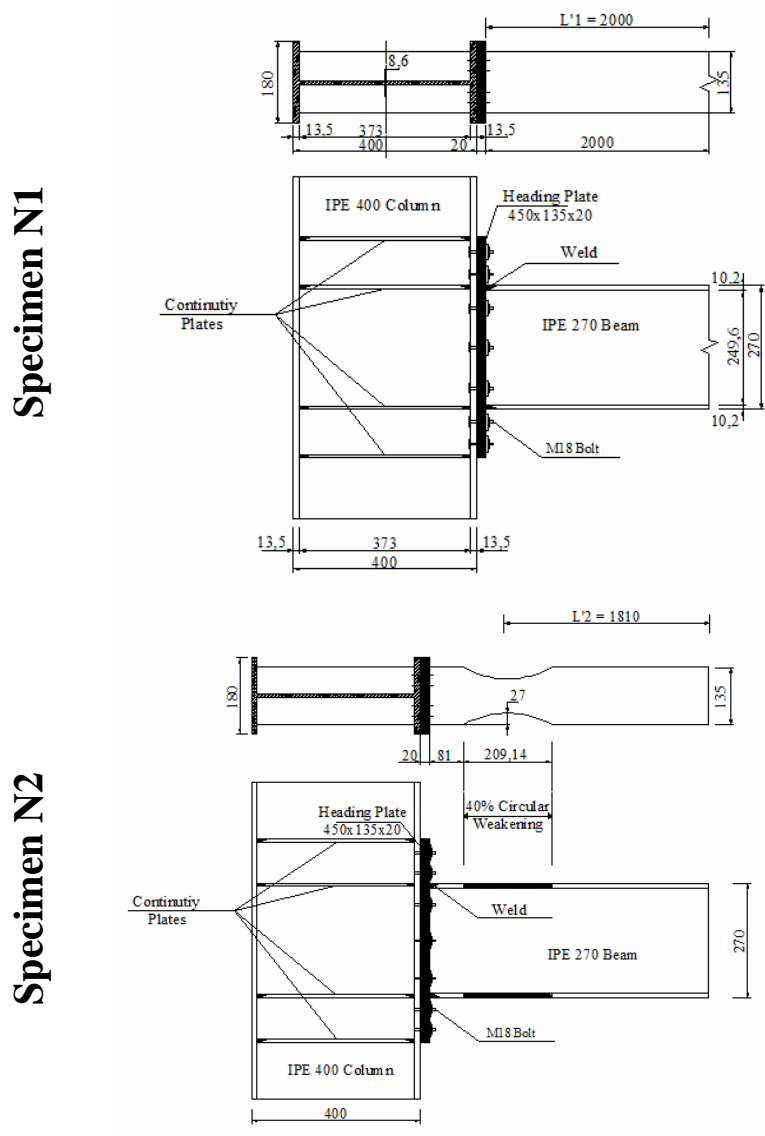

Beam-to-column connection
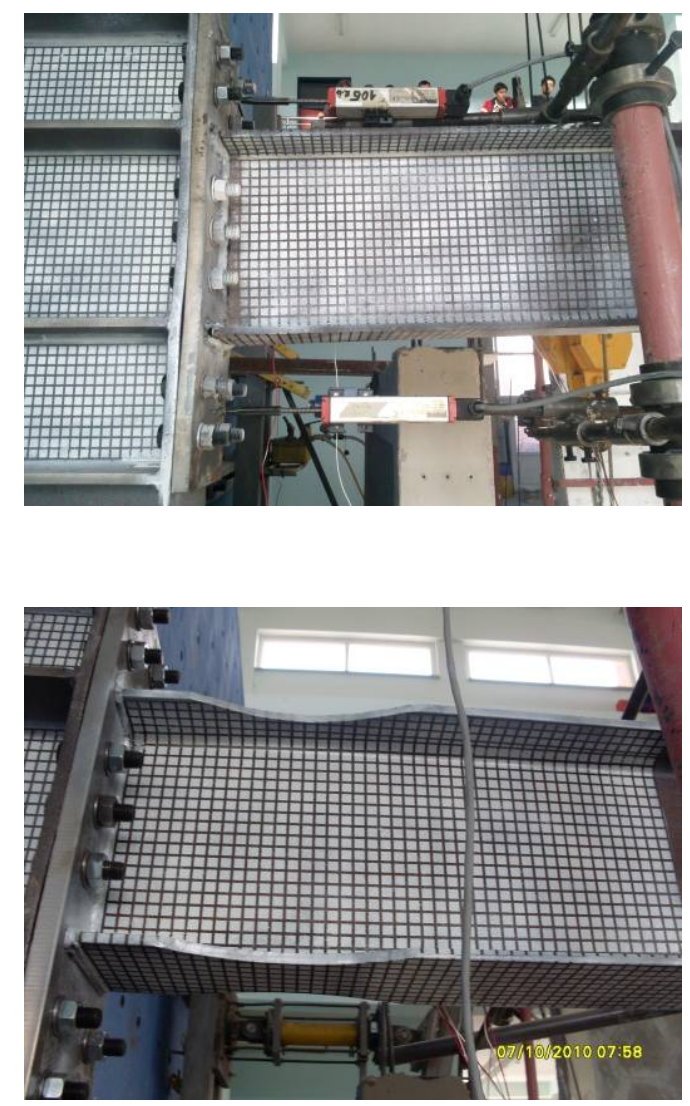

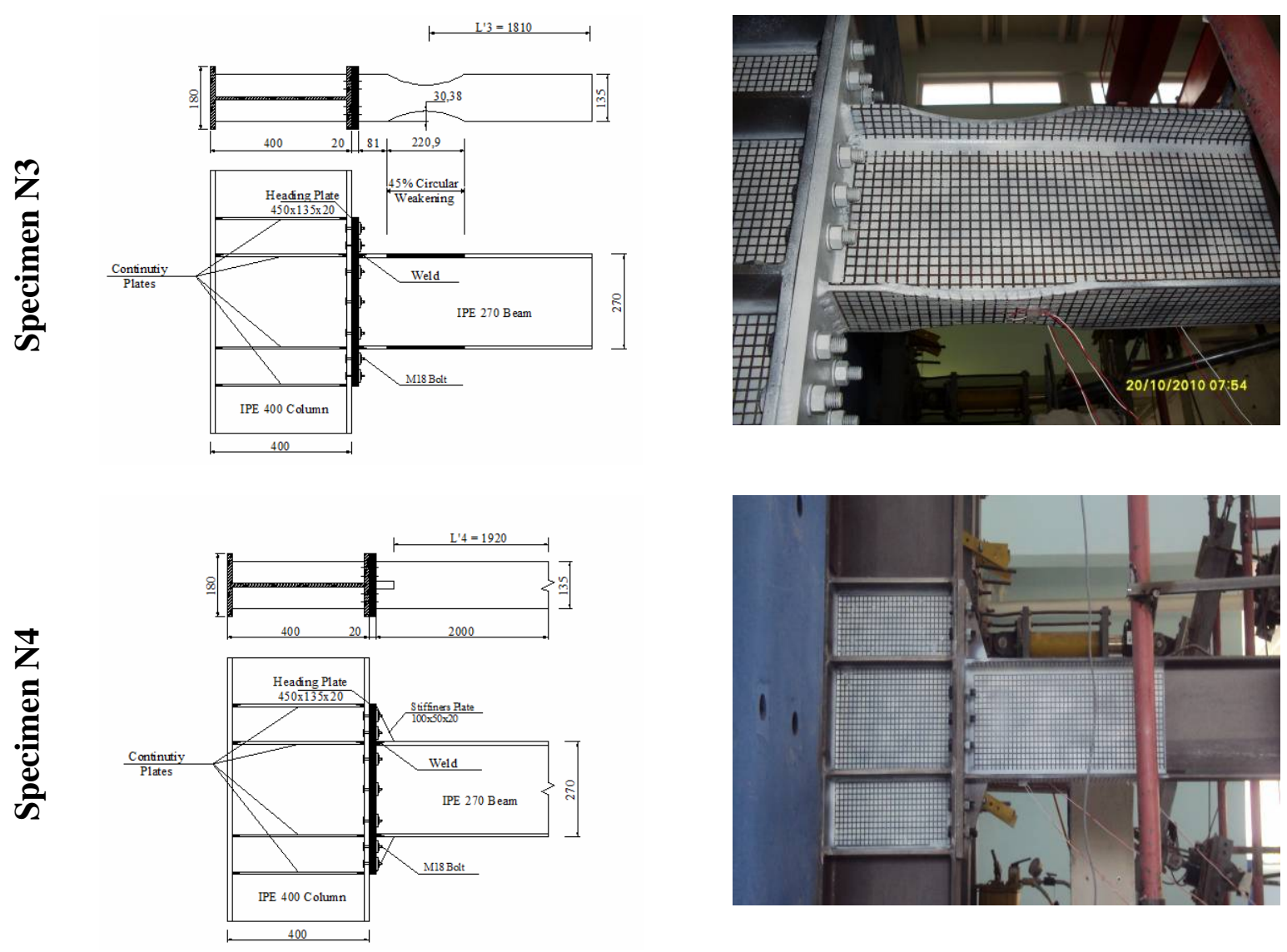

Figure 1. Properties (in mm) of the Test Specimens and Beam to Column Connections

\section{4}

\section{Experimental Set-up}

Four different beam to column connection specimens, which were designed in a manner that they could be loaded from the beam-ends, were tested in this study. Due to the fact that the $3 \mathrm{~m}$ column of the specimen was fixed to the rigid wall securely, any rotation or shifting at the supports of the system was prevented. Furthermore, the $2 \mathrm{~m}$ beam was connected to the mid-span of the column with a $63 \times 20 \times 3 \mathrm{~cm}$ flange plate using filled welding and M18 bolts. During the formation of the connection, maximum welding thickness was applied to prevent failure not at the welding site, but at the beam. Continuity plates and stiffness plates were used at the beam to column connection to strengthen the column panel region. Additionally, a reversed cyclic load was applied at the beam-end using a hydraulic jack and a pump, and recorded by the aid of a load cell. The test mechanism can be seen in Figure 2. 


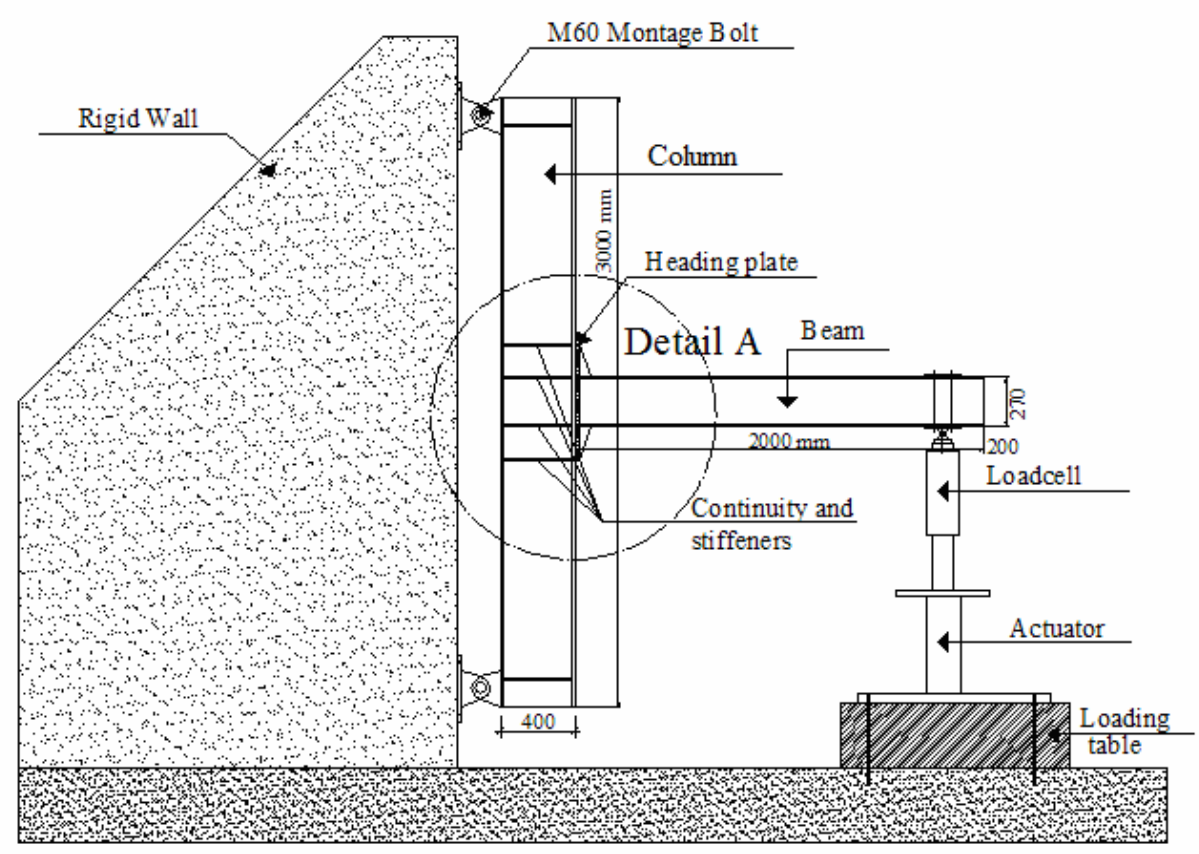

Figure 2. Experimental Set-up

\subsection{Measurement Mechanism and Loading Program Used in the Tests}

The measuring system of the test mechanism was built taking the test data for each beam to column connection from the same points of the specimens to the greatest extent possible. The displacement measurements were performed with the assistance of four linear variable differential transformers to understand the behavior of the beam to column connection by determining the displacements at the beam-ends and at the mid-points of the columns. Additionally, the measurement of force (F) applied by a hydraulic jack was recorded using a load cell (Figure 3).

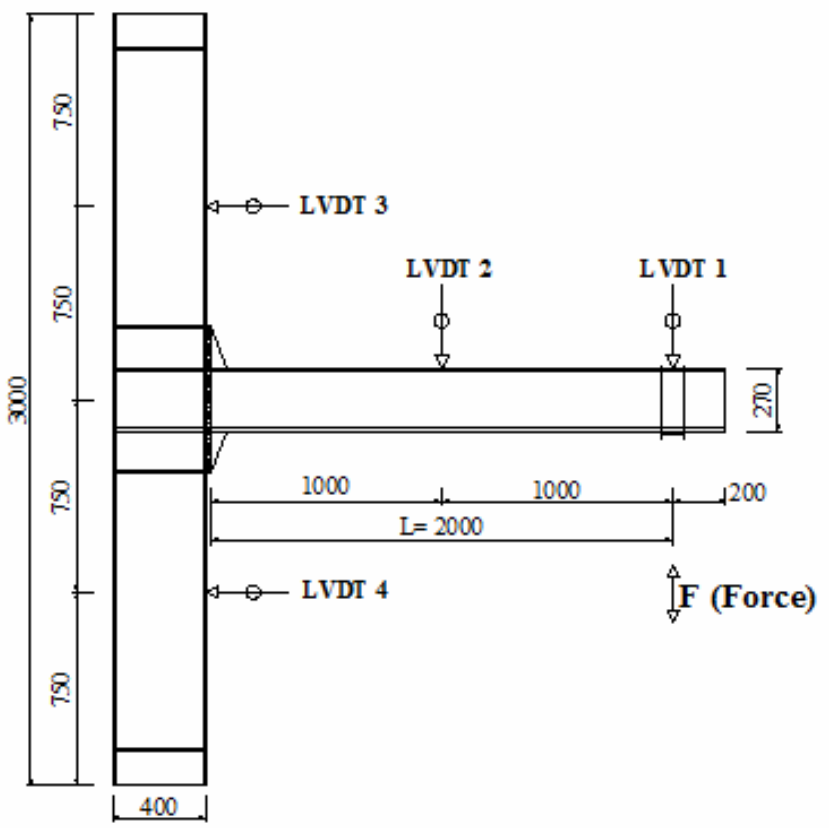

Figure 3. Measurement Mechanism Used in the Tests (in mm)

The loading program used in the tests is given in Table 2 where the rotation $(\Phi)$ is calculated dividing the displacement $(\delta)$ measured at the beam-end during the test by LVDT-1 to the beam span length $(\mathrm{L}=2000 \mathrm{~mm})$. 
Table 2. Loading Protocol

\begin{tabular}{|c|c|c|c|}
\hline Load step & $\begin{array}{c}\text { Rotation }(\Phi=\delta / L) \\
(\text { Radian })\end{array}$ & $\begin{array}{c}\text { Number of cycles } \\
(\mathrm{nj})\end{array}$ & $\begin{array}{c}\text { Displacement }(\delta) \\
(\mathrm{mm})\end{array}$ \\
\hline 1 & 0.00375 & 2 & 7.5 \\
2 & 0.00500 & 2 & 10 \\
3 & 0.00750 & 2 & 15 \\
4 & 0.01000 & 4 & 20 \\
5 & 0.01500 & 2 & 30 \\
6 & 0.02000 & 2 & 40 \\
7 & 0.03000 & 2 & 60 \\
8 & 0.04000 & 2 & 80 \\
9 & 0.05000 & 2 & 100 \\
10 & 0.06000 & & 120 \\
\hline
\end{tabular}

\section{ANALYSIS ON THE EXPERIMENTAL RESULTS}

The experimental results were evaluated in consideration of the properties of the test specimens appropriate to the objective of this study. Therefore, the test specimens were compared to each other in terms of strength envelope, stiffness reduction, and energy consumption capacity (Hatipoglu [1]).

The strength envelopes of the aforementioned specimens are given in Figure 4 where force $(\mathrm{F})$ denotes the force applied at the beam-end using a hydraulic jack and a pump, and recorded by a load cell, and the displacement $(\delta)$ indicates the displacement obtained at the beam-end by LVDT-1 shown in Figure 3.

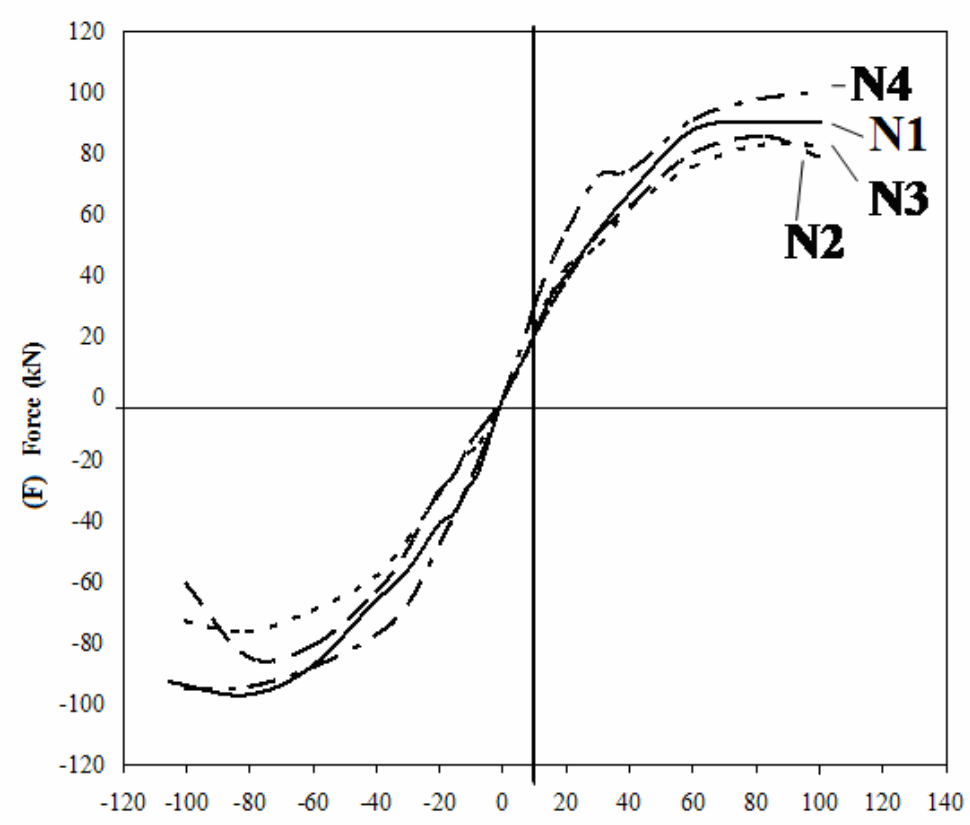

(ס) Displacement (mm)

Figure 4. Strength Envelopes of the Test Specimens 
As seen in Figure 4, the maximum average horizontal load-bearing values were determined as $96.95 \mathrm{kN}(\mathrm{N} 1), 85.48 \mathrm{kN}(\mathrm{N} 2), 82.83 \mathrm{kN}(\mathrm{N} 3)$, and $101.60 \mathrm{kN}(\mathrm{N} 4)$ respectively. When the N1 specimen that was not weakened or strengthened was considered as the reference, the N2 specimen was weakened with $40 \%$, the N3 specimen was weakened with $45 \%$, and the strengthened N4 specimen carried $12 \%$ less, $15 \%$ less and $5 \%$ more load, respectively. The displacement value of $100 \mathrm{~mm}$ and the drift ratio $(\delta / \mathrm{L})$ of 0.05 corresponding to the maximum loading value were reached for all the test specimens. After the boundary states of yielding and buckling were performed at these levels for the beam cross-section, the failure boundary states for the specimens were reached by the ruptures that occurred at the welding of the connection points.

Stiffness degradation diagrams obtained by the tests of the aforementioned specimens are given in Figure 5, where the stiffness value for each cycle was calculated using the following equation in which the forces $\left(\mathrm{F}_{1}, \mathrm{~F}_{2}\right)$ and the displacements $\left(\delta_{1}, \delta_{2}\right)$ were obtained from the Force-Displacement diagram.

Rigidity $=\frac{\left|F_{1}\right|+\left|F_{2}\right|}{\left|\delta_{1}\right|+\left|\delta_{2}\right|}$

The drift ratio was obtained by dividing the displacement $(\delta)$ at the beam-end to the span length $(\mathrm{L}=2000 \mathrm{~m})$ of the beam.

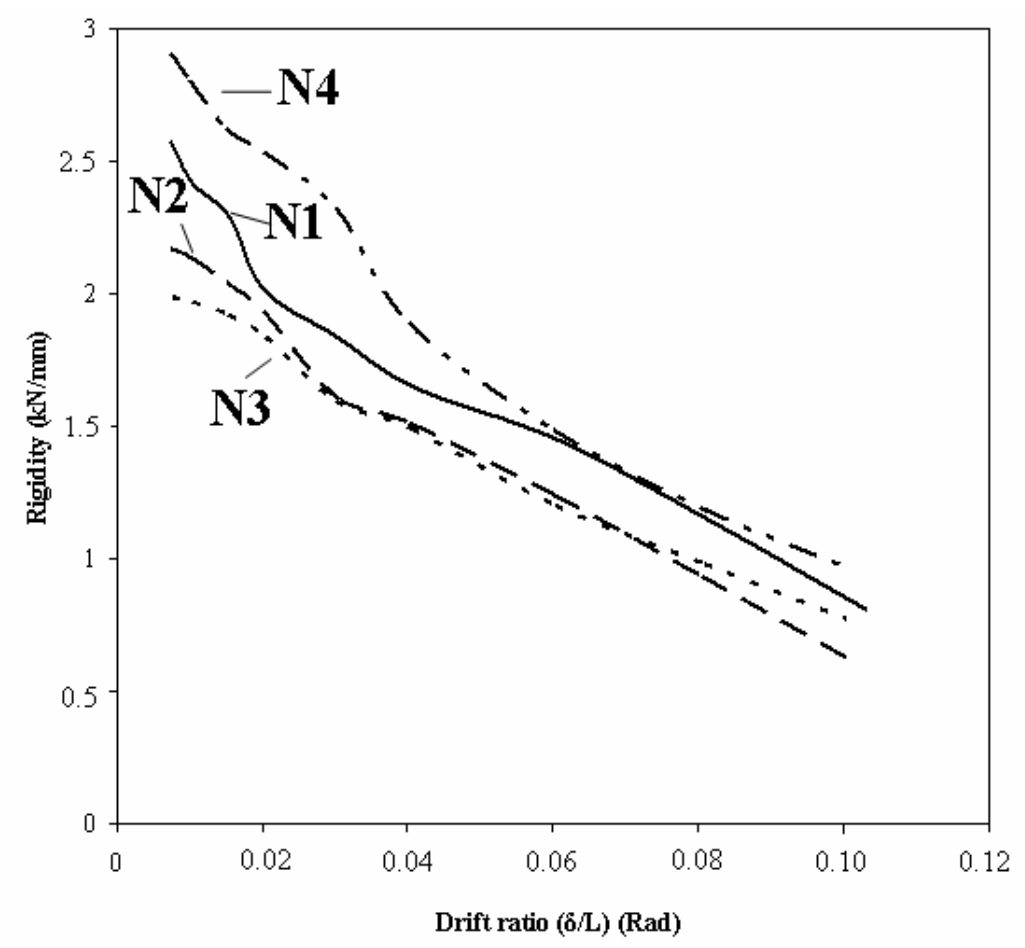

Figure 5. Stiffness Degradation Diagrams of the Test Specimens

As seen in Figure 5, although the first cycle stiffness values were calculated as $2.57 \mathrm{kN} / \mathrm{mm}(\mathrm{N} 1)$, $2.17 \mathrm{kN} / \mathrm{mm}(\mathrm{N} 2), 1.99 \mathrm{kN} / \mathrm{mm}(\mathrm{N} 3)$, and $2.91 \mathrm{kN} / \mathrm{mm}(\mathrm{N} 4)$, they decreased in the progressive cycles. The stiffness degradation occurred slightly more rapidly for the N2 and N3 specimens (having weakened cross-sections) in comparison to the other specimens. If the initial stiffness value of specimen N1 was taken as the "reference", the specimens N2, N3, and N4 would have 16\% less, $23 \%$ less, and $13 \%$ more initial stiffness values, respectively. As observed at the end of the tests, the specimens of drift ratio level $(\delta / \mathrm{L}=0.100)$ had stiffness values below $1 \mathrm{kN} / \mathrm{mm}$. The final stiffness values for this level were obtained as $0.811,0.630,0.775$, and 0.971 for specimens N1, N2, N3, and $\mathrm{N} 4$, respectively. 
The energy consumption was determined by calculating the areas inside the hysteretic load-displacement loops for each cycle, disregarding displacements beyond which lateral strength reduction was reached. In Figure 6, the cumulative energy consumption values were plotted against the corresponding cumulative drift ratio $\Sigma(\delta / \mathrm{L})$ that was calculated by successive summation of peak displacement ratios.

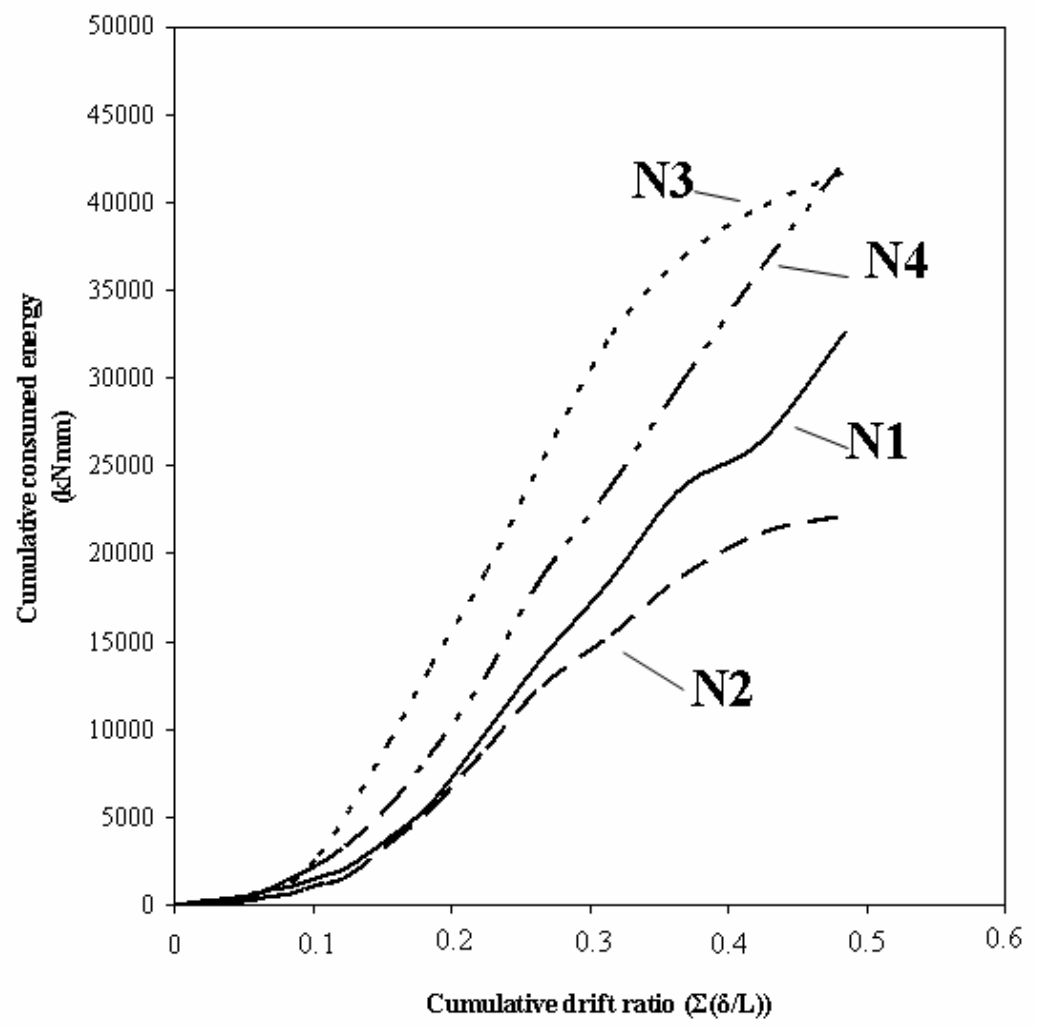

Figure 6. Diagrams of the Energy Consumption Capacities of the Test Specimens

As seen in Figure 6, the cumulative consumed energy values of the test specimens were obtained as $32,590 \mathrm{kNmm}, 22,194 \mathrm{kNmm}, 41,817 \mathrm{kNmm}$, and 42,374 kNmm, when the cumulative drift ratio $(\Sigma \delta / \mathrm{L})$ was 0.484 . When the reference specimen N1 was considered, the specimens N2, N3, and N4 consumed $32 \%$ less, $28 \%$ more, and 30\% more energy, respectively. The cause of less energy consumption for specimen $\mathrm{N} 2$ was due to the presence of a welding problem in this specimen earlier than the others (welding rupture).

\section{ANALYTICAL STUDY}

The test specimens were modeled using actual dimensions and material properties. However, after performing the supporting process of the columns and the application of $\mathrm{F}$ (force) at the beam-end according to the test mechanism, the static analysis of the system was executed and the cross-sectional influences were obtained. The force-bearing and moment-carrying capacities for the yielding and plastic boundary states of the test specimens were determined by the aid of the cross-sectional characteristics, material properties, and the cross-sectional influences of the specimens, which were obtained from the static analysis.

The moment bearing capacities can be calculated by using Eqs. 2 and 3 for yielding (elastic) and failure (plastic) states depending on the geometrical and strength characteristics of the beam cross-sections. 
$M_{y}=f_{y} \times W_{e}$

$M_{p}=f_{y} \times W_{p}$

In these expressions;

$f_{y}$ : The yielding stress $\left(302 \mathrm{~N} / \mathrm{mm}^{2}\right)$ of the material with which the test specimens were produced.

$M_{y}$ : The maximum moment carried by the beam for yielding (elastic) state.

$M_{p}$ : The maximum moment carried by the beam for failure (plastic) state.

$W_{e}$ : The strength moment calculated for elastic state.

$W_{p}$ : The strength moment calculated for plastic state.

Additionally, the reductions applied at the beam flange cross-sections were taken into account in determining the strength moments.

The force-moment relationship of the beam as a result of the static analysis can be expressed as in Eq. 4

$M=F \times L^{\prime}{ }_{i}$

In these expressions;

M: the maximum moment occurred at the beam under the force $F$,

$F$ : the force acting at the beam-end

$L^{\prime}{ }_{i}:$ is the beam span length, i.e. it is the distance between force and the column surface for N1 specimens $\left(L_{1}^{\prime}\right)$, it is the distance between force and the weakest cross-section at which reduction was made at the beam for $\mathrm{N2}\left(\mathrm{L}_{2}{ }_{2}\right)$ and $\mathrm{N} 3$ specimens $\left(\mathrm{L}_{3}{ }_{3}\right)$, and it is the distance between force and the end-point of the stiffness plate for $N 4$ specimens $\left(L^{\prime}{ }_{4}\right)$, as given in Figure 1.

Since $M=M_{r}$ for boundary states, the following expression can be written using the Eqs. 2, 3 and 4 .

After substituting Eq. 2 into Eq. 3, load F can be determined using Eq. 4 for the boundary states.

$$
\begin{aligned}
& F_{y}=\frac{f_{y} \times W_{e}}{L_{i}^{\prime}} \\
& F_{p}=\frac{f_{y} \times W_{p}}{L_{i}{ }_{i}}
\end{aligned}
$$

- Analytical calculations for yielding state: For the yielding state, the yielding stress and the elastic strength moment of the cross-section were used as stated above for the calculation of the yielding force $\mathrm{F}_{\mathrm{y}}$ and the yielding moment $\mathrm{M}_{\mathrm{y}}$.

- $\quad$ Analytical calculations for plastic state: For the plastic state, the yielding stress and the plastic strength moment of the cross-section were used as stated above for the calculation of the yielding force $F_{p}$ and the yielding moment $M_{p}$. Eq. 7, given similarly both in TEC [19] and FEMA 350 [3], was taken as the base during the plastic moment calculation. 
$M_{p}=1.1 \times D_{a} \times W_{p} \times f_{y}$

The increasing coefficient, $D_{a}$, in this expression varies between 1.1-1.2 depending on the material class and member type.

The calculations were carried out for each test specimen according to the principles explained above, and the analytical results were presented in Table 3 together with the experimental results.

Table 3. Analytical and Experimental Force-bearing Capacities of the Test Specimens

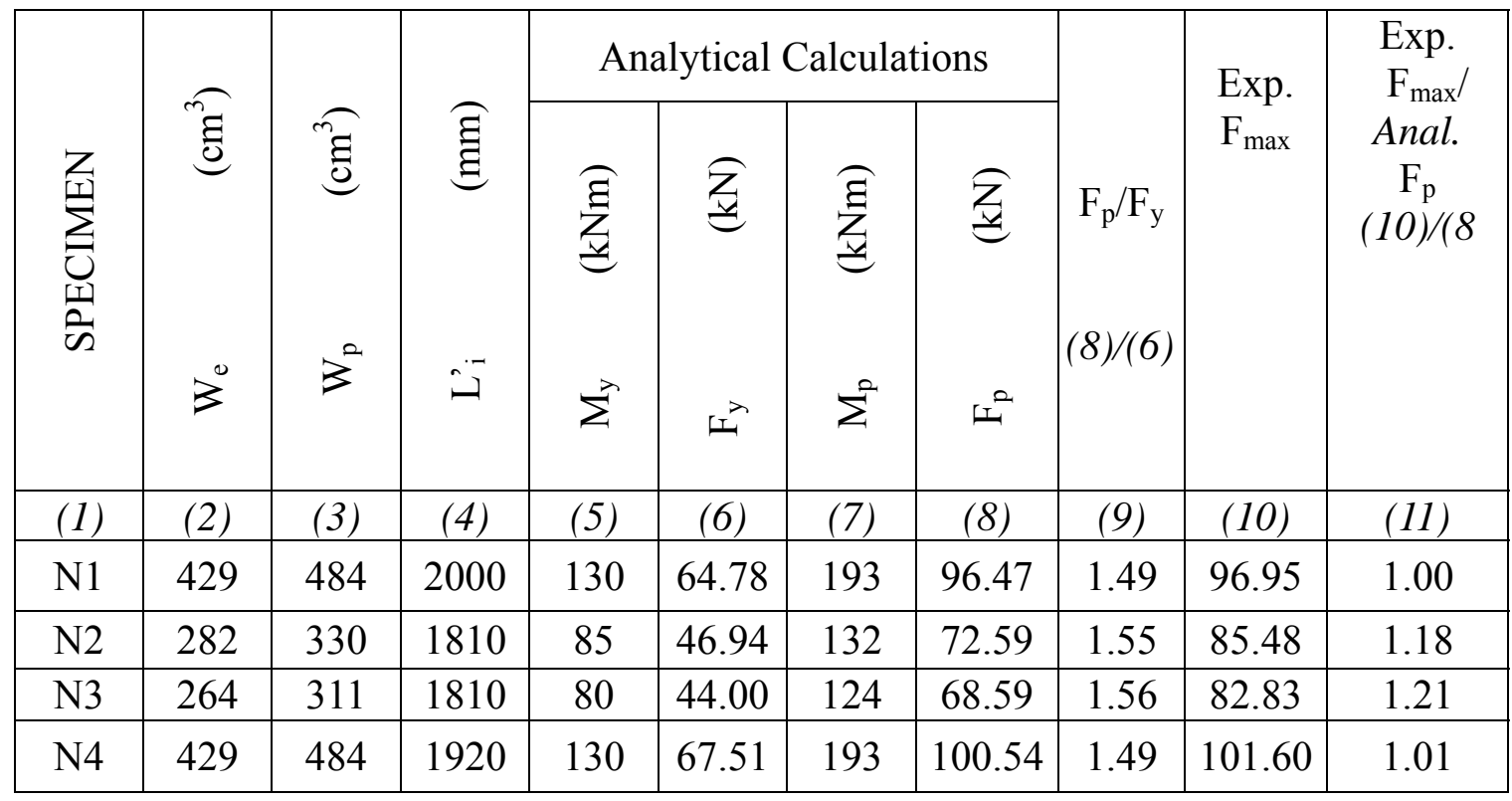

\section{RESULTS}

The following results were obtained from the experimental and analytical studies.

1. As a result of the tests, the maximum shear force carried by the beam was $101.60 \mathrm{kN}$ for specimen N4, and thus, specimen N4 carried 5\% more shear force ( moment), in comparison to the reference specimen, N1. The specimens N2 and N3 carried 12\% and 15\% less shear force, respectively, than that of the reference specimen N1 (Table 4).

2. When the initial stiffness values were considered, the maximum stiffness value was $2.57 \mathrm{kN} / \mathrm{mm}$ for specimen N4. Specimens N4, N2, and N3 had 13\% more, $16 \%$ less, and $23 \%$ less initial stiffness values, respectively, in comparison to the stiffness value of specimen N1 (Table 4).

3. When the consumed energy values were considered, specimen $\mathrm{N} 4$ had the maximum consumed energy of $42,374 \mathrm{kNmm}$. Specimens N4, N3, and N2 consumed 30\% more, $28 \%$ more, and 32\% less energy, respectively, when compared to that of the reference specimen N1. Specimen N2's lower energy consumption was due to the welding problem $\mathrm{N} 2$ faced earlier than the other specimens (Table 4). 
Table 4. Results Obtained from the Experimental Studies

\begin{tabular}{|c|c|c|c|c|}
\hline \multicolumn{5}{|c|}{ Experimental Results } \\
\hline Specimen & $\begin{array}{l}\mathrm{F}_{\max } \\
(\mathrm{kN})\end{array}$ & $\begin{array}{l}\text { Max. } \\
\text { Stiffness } \\
(k N / m m)\end{array}$ & $\begin{array}{c}\text { Stiffness degradation } \\
\text { (Final stiffness/Initial stiffness) }\end{array}$ & $\begin{array}{c}\text { Cumulative consumed } \\
\text { energy } \\
(k N \times m m)\end{array}$ \\
\hline N1 & 96.95 & 2.57 & $0.811 / 2.57=0.32$ & 32590 \\
\hline N2 & 85.48 & 2.17 & $0.630 / 2.17=0.29$ & 22194 \\
\hline N3 & 82.83 & 1.99 & $0.775 / 1.99=0.39$ & 41817 \\
\hline N4 & 101.60 & 2.91 & $0.971 / 2.91=0.33$ & 42374 \\
\hline
\end{tabular}

4. When comparing the experimental and analytical results:

- $\quad$ The maximum shear force values obtained and calculated for specimens N1 and N4 were almost the same. Moreover, the experimental shear force values obtained for specimens N2 and N3 (having reduced cross-sections) were $20 \%$ more than the values obtained by the analytical solution.

- During the analytical calculations, the "Da" coefficient was taken as 1.2, and the actual cross-sectional characteristics were used for the reduced cross-sections. The formula proposed for plastic calculations presented much closer results to the exact values for the other specimens, but a lower amount of deviation was observed for the reduced cross-sections. Therefore, a reevaluation of the formula used for the analytical calculations of the reduced cross-sections can be considered.

5. When the failure types of the test specimens were considered, yielding occurred at the top and bottom flanges of the steel beam during the further cycle stages at maximum stress levels. Buckling occurred at the flanges and moved through the beam body in the subsequent stages. At this time, the damage formation at the welding was observed. In particular, the rupturing of the flange weldings during the test on specimen N2 was experienced earlier than expected. This state did not have a significant effect on maximum shear force and moment values, but caused less stiffness and energy consumption than expected.

\section{CONCLUSIONS}

The following conclusions were obtained in light of the experimental and analytical studies.

- The strengthening of the beam cross-section at the beam to column connection using a stiffness panel increased the beam shear force and also the moment capacity.

- The use of a stiffness panel at the beam to column connection increased the initial stiffness, and the reduction at the beam-cross section decreased the initial stiffness by $20 \%$.

- As a general expression, both strengthening the cross-section using a stiffness panel and making a reduction at the beam cross-section increased the consumed energy by nearly by $30 \%$, which favorably affects the performance of this type of system under seismic conditions.

- According to the results obtained by the analytical solution, the bearing shear force values of the test specimens for failure boundary states (plastic states) were $49-55 \%$ larger than those for the yielding boundary states for all the specimens.

The use of reduced beam sections and strengthened beam to column connections favorably affected the behavior of the frame system in a manner that the failure formation occurred not at the connection members, but at the end-sections of the beams. Additionally, the use of a strengthened beam to column connection considerably increased the force and moment carrying capacities, initial stiffness, and energy consumption capacities of the steel frames. Therefore, the use of reduced beam sections and strengthened beam to column connections can be suggested for the steel frame constructions under the risk of earthquake forces. 


\section{ACKNOWLEDGEMENT}

This study was supported by Scientific Research Projects Office of Selcuk University in the scope of Project No: 10201032. The experimental data used for the study was provided from the Master of Science dissertation titled "Weakened and Strengthened Type Steel Column-Beam Junctions to Investigate the Behavior under Earthquake Loading" (Hatipoglu [1]).

\section{REFERENCES}

[1] Hatipoglu, E.T., "Weakened and Strengthened Type Steel Column-Beam Junctions To Investigate The Behavior Under Earthquake Loading", Master of Science Dissertation, Selcuk University, Institute of Graduate and Applied Sciences, Konya, Turkey, 2011.

[2] Pachoumis, D.T, Galoussis, E.G., Kalfas, C.N. and Efthimiou, I.Z.,"Cyclic Performance of Steel Moment-resisting Connections with Reduced Beam Sections-experimental Analysis and Finite Element Model Simulation", Engineering Structures, 2010, Vol. 32, pp. 2683-2692.

[3] FEMA 350, "Recommended Seismic Design Criteria for New Steel Moment-frame Buildings", Washington (DC), 2000.

[4] Engelhardt, M.D. and Husain, A.S., "Cyclic-loading Performance of Welded Flange-bolted Web Connections”, J. Struct. Eng., 1993, Vol. 119, No. 12, pp. 3537-3549.

[5] Tsai, K.C., Shun, W. and Popov, E., "Experimental Performance of Seismic Steel Beam to Column Moment Joints”, J. Struct. Eng., 1995, Vol. 121, No. 6, pp. 925-931.

[6] Plumier, A., "Behaviour of Connections", J. Constr. Steel Res., 1994, Vol. 29, pp.95-119.

[7] Pachoumis, D.T., Galoussis, E.G., Kalfas, C.N. and Efthimiou, I.Z., "Reduced Beam Section Moment Connections Subjected to Cyclic Loading: Experimental Analysis and FEM Simulation" Engineering Structures, 2009, Vol. 31, pp.216-223.

[8] Lee, C.H. and Chung, S.W., "A Simplified Analytical Story Drift Evaluation of Steel Moment Frames with Radius-cut Reduced Beam Section", Journal of Constructional Steel Research, 2007, Vol. 63, pp. 564-570.

[9] Bruneau, M, Uang, C.M. and Whittaker A., "Ductile Design of Steel Structures", New York: McGraw-Hill; 1998.

[10] Chen, S.J., Yeh, C.H. and Chu, J.M., "Ductile Steel Beam-to-column Connections for Seismic Resistance", Journal of Structural Engineering ASCE, 1996, Vol. 122, No. 11, pp. 1292-1299.

[11] Plumier, A., "The Dogbone: Back to the Future", Engineering Journal AISC, 1997, Vol. 34, No. 2, pp.61-67.

[12] Zekioglu, A., Mozaffarian, H., Chang, K.L. and Uang, C.M., "Designing after Northridge”, Modern Steel Construction AISC, 1997, Vol. 37, No. 3, pp. 36-42.

[13] Engelhardt, M.D., Winneberger, T., Zekany, A.J. and Potyraj, T.J., "Experimental Investigations of Dogbone Moment Connections", Engineering Journal AISC, 1998, Vol. 35, No. 4, pp. 128-139.

[14] Jones, S.L, Fry, G.T. and Engelhardt, M.D., "Experimental Evaluation of Cyclically Loaded Reduced Beam Section Moment Connections", Journal of Structural Engineering ASCE, 2002, Vol. 128, No. 4, pp. 441-451.

[15] Uang, C.M. and Fan, C.C., "Cyclic Stability Criteria for Steel Moment Connections with Reduced Beam Section”, Journal of Structural Engineering ASCE, 2001, Vol. 127, No. 9, pp. 1021-1027. 
[16] Lee, C.H, Jeon, S.W., Kim, J.H. and Uang, C.M., "Effects of Panel Zone Strength and Beam Web Connection Method on Seismic Performance of Reduced Beam Section Steel Moment Connections", Journal of Structural Engineering ASCE, 2005, Vol. 131, No. 12, pp. $1854-1865$.

[17] FEMA 351, "Recommended Seismic Evaluation and Upgrade Criteria for Existing Welded Steel Moment Frame Buildings", Washington (DC), 2000.

[18] EC 8. "Part 3: Design of Structures for Earthquake Resistance, Assessment and Retrofitting of Buildings", EN 1998-3, June 2005.

[19] Turkish Earthquake Code (TEC), Ankara, Turkey, 2007. 


\title{
STEADY STATE RESPONSE AND STABILITY OF AN ELASTICALLY RESTRAINED TAPERED BEAM
}

\author{
M.S. Abdel-Jaber ${ }^{1}$, A.A. Al-Qaisia ${ }^{2, *}$, M. Abdel-Jaber ${ }^{3}$ and R.G. Beale ${ }^{4}$ \\ ${ }^{1}$ Associate Professor, Department of Civil Engineering, The University of Jordan, Amman, Jordan \\ ${ }^{2}$ Professor, Department of Mechanical Engineering, The University of Jordan, Amman, Jordan \\ ${ }^{3}$ Associate Professor, Department of Civil Engineering, Faculty of Engineering and Technology, \\ Applied Science University, Amman, Jordan \\ ${ }^{4}$ Reader, Department of Mechanical Engineering and Mathematical Sciences, \\ Oxford Brookes University, Oxford, United Kingdom \\ *(Corresponding author: E-mail: alqaisia@ju.edu.jo)
}

Received: 4 June 2012; Revised: 2 July 2012; Accepted: 8 October 2012

\begin{abstract}
An analytical method for the study of the nonlinear forced vibrations and their stabilities of an elastically restrained tapered cantilever beam due to a direct periodic excitation is developed. The method of harmonic balance is used to study the steady state frequency response of the beam system for different values of physical parameters such as the root translational and rotational stiffness and the beam taper ratio. Results are presented for the first three modes of vibration. The stability of the frequency response for some selected values of the physical parameters is investigated, i.e. the regions on the frequency response curves at which the solution may bifurcate and then culminate into chaos. The qualitative features of the solutions are studied and identified using phase plane, Poincare maps and Fast Fourier Transform. The results are presented, discussed and conclusions on the elastically restrained tapered beam nonlinear dynamics are drawn.
\end{abstract}

Keywords: Forced vibration, tapered beam, elastically restrained, stability, period doubling, chaos

\section{INTRODUCTION}

Beams with continuous changes in cross sectional area along with the beam axis, i.e. tapered beams, have been extensively used in many civil and mechanical engineering structures such as; such as offshore structure piles, oil platform supports, oil-loading terminals, tower structures, bridges, lighting standards, rotating tapered blades and moving/rotating arms. Tapered beams are also increasingly being used in the construction industry, due to their particular specifications and unique ability to combine efficiency, economy and aesthetic architectural needs. They have the capability to optimise weight and strength despite the cost of fabrication of tapered members.

Since tapered beams can model many engineering structures that require variable stiffness along the beam axis "length", designs and analyses of such structures have attracted considerable interest and many researchers have directed their efforts and much research have been devoted towards the mathematical modelling and dynamic behaviour.

Studying the dynamic analysis and vibrational behaviour of tapered beams enables the predetermination of undesirable behaviour such as resonance, large vibration levels and unstable vibration behaviour. The results of which will help designers and engineers predict the dynamic behaviour and enable them to impose suitable vibration control strategies to achieve optimum and safe behaviour.

Having realized the vital role of the accurate mathematical modelling of tapered beams and having recognized their importance in studying dynamic behaviour researchers published many studies and reported analysis to deal with calculating natural frequencies and modes shapes either for small or large amplitude vibrations. Broad surveys and literature on these subjects can be found in [1-14]. 
In fact, most of the previous research in this direction has been oriented towards the calculation of linear natural frequencies and mode shapes, with different end conditions and with attached inertia elements at the free end of the beam.

In general, tapered beams may have relatively high flexibility due to their high aspect ratio and as they are usually subjected to various excitation loads such as wind loads, wave loads, etc., the prediction of their steady state response, nonlinear forced vibrations and stability of these large amplitude vibrations is extremely important for design, control and analysis.

The objective of the present work is to extend the analysis and the results obtained in $[13,14]$ by studying the non-linear, planar, large amplitude forced vibrations of an elastically restrained tapered beam for the cases of a double taper beam and a single taper "wedge shaped beam". The mathematical model is derived using the Lagrange method and the resulting continuous equation is discretised using the assumed mode method. The inextensibility condition [14-17] is used to determine the axial shortening due to transverse deflection in the formulation of the kinetic energy of the beam and the nonlinear curvature is used in the potential energy expression.

Abdel-Jaber et al. $[13,14]$ undertook a complete study into the non-linear natural frequencies of an elastically restrained tapered cantilever. Their results documented a parametric study into the frequency-amplitude nonlinear relation under different physical parameters and combinations. The tapered beam system results have shown that, for the first and second modes the behaviour is changed from a hardening type to a softening type when the taper ratio is increased, whilst the third mode is always of a softening type regardless the value of the taper ratio (a hardening behaviour leads to an increase in the natural frequency of the beam when the vibration amplitude increases and a softening behaviour to a decrease in natural frequency). For a given value of taper ratio the authors showed that the nonlinear natural frequency of a double tapered beam is higher than that of a single tapered beam. The authors also produced results for the effect of the stiffness of the connection between the cantilever and the ground on the nonlinear natural frequency; it was shown that the nonlinear natural frequency changes from a softening to a hardening behaviour depending upon combinations of the physical parameters of the connection stiffness and the vibration amplitude.

As the physical properties of cantilever beam systems such as connection stiffness may change during operation studying the steady state response under periodic excitation is extremely important.

In the light of the above review, the objective of this work is to extend the analyses in $[13,14]$ and to analyze the periodic steady state response of the nonlinear oscillator which describes large amplitude planar vibrations of an elastically restrained tapered beam, under different values of root translational and rotational flexibilities. Furthermore, the stability of the obtained solutions is investigated and discussed to determine for a selected range of system parameters the regions of period doubling bifurcations and chaos on frequency response curves.

To the authors' knowledge, despite its physical importance, studies dealing with forced vibrations and their stability of tapered beams are not commonly available. 


\section{DERIVATION OF THE EQUATION OF MOTION}

For the system shown in Figure 1 a complete derivation of the equation of motion is presented in [14] and for the sake of brevity it will not be presented here.

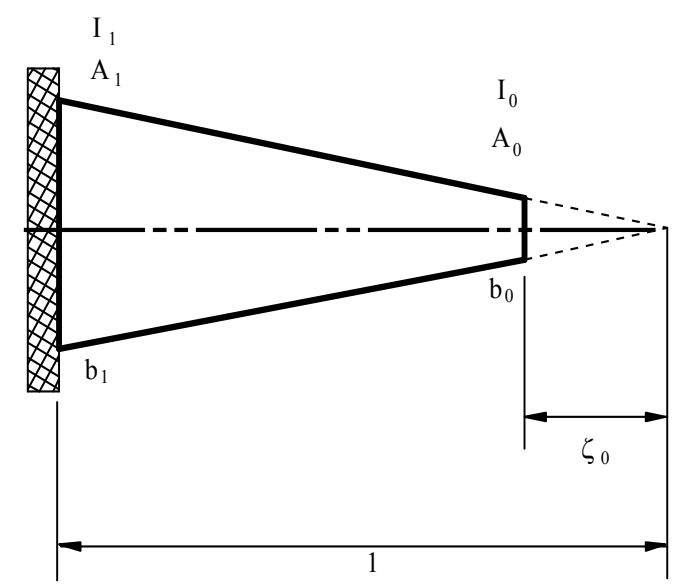

(a) Schematic for the tapered beam

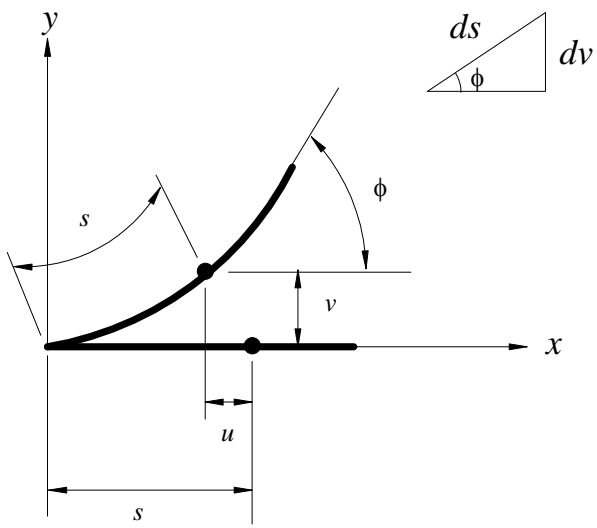

(b) The deformed inextensible beam

Figure 1. Beam Schematics

The rotational and translational stiffnesses of the elastic restraint at the cantilever root are denoted by $K_{r}$ and $K_{t}$ respectively. The Lagrangian of the system under consideration is given by:

$$
L=\rho l^{3}\left(\beta_{1} \dot{q}^{2}+\beta_{2} q^{2} \dot{q}^{2}-\beta^{2} \beta_{3} q^{2}-\beta^{2} \beta_{4} q^{4}\right)
$$

where

$\beta_{1}=\int_{0}^{1} A_{1}^{*} \phi^{2} \mathrm{~d} \zeta$

$\beta_{2}=\int_{0}^{1} A_{1}^{*}\left\{\int_{0}^{\zeta} \phi^{\prime 2} \mathrm{~d} \chi\right\}^{2} \mathrm{~d} \zeta$

$\beta_{3}=\int_{0}^{1} I_{1}^{*} \phi^{\prime 2} \mathrm{~d} \zeta+\frac{K_{t} l^{3}}{E I_{1}} \phi(1)^{2}+\frac{K_{r} l}{E I_{1}} \phi^{\prime}(1)^{2}$

$\beta_{4}=\int_{0}^{1} I_{1}^{*} \phi^{\prime 2} \phi^{\prime 2} \mathrm{~d} \zeta$

$\phi(\zeta)$ is the normalized, self-similar (i.e. independent of the motion amplitude) assumed mode shape of the beam and $q(\hat{t})$ is an unknown time modulation of the assumed deflection mode $\phi(\zeta)$. A dot is used to denote a derivative with respect to the non-dimensional time.

For a double tapered beam $A_{1}^{*}=A_{1} \zeta^{2}$ and $I_{1}^{*}=I_{1} \zeta^{4}$ and for a single tapered wedge beam $A_{1}^{*}=A_{1} \zeta$ and $I_{1}^{*}=I_{1} \zeta^{3}$. As can seen $\beta_{i}, i=1, . ., 4$ are functions of the system physical parameters, so that any variation in any physical quantity such as the root flexibility will be reflected in the calculated values of $\beta_{i}$. 
To study the forced planar response of the beam system, a periodic excitation $Q(\hat{t})$ is assumed to act only in the $y$ direction, the beam transverse direction. Upon the application of the Euler-Lagrange equation

$Q=\frac{\partial}{\partial \hat{t}}\left(\frac{\partial L}{\partial \dot{q}}\right)-\frac{\partial L}{\partial q}$

where $Q$ is the generalized force, which can be determined from the principle of virtual work, $(\delta W=Q \cdot \delta y)$. Assuming $Q(\ell)=\bar{F}_{0} \cos (\Omega t)$, the discrete beam nonlinear equation becomes

$\beta_{1} \ddot{q}+\beta^{2}\left(\beta_{3} q+2 \beta_{4} q^{3}\right)+\beta_{2}\left(q^{2} \ddot{q}+q \dot{q}^{2}\right)=\beta_{5} \bar{F}_{0} \cos (\Omega \hat{t})$

where $\beta_{5}=\phi\left(\zeta_{c}\right)$ for a concentrated load which is assumed to act at an arbitrary point $\zeta_{c}$ along the beam span and $\beta_{5}=\int_{\chi}^{1} \phi(\zeta) \mathrm{d} \zeta$ for a distributed load acting from $\chi$ to the end of the beam. It is to be noted that some of the coefficients $\beta_{i}$ in Eqs. 2-5, increase sharply and attain relatively large values at higher modes of the beam. Therefore, for convenience, Eq. 7 is scaled and converted to the dimensionless form

$\ddot{q}+q+\varepsilon_{1}\left(q^{2} \ddot{q}+q \dot{q}^{2}\right)+\varepsilon_{2} q^{3}=\varepsilon_{3} \bar{F}_{0} \cos (\Omega t)$

where $t=\left(\beta^{2} \beta_{3} / \beta_{1}\right)^{1 / 2} \hat{t}$ and $\varepsilon_{1}=\frac{\beta_{2}}{\beta_{1}}, \varepsilon_{2}=\frac{2 \beta_{4}}{\beta_{3}}$ and $\varepsilon_{3}=\frac{\beta_{5}}{\beta_{3}}$ are dimensionless coefficients.

For the stability analysis the damping of the beam system is assumed to be viscous, with damping coefficient $\delta$, which can be added to the system, also the excitation level for convenience is rescaled such that $\varepsilon_{3} \bar{F}_{0}=F_{0}$. The equation of motion takes the form:

$\ddot{q}+q+\delta \dot{q}+\varepsilon_{1}\left(q^{2} \ddot{q}+q \dot{q}^{2}\right)+\varepsilon_{2} q^{3}=F_{0} \cos (\Omega t)$

Eq. 9 describes the non-linear, planar, flexural free vibration of the inextensible elastically restrained tapered beam. In this equation, the terms $\varepsilon_{1} \ddot{q} q^{2}$ and $\varepsilon_{1} q \dot{q}^{2}$ are inertial non-linearities due to the kinetic energy of the axial motion which arise as a result of using the inextensibility condition and they are of a softening type. The non-linear term $\varepsilon_{2} q^{3}$ is due to the potential energy stored in bending and arises as a result of using non-linear curvature and it is of a hardening static type.

\section{ANALYSIS}

Approximate analytical solutions for the periodic steady state response, having the same period as the excitation, of the nonlinear oscillator described by Eq. 9 are obtained using the harmonic balance method (HB). To simplify the analysis a new time $T=\Omega t$ is introduced so that Eq. 9 becomes 
$\Omega^{2} \ddot{q}+\Omega \delta \dot{q}+q+\varepsilon_{1} \Omega^{2} q^{2} \ddot{q}+\varepsilon_{1} \Omega^{2} q \dot{q}^{2}+\varepsilon_{2} q^{3}=F_{0} \cos (T)$

where dots are derivatives with respect to the new time $T$.

\subsection{Steady State Solution, Harmonic Balance Method (HB)}

According to the Harmonic Balance method, an approximate single term solution (SHB) of Eq. 10 should contain sine and cosine terms, but with the same harmonic. To avoid this, an unknown phase $\phi$ can be introduced to the excitation, and Eq. 10 takes the form

$$
\Omega^{2} \ddot{q}+\Omega \delta \dot{q}+q+\varepsilon_{1} \Omega^{2} q^{2} \ddot{q}+\varepsilon_{1} \Omega^{2} q \dot{q}^{2}+\varepsilon_{2} q^{3}=F_{0} \cos (T+\phi)
$$

In this way, one may introduce a fundamental harmonic response containing a single trigonometric term only, which takes the form

$$
q(T)=A \cos T
$$

where $A$ is the steady state response amplitude. Substituting Eq. 12 into Eq. 11, neglecting any third harmonics which arise, and equating coefficients of first harmonics the following equations are obtained:

$$
\begin{aligned}
& \left(\frac{3}{4} \varepsilon_{2}-\frac{\varepsilon_{1}}{2} \Omega^{2}\right) A^{3}+\left(1-\Omega^{2}\right) A=F_{0} \cos \varphi \\
& -\Omega \delta A=F_{0} \sin \phi
\end{aligned}
$$

To eliminate the unknown phase $\phi$, the steady state frequency response is obtained by squaring and adding Eq. 13 to Eq. 14 and solving for $\Omega^{2}$, for a given value $A$.

The accuracy of the solution obtained from the SHB approximation can be improved by adding higher harmonics in the assumed solution given in Eq. 12. In this paper one more term is added to this equation, whereby the two-term approximation (2THB) to the steady state solution of the Eq. 11 with odd nonlinearities in the form

$q(T)=A_{1} \cos T+A_{3} \cos 3 T+B_{3} \sin 3 T$

Substituting Eq. 15 into Eq. 12 and following the same procedure, i.e. neglecting higher-order harmonics, the following coupled nonlinear algebraic equations for $A_{1}, A_{3}, B_{3}$ and the phase $\phi$ are obtained:

$$
\begin{aligned}
& \frac{3}{4} \varepsilon_{2} A_{1}^{3}+\frac{3}{4} \varepsilon_{2} A_{1}^{2} A_{3}+\frac{3}{2} \varepsilon_{2} A_{1} A_{3}^{2}+\frac{3}{2} \varepsilon_{2} A_{1} B_{3}^{2}+A-A \Omega^{2}-\frac{\varepsilon_{1}}{2} \Omega^{2} A^{3} \\
& -\frac{3}{2} \varepsilon_{1} \Omega^{2} A_{1}^{2} A_{3}-5 \varepsilon_{1} \Omega^{2} A_{1}^{2} A_{3}-5 \varepsilon_{1} \Omega^{2} A_{1}^{2} B_{3}=F_{0} \cos \phi \\
& \frac{3}{4} \varepsilon_{2} A_{1}^{2} B_{3}-\Omega \delta A_{1}-\frac{3}{2} \varepsilon_{1} \Omega^{2} A_{1}^{2} B_{3}=F_{0} \sin \phi
\end{aligned}
$$




$$
\begin{aligned}
& \frac{3}{2} \varepsilon_{2} A_{1}^{2} B_{3}+\frac{3}{4} \varepsilon_{2} A_{3}^{2} B_{3}+\frac{3}{4} \varepsilon_{2} B_{3}^{3}+B_{3}-3 A_{3} \delta \Omega-9 \Omega^{2} B_{3}+ \\
& -5 \varepsilon_{1} \Omega^{2} A_{1}^{2} B_{3}-\frac{9}{2} \varepsilon_{1} \Omega^{2} A_{3}^{2} B_{3}-\frac{9}{2} \varepsilon_{1} \Omega^{2} B_{3}^{3}=0 \\
& \frac{\varepsilon_{2}}{4} A_{1}^{3}+\frac{3}{2} \varepsilon_{2} A_{1}^{3} A_{3}+\frac{3}{4} \varepsilon_{2} A_{3}^{2}+\frac{3}{4} \varepsilon_{2} A_{3} B_{3}^{2}+A_{3}+3 B_{3} \delta \Omega-9 A_{3} \Omega^{2}+ \\
& -\frac{\varepsilon_{1}}{2} \Omega^{2} A_{1}^{3}-5 \varepsilon_{1} \Omega^{2} A_{1}^{2} A_{3}-\frac{9}{2} \varepsilon_{1} \Omega^{2} A_{3}^{2}-\frac{9}{2} \varepsilon_{1} \Omega^{2} A_{3} B_{3}^{2}=0
\end{aligned}
$$

A steady state solution of the system can be obtained by solving the nonlinear equations given in Eq. 12 and Eq. 13 for the SHB and by the nonlinear equations given in Eqs. 16-19 for the 2THB using a numerical procedure. For the sake of brevity, a detailed procedure for solving such nonlinear systems is not given in this paper but is presented in [15-17].

\section{STABILITY OF STATE SOLUTIONS}

The stability analysis of the approximate harmonic balance solutions given in Eq. 11 and Eq. 14 may be carried out by introducing a small perturbation $v(T)$ to the assumed solution in Eq. 12 by substituting

$$
u(T)=A \cos T+v(T)
$$

into Eq. 10. This leads to the following non-linear variational equation

$$
\begin{aligned}
& \ddot{v} \Omega^{2}\left(1+\varepsilon_{1} \frac{A^{2}}{2}+\varepsilon_{1} v^{2}+2 \varepsilon_{1} v A \cos T+\varepsilon_{1} \frac{A^{2}}{2} \cos 2 T\right)+ \\
& \dot{v}\left(\delta \Omega-2 \varepsilon_{1} \Omega^{2} A v \sin T-\varepsilon_{1} \Omega^{2} A^{2} \sin 2 T\right)+ \\
& v\left(\frac{3}{2} \varepsilon_{2} A^{2}+1-\varepsilon_{1} \Omega^{2} \frac{A^{2}}{2}+\varepsilon_{1} \Omega^{2} \dot{v}^{2}+\frac{3}{2} \varepsilon_{2} A^{2} \cos 2 T-\frac{3}{2} \varepsilon_{1} \Omega^{2} A^{2} \cos 2 T\right)+ \\
& \varepsilon_{1} \Omega^{2} A^{2} \dot{v}^{2} \cos T+v^{2} A \cos T\left(3 \varepsilon_{2}-\varepsilon_{1} \Omega^{2}\right)+\varepsilon_{2} v^{3}=\frac{A^{2}}{4}\left(2 \varepsilon_{1} \Omega^{2}-\varepsilon_{2}\right) \cos 3 T
\end{aligned}
$$

The stability is governed by the linearised version of Eq. 21 . In addition, the excitation term on the right-side is deleted, because it has no influence on stability, this leads to the following Hill's type equation:

$$
\begin{aligned}
& \ddot{v} \Omega^{2}\left(1+\varepsilon_{1} \frac{A^{2}}{2}(1+\cos 2 T)\right)+\dot{v}\left(\delta \Omega-\varepsilon_{1} \Omega^{2} A^{2} \sin 2 T\right)+ \\
& v\left(1+\frac{A^{2}}{2}\left(3 \varepsilon_{2}-\varepsilon_{1} \Omega^{2}\right)+\frac{3}{2} A^{2} \cos 2 T\left(\varepsilon_{2}-\varepsilon_{1} \Omega^{2}\right)\right)=0
\end{aligned}
$$

By virtue of Floquet theory, a particular solution of the linearised variational equation, is sought in the form [17]: 
$v(T)=e^{\beta T} \eta(T)$

where $\beta$ is defined as the characteristic exponent and $\eta(T)$ is a periodic function with periods $T$ and $T / 2$ since the dimensionless frequencies of the sine and cosine terms in Eq. 22 are 2, this introduce the periods $\mathrm{T}$ and $\mathrm{T} / 2$. The solution of $v(T)$ is stable (respectively, unstable) if the real part of $\beta$ is negative (positive); and the real part of $\beta$ is zero on the boundary between stable and stable regions. In addition, some results are presented for the case of asymmetric solution and their stability by substituting

$u(T)=A_{0}+A_{1} \cos T+v(T)$

where $A_{0}$ is a constant bias and $A_{1}$ is the amplitude. The results are of importance because they give good indication about the region at which the steady state solution bifurcates and causes period doubling and then chaotic behaviour.

For a full detailed procedure regarding the stability analysis either using single term as the one assumed in Eq. 20, two terms or biased solution as in Eq. 24, the readers are invited to consult reference [17].

\section{RESULTS AND DISCUSSION}

The steady state frequency response of the non-linear, single mode, temporal equation of motion Eq. 9 of the elastically restrained tapered beam as shown in Figure 1, was calculated analytically using the harmonic balance method and with an excitation level $F_{\mathrm{o}}$, for different values of the physical system parameters $K_{r}, K_{t}, \alpha, \delta$ where $K_{r}$ is the rotational stiffness and $K_{t}$ is the translational stiffness of the elastic restraint at the cantilever root; $\alpha$ is the taper ratio defined by $\alpha=\frac{b_{1}}{b_{2}}$ and $\delta$ is the damping coefficient. Here and for the sake of convenience the beam root stiffnesses are introduced in terms of their flexibilities, $C_{r}=E I_{1} / K_{r} l$ and $C_{t}=E I_{1} / K_{t} I^{3}$. For example, for a clamped end $C_{r}=C_{t}=0$.

To calculate the parameters $\varepsilon_{1}$ and $\varepsilon_{2}$ given in the nonlinear Eq. 9, for selected values of the physical parameters, the integrals in Eqs. 2-5 defining the coefficients $\beta_{i}$ were evaluated numerically.

The results show that for a given value of $\alpha$ the nonlinear natural frequency of a double tapered beam is higher than that of a single tapered beam. In addition, the effect of the beam's root flexibility, was shown in [14] to have a significant role in the behaviour and dynamics of the beam, i.e. the behaviour was changed form a softening to a hardening behaviour depending on combinations of the physical parameters of the beam's root flexibilities $C_{r}$ and $C_{t}$.

The nonlinear frequency response of the beam due to excitation are dominated by the two competing non-linearities - softening " $\varepsilon_{1}\left(q^{2} \ddot{q}+q \dot{q}^{2}\right)$ " and hardening " $\varepsilon_{2} q^{3}$ " nonlinearities, and the behaviour of the elastically restrained tapered beam considered in this paper is either hardening or softening depending on the ratio $\varepsilon_{1} / \varepsilon_{2}$ [9], which are calculated from values of $\beta_{i}$ given in Eqs. $2-5$. 
In Table 1, some numerical values for the ratio $\left(\varepsilon_{1} / \varepsilon_{2}\right)$ are presented for different values of $C_{r}$ and $C_{t}$ and for the first three modes of vibration.

Table 1. Sample numerical values for the ratio $\left(\varepsilon_{1} / \varepsilon_{2}\right)$ for different values of $C_{r}$ and $C_{t}$ of the first three modes

\begin{tabular}{|c|c|c|c|c|c|c|}
\hline & & & \multicolumn{4}{|c|}{ Rotational Flexibility $C_{r}$} \\
\hline & & & $C_{r}=0$ & $C_{r}=1$ & $C_{r}=5$ & $C_{r}=10$ \\
\hline \multirow{4}{*}{$\begin{array}{l}\text { First } \\
\text { Mode }\end{array}$} & \multirow{4}{*}{$\begin{array}{c}\text { Translational } \\
\text { Rotational } \\
\text { Flexibility } \\
C_{t}\end{array}$} & $C_{t}=0$ & 0.36 & 8 & 56 & 611.1 \\
\hline & & $C_{t}=0.5$ & 2.36 & 8.70 & 33.4 & 299.2 \\
\hline & & $C_{t}=1$ & 2.45 & 11.09 & 30.11 & 176.74 \\
\hline & & $C_{t}=5$ & 2.57 & 30.87 & 46.6 & 93.47 \\
\hline \multirow{4}{*}{$\begin{array}{c}\text { Second } \\
\text { Mode }\end{array}$} & \multirow{4}{*}{$\begin{array}{c}\text { Translational } \\
\text { Rotational } \\
\text { Flexibility } \\
C_{t}\end{array}$} & $C_{t}=0$ & 1.35 & 1.476 & 1 & 2.468 \\
\hline & & $C_{t}=0.5$ & 0.61 & 8.7 & 9.44 & 9.54 \\
\hline & & $C_{t}=1$ & 0.51 & 4.9 & 16.46 & 24.225 \\
\hline & & $C_{t}=5$ & 0.44 & 5.11 & 34.0 & 209.9 \\
\hline \multirow{4}{*}{$\begin{array}{l}\text { Third } \\
\text { Mode }\end{array}$} & \multirow{4}{*}{$\begin{array}{c}\text { Translational } \\
\text { Rotational } \\
\text { Flexibility } \\
C_{t}\end{array}$} & $C_{t}=0$ & 2.95 & 2.48 & 2.4697 & 2.468 \\
\hline & & $C_{t}=0.5$ & 1.63 & 1.80 & 1.40 & 1.28 \\
\hline & & $C_{t}=1$ & 1.63 & 1.78 & 1.35 & 1.22 \\
\hline & & $C_{t}=5$ & 1.63 & 1.76 & 1.32 & 1.19 \\
\hline
\end{tabular}

As an example and to shed more light on the nonlinear dynamics of a tapered beam, results for forced vibration are obtained and presented in Figure 2 for selected values of the physical parameters $C_{r}, C_{t}, \alpha$ and $\delta$. In Figure 2(a), results of the steady state frequency response are obtained for the first mode of vibration for $C_{t}=0, \alpha=0.1, \delta=0.1$ and for the indicated values of $C_{r}$. These results show that the frequency response of the first mode is bent towards the right, i.e. the frequency exhibits a hardening behaviour, when the value of $C_{r}=0$, and the frequency exhibits a softening behaviour " bend to the left" for other values of $C_{r}$. This is due to the fact that when $\varepsilon_{1} / \varepsilon_{2}<1.6$ the behaviour is of hardening type and when $\varepsilon_{1} / \varepsilon_{2}>1.6$ is of a softening type $[16,18]$. For the second mode, the behaviour is of hardening type for all values of $C_{r}$ except the case $C_{r}=10$ (see Figure 2(b)). In Figure 2(c) the behaviour of the third mode is of softening type, for all values of $C_{r}$ and $C_{t}$. Note that in this case the curves for $C_{r}=1, C_{r}=5$ and $C_{r}=10$ have coalesced onto the same curve. 


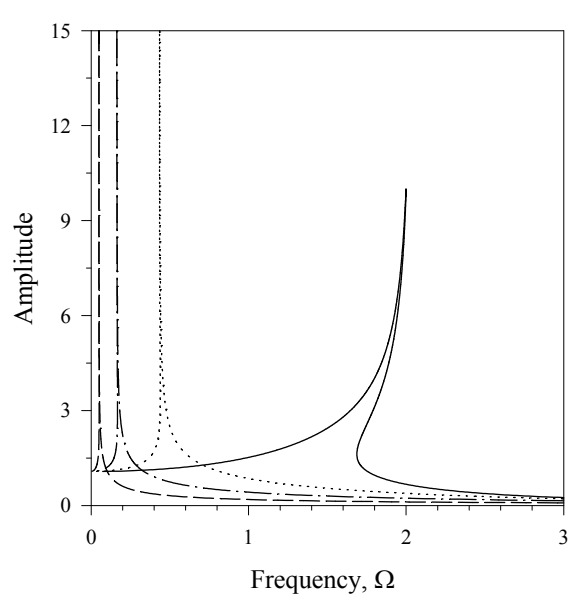

(a) First mode

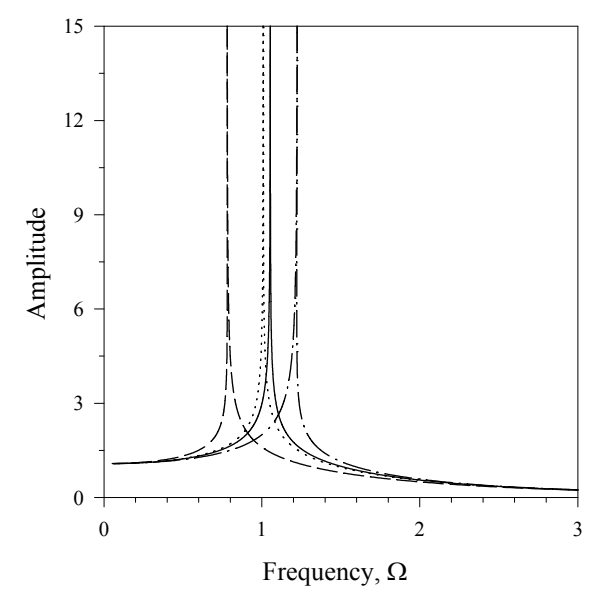

(b) second mode

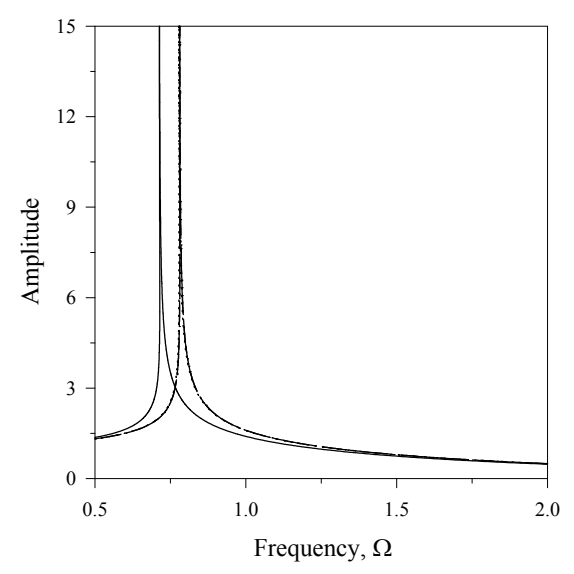

(c) Third mode

Figure 2. Steady State Frequency Responses for $\alpha=0.1, C_{t}=0$ and $C_{r}=0,1,5,10$

$$
\left(C_{r}=0 \longrightarrow, C_{r}=1 \cdots \cdots \cdots \cdot C_{r}=5-\cdots \cdot-\text { and } C_{r}=10----\right)
$$

The stability analysis of the nonlinear oscillator described in Eq. 9 was verified near the principal resonance zone for selected values of system parameters $F_{0}, \varepsilon_{1}, \varepsilon_{1}$ and $\delta$, using computer simulation and with the aid of Time histories, Phase Plane, Poincare Map and Fast Fourier Transforms (FFT).

Results for a softening type oscillators, i.e. $\varepsilon_{1} / \varepsilon_{2}>1.6$, are presented in Figure 3 with the parameters $F_{0}, C_{r}, C_{t}, \alpha$ and $\delta$ chosen to be $5,0.5,10,0.1$ and 0.1 respectively of the second mode of vibration of the elastically restrained tapered beam. 


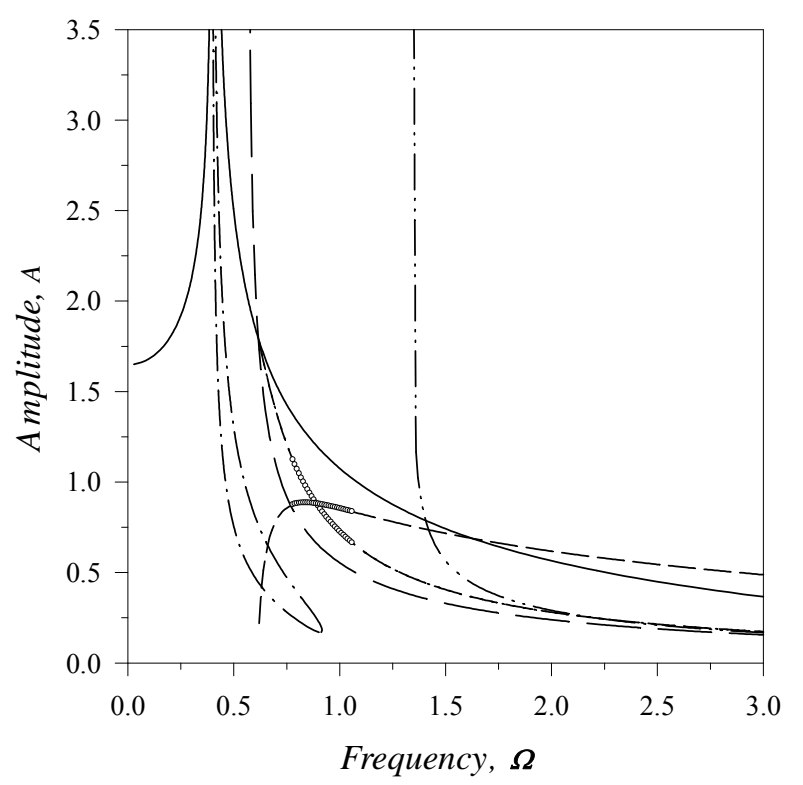

Figure 3. Steady State Frequency Response (SSFR), First Order Stability (1 ${ }^{\text {st }}$ Stab.), Second order Stability ( $2^{\text {nd }}$ Stab.), Biased Solution and Its Stability. $F_{0}=5, C_{t}=0.5, C_{r}=10$ and $\delta=0.1$ for the second mode:

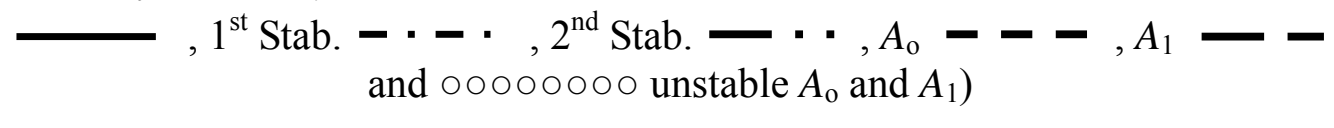

In Figure 3, using the HB method, the steady state response first and second order unstable regions are obtained using a single term only, in addition to the biased solution and its stability given in Eq. 24. It is known that the first order unstable region intersects the steady state response curve at the vertical tangency point. In the same figure the biased solution and its stability are also shown. The dynamics behaviour was verified numerically and steady state numerical solutions were obtained in the resonance area. The steady state response curve enters the second unstable region at $\Omega>1.4$, and the biased solution is unstable at $0.78<\Omega<1.06$, at which there is a possibility of period doubling bifurcation PDB, i.e. the PDB can occur also for $\Omega>1.40$ in addition to range predicted by the stability analysis of the biased solution. Numerical simulations have shown that, by increasing the frequency, the PDB is first observed at $\Omega=0.99$ followed by $3 T$ and $9 T$ attractors at $\Omega=1.04$ and $\Omega=1.055$ respectively, and they develop into chaos at $\Omega=1.11$. The first chaotic zone observed is in the range $1.11<\Omega \leq 1.29$ and then ends by a $3 T$ attractor. The $3 T$ attractor disappears and chaos returns in the range $2.09 \leq \Omega \leq 2.15$, followed by period doubling at $\Omega=2.3$ and higher period doubling, i.e. $4 T$ at $\Omega=2.35$. These period doublings do not develop into chaos. Further investigations showed that a PDB was observed in the range $2.95<\Omega \leq 3.05$ and the periodicity returns to the system for $\Omega>3.1$. In Figures $4-9$ the time histories, phase planes, Poincare maps and FFT are shown for different values of $\Omega$ and for the parameters $\left(F_{\mathrm{o}}=5, C_{t}=0.5, C_{r}=10, \alpha=0.1, \delta=0.1\right)$. 


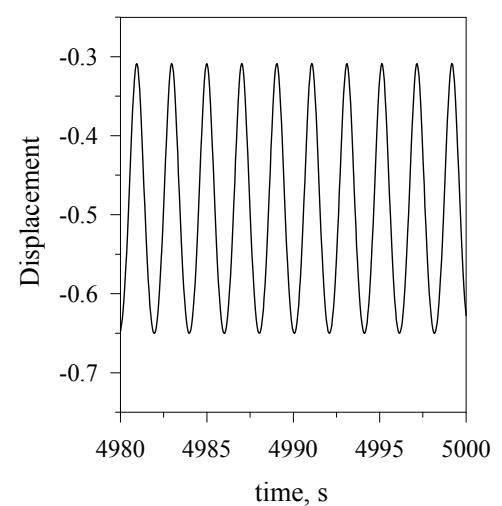

(a) time history

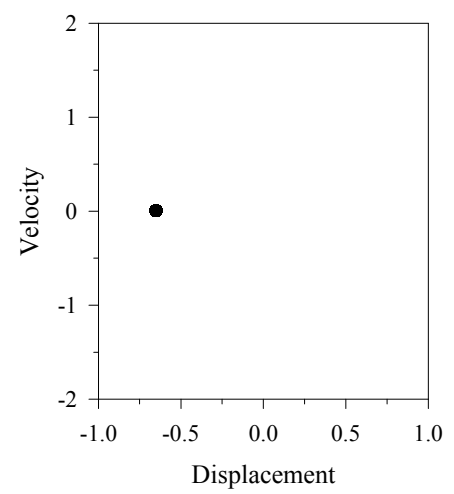

(c) Poincare map

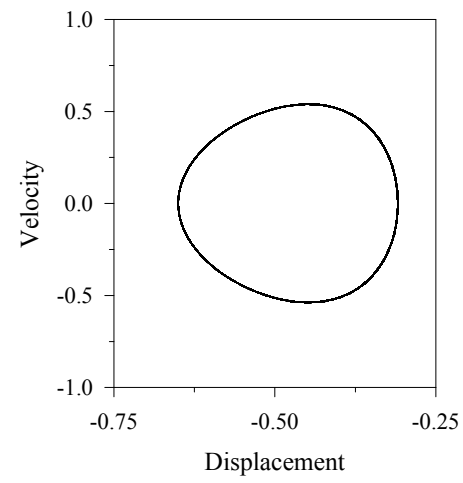

(b) Phase Plane

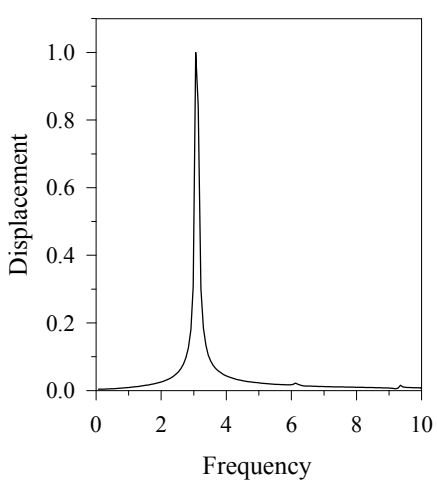

(d) Fast Fourier Transform

Figure 4. Time history, Phase Plane, Poincare map and Fast Fourier Transform (FFT). $F_{0}=5, C_{t}=0.5, C_{r}=10, \delta=0.1$ and $\Omega=3.1$ periodic $(1 \mathrm{~T})$ for the second mode 


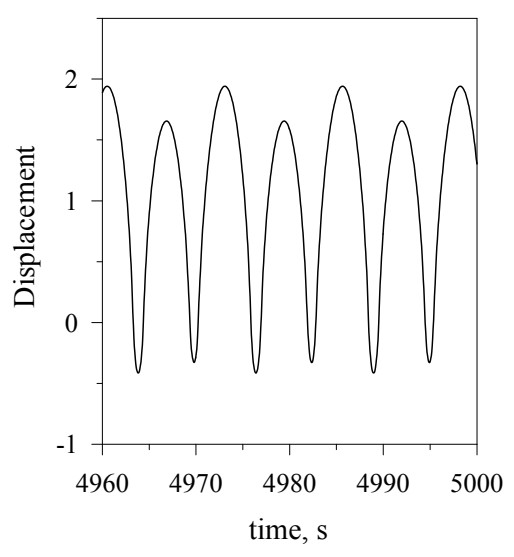

(a) time history

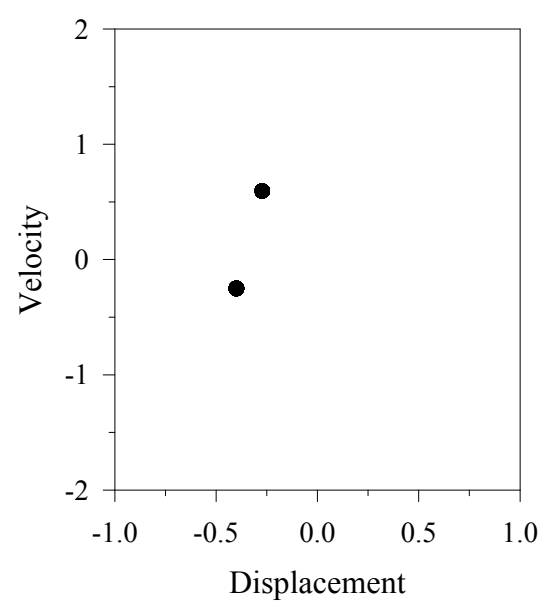

(c) Poincare map

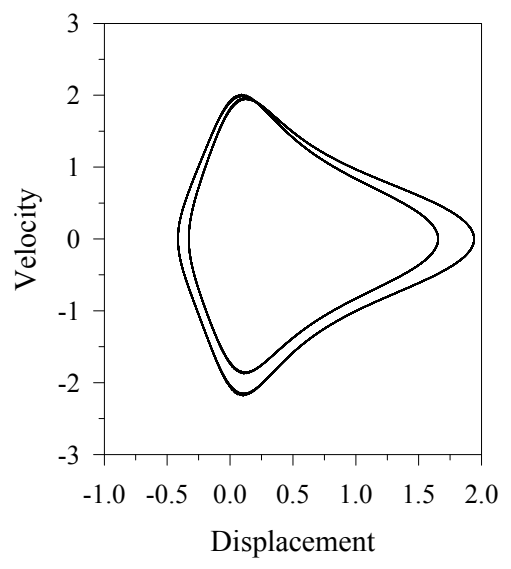

(b) Phase Plane

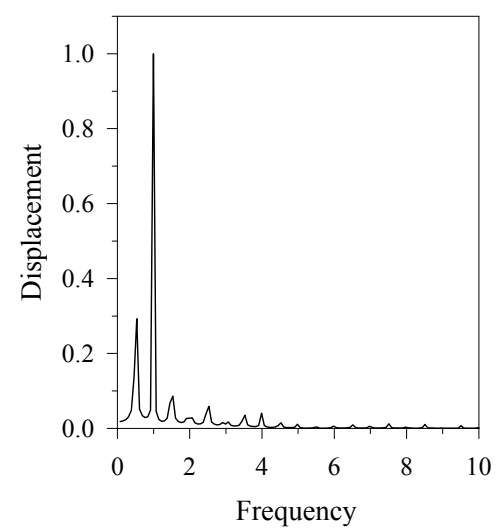

(d) Fast Fourier Transform

Figure 5. Time history, Phase Plane, Poincare map and Fast Fourier Transform (FFT).

$F_{0}=5, C_{t}=0.5, C_{r}=10, \delta=0.1$ and $\Omega=1.0$ periodic doubling (2T) for the second mode 


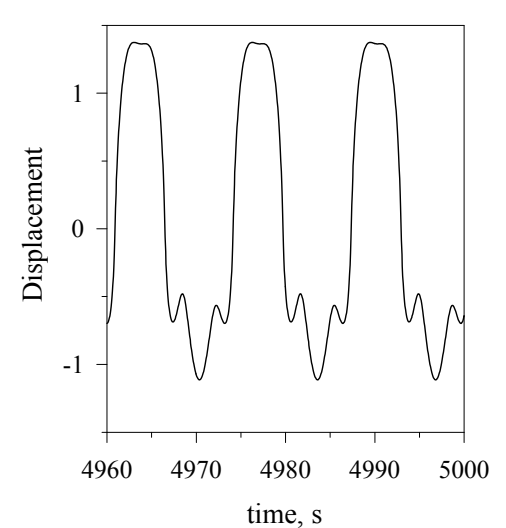

(a) time history

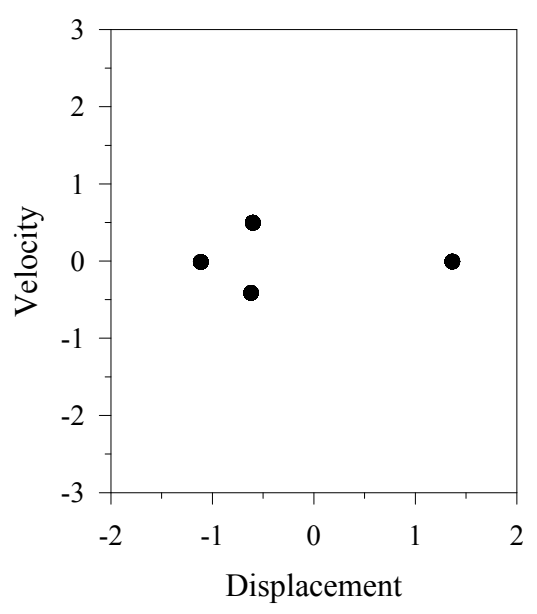

(c) Poincare map

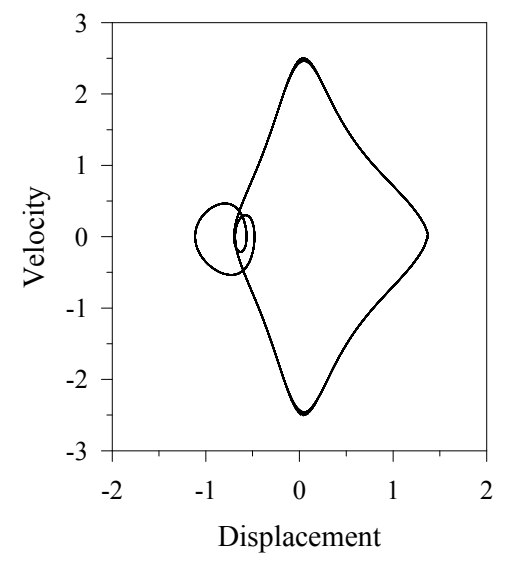

(b) Phase Plane

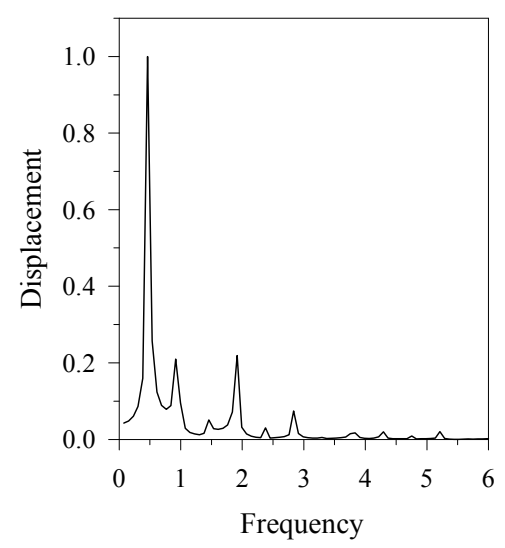

(d) Fast Fourier Transform

Figure 6. Time history, Phase Plane, Poincare map and Fast Fourier Transform (FFT).

$F_{0}=5, C_{t}=0.5, C_{r}=10, \delta=0.1$ and $\Omega=1.9$ higher period doubling (4T) for the second mode 


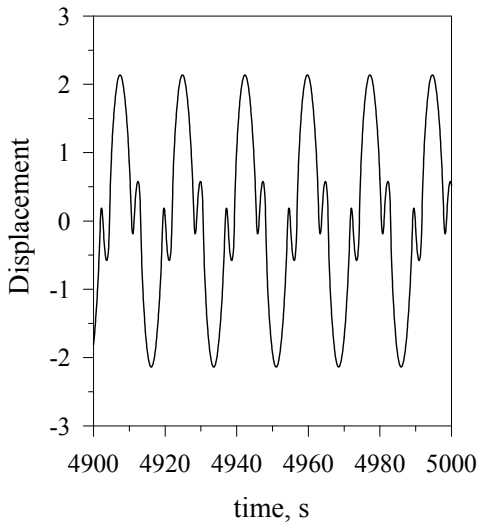

(a) time history

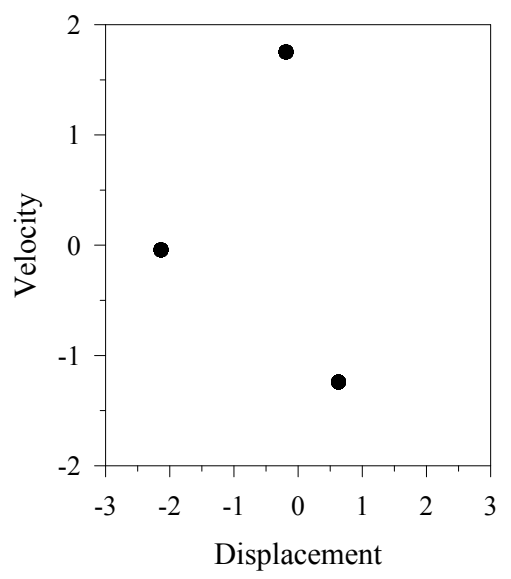

(c) Poincare map

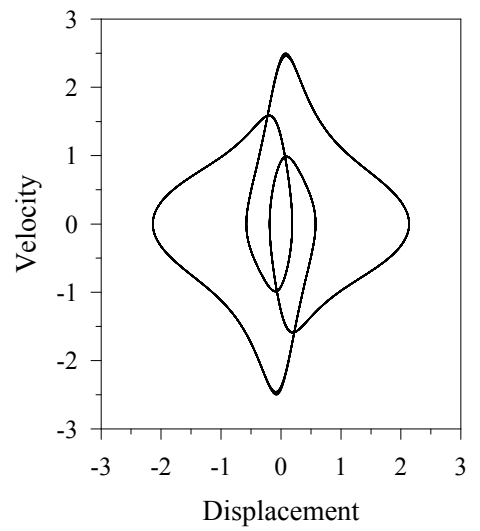

(b) Phase Plane

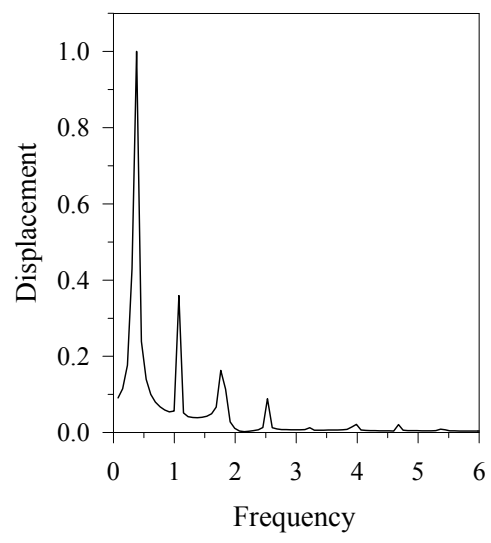

(d) Fast Fourier Transform

Figure 7. Time history, Phase Plane, Poincare map and Fast Fourier Transform (FFT). $F_{0}=5, C_{t}=0.5, C_{r}=10, \delta=0.1$ and $\Omega=1.08$ (3T attractor) for the second mode 


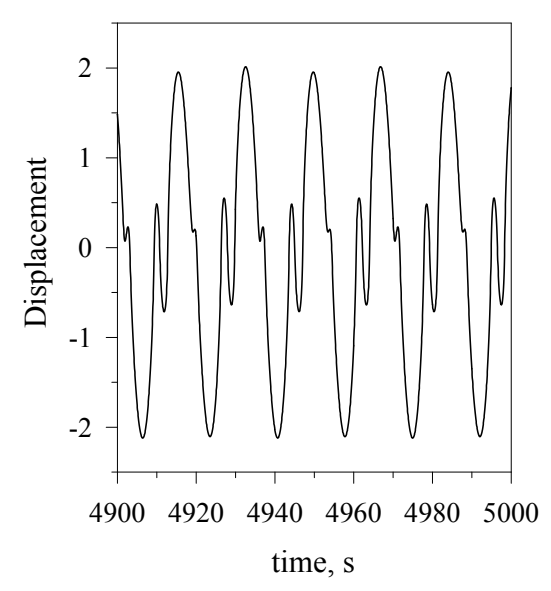

(a) time history

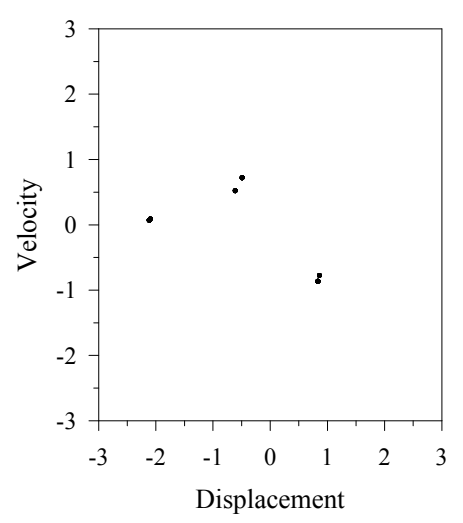

(c) Poincare map

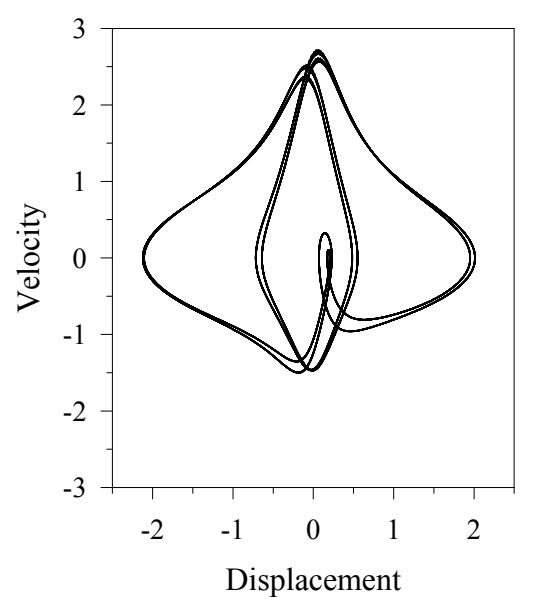

(b) Phase Plane

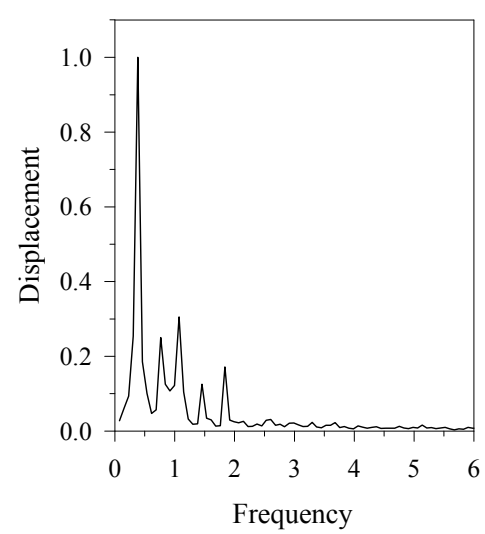

(d) Fast Fourier Transform

Figure 8. Time history, Phase Plane, Poincare map and Fast Fourier Transform (FFT). $F_{0}=5, C_{t}=0.5, C_{r}=10, \delta=0.1$ and $\Omega=1.1$ (6T attractor) for the second mode 


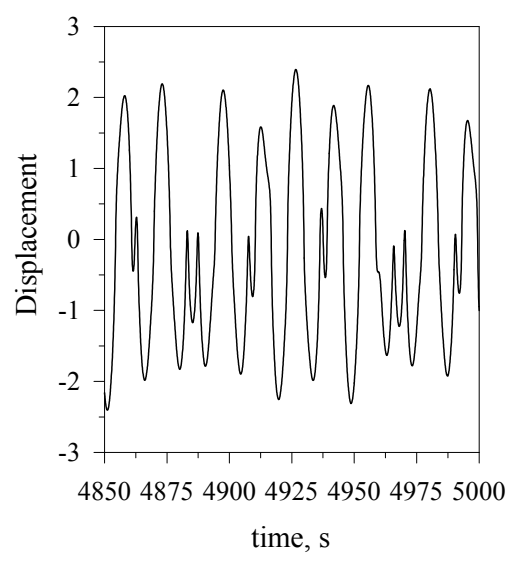

(a) time history

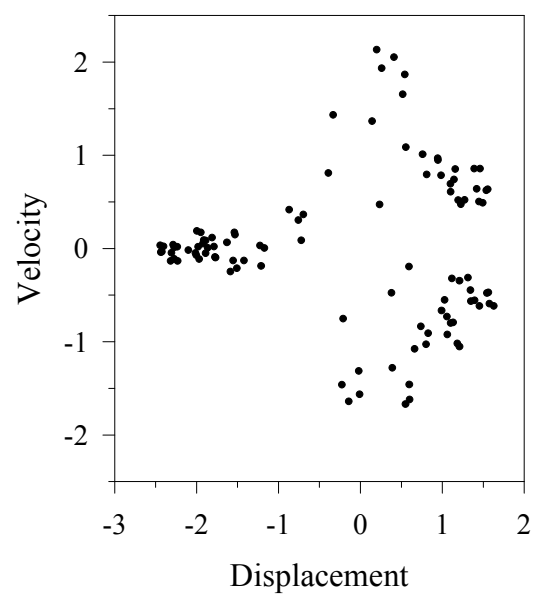

(c) Poincare map

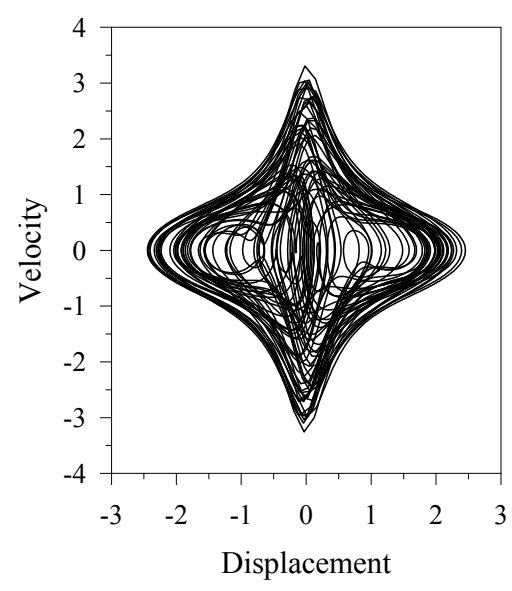

(b) Phase Plane

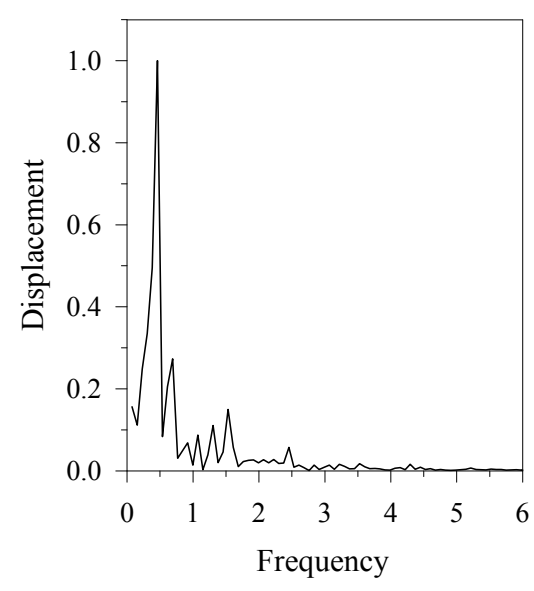

(d) Fast Fourier Transform

Figure 9. Time history, Phase Plane, Poincare map and Fast Fourier Transform (FFT). $F_{0}=5, C_{t}=0.5, C_{r}=10, \delta=0.1$ and $\Omega=1.29$ (Chaotic behaviour) for the second mode

Results presented in Figure 3 and with the aid of computer simulations (Figures 4-9) show that, as one may expect, the resonance curves of the asymmetric solution intersect those of the symmetric solution near the region of chaotic motion, which lies in the zone where the principal resonance curves of the symmetric solution may enter the second unstable region. Results for a hardening type oscillator, i.e. $\varepsilon_{1} / \varepsilon_{2}<1.6$, are presented in Figure 10 with the parameters $F_{0}=35, C_{r}=5$, $C_{t}=1, \alpha=0.1$ and $\delta=0.1$, for the third mode of vibration of the tapered beam under consideration. In this figure, the steady state response, first order and second unstable boundaries, biased solution and stability of the biased solution "Asymmetric" are also presented for the nonlinear oscillator with hardening characteristics. The first order unstable region intersects the response curve at the point of vertical tangency and the second unstable region has two boundaries; the first one is located at the super-harmonic resonance zone at $0.6<\Omega<0.635$ and the second intersects with the response curves at $\Omega=2.42$. From the figure, the asymmetric solution intersects with symmetric one at $\Omega \cong 1.60$, i.e. before the steady state response enters the second 
boundary of the second unstable region. In addition the biased solution is unstable at $1.91<\Omega<2.19$, at which there is a possibility of period doubling bifurcation (PDB). Results obtained, but not shown for the sake of brevity, indicated that the PDB and chaos may occur inside the regions $0.6<\Omega<0.635, \Omega>2.42$ and $1.91<\Omega<2.19$, at which the PDB may develop into higher period doublings and then culminates into chaos.

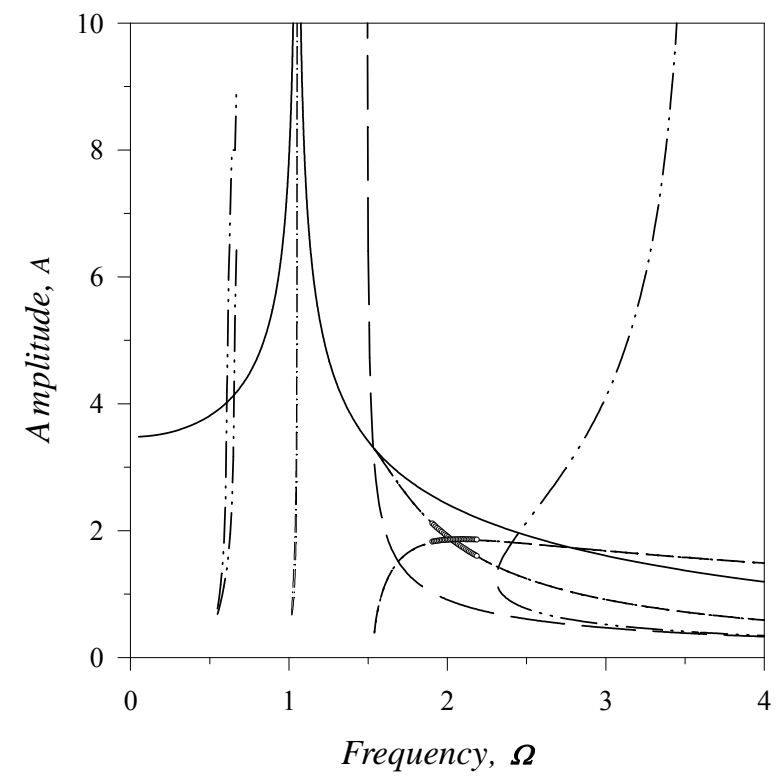

Figure 10. Steady State Frequency Response (SSFR), First Order Stability ( $1^{\text {st }}$ Stab.), Second order Stability ( $2^{\text {nd }}$ Stab.), Biased Solution and Its Stability. $F_{0}=35, C_{t}=1, C_{r}=5$ and $\delta=0.02$ for the third mode: Steady State Frequency Response (SSFR), First Order Stability ( ${ }^{\text {st }}$ Stab.), Second order Stability ( $2^{\text {nd }}$ Stab.),

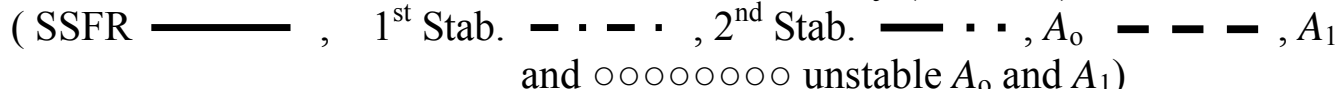

and 00000000 unstable $A_{0}$ and $A_{1}$ )

\section{CONCLUSIONS}

The present work has studied the steady state frequency response of an elastically restrained cantilever tapered beam. The nonlinear uni-modal equation of motion was taken from [14]. The steady state responses under a sinusoidal excitation were obtained for different values of physical parameter; rotational flexibility $C_{r}$, translational flexibility $C_{t}$, taper ratio $\alpha$, damping $\delta$ and excitation level $F_{0}$. The steady state frequency response curves are presented for the first three modes of vibration using the method of harmonic balance.

It was shown that the variation of $C_{r}$ and $C_{t}$ is associated with a qualitative change in the dynamics behaviour of the steady state response.

It has been shown that the frequency response curves of the asymmetric solution intersect those of the symmetric solution before the symmetric solutions penetrate into the second unstable region, regardless the characteristic type of the nonlinear equation of motion, i.e. softening or hardening. In addition, it has been shown that at the point of intersection between asymmetric and symmetric 
solutions, i.e. when $A_{0}$ in the biased solution has non-zero real value, the symmetric solution bifurcates into an asymmetric one and the PDB appears in this area and in some cases the PDB developed into chaos.

\section{ACKNOWLEDGMENT}

A.A. Al-Qaisia and M. S. Abdel-Jaber acknowledge the support of the Deanship of Scientific Research, The University of Jordan, Amman-Jordan.

\section{REFERENCES}

[1] Kanga, J. H. and Leissa, A. W. "Three-dimensional Vibration Analysis of Thick, Tapered Rods and Beams with Circular Cross-section", International Journal of Mechanical Sciences, 2004, Vol. 46, pp. 929-944.

[2] Andrade, A., Providência, P. and Camotim, D. "Elastic Lateral-torsional Buckling of Restrained Web-tapered I-beams", Computers and Structures, 2010, Vol. 88, pp. 1179-1196.

[3] Das, D., Sahoo, P. and Saha, K. "Out-of-plane Free Vibration Analysis of Rotating Tapered Beams in Post-elastic Regime”, Materials and Design, 2009, Vol. 30, pp. 2875-2894.

[4] Hoseini, S. H., Pirbodaghi, T., Ahmadian, M. T., and Farrahi, G. H. "On the Large Amplitude Free Vibrations of Tapered Beams: an Analytical Approach", Mechanics Research Communications, 2009, Vol. 36, pp. 892-897.

[5] De Rosa, M.A., Lippiello, M., Maurizi, M. J. and Martin, H. D., "Free Vibration of Elastically Restrained Cantilever Tapered Beams with Concentrated Viscous Damping and Mass", Mechanics Research Communications, 2010, Vol. 37, pp. 261-264.

[6] Cheng, Y. Yu, Z., Wub, X. and Yuan Y., "Vibration Analysis of a Cracked Rotating Tapered Beam using the p-version Finite Element Method", Finite Elements in Analysis and Design, 2011, Vol. 47, pp.825-834.

[7] Ozgumus, O.O. and Kaya, M.O., "Energy Expressions and Free Vibration Analysis of a Rotating Double Tapered Timoshenko Beam Featuring Bending-torsion Coupling", International Journal of Engineering Science, 2007, Vol. 45, pp. 562-586.

[8] Auciello, N.M. and Nole, G. "Vibrations of a Cantilever Tapered Beam with varying section properties and Carrying a Mass at the Free End," Journal of Sound and Vibration, 1998, Vol. 214, pp. 105-119.

[9] Nagaya, K. and Hai, Y. "Seismic Response of Underwater members of Variable Cross Section", Journal of Sound and Vibration, 1985, Vol. 119, pp. 119-138.

[10] Laura, P.A.A. and Gutierrez, R.H. "Vibrations of an Elastically restrained Cantilever Beam of Varying Cross Sections with Tip Mass of Finite Length", Journal of Sound and Vibration, 1986, Vol. 108, pp.123-131.

[11] Shong, J.W. and Chen, C.T. "An Exact Solution for the Natural Frequency and Modes Shapes of an Immersed Elastically Wedge Beam Carrying an Eccentric Tip Mass with Mass Moment of Inertia", Journal of Sound and Vibration, 2005, Vol. 286, pp. 549-568.

[12] Chen, D.W. and Wu, J.S. "The Exact Solutions for the Natural Frequency and Modes Shapes of Non-Uniform Beams with Multiple Spring-Mass Systems", Journal of Sound and Vibration, 2008, Vol. 313, pp. 772-783.

[13] Abdel-Jaber, M.S., Al-Qaisia, A.A., Abdel-Jaber, M. and Beale R.G., Nonlinear Natural Frequencies of an elastically restrained tapered beam, Journal of Sound and Vibration, 2008, Vol. 255, pp. 299-322.

[14] Abdel-Jaber, M., Al-Qaisia, A.A. and Abdel-Jaber, M.S.”Non-linear natural frequencies of a tapered cantilever beam”, Advanced Steel Construction, 2009, 5, pp259-272. 
[15] Al-Qaisia, A.A. and Hamdan, M.N. "Bifurcation and Chaos of an Immersed Cantilever Beam in a Fluid and Carrying an Intermediate Mass", Journal of Sound and Vibration, 2002, Vol. 253, pp. 859-888.

[16] Al-Qaisia, A.A. and Hamdan, M.N. "On the Steady State Response of Oscillators with Static and Inertia Non-Linearities", Journal of Sound and Vibration, 1999, Vol. 223, pp. 49-71.

[17] Al-Qaisia, A.A. and Hamdan, M.N., "Bifurcations of Approximate Harmonic Balance Solutions and Transition to Chaos in an oscillator with Inertial and Elastic Symmetric Nonlinearities", Journal of Sound and Vibration, 2001, Vol. 244, pp. 453-479.

[18] Al-Qaisia, A.A. and Hamdan, M.N. and Al-Bedoor, B., "On the Steady State Response of a Cantilever Beam Partially Immersed and Carrying an Intermediate Mass", Shock and Vibration, 2000, Vol. 7, pp. 179-194. 


\title{
DUCTILITY REQUIREMENTS FOR THE DESIGN OF BOLTED LAP SHEAR CONNECTIONS IN BEARING
}

\author{
J. Henriques ${ }^{1}$, J-P. Jaspart ${ }^{2}$ and L. Simões da Silva ${ }^{3}$ \\ ${ }^{1}$ ISISE, University of Coimbra, Civil Engineering Department, Coimbra, Portugal \\ ${ }^{2}$ University of Liège, ArGEnCo Department, Liège, Belgium \\ ${ }^{3}$ ISISE, University of Coimbra, Civil Engineering Department, Coimbra, Portugal \\ *(Corresponding author: E-mail:jagh@dec.uc.pt)
}

Received: 9 July 2012; Revised: 13 August 2012; Accepted: 23 December 2012

\begin{abstract}
The resistance of bolted lap shear connections in bearing is traditionally evaluated by considering an equal distribution of internal forces amongst the bolts. In fact, such an assumption may only be seen as the result of a plastic redistribution of the internal forces, what requires shear ductility in the vicinity of the bolts. In the present paper, ductility requirements are proposed that ensure that, in the presence of real geometric imperfections, plastic resistance can be attained.
\end{abstract}

Keywords: Shear bolted connections, equivalent bolt zone component, available deformation capacity, required deformation capacity, ductility criteria

\section{INTRODUCTION}

A connection can be classified as a Shear Bolted Connection when the forces transferred between the elements induce predominantly shear in the bolts. Two types of shear connections, also called lap connections, may be found: single and double overlap connections. The difference consists in the number of shear planes that cross the bolt shanks (Figure1). In the case of single lap connections, the eccentricity of the loading generates secondary bending actions in the bolts and as result tension load is also applied to the bolts. Consequently, the shear resistance of the bolt may be affected. According to 0 , the loss of shear capacity is up to $10 \%$, being higher for longer bolts.

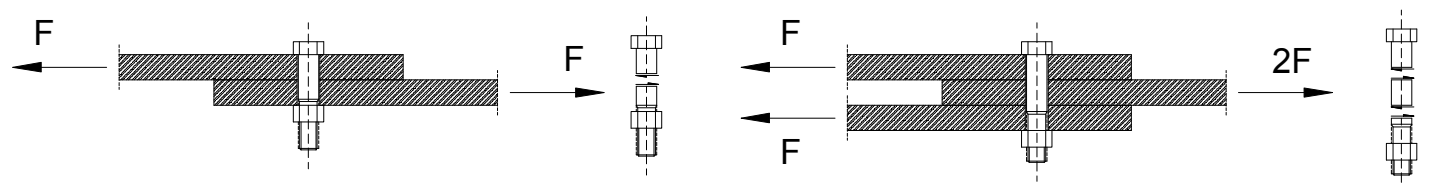

Figure 1. Single and Double Overlap Connections

In shear bolted connections, two different elements may be distinguished: connectors (bolts) and connected elements (plates). The term plate is used to refer to column flanges, beam flanges, beam webs, splice plates, etc.

The behaviour of shear bolted connections in bearing is known [2] to be divided in three stages: i) initially, load is transferred without deformation until the small friction developed by the hand tightened bolts is overcome; ii) subsequently, because of the hole clearance, free slip occurs until the bolts are in contact with the connected parts; iii) finally, bolt and plate are in contact, the load and deformation increase up to failure. The level of deformation depends on the type of failure governing the connection behaviour. Neglecting the small friction developed between the plates and the negligible bending of the bolt, four different resistance and deformation modes should be considered:

$>$ Bearing of the plate and/or bolt;

$>$ Shear in the plates;

$>$ Tension in the plates;

$>$ Shear in the bolt shanks. 
From these, the behaviour of a shear bolted connection can be defined by the response of two different parts: bolt zone, where bearing and shear forces develop; and the plate between holes where direct forces develop in the plate. The work presented in this article focuses on the bolt zone; so the failure of the connection by excess of tension in the connected plates is here not considered.

The performance of a bolted connection is complicated and both the stress distribution in the connection and the forces in the bolts depend on the stiffness of the bolts, and the connecting steel elements. Consequently, an exact theoretical analysis is not possible. The design of shear bolted connections in bearing can then performed by means of reliable empirical formulae available in classical books [2]-[5], design guides[6]-[7] or in design codes [8]-[10], The present work is carried out within the scope of European Standards; therefore, [8] is used as a basis. In section 2 of this paper, the design approach prescribed by this Standard is further discussed.

In bolted lap shear connections in bearing, the load to be transferred between the plates is distributed non-uniformly amongst the bolt-rows (Figure 2a), Owens [2]. If sufficient deformation is provided around each connector, a full plastic redistribution of forces may be noticed, otherwise failure is reached by lack of ductility and the maximum external force to be transferred is lower than the one corresponding to a full plastic distribution. Schematically, the different stages of forces distribution in a shear bolted connection may be represented as in Figure 2.

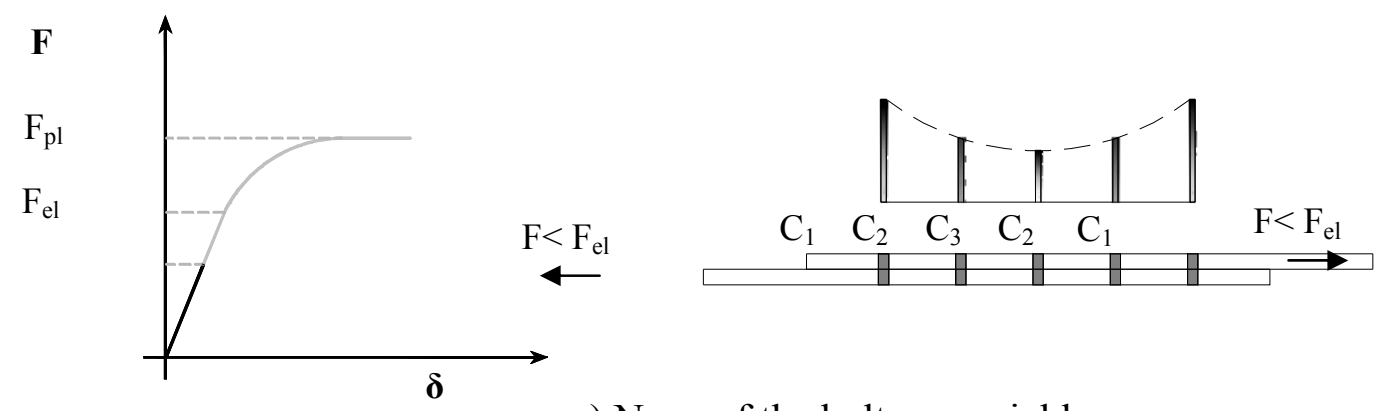

a) None of the bolt rows yield;
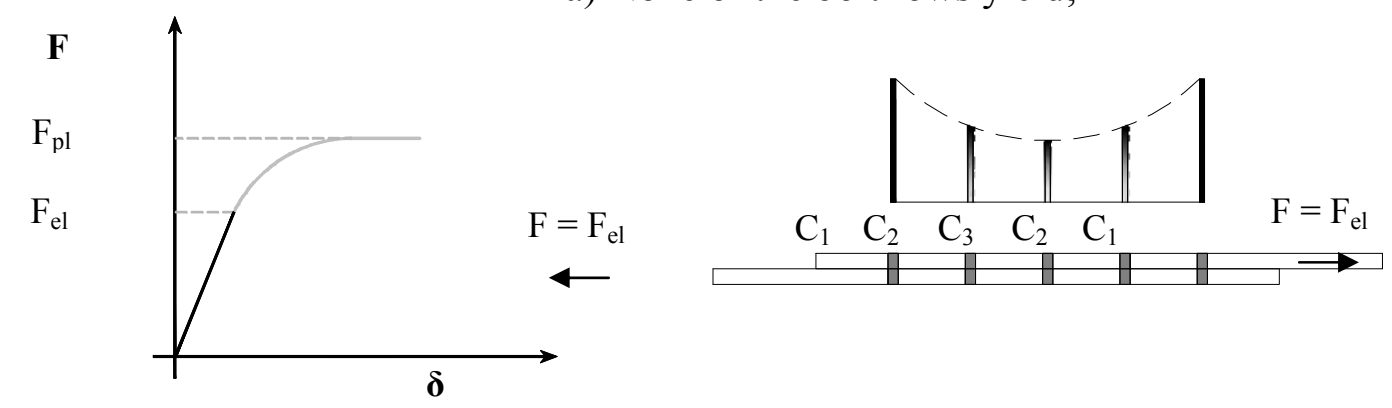

b) Outer bolt rows yield (elastic resistance of the connection);
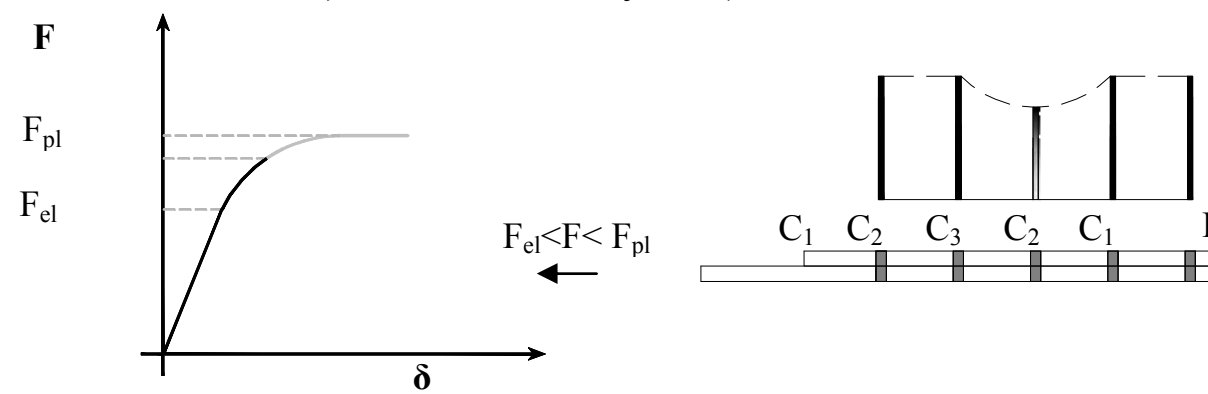

c) Progressive yielding of bolt rows from outside to inside 


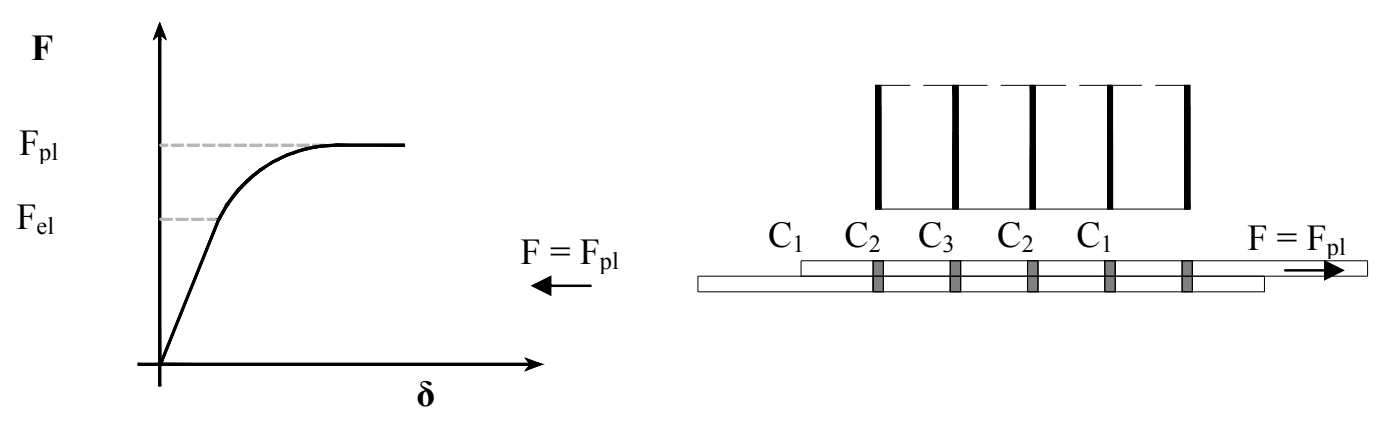

d) All bolt rows yield (full plastic resistance of the connection)

Figure 2. Different Stages of Force Distribution in Shear Bolted Connections

In [11], Ju et al. showed that in the nonlinear range the maximum load achieved by the connection is almost linearly proportional to the number of bolts in the connection. In part 1-8 of Eurocode 3 [8], a full plastic distribution of forces can be assumed as long as the connection length is limited. A similar prescription is given in the AISC design manual [9]. However, for long steelwork joints of normal proportions this behaviour will be insufficient to produce an equal load distribution. The end-bolts will reach their deformation limit and fail before the remaining ones have been fully loaded. This will result in progressive failure at an average shear value per bolt below the single-bolt shear resistance. Tests have shown that the influence of the length of the joint, rather than with the number of bolts, is a dominant parameter [7]. Accordingly, the codes [8]-[10]prescribe a reduction factor for high connection lengths.

Pietrapetrosa el al.[12] approached the subject by only considering fitted bolts. Their study showed that, inside the limits given by the code and by practical guidance, sufficient ductility to achieve a full plastic distribution of internal forces is available. However, the common practice is the use of non fitted bolts and the presence of geometrical imperfections (bolt /holes misalignment)is also a reality. Consequently, the lack-of-fit will increase the demands of ductility as some bolts bear before the others, as verified by Wald et al.[13]. They showed that for certain values of gap in some bolt rows, failure was first attained in the extreme bolts and therefore a full plastic resistance was not reached. According to [2] and [7], the reduction of shear resistance is up to $50 \%$ of that if equal distribution of load was observed.

Based on the principles of the component method, it is the objective of the present paper to derive general formulae to determine the deformation capacity required in the bolt zone components in order to reach, in actual shear bolted connections, full plastic resistance. To this end, the maximum geometrical imperfections were evaluated according to the hole clearances and fabrication tolerances. Then, the component based mechanical model proposed in [12] for shear bolted connections is used. Furthermore, the behavioural characterization of the activated components is obtained by means of numerical, experimental and analytical data. Finally, the required and available deformation capacities on the bolt zone are derived and ductility requirements are proposed. 


\section{EUROCODE 3 DESIGN PROCEDURE FOR BOLTED CONNECTIONS IN SHEAR}

Part 1.8 of Eurocode 3 [8] is dedicated to the design of joints in steel structures. It prescribes the component approach for the evaluation of the mechanical properties of the joints, Jaspart [14] and Weynand et al, [15]. However, the analysis of shear bolted connections is not specifically treated, although the code gives recommendations for the evaluation of the stiffness and resistance properties of several individual components. According to the principles of the component method, it is up to the designer to identify the relevant components and to assemble them according to a representative mechanical model in order to be able to predict the response of the whole connection.

According to the classification system for joints in Eurocode 3 part 1.8 [8], the connections considered here belong to category A: Shear Bolted Connections - Bearing Type. These ones resist by transferring forces through plate/bolt contact and bolt shearing. Non preloaded bolts are used and the small friction resistance between the contact surfaces is neglected. Considering the resistance and deformation modes listed in the introduction and that are relevant for shear bolted connections, among the list of individual components presented in Table 6.1 of part 1.8 of Eurocode 3 [8], the following should be considered: bolt in shear (Component 11), plate/bolt in bearing (Component 12) and plate in tension (Component 9). Furthermore it is then assumed that the failure mode of a bolt zone (i.e. a zone where a shear force is locally transferred from one plate to another) is associated to that of the weakest component. Through this procedure, the resistance and stiffness properties of the bolt zone may so be evaluated. It is noted, however, that part 1.8 of Eurocode 3 gives no information on the deformation capacity of these components. Table 1 summarises the characterization of the relevant components.

The evaluation of the response of a shear bolted connection (Figure 3a) by assembly of the relevant components is accurately obtained using the mechanical model of Figure 3b, Pietrapetrosa el al. [12] and Gresnigt et al. [16]. In this simple rational model, with higher practical interest than any sophisticated FE model, each individual component is modelled through extensional springs. In the bolt zone, one observes that three springs act in series: the bolt in shear $\left(\mathrm{S}_{\mathrm{b}}\right)$; and twice the plate/bolt in bearing $\left(\mathrm{S}_{\mathrm{pi}}\right)$. Assembling these three springs into an equivalent spring $\mathrm{S}_{\mathrm{eq}}$ (describing the bolt zone response) leads to the simplified model of Figure $3 \mathrm{c}$ where the components at the bolt zone are represented by a so-called equivalent bolt zone component (Table 1). It should be noted that this model neglects the secondary bending actions that may develop in the case of single lap joints. Though, these bending actions have decreasing effect with the increasing of the length of the joint [17]. Furthermore, often the connected members are prevented from significant bending because of the presence of webs and therefore, the tensile component on the bolt is of minor importance. Nevertheless, the bending action can be indirectly introduced by affecting the components response. For the previous reasons, this is not the case in the present work and the secondary bending actions are disregarded, 
Table 1. Eurocode 3 Expressions to Evaluate the

Characteristic Resistance $\left(R_{c}\right)$ and the Stiffness $\left(S_{c}\right)$ of the Basic Components

\begin{tabular}{|c|c|}
\hline & $R_{c}$ \\
\hline $\begin{array}{c}\text { Plate in } \\
\text { tension } \\
\text { (Component } \\
9)\end{array}$ & $R_{p l}=\min _{A_{\text {net }}(A)}\left(A f_{y}\right) ; 0,9$ \\
\hline $\begin{array}{c}\text { Bolt in } \\
\text { shear } \\
\text { (Component } \\
11)\end{array}$ & $S_{b}=8 d^{2} f_{u b} / d_{M 16}$ \\
\hline $\begin{array}{c}\text { Plate in } \\
\text { bearing } \\
\text { (Component } \\
\text { 12) }\end{array}$ & $S_{p}=12 \mathrm{k} b \mathrm{k} t d f_{u}$ \\
\hline$\leftarrow \square$ & $\begin{array}{cc}S_{e q}= & R_{e q}=\min \left(R_{b,} R_{p 1}\right. \\
\left(S_{b 2}{ }^{-1}+S_{p 1}{ }^{-1}+S_{p 2}{ }^{-1}\right)^{-1} & \end{array}$ \\
\hline $\begin{array}{ll}E & \text { Young Modulus } \\
A & \text { gross area of the plate } \\
A_{n e t} & \text { net area of the plate } \\
p_{b} \quad \text { pitch distance (// to load transfer) } \\
e_{b} \text { end distance (// to load transfer) } \\
f_{y} \text { yield strength of the plate } \\
f_{u} \quad \text { ultimate strength of the plate } \\
t \quad \text { thickness of the plate } \\
A_{b} \quad \text { shear area of the bolt (nominal or } \\
& \text { stress area) } \\
f_{u b} & \text { ultimate strength of the bolt }\end{array}$ & 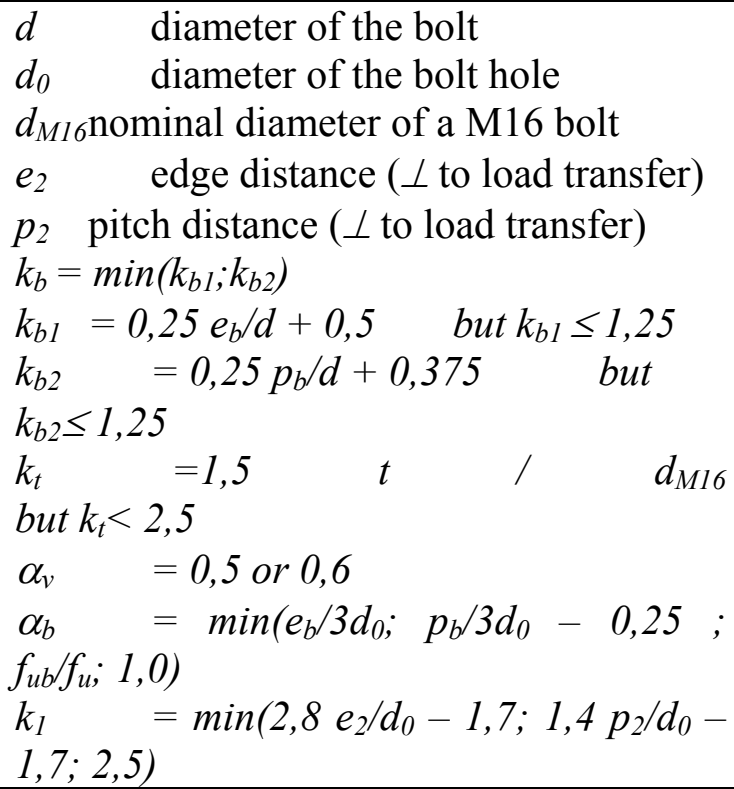 \\
\hline
\end{tabular}

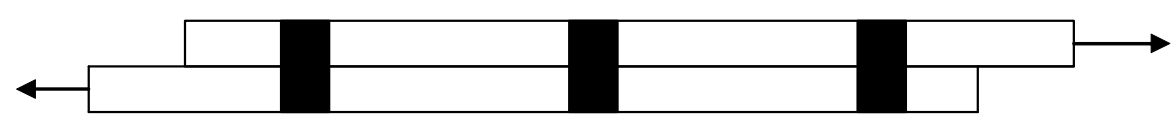

a) Shear connection with three bolts

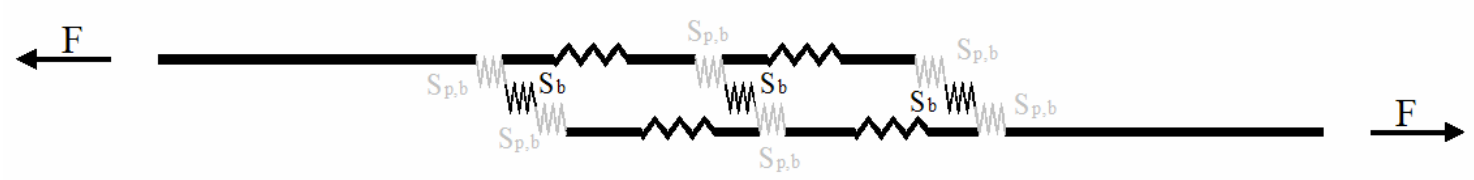

b) Actual mechanical model 


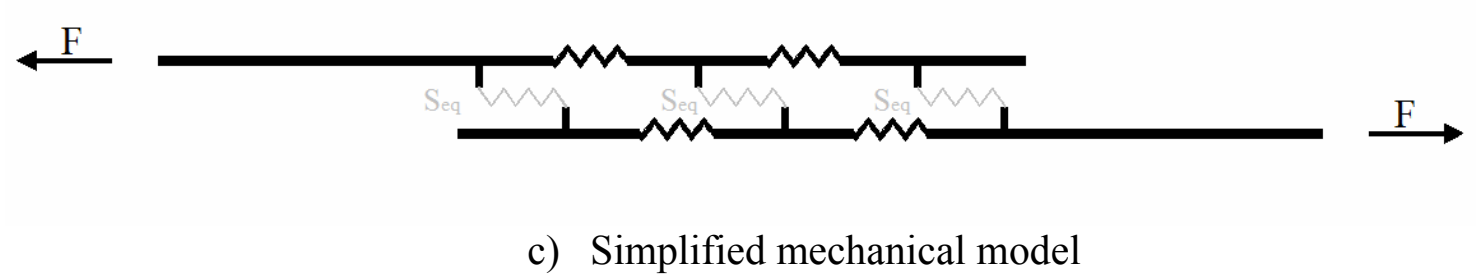

Figure 3. Mechanical Models

For shear connections with more than one bolt zone "in length", two recommendations given by the code are relevant. The first is related to the resistance of connections with a limited number of bolt zones along the length (EN1993-1-8: 3.7 [8]):

$$
\left\{\begin{array}{l}
\text { if } F_{v, R d, i} \geq F_{b, R d, i} \forall i \Rightarrow F_{R d}=\sum F_{b, R d, i} \\
\text { if not } F_{R d}=n \min \left\{F_{R d, i}\right\} \quad \text { with } F_{R d, i}=\min \left(F_{v, R d, i} ; F_{b, R d, i}\right)
\end{array}\right.
$$

where:

- $\quad F_{R d}$ is the resistance of the whole connection;

- $\quad n$ is the number of bolt zones "in length;

- $i$ indicates the bolt zone number;

- $\quad F_{b, R d, i}$ and $F_{v, R d, i}$ are, respectively, the bearing and the shear resistances of bolt zone $i$.

The second rule is related to long joints where the shear resistance should be reduced if the connection length $\left(L_{j}\right)$ exceeds $15 \mathrm{~d}$. In this case, the following reduction factor $\left(\beta_{j}\right)$ should be applied to the shear resistance $\left(\mathrm{F}_{\mathrm{v}, \mathrm{Rd}}\right)$ of the bolts (EN1993-1-8: 3.8 [8]):

$$
\beta_{L f}=1-\frac{L_{j}-15 d}{200 d} \text { but } 0.75 \leq \beta_{L F} \leq 1.0
$$

Similar limitations to the shear resistance of the bolted connection are given in [9] and [10].

\section{EVALUATION OF THE GEOMETRICAL IMPERFECTIONS/LACK OF FIT}

As in every construction type, imperfections related to fabrication have to be considered in steel structures. As far as the response of shear connections is concerned, the discrepancy between the nominal and the actual values of bolt diameters, hole diameters and positions (pitches and end distances) may affect the behaviour of the connections as the geometrical imperfections will lead to a non simultaneous transfer of forces between the bolts, as it would be the case for "perfect" connections (for instance, connections with fitted bolts).

Values of tolerances are given in the European Standard for the Execution of Steel Structures and Aluminium Structures, EN 1090-2 [18], in ISO/DIS 4759-1 [18] and in ISO286-2 [20]. Based on these values, the lack of fit in bolted connections may be quantified. However, due to the multiple parameters involved, this task is complex. In order to simplify, and have in consideration the evaluation of the maximum required deformation in a bolt zone, some assumptions are established in order to get the "worst situation" (i.e. the one for which the highest demand in terms of ductility is required from a bolt zone): 
Possibility to have different values of actual hole diameters in every plate;

$>$ Possibility to have different hole deviations in every plate, and consequently different values of pitch and end distances in every plate;

$>$ The bolt initially in contact with the plates is one of the outer bolts (henceforth this bolt will be designated as FBW [First Bolt Working], while the notation RB [Rest of the Bolts] will be used for all the others), this allows to maximise the requested deformation capacity for the FWB bolts;

$>$ The "worst situation" results from the combination of all these possibilities. Even if this is not the more realistic pattern, it could anyway happen; and for sure it is the one leading to the highest request in terms of ductility.

Using the values for tolerances from the standards (EN1090-2: 6.6 and D.2.8 [18]) and the previous assumptions, several connection layouts may be drawn to identify the "worst case", as illustrated in Figure 4. A detailed description on how these values were obtained is given in [21].

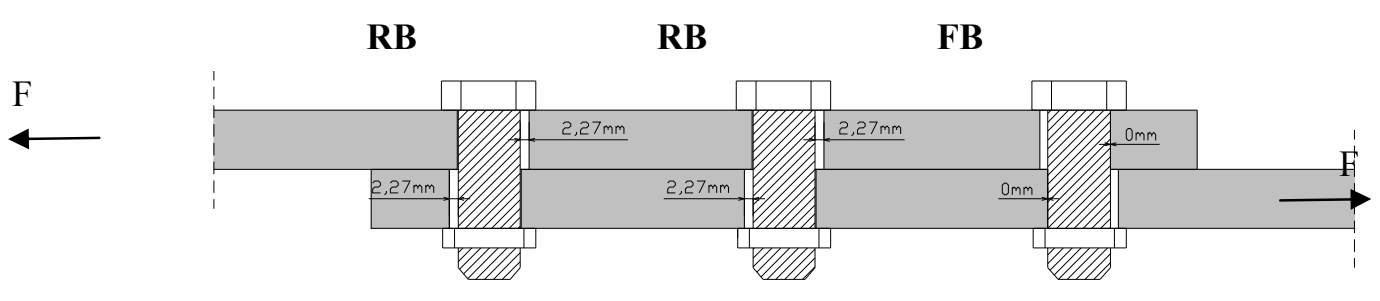

Figure 4. Connection Layout Considering the Presence of Geometrical Imperfections

Analysing several situations, as different bolt diameters, one obtains the gaps to be considered in a bolted connection that respect the previous assumptions. Table 2 presents maximum gaps that may be observed in a connection layout according to the bolt diameter used. The main factors which distinguish the different values obtained are the hole clearance and the tolerances allowed by standards, for different bolt diameters.

Table 2. Gaps in Bolted Connections

\begin{tabular}{cccc}
\hline \multirow{2}{*}{ Bolts } & \multicolumn{3}{c}{2,3 or more bolts } \\
& FBW gap & RB gap & Max. Gap \\
\hline M12-M14 & 0.00 & 3.08 & 3.08 \\
M16 & 0.00 & 4.54 & 4.54 \\
M18-M24 & 0.00 & 4.66 & 4.66 \\
M27 & 1.00 & 5.66 & 4.66 \\
over & 1.00 & 5.78 & 4.78 \\
\hline
\end{tabular}




\section{RESPONSE OF THE INDIVIDUAL COMPONENTS}

As mentioned before, two different individual components interact in the bolt zone: the bolt in shear and the plate/bolt in bearing. In order to analyse shear bolted connections, the behaviour of these components has first to be predicted. Hereafter, code recommendations and results of former investigations are used to achieve it.

\subsection{Bolt in Shear}

In Moscow, Karmalin et al.[22] have performed numerous experimental tests on bolts in shear. Resistance, stiffness and deformation capacity of bolts subjected to shear have been measured for M16, M20 and M24 with grades 5.8, 8.8 and also for bolts with a minimum tensile strength equal to $1100 \mathrm{MPa}$ (high strength). The tested specimens consisted of single bolted connections with two-shear planes, see Figure 5. Table 3 presents the test results.

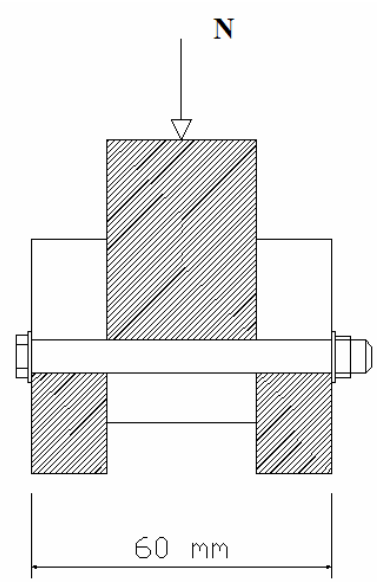

Figure 5. Test Set-up of Moscow Experiments

Table 3. Moscow Test Results

\begin{tabular}{ccccccc}
\hline \multirow{2}{*}{ Bolts Grade } & \multicolumn{3}{c}{$\mathrm{R}_{\mathrm{u}, \mathrm{b}}[\mathrm{kN}]$} & \multicolumn{3}{c}{$\delta_{\mathrm{u}, \mathrm{b}}[\mathrm{mm}]$} \\
& $\mathrm{M} 16$ & $\mathrm{M} 20$ & $\mathrm{M} 24$ & $\mathrm{M} 16$ & $\mathrm{M} 20$ & $\mathrm{M} 24$ \\
\hline 5.8 & $63-72$ & $97-110$ & $137-150$ & $2.9-3.4$ & $3.4-3.8$ & $4.1-4.4$ \\
8.8 & $81-93$ & $124-141$ & $175-193$ & $2.2-2.5$ & $2.6-3.0$ & $3.1-3.5$ \\
High-strength & $126-150$ & $195-220$ & $275-308$ & $1.6-2.0$ & $1.8-2.2$ & $2.1-2.7$ \\
\hline
\end{tabular}

Based on the EC3 part 1.8 [8] expressions (see Table 1) and on these experimental results, expressions to determine the ultimate deformation capacity, ultimate resistance and strain-hardening stiffness of bolts in shear have been derived. With the aim to refer explicitly to Eurocode 3, the here-above listed parameters are expressed as a function of the initial stiffness $\left(S_{b}\right)$ and of the nominal resistance $\left(R_{b}\right)$ (see Table 1). Table 4 presents these expressions. A detailed derivation being found in Henriques thesis [21]. 
Table 4. Ultimate Resistance, Ultimate Deformation Capacity and Strain-hardening Stiffness for the "Bolt in Shear" Component

\begin{tabular}{|c|c|c|c|c|c|}
\hline \multirow{2}{*}{ Bolts Grade } & \multicolumn{3}{|c|}{$\delta_{\mathrm{u}, \mathrm{b}}$} & \multirow{2}{*}{$\mathrm{S}_{\mathrm{st}, \mathrm{b}}$} & \multirow{2}{*}{$\mathrm{R}_{\mathrm{u}, \mathrm{b}}$} \\
\hline & M16 & M20 & M24 & & \\
\hline 5.8 & $\begin{array}{c}4.7 \\
\mathrm{R}_{\mathrm{b}} / \mathrm{S}_{\mathrm{b}}\end{array}$ & $5.5 \mathrm{R}_{\mathrm{b}} / \mathrm{S}_{\mathrm{b}}$ & $6.7 \mathrm{R}_{\mathrm{b}} / \mathrm{S}_{\mathrm{b}}$ & $\mathrm{S}_{\mathrm{b}} / 2.5$ & $1.58 \mathrm{R}_{\mathrm{b}}$ \\
\hline 8.8 & $\begin{array}{c}3.0 \\
\mathrm{R}_{\mathrm{b}} / \mathrm{S}_{\mathrm{b}}\end{array}$ & $3.5 \mathrm{R}_{\mathrm{b}} / \mathrm{S}_{\mathrm{b}}$ & $4.2 \mathrm{R}_{\mathrm{b}} / \mathrm{S}_{\mathrm{b}}$ & $\mathrm{S}_{\mathrm{b}} / 7.0$ & $1.05 \mathrm{R}_{\mathrm{b}}$ \\
\hline High-strength & $\begin{array}{c}2.6 \\
\mathrm{R}_{\mathrm{b}} / \mathrm{S}_{\mathrm{b}}\end{array}$ & $2.9 \mathrm{R}_{\mathrm{b}} / \mathrm{S}_{\mathrm{b}}$ & $3.4 \mathrm{R}_{\mathrm{b}} / \mathrm{S}_{\mathrm{b}}$ & $\mathrm{S}_{\mathrm{b}} / 1.5$ & $1.44 \mathrm{R}_{\mathrm{b}}$ \\
\hline
\end{tabular}

\subsection{Plate/Bolt in Bearing}

Bearing problems are complex as they deal with contact between two bodies. The development of a numerical model for the simulation of bearing phenomena was carried out using the Lagamine code[23], a software developed at the ArGEnCo Department of the University of Liège. Available tests made in other universities were used to calibrate the numerical model: tests on shear bolted connections at the University of Ljubljana [24] and at the Technical University of Delft [25].

The idealized numerical model consisted in a plate with a hole fixed in one edge (width edge) and free in all the others. In the hole was placed a rigid element which simulated the bolt. This element is "pulled" against the plate in the opposite direction of the supports. Figure 6 illustrates the idealized model.

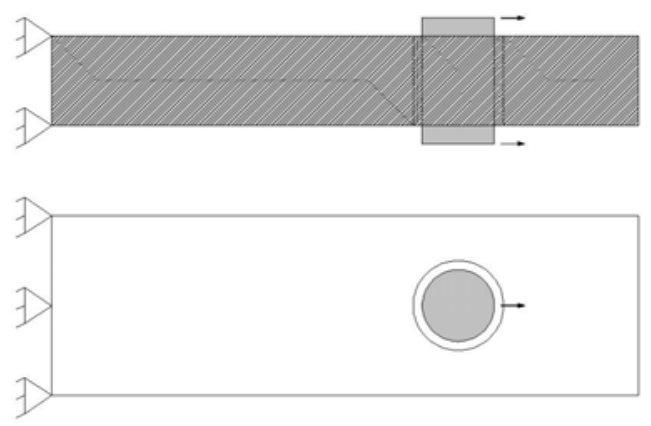

Figure 6. Idealized Model for Bearing

The plate was modelled using 3D volume elements (BLW3D) available in LAGAMINE. This element is defined by 8 nodes and 1 Gauss integration point. The bolt was modelled as a rigid body (FOUNDATION). As in the experiments, double overlap connections have been tested, only part of the external plates has been modelled. The confinement effect provided by these plates has been simulated, but only in the region where its influence is relevant, see Figure 7. For these plates the same type of 3D volume elements has been used. Finally, to model the contact, plane elements (CIF3D) able to simulate three-dimensional mechanical contact problems were used. This element is composed by 4 nodes and 4 Gauss integration points. Two contact zones have been defined: bolt - plates contact; main plate - external plate contact. 


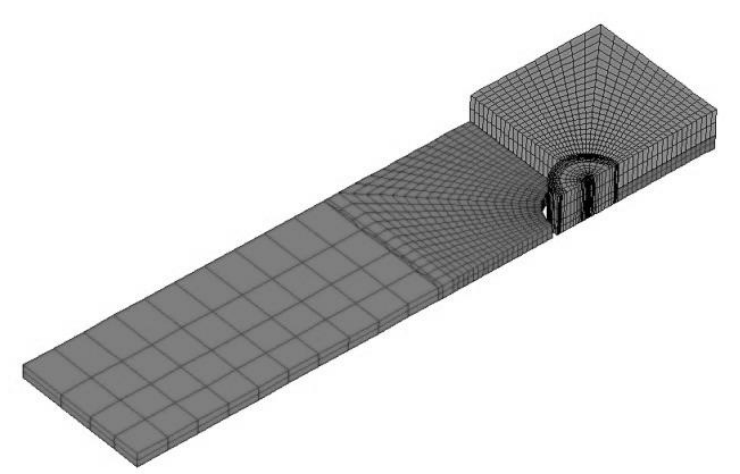

Figure 7. Model with Cover late

One of the main objectives was to be able to model bearing failure; this goal was not completely achieved. As one can see, as an example, in Figure 8, for one of the tested specimens, the numerical model can rather well approximate the whole connection behaviour, but no reliable failure criterion, indicating when the simulation should be stopped, has been finally identified. Further related investigations are therefore still needed.

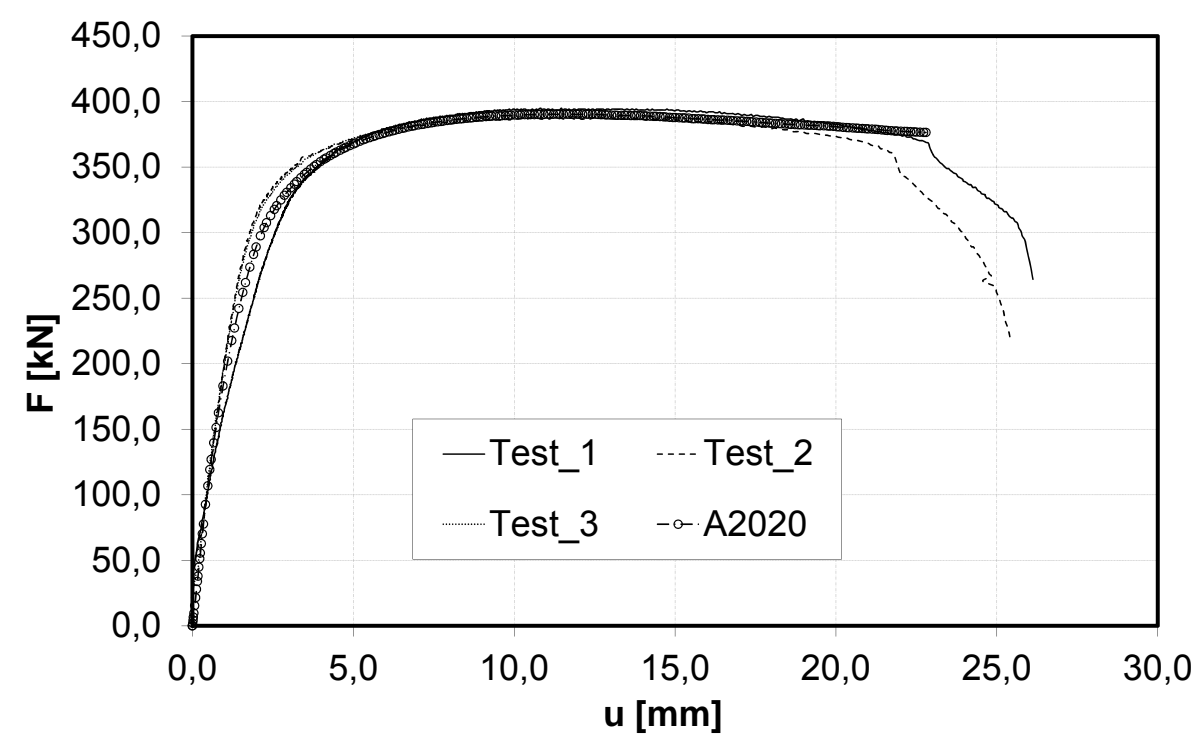

Figure 8. Simulation of A2020 Specimen [25] and Comparison with Tests

As a consequence, the characterization of the plate/bolt in bearing behaviour is based hereafter on the existing knowledge: the elastic stiffness and the nominal resistance are determined using code recommendations(see Table 1), while, for the other parameters (strain-hardening stiffness, ultimate resistance and ultimate deformation), expressions from previous works ([14], [12] and [21]) are used.

$$
\begin{aligned}
& S_{s t, p, b}=\frac{S_{p, b}}{40} \\
& R_{u, p, b}=1.25 R_{p, b} \\
& \delta_{u, p, b}=11 \frac{R_{p, b}}{S_{p, b}}
\end{aligned}
$$




\subsection{Plate in Tension}

Although present research work focuses on the bolt zone and on its capability to redistribute forces, the deformability of a plate in tension has an important influence on the distribution of forces amongst the bolts. The stiffness of the plate in tension has therefore also to be predicted; an expression is provided in Table 1.

\section{ASSEMBLY OF THE BASIC COMPONENTS}

In this section, the individual basic components are assembled with the objective to derive the available ductility of the equivalent bolt zone components and the ductility required to allow a full redistribution of internal forces in shear bolted connections.

\subsection{Available Deformation Capacity of the Equivalent Bolt Zone Component}

The deformation available in the equivalent bolt zone component is obtained through the "association" of the two basic components: the bolt in shear and the plate/bolt in bearing. Each basic component is characterized and the deformation capacity evaluated according to the previous sections. Subsequently assembly is done according to their resistance and deformability. The complete behaviour of the equivalent bolt zone component is then obtained.

The derivation of formulae to determine the available deformation capacity of the equivalent component depends on several factors such as: single or double overlap connections, plates with equal or different responses (different thickness, different steel properties), and the relation between the resistances of the individual components. So, many cases may be obtained. Figure 9 exemplifies one of these cases and Table 5 presents a list of expressions for several common cases. A comprehensive list of cases can be found in Henriques [21].

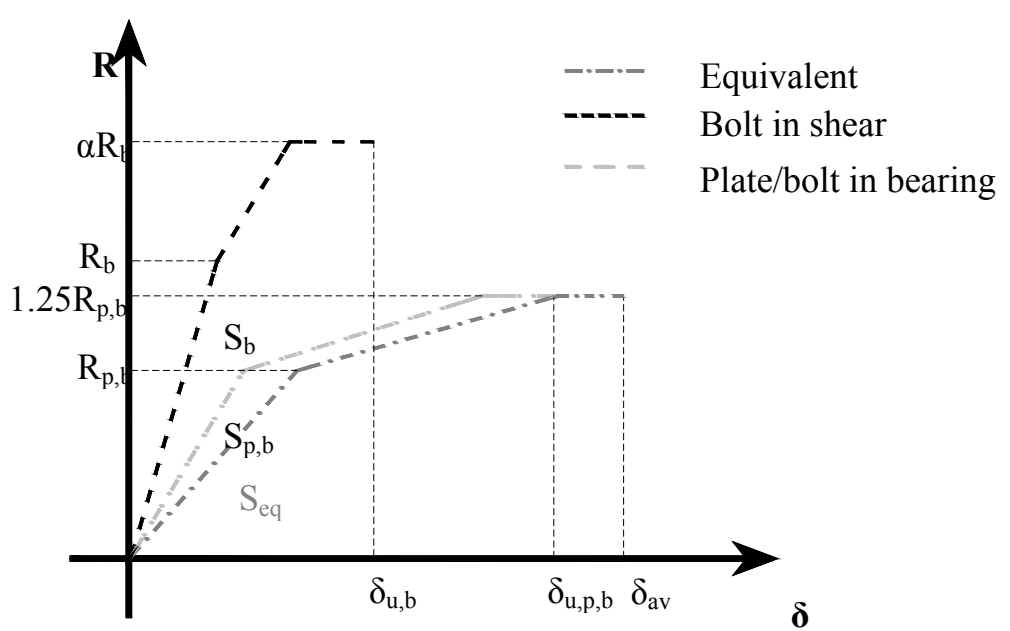

Figure 9. Assembly of the Individual Component Responses 
Table 5. Derived Expressions to Determine the Available Deformation Capacity

Plates with equal mechanical and geometrical properties

Single Overlap Connections

Double Overlap Connections

Case: $R_{b}>1.25 R_{p, b}$

$\delta_{a v}=\frac{R_{e q}}{S_{e q}}+2 *\left(\delta_{u, p, b}-\frac{R_{e q}}{S_{p, b}}\right)+\frac{0.25 R_{e q}}{S_{b}} \quad \delta_{a v}=\frac{R_{e q}}{S_{e q}}+\left(\delta_{u, p, b}-\frac{R_{e q}}{S_{p, b}}\right)+\frac{0.125 R_{e q}}{S_{b}}+\frac{0.125 R_{e q}}{S_{p, b}}$

Case: $R_{p, b}>\alpha R_{b}$

$\delta_{a v}=\frac{R_{e q}}{S_{e q}}+\left(\delta_{u, b}-\frac{R_{e q}}{S_{b}}\right)+2 * \frac{(\alpha-1) R_{e q}}{S_{p, b}} \quad \delta_{a v}=\frac{R_{e q}}{S_{e q}}+\left(\delta_{u, b}-\frac{R_{e q} / 2}{S_{b}}\right)+\frac{(\alpha-1) R_{e q}}{S_{p, b}}+\frac{(\alpha-1) R_{e q} / 2}{S_{p, b}}$

Case: $1 \leq R_{b} / R_{p, b} \leq 1.25$

$\delta_{a v}=\frac{R_{e q}}{S_{e q}}+2 *\left(\delta_{u, p, b}-\frac{R_{e q}}{S_{p, b}}\right)+\frac{R_{e, b}-R_{e q}}{S_{b}}+\frac{\left(1.25 R_{e q}-R_{e, b}\right)}{S_{b} / \beta} \mid \delta_{a v}=\frac{R_{e q}}{S_{e q}}+\left(\delta_{u, p, b}-\frac{R_{e q}}{S_{p, b}}+\frac{0.125 R_{e q}}{S_{p, b}}+\frac{R_{e, b}-0.5 R_{e q}}{S_{b}}+\frac{\left(0.625 R_{e q}-R_{e, b}\right)}{S_{b} / \beta}\right.$

Case: $1 \leq R_{p, b} / R_{b} \leq \alpha$

$\delta_{a v}=\frac{R_{e q}}{S_{e q}}+\left(\delta_{u, b}-\frac{R_{e q}}{S_{b}}\right)+2 * \frac{R_{p, b}-R_{e q}}{S_{p, b}}+2 * \frac{\left(1.25 R_{e q}-R_{p, b}\right)}{S_{p, b} / 40} \quad \delta_{a v}=\frac{R_{e q}}{S_{e q}}+\left(\delta_{u, b}-\frac{R_{e q} / 2}{S_{b}}\right)+\frac{R_{p, b}-2 R_{e q}}{S_{p, b}}+\frac{\left(2 \alpha R_{e q}-R_{p, b}\right)}{S_{p, b} / 40}+\frac{\alpha^{*} R_{e q} / 2}{S_{p, b}}$

\subsection{Required Deformation Capacity in Actual Shear Bolted Connections}

The required deformation capacity is the deformation which should be reached in the most loaded bolt zone in order to get a full plastic redistribution of forces in the connection. In the work done by Pietrapertosa el al.[12] expressions to determine the required deformation of the equivalent bolt zone component for fitted bolts have been proposed. Based on that study, similar expressions for actual connections, taking into account the presence of geometrical imperfections, are here proposed. The derived expressions should consider the most demanding situation that has been assumed before; i.e. the case where one of the extreme bolts is in contact while the others are not. Several cases have been analysed and it has been concluded that the most demanding case is obtained when the middle bolt zone (or middle bolt zones in the case of even number of bolt rows) is (are) the last one(s) to reach its (their) maximum resistance. Figure 10 shows the deformed shape and the distribution of internal forces for a connection with 5 bolt rows. 


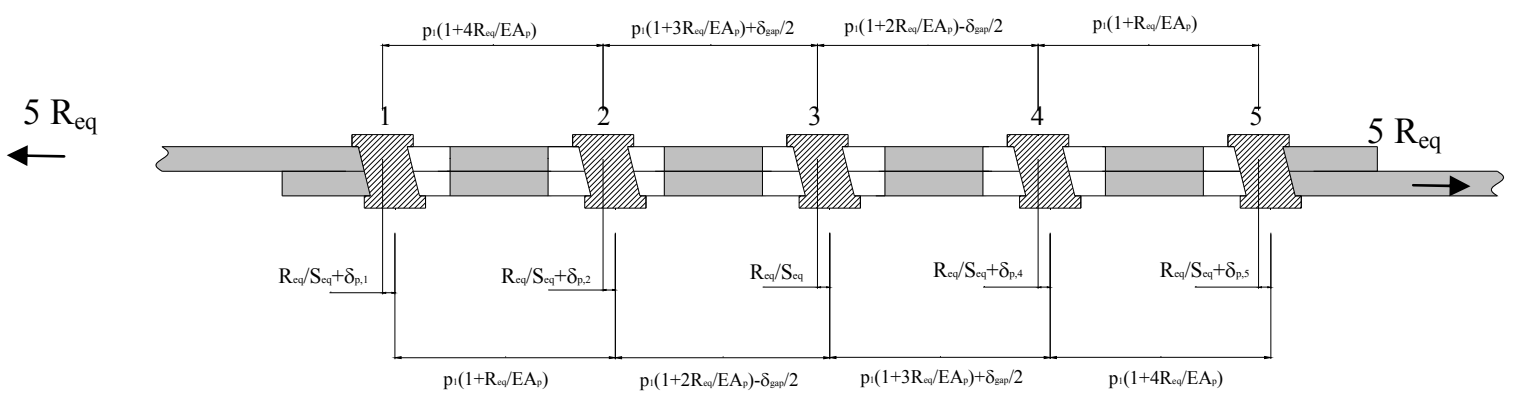

Figure 10. Connection with 5 Bolt Rows

Expressing the compatibility of displacements, the following equations are found:
(a) $p_{1}\left(1+\frac{4 R_{e q}}{E A_{p}}\right)+\frac{R_{e q}}{S_{e q}}+\delta_{p, 2}=p_{1}\left(1+\frac{R_{e q}}{E A_{p}}\right)+\frac{R_{e q}}{S_{e q}}+\delta_{p, 1}$
(b) $p_{1}\left(1+\frac{3 R_{e q}}{E A_{p}}\right)+\frac{R_{e q}}{S_{e q}}=p_{1}\left(1+\frac{2 R_{e q}}{E A_{p}}\right)+\frac{R_{e q}}{S_{e q}}+\delta_{p, 2}$
(c) $p_{1}\left(1+\frac{2 R_{e q}}{E A_{p}}\right)+\frac{R_{e q}}{S_{e q}}+\delta_{p, 4}=p_{1}\left(1+\frac{3 R_{e q}}{E A_{p}}\right)+\frac{R_{e q}}{S_{e q}}$
(d) $p_{1}\left(1+\frac{R_{e q}}{E A_{p}}\right)-\frac{\delta_{g a p}}{2}+\frac{R_{e q}}{S_{e q}}+\delta_{p, 5}=p_{1}\left(1+\frac{4 R_{e q}}{E A_{p}}\right)+\frac{\delta_{g a p}}{2}+\frac{R_{e q}}{S_{e q}}+\delta_{p, 4}$

Solving the system of equations, the plastic deformation in bolt zone 1,2, 3 and 4 is determined:
(a) $\delta_{p, 1}=\frac{4 R_{e q}}{E A_{p}} p_{1}$
(b) $\delta_{p, 2}=\frac{R_{e q}}{E A_{p}} p_{1}$
(c) $\delta_{p, 4}=\frac{R_{e q}}{E A_{p}} p_{1}$
(d) $\delta_{p, 5}=\delta_{g a p}+\frac{4 R_{e q}}{E A_{p}} p_{1}$

Finally, the required deformation for the equivalent bolt zone component is obtained:

$\delta_{r e q}=\frac{R_{e q}}{S_{e q}}+\delta_{g a p}+\frac{4 R_{e q}}{E A_{p}}$

This analysis has been extended to other cases (different number of bolt rows) and the following general expression has been obtained:

$\delta_{\text {req }}=R_{e q}\left(\frac{1}{S_{e q}}+\rho \frac{p_{1}}{E A_{p}}\right)+\delta_{g a p}$

with

$$
\begin{aligned}
& \rho=\sum_{i=1}^{n_{1} / 2}\left(n_{1}-2 i\right) \text { for an even value of } n \\
& \rho=\sum_{i=1}^{\left(n_{1}-1\right) / 2}\left(n_{1}-2 i\right) \text { for an odd value of } n
\end{aligned}
$$


At the same time, a numerical model, based on the use of the Liège home-made nonlinear FEM software FINELG[26], allowed validating all the analytical results. The numerical model is based on the simplified model presented in Figure 3c. This simple model avoids the contact problems, which are always difficult to manage; the numerical model is then defined by modelling the plate in tension behaviour through the use of beam elements and the bolt zone by means of springs. Using the numerical model, analytical expressions and numerical results are compared: in Figure 11, the required deformation capacity to the bolt zone component calculated through expression (8) and the numerical model, for a connection with 5 bolt rows; in Figure 12, the plastic deformation achieved by each bolt zone when the last one reaches $R_{\text {eq }}$ by means of expressions (7), again for a case with 5 bolt rows.

The different cases analysed correspond to the different values of defined gap. The values considered for the gap varies proportionally to the conventional limit of elastic deformation of the equivalent bolt zone component and are the following: $\delta_{\text {gap }}=\delta_{\text {el }}$ (case 1 ); $\delta_{\text {gap }}=1.1 * \delta_{\text {el }}$ (case 2 ); $\delta_{\text {gap }}=1.2 * \delta_{\text {el }}($ case 3$) ; \delta_{\text {gap }}=1.3 * \delta_{\text {el }}$ (case 4$)$. In Figure 12 , only case 1 is represented as the results for the other cases are the same.

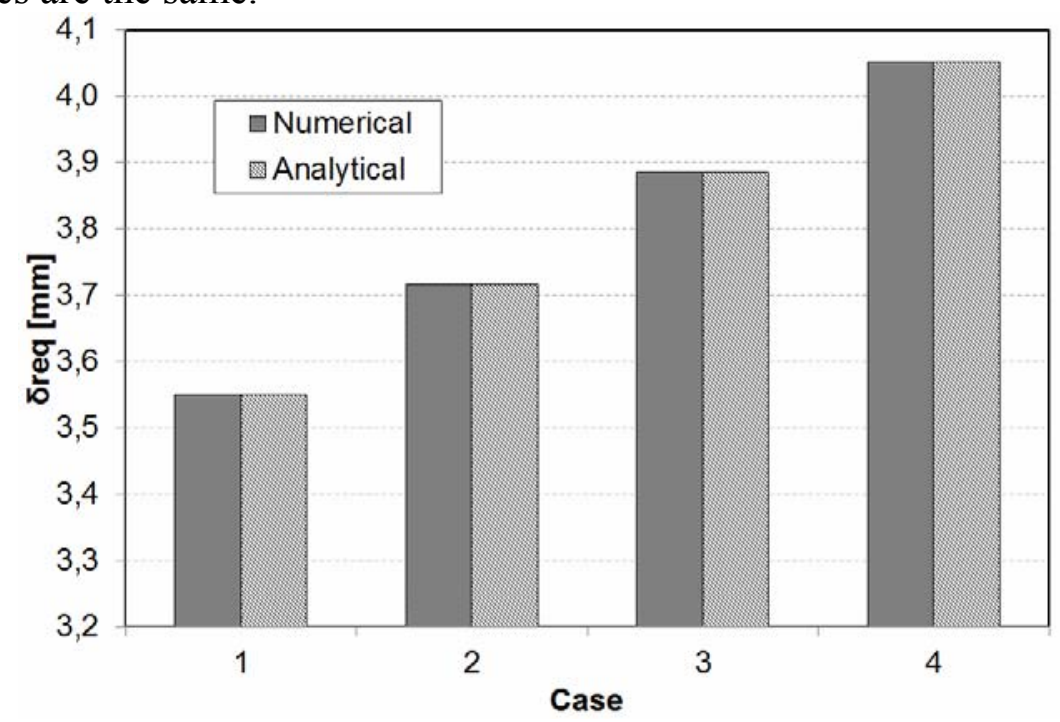

Figure 11. Comparison of Required Deformation between Numerical Model and Formulae

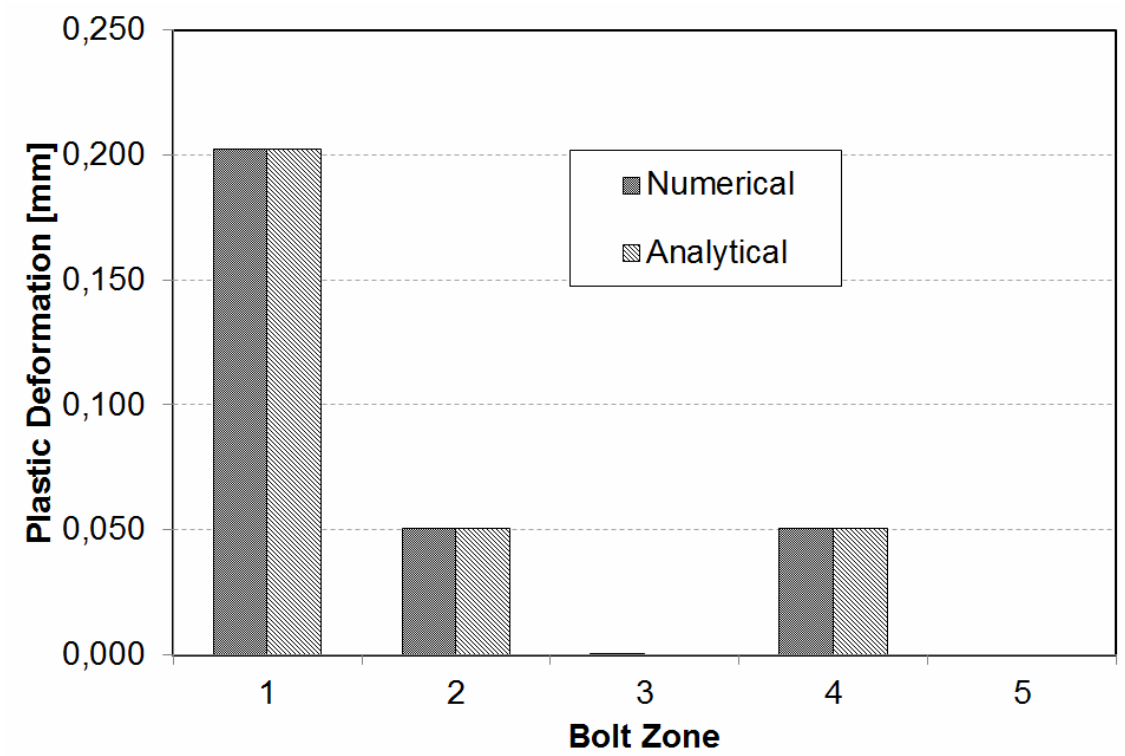

Figure 12. Comparison of Plastic Deformation between Numerical Model and Formulae (case 1) 


\section{DUCTILITY REQUIREMENTS FOR BOLTED SHEAR CONNECTIONS}

In order to determine ductility requirements that a connection should satisfy so as to ensure a full plastic redistribution of the internal forces amongst the bolt zones, reference will obviously be made to the expressions derived before for the available and required ductility in bolt zone components; hence, such ductility requirements are for sure dependent on all the geometrical and mechanical parameters that influence the two previously mentioned values of ductility:

$>$ Steel grade of the plate;

$>$ Bolt grade;

$>$ Geometrical properties of the connection $\left[\mathrm{t}, \mathrm{b}, \mathrm{e}_{1}, \mathrm{e}_{2}, \mathrm{p}_{1}, \mathrm{p}_{2}, \mathrm{~d}, \mathrm{~d}_{0}\right]$;

$>$ Number of bolt rows $\left(\mathrm{n}_{1}-\right.$ in the direction of loading) and number of bolt lines $\left(\mathrm{n}_{2}-\right.$ in the perpendicular direction of loading).

The ductility criterion which is expressed below and which constitutes the main outcome of the study is based on an intensive parametrical study where all the above-listed geometrical and mechanical parameters have been considered, but for single overlap connections only (what is not really restrictive). As mentioned before, situations where tension plate failure is relevant have been omitted.

The problem is dependent on many basic parameters (listed above). Therefore, fundamental parameters which embody all these and simplify the task by avoiding multiple sub-criteria have been defined. Two fundamental parameters have been defined in view of the derivation of a ductility criterion, as illustrated in Figure 13.

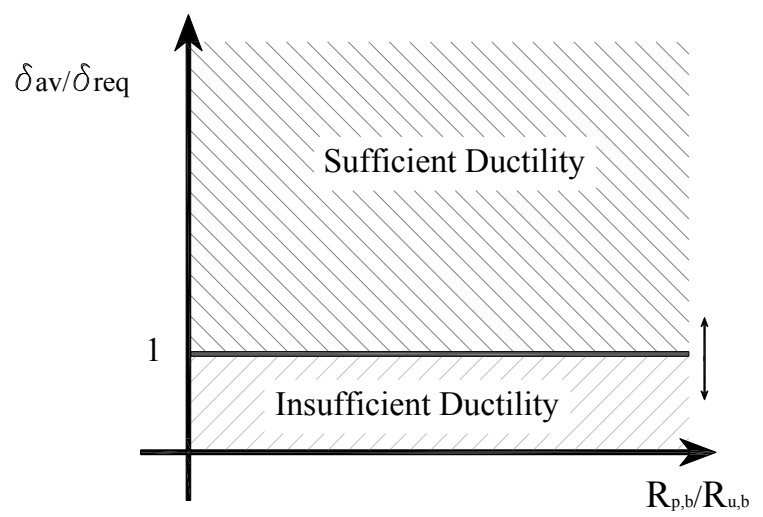

Figure 13. Two Fundamental Parameters

The parameter on the vertical axis represents the ratio between the available and the required deformation capacities. This ratio reflects the sufficient or insufficient ductility exhibited by the equivalent bolt zone component. The second fundamental parameter represents the ratio between the nominal resistance of the plate/bolt in bearing component and the ultimate resistance of the bolt in shear component. These two parameters embody all the important mechanical and geometrical parameters listed before.

This being, the influence of each basic parameter was analyzed and "ductility functions" were obtained. Figure 14 presents the results of the parametrical analysis in which the following variation of the basic parameters have been considered:

$>$ Steel grade: S235 and S355;

$>$ Bolt diameters: M16, M20 and M24;

$>$ Spacing, end and edge distances: $\max$ and $\min$ of $e_{1}, e_{2}, p_{1}$ and $p_{2}$; 
$>$ Width of the plates: max and min values $e_{2}$ and $p_{2}$ as well as max and min values of $b$ taken into account;

$>$ Thickness of the plate: the variation of $t$ is made in order to cover the whole ranges of $R_{p, b} / R_{u, b}$

$>$ Finally, the number of bolt rows and lines varies: $\mathrm{n}_{1}$, from 2 to 10 , and $n_{2}$, from 1 to 5 .

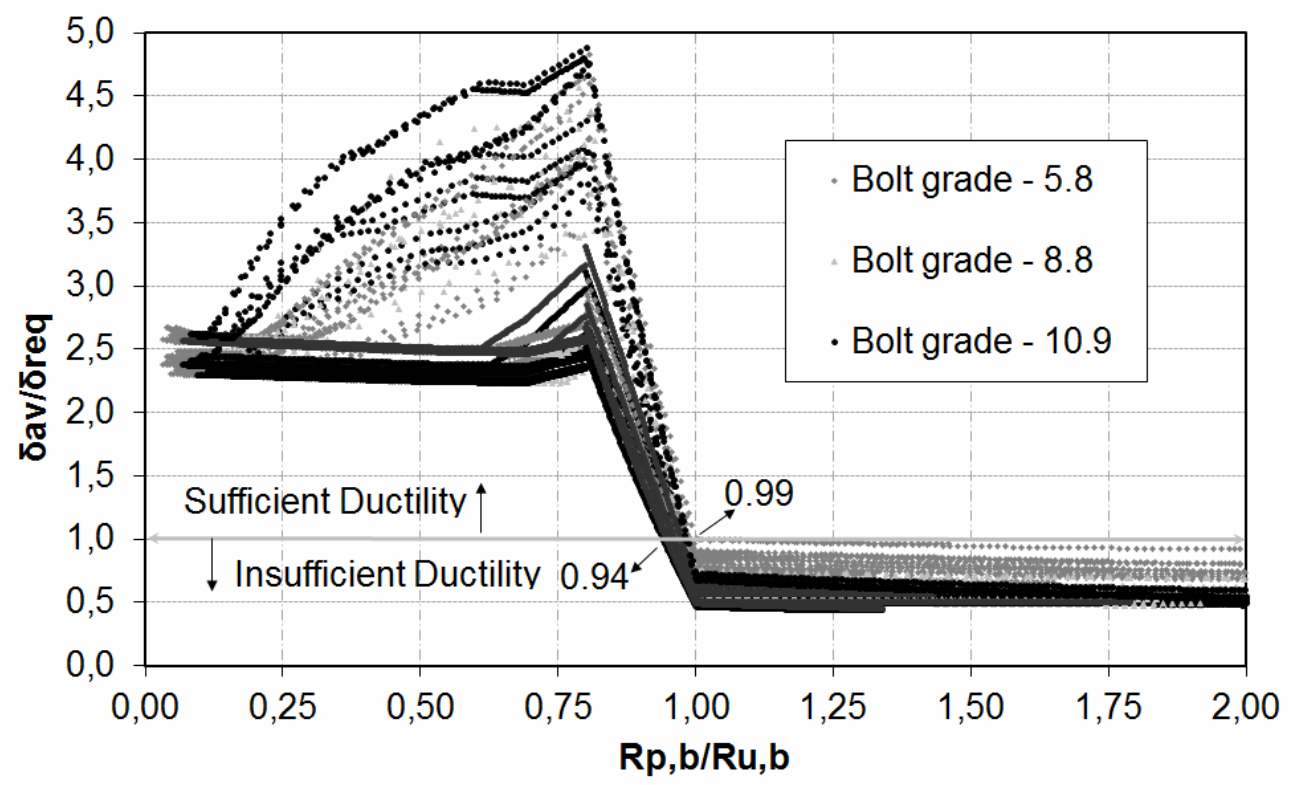

Figure 14. Parametric Analysis Results

One can observe that the variation of the fundamental parameter $R_{p, b} / R_{u, b}$, close to the boundary between sufficient and insufficient ductility $\left(\delta_{a v} / \delta_{\text {req }}=1\right)$ is small, from 0.94 to 0.99 . So, a safe and simplified ductility criterion may be suggested as follows:

$\left\{\begin{array}{l}\text { If } \frac{R_{p, b}}{R_{u, b}} \leq 0.94 \Rightarrow F_{r, c}=n_{1} n_{2} R_{e q} \text { (plastic distribution of int ernal forces allowed) } \\ \text { If } \frac{R_{p, b}}{R_{u, b}}>0.94 \Rightarrow F_{r, c}<n_{1} n_{2} R_{e q} \text { (plastic distribution of int ernal forces not allowed) }\end{array}\right.$

Figure 14 clearly identifies the plate/bolt in bearing as ductile component and the bolt in shear as a brittle one. When the plate/bolt bearing is the strongest component and its contribution to the deformation of the equivalent component is small, insufficient ductility is exhibited by the equivalent bolt zone component to reach a complete plastic redistribution in the connection.

In order to apply the criterion, some practical cases have been considered and the results have been compared with the present Eurocode 3 rules. This comparison considered two situations, one where the criterion is verified and another where it is not. The obtained results are presented in Figure 15. In the horizontal axis is represented the length of the joint, according to the code, and in the vertical axis the reduction factor $\beta_{\mathrm{LF}}$ for long joints. The analysed cases consider the variation of the connection length by varying the number of bolt rows (number of bolts along load direction). All the other properties were kept constant. The number of lines of bolts is 2 (number of bolts over the transversal direction of the applied load). 
The results confirm that if the condition expressed in (10) is verified, the available ductility is sufficient to achieve a full plastic resistance of the connection even in joints that exceed the limit imposed by the code. One can also observe that, in the case of a low contribution by the plate/bolt in bearing component to the deformation of the equivalent one, the available ductility is clearly insufficient and the maximum load the connection is able to transfer is considerably reduced.

The comparison with Eurocode 3 criterion shows a significant difference. The code establishes as main condition the length of the joint while the proposed criterion is based in the contribution of the basic components to the available deformation of the equivalent bolt zone component. For cases where ratio $R_{p, b} / R_{u, b}$ is smaller than 0.94 (high contribution of the plate/bolt in bearing) the code approach is conservative while for higher values of this ratio the code is on the unsafe side.

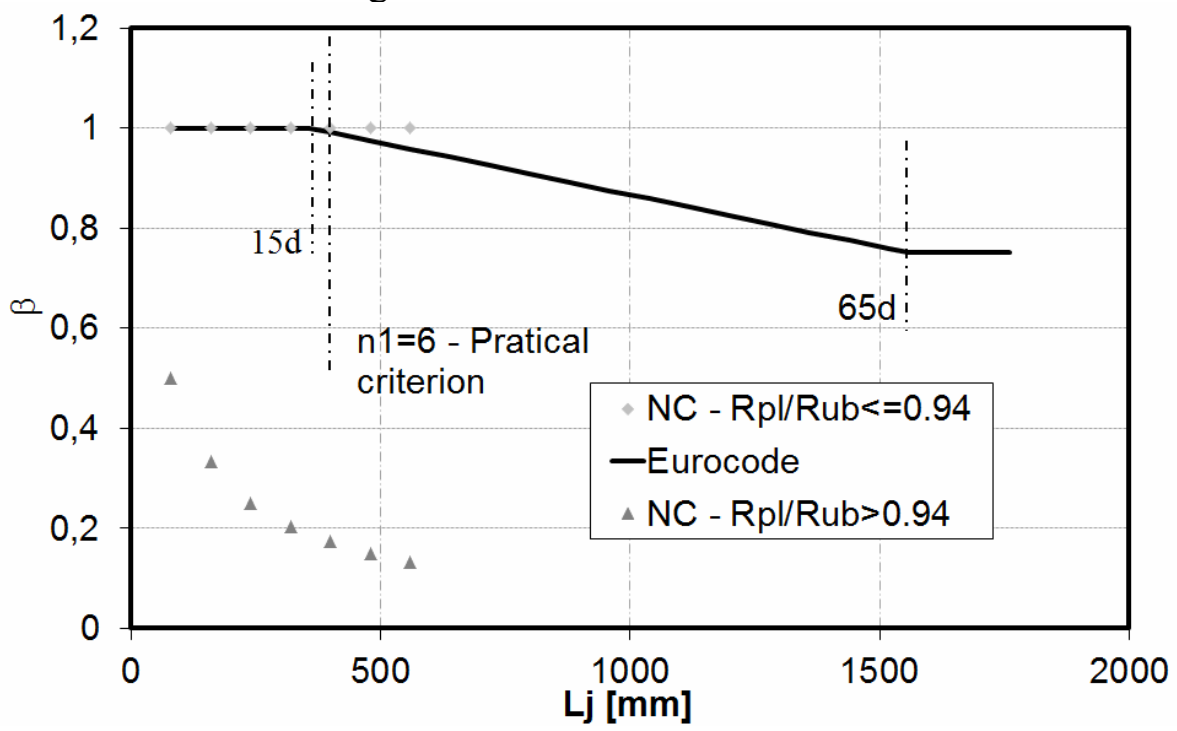

Figure 15. Comparison with the Eurocode 3 Criterion

\section{CONCLUSIONS}

The present work proposes a criterion to check whether sufficient ductility for a full plastic redistribution of internal forces may be contemplated in actual shear connections with non preloaded bolts. It is based on the presence of geometrical imperfections in the connection layout which can lead to situations where some bolts bear before the others.

All the aspects inherent to shear bolted connections have been approached: the evaluation of geometrical imperfections according to the standards for tolerances; the characterization of the individual component response; the derivation of expressions to determine the available deformation capacity in the bolt zone component; the required deformation in the bolt zone component for a full plastic redistribution of forces.

From the analysis of several layouts it has been verified that geometrical imperfections should be applied in order to minimize the gap in one of the external bolt zone which starts transferring load first and maximize the gap in all the others. The values proposed vary according to the bolt diameter; however the general configuration of the connection is the same. These values define extreme situations that can be observed in a connection layout obeying to the standards recommendations for tolerances. 
Empirical functions to characterize the behaviour of bolts in shear have been proposed. These functions confirmed that ductility decreases with the increase of the bolt grade. Tri-linear laws have been proposed using Eurocode design functions. The ultimate deformation of bolts in shear is evaluated using these design functions; thus, a lack in the code could be filled and the deformation capacity of the bolt in shear estimated.

The expressions proposed to determine the available deformation capacity of the equivalent component, show that the available deformation depends on the level of contribution of the two components. The application of these expressions shows the expected results: high deformation is available if the plate/bolt in bearing has high contribution to the global deformation while the opposite is observed if the bolt in shear is the leading basic component. The presented expressions include a limited group of situations considered as the most usual ones. Based on these, any other situation can be derived.

In the work of Pietrapertosa et al. (2004)[12] the evaluation of required deformation capacity in shear bolted connections with fitted bolts has been done. Using the same principles, this evaluation has been extended to actual shear bolted connections and the effect of geometrical imperfections introduced. Higher deformation capacity is obviously required. The obtained expression is similar to the one presented by the referred authors; the modification consists in the addition of the gap presented by the last bolt zone to reach its yield strength $R_{\text {eq }}$.

Through the evaluation of the available and required deformation capacity in the equivalent bolt zone component a ductility criterion has been derived. The proposed criterion, equation (10), is simplified by the use of two fundamental parameters which involve all basic ones that need to be taken into account. One considers the sufficient or insufficient deformation capacity presented by the equivalent component $\left(\delta_{\mathrm{av}} / \delta_{\text {req }}\right)$, while the other takes into account the participation of each basic component in the global deformation of the equivalent bolt zone component $\left(\mathrm{R}_{\mathrm{p}, \mathrm{b}} / \mathrm{R}_{\mathrm{u}, \mathrm{b}}\right)$.

The application of the proposed criterion showed considerable differences between the code criterion and the proposed one. This fact shows that geometrical imperfections may have a relevant effect in the connection behaviour if the bolt in shear component is the "weakest". Actually, in these cases the transferred force is considerably smaller than the one determined according to the code provisions, as observed in Figure 15. This situation should then be further investigated in future works. At the same time the evaluation of the imperfections in the connection layout should be better analysed. The values here obtained (based on the "worst" layout of imperfections) seem to be too severe for the case of "weak" bolts, as seen in Figure 15.

\section{ACKNOWLEDGMENTS}

For sharing their experimental data, the authors would like to express their thanks to Delft University of Technology in the name of Prof. F. S. K. Bijlaard and to University of Ljubljana in the name of Prof. Darko Beg. Concerning the use of LAGAMINE code, a word of gratitude should be said to the "LAGAMINE Group" of ArGEnCo Department of the University of Liège. Finally, Mr. Piraprez is acknowledged for sharing his knowledge and documents. 


\section{REFERENCES}

[1] Shakir-Khalil, H. and Ho, C.M., "Black Bolts under Combined Tension and Shear", The Structural Engineer, 1979, Vol. 11.

[2] Owens, G. W. and Cheal B.D., "Structural Steelwork Connections", Butterworths \& Co., 1989.

[3] McGuire, W., "Steel Structures”, Englewood Cliffs, NJ: Prentice-Hall; 1968.

[4] Fisher, J.W. and Struik, J.H.A., "Guide to Design Criteria for Bolted and Riveted Joints", John Wiley \& Sons, 1974.

[5] Ballio, G. and Mazzolani, F., "Theory and Design of Steel Structures", London: Chapman and Hall, 1983.

[6] ECCS, "European Recommendations for the Design of Simple Joints in Steel Structures", ECCS publication no 126, Technical Committee 10, Structural Connections, Belgium, 2009.

[7] Kulak, G.L., Fisher, J.W. and Struik, J.H., "A Guide to Design Criteria for Bolted and Riveted Joints", $2^{\text {nd }}$ Edition, Willey, 1987.

[8] CEN, "ENV 1993-1-8: Design of Steel Structures - Part 1-8: Design of Joints. CEN, Brussels", Belgium, 2005.

[9] AISC, "Steel Construction Manual", 14 ${ }^{\text {th }}$ Edition, 2011.

[10] BSI, "BS 5950-1:2000 Structural Use of Steelwork in Building - Part 1: Code of Practice for Design - Rolled and Welded Sections", May 2001.

[11] Ju S-H., Fan, C-Y, and Wu, G.H., "Three-dimensional Finite Elements of Steel Bolted Connections", Engineering Structures, 2004, Vol. 26, pp. 403-413.

[12] Pietrapertosa, C., Piraprez, E. and Jaspart, J-P., "Ductility Requirements in Shear Bolted Connections", ECCS/AISC Workshop: Connections in Steel Structures V: Behaviour, Strength and Design, Amsterdam, 2004; pp. 335-345.

[13] Wald, F., Sokol, Z., Moal, M., Mazura, V, and Muzeau, J.P., "Stiffness of Cover Plate Connections with Slotted Holes", Eurosteel: Third European Conference on Steel Structures, Coimbra, 2002, pp. 1007-1016.

[14] Jaspart, J-P., "Etude de la Semi-rigidité des nœuds Pouter-colonne et Son Influence Sur la Résistance et la Etabilité des Ossatures en acier”,Ph. D. Thesis, M\&S Departement, Liège University, Belgium, 1991.

[15] Weynand, K,, Jaspart, J-P, and Steenhuis, M., " The Stiffness Model of Revised Annex J of Eurocode 3”, In: Proceedings of $3^{\text {rd }}$ International Workshop on Connections, Trento, 1995, pp. 441-452.

[16] Gresnigt, A.M, and Steenhuis, C.M., "Stiffness of Lap Joints with Preloaded Bolts", In: L. Baniotopoulos and F. Wald (eds.), The paramount role of joints into the reliable response of structures, NATO ASI Series, Kluwer Academic Publishers; 2000, pp. 435-448.

[17] Shoukry, Z. and Haisch, W.T., "Bolted Connections with Varied Hole Diameters," Journal of the Structural Division, ASCE, Vol. 96, 1970.

[18] CEN, "EN 1090-2: Execution of Steel Structures and Aluminium Structures - Part 2: Technical Requirements for the Execution of Steel Structures", Brussels, 2011.

[19] ISO, "ISO/DIS 4759-1.2: Tolérances des éléments de Fixation - Partie 1: Vis, goujons et écrous - Grades A, B et C. Projet de Norme Internationale“, 1999.

[20] ISO, "ISO 286-2: Geometrical Product Specifications (GPS) -- ISO Code System for Tolerances on Linear Sizes -- Part 2: Tables of Standard Tolerance Classes and Limit Deviations for Holes and Shafts", 2010.

[21] Henriques J., "Ductility Requirements in Shear Bolted Connections", Master Thesis, University of Coimbra, Portugal, 2008.

[22] Karmalin V.V, and Pavlov A.B., "Load Capacity and Deformability of Bearing and Friction-bearing Connections", In: Proceedings of the International Colloqquium on Bolted and Special Structural Connections, Moscow,1989; pp. 52-60. 
[23] LAGAMINE Dode, Finite Element Software, ArGEnCO Department, Liège University, Belgium.

[24] Moze, P., Beg, D., and Lopatic, J., "Ductility and Strength of Bolted Connections Made of High Strength Steel", In: International conference in Metal Structures "Steel - A New and Traditional Material for Buildings", Poiana Brasov, 2006; pp. 323-330.

[25] Freitas, S.T., "Experimental Research Project on Bolted Connections in Bearing for High Strength Steel", Final Report of the Framework of the Socrates-Erasmus Program, 2005.

[26] FineLg User's manual, V9.0. University of Liège (M\&S) / Design office Greisch, Belgium; 2004. 


\title{
A PARAMETRIC STUDY ON SEISMIC CHARACTERISTICS OF COLD-FORMED STEEL SHEAR WALLS BY FINITE ELEMENT MODELING
}

\author{
S. Hatami ${ }^{1} *$, A. Rahmani ${ }^{2}$, A. Parvaneh ${ }^{3}$ and H.R. Ronagh ${ }^{4}$ \\ ${ }^{I}$ Assistant Professor, Department of Civil Engineering, Yasouj University, Yasouj, Iran \\ ${ }^{2}$ Graduate Student, Department of Civil Engineering, Islamic Azad University, Bushehr, Iran \\ ${ }^{3}$ Former Graduate Student, Department of Civil Engineering, Sharif University of Technology, Tehran, Iran \\ ${ }^{4}$ Senior lecturer, School of Civil Engineering, The University of Queensland, Brisbane, Australia \\ *(Corresponding author: E-mail: hatami@yu.ac.ir)
}

Received: 12 July 2012; Revised: 17 October 2012; Accepted: 5 December 2012

\begin{abstract}
Shear wall panels, including cold-formed steel frames and its attached sheathing, are common lateral load resisting systems of cold-formed steel structures. In this paper, the finite element method is used to study the lateral performance of shear wall panels. The finite element model is validated against experimental results of other researchers. Using the validated model, a parametric study is described to determine strength, drift and seismic behavior of the shear wall panels. Based on the results, it is concluded that the initial stiffness and ultimate lateral strength are dramatically affected by the thickness of the frame members, type of sheathing material, edge screw spacing, height of the frame, while some parameters such as field screw spacing have a minor effect on the initial stiffness and the ultimate lateral strength. In addition, this study looks into the earthquake performance of the shear wall panels and presents the corresponding ductility factor and force reduction factor (R-factor) of shear wall panels.
\end{abstract}

Keywords: Cold-formed steel, shear wall, light steel framing, racking performance, lateral strength, drift ratio, R factor

\section{INTRODUCTION}

Light-weight construction leads to saving in materials, transportation and installation costs. On the other hand, it reduced dead load and decreases its earthquake load demand. Light Steel Framing (LSF), in addition to being light, is a structural system with potential for industrial production and pre-fabrication which can meet qualitative and quantitative demands of an advanced construction industry. In earthquake prone areas, an important consideration in the performance of LSF is its behavior against seismic loads. The main component to resist earthquake forces in a light steel building is shear wall. Shear walls in LSF are cold-formed steel frames braced by diagonal steel straps or sheathed with steel sheets or shear panels. The most common types of shear panels are made from wood-based or gypsum-based materials; panels are generally connected to the frame members by self-drillings screws.

During the two last decades, some experimental and theoretical studies have been conducted in relation with seismic behavior of shear wall panels. Determination of lateral strength and ductility of the shear walls, as the fundamental characteristic of seismic design, has been the main scope of these studies. Serrette et al. [1,2] conducted a series of tests on shear wall panels in cold-formed steel framing with different sheathing materials, such as gypsum wall board (GWB), oriented strand board (OSB), and plywood. Their results contributed to the development of the Standard for ColdFormed Steel Framing-Lateral Design published by the American Iron and Steel Institute [3]. Rogers et al. [4] performed tests of shear wall panels with American and Canadian wood-based sheathing materials. The objective was to develop design guidelines for seismic application of shear wall panels to be adopted for the National Building Code of Canada. Fulop and Dubina [5] conducted a series of tests for determining the lateral strength of shear wall panels. They proposed a 
simplified model for determining the lateral strength of shear wall panels by replacing the sheathing with a pair of equivalent cross-bracing [6]. In 2006, Xu and Martines [7] employed analytical methods for the determination of lateral strength and drift of shear walls. In order to obtain accurate results, effective parameters such as material properties, geometric dimensions, screw spacing and construction details were considered in the analytical methods. Recently Pan and Shan [8] have experimentally studied the structural strength of cold-formed steel wall frames with sheathing under monotonic shear loading. Three different kinds of sheathing material, GWB, calcium silicate board, and OSB were adopted in the test specimens. The ultimate strength, stiffness, energy absorption, and ductility ratio were studied for each test specimen.

While experimental testing is the best method for evaluation of the lateral behavior of shear walls in cold formed steel structures, the evaluation of all structural parameters is either not possible by experiments or is too costly. Therefore, in this study, finite element analysis using ANSYS the general purpose finite element program, which has capabilities in the modeling of material and geometric nonlinearity, is employed for the evaluation of the racking performance of the coldformed steel shear wall panels. In order to achieve a higher level of reliability, the finite element results are compared with the results of recent experimental tests $[1,2,3,4,5]$ conducted on the 28 shear wall panels. Using the verified finite element model, a parametric study on racking performance of shear wall panels is performed and lateral load-displacement curves of some walls with different parameters such as member thickness and screw spacing are drawn. Finally, the force reduction factor ( $\mathrm{R}$-factor) of all walls is determined so as to investigate the effect of the abovementioned parameters on the seismic behavior of shear wall panels.

\section{NONLINEAR BEHAVIOR AND R-FACTOR}

It is well known that in the event of an earthquake, lower lateral forces are generated in a structure that can accommodate larger nonlinear displacements prior to collapse in comparison with a structure that behave elastically. This is shown in Figure 1 as the envelope of load-drift for a typical structure. In practice, force reduction factor (in the limit state or ultimate strength seismic codes) is defined as the ratio of the demand load of the elastic structure, $V_{e}$ to the design load of the inelastic structure, $V_{s y}$. This factor can be calculated from two components of ductility reduction factor, $R_{\mu}$ and Over-strength factor, $\Omega$.

$$
R=R_{\mu} \times \Omega
$$

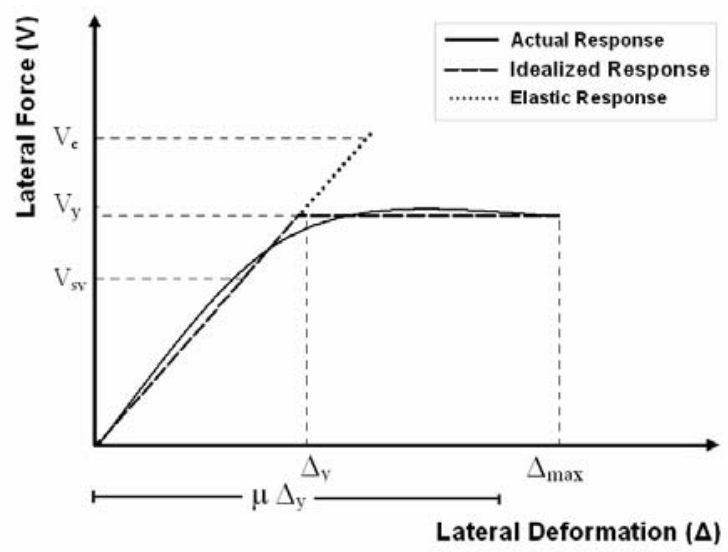

Figure 1. Envelope of Load-drift Curve 
$R_{\mu}$ is the ratio of the demand of the elastic structure to that of the inelastic structure.

$$
R_{\mu}=\mathrm{V}_{\mathrm{e}} / \mathrm{V}_{\mathrm{y}}
$$

$R_{\mu}$ is proportional to the structure ductility factor, $\mu$. The ductility factor can be determined by dividing the maximum displacement of the nonlinear structure $\Delta_{\max }$ to displacement of yielding point of ideal model, $\Delta_{y}$ (Figure 1).

$$
\mu=\Delta_{\max } / \Delta_{y}
$$

Different relations have been presented for determination of the ductility reduction factor, $R_{\mu}$, in the literature. On the basis of the natural period of the structure, $T$, Newmark and Hall [9] developed the following relations in terms of $\mu$ for the ductility reduction factor.

$$
\begin{array}{lrl}
R_{\mu}=\mu & (T>0.5 \mathrm{sec}) \\
R_{\mu}=\sqrt{2 \mu-1} & (0.1<T<0.5 \mathrm{sec}) \\
R_{\mu}=1 & (T<0.03 \mathrm{sec})
\end{array}
$$

The over-strength factor results from the strength that the structure undergoes beyond the design strength $\left(V_{s y}\right)$ and can be expressed by Eq. 7.

$$
\Omega=\mathrm{V}_{\mathrm{y}} / \mathrm{V}_{\mathrm{sy}}
$$

\section{FINITE ELEMENT MODEL}

The numerical model for the cold formed steel shear walls were developed using the nonlinear finite element program ANSYS.

Lateral behavior of shear wall panels is dependent on the performance of steel frame and sheathing. The steel frame is composed of studs and tracks. The element type in ANSYS which used to model the studs and tracks is SHELL181 (Figure 2). In the case of cold formed steel members in a shear wall frame, several types of nonlinearity such as post local or distortional buckling, large strain adjacent to the screw connections and large displacement are probable. SHELL181 element is wellsuited for large displacement and rotation, and/or large strain nonlinear applications for analyzing thin to moderately-thick shell structures. It is a four-node element with six degrees of freedom at each node: translations in the $\mathrm{x}, \mathrm{y}$, and $\mathrm{z}$ directions, and rotations about the $\mathrm{x}, \mathrm{y}$, and $\mathrm{z}$ axes. In the modeling of frame members, an elastic-perfectly plastic bilinear stress-strain curve is used to simulate martial nonlinearity of steel. Figure 3 shows the dimensions and FE modeling of a sample back-to-back stud section. 


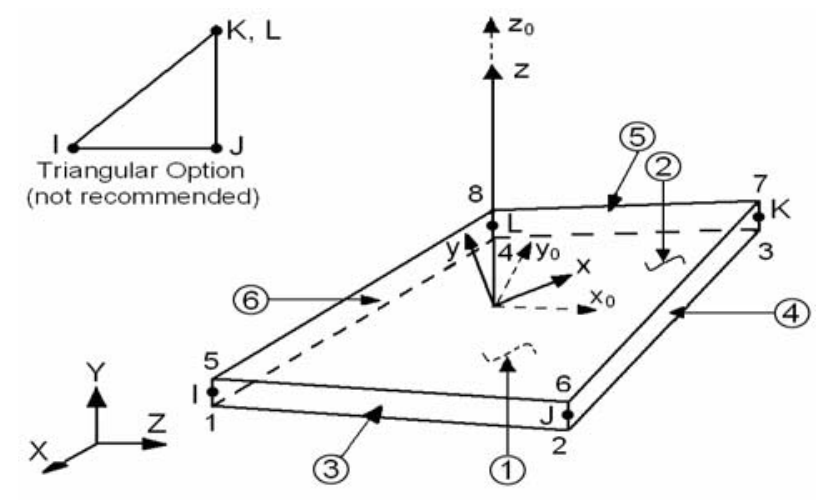

Figure 2. SHELL181 Element

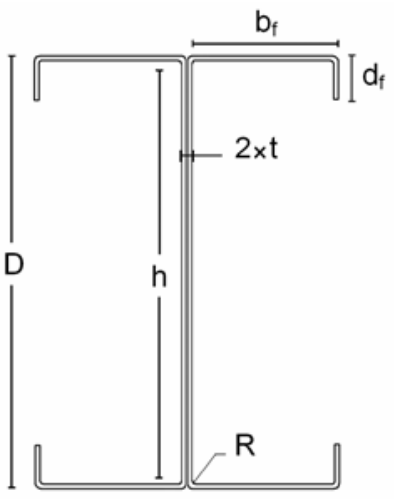

(a)

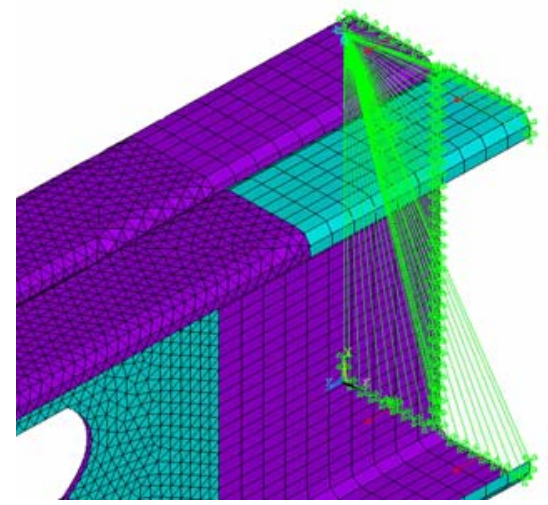

(b)

Figure 3. Back-to-back Double Stud; a) Section Parameters, b) Finite Element Model

For compatibility, SHELL181 element was used to model the sheathing of the shear walls, as well. The sheathings were made of gypsum or wooden based materials such as Oriented Strand Board (OSB), Canadian softwood plywood (CSP), Douglas-fir plywood (DFP) and Gypsum wall board (GWB). The stress-strain curve of sheathing material is simulated by a bilinear curve with an initial module of elasticity and the secondary module equal to 12 percent of initial one. Specifications of the sheathing material of shear wall panels are presented in Table 1 which given from $\mathrm{Xu}$ and Martinez [7].

Table 1.Specifications of Sheathing Materials [7]

\begin{tabular}{llll}
\hline $\begin{array}{l}\text { Type of Sheathing } \\
\text { materials }\end{array}$ & $\begin{array}{l}\text { Ultimate stress } \\
(\mathrm{MPa})\end{array}$ & $\begin{array}{l}\text { Initial Modulus of } \\
\text { Elasticity } \\
(\mathrm{MPa})\end{array}$ & $\begin{array}{l}\text { Poisson's } \\
\text { ratio }\end{array}$ \\
\hline OSB & 4.2 & 9917 & 0.30 \\
Ply wood (CSP) & 4.0 & 7376 & 0.25 \\
Ply wood (DFP) & 4.5 & 10445 & 0.30 \\
GWB & 2.5 & 1290 & 0.20 \\
\hline
\end{tabular}

All screw connections between different members of the shear wall are modeled by "Coupling" in ANSYS. When we couple two or more Degrees of Freedom (DOFs) together in the finite element model, we force these DOFs to take on the same value. A set of coupled DOFs contains a prime DOF, and one or more other DOFs. Coupling will cause only the prime DOF to be retained in the analysis' matrix equations, and will cause all the other DOFs in a coupled set to be eliminated. The value calculated for the prime DOF will then be assigned to all the other DOFs in a coupled set. 
In this study, coupling is used to connect sheathing to the frame in the location of screws, as shown by green signs in Figure 4. Furthermore, all nodes of the top track were coupled to one prime node at the corner of the track which provided a displacement control reference as illustrated by the green lines in Figure 4. In order to permit the buckling of studs, the prime node of the top track was restrained only in the perpendicular direction to the plane of panel. Screws which utilized to joint two studs together and make one double stud are simulated by coupling, as well. The finite element modeling of a double stud is seen in Figure 5 and screw connection of two studs is shown by green signs.

It should be mentioned that the coupling technique cannot model the relative displacement of adjacent members in the screw position, although the relative rotation can occur. Relative displacement can be modeled by using a spring element having stiffness equivalent to the screw rotation of a single shear screw lap joint. Nevertheless the authors could not achieve good convergence when the spring elements of ANSYS used to model screw connections.

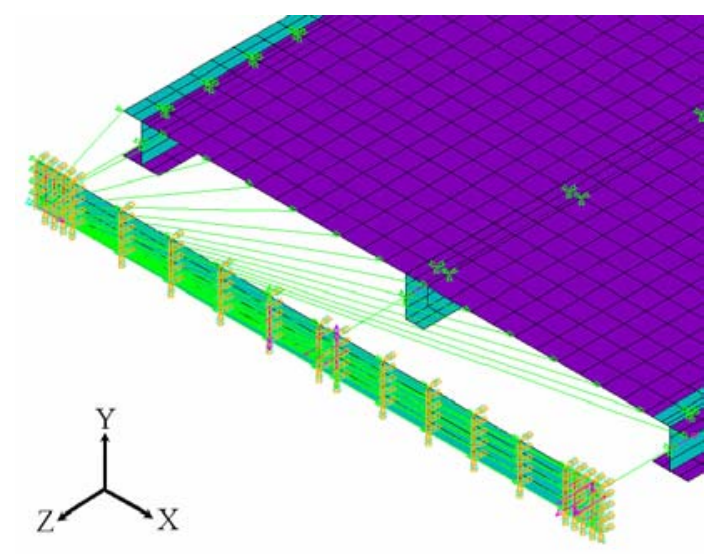

Figure 4. Connection of Track to Stud by Coupling in Three Directions of X, Y and Z

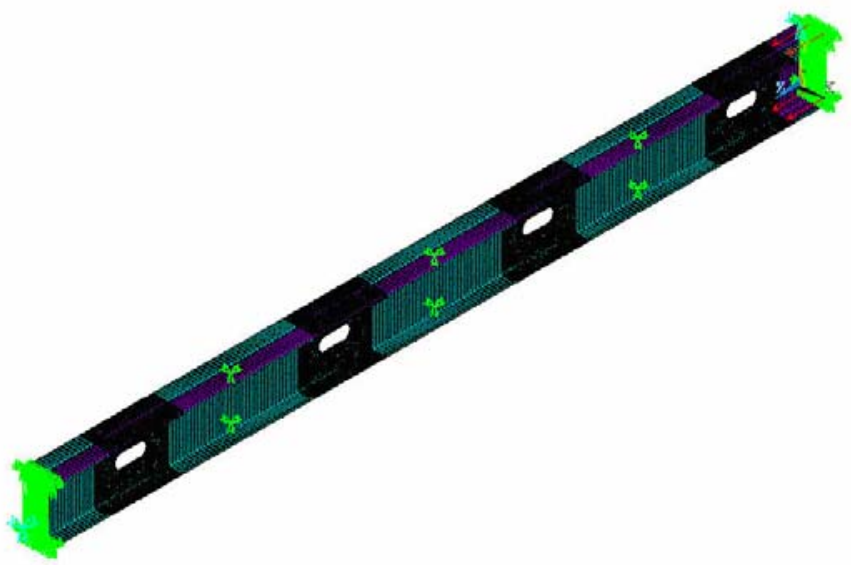

Figure 5. Finite Element Model of a Double Stud

To assess racking performance of the shear wall panels, a pushover analysis is carried out. An incremental racking displacement is applied to the prime node of the top track and the corresponding racking force is recorded which creates a displacement control method. Both geometry and material nonlinearities are included in the finite element push over analysis. ANSYS employs the "Newton-Raphson" approach to solve nonlinear problems. Before each solution, the Newton-Raphson method evaluates the out-of-balance load vector, which is the difference between the restoring forces (the loads corresponding to the element stresses) and the applied loads. The program then performs a linear solution, using the out-of-balance loads, and checks for convergence. If convergence criteria are not satisfied, the out-of-balance load vector is re- 
evaluated, the stiffness matrix is updated, and a new solution is obtained. This iterative procedure continues until the problem converges.

A mesh size sensitivity study is performed to evaluate the optimum size of elements in the FE model of shear walls. Figure 6 illustrate Load-Displacement curves for a cold-formed steel shear wall with $1.2 * 2.4 \mathrm{~m}$ dimensions sheathed by a plywood panel with $12.5 \mathrm{~mm}$ thickness. The sheathing panel is divided by square elements and the frame members are composed of shell elements whose larger dimensions is equal to element size of the sheathing, as shown in Figure 4. The load-displacement curves in Figure 6 are drawn for four sheathing mesh sizes of 150, 100, 50 and $25 \mathrm{~mm}$. the maximum shear force of the wall for these mesh sizes is 16351, 17851, 18818 and $19301 \mathrm{~N}$, respectively. It means by changing the element size from $50 \mathrm{~mm}$ to $25 \mathrm{~mm}$, the maximum load will change 2.5 percent. Thus, in this study the size of sheathing elements has been chosen equal to $50 \mathrm{~mm}$ as an optimum size that give a good accuracy and an acceptable analysis time.

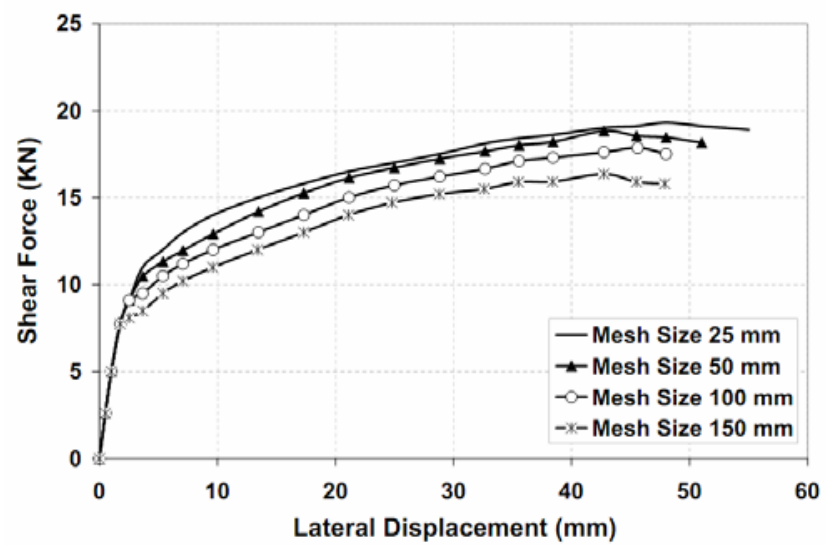

Figure 6. Mesh Size Sensitivity

\section{VERIFICATION OF THE SHEAR WALL MODEL}

In order to evaluate the system behavior, a push-over analysis with geometry and material nonlinearity was performed on different specimens. For this purpose, it was necessary to consider different drifts on the wall and record the corresponding lateral force. This procedure had to be continued until the structure reached its maximum lateral strength for a certain drift. In this section, the results of these analyses are compared with the experimental results of other researchers. Comparison of the experimental and FEM results for shear wall panels are presented in Table 2 through 4. Moreover, in order to have a better understanding, the ratios of the finite element results to the test results are included.

The experimental results of references $[1,2,3,4,5]$ are used to validate the accuracy of the presented numerical method. For the purpose of the analyses, the geometric gross properties of the steel studs were determined on the basis of cross-sectional dimensions presented in the literature. Unless specified differently for individual cases, the yield strength, Young's modulus and Poisson's ratio of steel are considered to be $230 \mathrm{MPa}, 203 \mathrm{GPa}$ and 0.3 respectively. The standard nomenclature including member size (both depth and flange width), style, and material thickness is used to introduce frame members. For example $92 \mathrm{~S} 41-1.12 \mathrm{~mm}$ introduce a stud with $92 \mathrm{~mm}$ depth, $41 \mathrm{~mm}$ flange width and $1.12 \mathrm{~mm}$ material thickness. The following material properties for the sheathing material are also utilized in the study: the modulus of elasticity for OSB, DFP and CSP are 9917 [10], 10,445 and 7376MPa [11], respectively. For gypsum wall board (GWB), the modulus of elasticity is $1290 \mathrm{MPa}$ [12]. A schematic view of a studied shear wall panel is illustrated in Figure 7. 


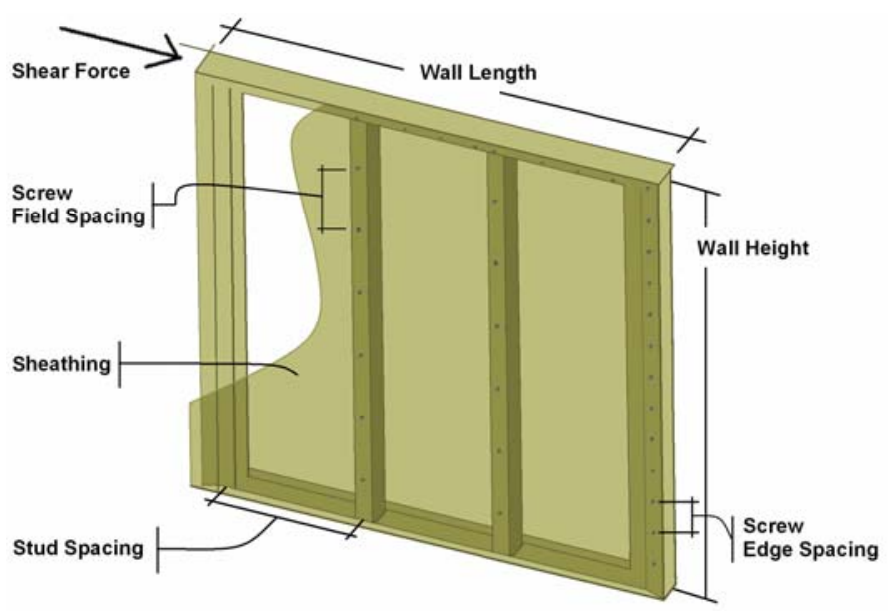

Figure 7. Schematic View of Shear Wall Panel

Table 2 compares the current numerical results with the test results of Rogers et al. [4] for lateral strengths and lateral displacements. The sheathing materials are OSB, DFP and CSP with thicknesses of $11,12.5$ and $12.5 \mathrm{~mm}$, respectively. The $\mathrm{C}$-shape cold-formed steel studs were 92S41-1.12mm (362S162-44 mils), spaced 610mm (24 in) center by center. Double C-shape backto-back studs were placed at the ends of the panel. The sheathing was attached on one side of the panel using No. 8 (diameter $=4.06 \mathrm{~mm}$ ) screws. The spacing of screws within the panel was $305 \mathrm{~mm}$ (12 in) and their spacing at the edges of panel as listed in Table 2.

It is apparent from Table 2 that the maximum difference between numerical and experimental results of the shear wall panels for lateral strength and ultimate lateral displacements is $22 \%$ and $19 \%$, respectively.

Table 2. Comparison between Numerical and Experimental Results [4]

\begin{tabular}{|c|c|c|c|c|c|c|c|c|}
\hline \multirow{2}{*}{$\begin{array}{l}\text { Shear wall panels } \\
\text { description } \\
\text { (Steel stud: 92S41-1.12 } \\
\mathrm{mm} \text { ) }\end{array}$} & \multirow{2}{*}{$\begin{array}{l}\text { Sheathing } \\
\text { material and } \\
\text { thickness }\end{array}$} & \multirow{2}{*}{$\begin{array}{l}\text { Edge } \\
\text { screw } \\
\text { spacing } \\
(\mathrm{mm})\end{array}$} & \multicolumn{3}{|c|}{$\begin{array}{l}\text { Lateral strength } \\
(\mathrm{kN})\end{array}$} & \multicolumn{3}{|c|}{$\begin{array}{l}\text { Ultimate lateral displacement } \\
(\mathrm{mm})\end{array}$} \\
\hline & & & $\begin{array}{l}\text { Test } \\
{[4]}\end{array}$ & FEM & $\begin{array}{l}\text { Ratio } \\
\text { FEM/ } \\
\text { Test }\end{array}$ & $\begin{array}{l}\text { Test } \\
{[4]}\end{array}$ & FEM & $\begin{array}{l}\text { Ratio } \\
\text { FEM/ } \\
\text { Test }\end{array}$ \\
\hline \multirow{9}{*}{$\begin{array}{l}\text { Wall length and height: } \\
1219 \mathrm{~mm}, 2438 \mathrm{~mm} \text {. } \\
\text { Sheathing length and height: } \\
1219 \mathrm{~mm}, 2438 \mathrm{~mm} \text {. }\end{array}$} & OSB & 152 & 16.10 & 16.66 & 1.03 & 41.1 & 35.4 & 0.86 \\
\hline & $11 \mathrm{~mm}$ & 102 & 23.52 & 22.36 & 0.95 & 39.5 & 37.5 & 0.95 \\
\hline & One side & 76 & 28.64 & 24.14 & 0.84 & 40.7 & 48.5 & 1.19 \\
\hline & DFP & 152 & 19.50 & 20.73 & 1.06 & 54.8 & 48.0 & 0.88 \\
\hline & $12.5 \mathrm{~mm}$ & 102 & 29.01 & 28.86 & 1.00 & 60.6 & 55.2 & 0.91 \\
\hline & One side & 76 & 36.20 & 29.52 & 0.82 & 58.2 & 58.8 & 1.01 \\
\hline & CSP & 152 & 15.48 & 18.81 & 1.22 & 50.7 & 45.5 & 0.90 \\
\hline & $12.5 \mathrm{~mm}$ & 102 & 20.23 & 23.93 & 1.18 & 60.6 & 53.5 & 0.88 \\
\hline & One side & 76 & 30.59 & 26.13 & 0.85 & 61.0 & 63.6 & 1.04 \\
\hline \multirow{4}{*}{$\begin{array}{l}\text { Wall length and height: } \\
609 \mathrm{~mm}, 2438 \mathrm{~mm} \text {. } \\
\text { Sheathing length and height: } \\
609 \mathrm{~mm}, 2438 \mathrm{~mm} \text {. }\end{array}$} & OSB $11 \mathrm{~mm}$ & 152 & 7.62 & 6.69 & 0.88 & 78.4 & 78.3 & 1.00 \\
\hline & One side & 102 & 11.21 & 10.94 & 0.98 & 78.0 & 83.1 & 1.07 \\
\hline & CSP $12.5 \mathrm{~mm}$ & 152 & 7.43 & 7.54 & 1.02 & 103.3 & 95.3 & 0.92 \\
\hline & One side & 102 & 10.97 & 11.65 & 1.06 & 107.0 & 102.3 & 0.96 \\
\hline Wall length and height: & CSP $12.5 \mathrm{~mm}$ & 152 & 33.16 & 40.18 & 1.21 & 50.5 & 42.3 & 0.84 \\
\hline $2438 \mathrm{~mm}, 2438 \mathrm{~mm}$. & One side & 102 & 49.98 & 50.16 & 1.00 & 55.6 & 49.3 & 0.89 \\
\hline $\begin{array}{l}\text { Sheathing length and height: } \\
\text { (2) } 1219 \mathrm{~mm}, 2438 \mathrm{~mm} \text {. }\end{array}$ & & 76 & 64.11 & 66.96 & 1.04 & 64.1 & 59.9 & 0.93 \\
\hline Average & & & & & 1.01 & & & 0.95 \\
\hline Standard deviation & & & & & 0.12 & & & 0.09 \\
\hline
\end{tabular}


Table 3 provides a comparison between the numerical lateral strengths of shear wall panels with OSB sheathing published in the Standard for Cold-Formed Steel Framing-Lateral Design by AISI [3]. The length and height of the shear wall panels are $1219 \mathrm{~mm}(4 \mathrm{ft})$ and $2438 \mathrm{~mm}(8 \mathrm{ft})$, respectively. The steel stud size is $89 \mathrm{~S} 41 \mathrm{~mm}$ and four different stud thicknesses listed in the standard are $0.838 \mathrm{~mm}$ (33 mils), $1.092 \mathrm{~mm}$ (43 mils), $1.372 \mathrm{~mm}$ (54 mils), and $1.727 \mathrm{~mm}$ (68 mils). Double studs are utilized for the end studs. OSB sheathing was attached on one side of the panel using No. 8 or No. 10 screws at every $305 \mathrm{~mm}$ (12 in) in the field. The spacing of tow edge screw is $102 \mathrm{~mm}$ (4 in) and $152 \mathrm{~mm}$ (6 in). As cited in Table 3, there is good agreement between the numerical and experimental results for the shear wall panels' lateral strength.

Table 3. Comparison between Numerical and Experimental Results [3]

\begin{tabular}{|c|c|c|c|c|c|c|c|}
\hline \multirow{2}{*}{$\begin{array}{l}\text { Shear wall panels } \\
\text { description }\end{array}$} & \multirow{2}{*}{$\begin{array}{l}\text { Stud } \\
\text { thickness } \\
(\mathrm{mm})\end{array}$} & \multirow{2}{*}{$\begin{array}{l}\text { Sheathing } \\
\text { material and } \\
\text { thickness }\end{array}$} & \multirow{2}{*}{$\begin{array}{l}\text { Edge } \\
\text { screw } \\
\text { Spacing } \\
(\mathrm{mm})\end{array}$} & \multicolumn{3}{|c|}{ Lateral strength $(\mathrm{kN})$} & \multirow{2}{*}{$\begin{array}{l}\text { Ultimate } \\
\text { lateral } \\
\text { displacement } \\
(\mathrm{mm})\end{array}$} \\
\hline & & & & $\begin{array}{l}\text { AISI } \\
{[3]}\end{array}$ & FEM & $\begin{array}{l}\text { Ratio } \\
\text { FEM/ AISI } \\
{[3]}\end{array}$ & \\
\hline Steel stud: 89S41mm & 0.838 & OSB & 152.4 & 12.46 & 13.81 & 1.11 & 31.8 \\
\hline Wall length And height: & & $11.1 \mathrm{~mm}$ & 101.6 & 16.28 & 17.71 & 1.09 & 40.1 \\
\hline $1219 \mathrm{~mm}, 2438 \mathrm{~mm}$ & 1.092 & One side & 152.4 & 14.68 & 16.62 & 1.13 & 32.8 \\
\hline Sheathing Length And height: & & & 101.6 & 21.97 & 21.58 & 0.99 & 42.4 \\
\hline $1219 \mathrm{~mm}, 2438 \mathrm{~mm}$ & 1.372 & & 152.4 & 16.73 & 19.63 & 1.17 & 31.4 \\
\hline & & & 101.6 & 25.09 & 23.62 & 0.94 & 42.7 \\
\hline & 1.727 & & 152.4 & 21.92 & 23.63 & 1.08 & 24.4 \\
\hline & & & 101.6 & 32.88 & 25.64 & 0.78 & 41.2 \\
\hline Average & & & & & & 1.04 & \\
\hline Standard deviation & & & & & & 0.13 & \\
\hline
\end{tabular}

The numerical and experimental results for lateral strengths and displacements, conducted by Serrette et al. [2] are compared in Table 4. Dimensions of shear wall panels were $1219 \mathrm{~mm}(4 \mathrm{ft}) \times$ $2438 \mathrm{~mm}$ ( $8 \mathrm{ft}$ ). OSB sheathing was fastened on one side or both sides of the panel using No. 8 or No. 10 screws. The screw spacing at the edge and within the sheathing was $51 \mathrm{~mm}(2 \mathrm{in})$ and $305 \mathrm{~mm}$ (12 in), respectively. The framing steel studs used in the experiment was 89S41 mm and had thicknesses of $1.37 \mathrm{~mm}$ (54 mils), and yield strengths of 407MPa (59 ksi). Single studs spaced at $610 \mathrm{~mm}(24 \mathrm{in})$ were placed at the middle while double studs were used at the ends of the shear wall panels.

Table 4 compares the numerical and experimental results for lateral strengths and lateral displacements conducted by Fulop and Dubina [5] and Serrette [1] as well. In first case, OSB sheathing was placed on one side of the panel, and the steel studs spaced $610 \mathrm{~mm}(24 \mathrm{in})$ were employed at the middle. Contrary to the previous experiments, the shear wall panel had lengths and heights of $3600 \mathrm{~mm}(\approx 12 \mathrm{ft})$ and $2440 \mathrm{~mm}(8 \mathrm{ft})$, respectively.

In second case, the length and height of the shear wall panel were $2438 \mathrm{~mm}(8 \mathrm{ft})$ and $2438 \mathrm{~mm}(8$ $\mathrm{ft}$ ), respectively. The GWB sheathing was fastened to both sides of the panel with No. 6 screws. The screw spacing on the edge and field of the panel was $152 \mathrm{~mm}$ (6 in) and $305 \mathrm{~mm}$ (12 in), respectively. Steel studs were $150 \mathrm{~S} 32$ (600S125) with thickness of $0.88 \mathrm{~mm}$ (33 mils). The studs were spaced $610 \mathrm{~mm}(24 \mathrm{in})$ at the centre, and the sheathing was attached to the studs using No. 6 screws. The value of lateral strength in Table 4 is the average of lateral strength of four specimens. 
Table 4. Comparison between Numerical and Experimental Results [2,5,1]

\begin{tabular}{|c|c|c|c|c|c|c|c|c|}
\hline \multirow[t]{2}{*}{$\begin{array}{l}\text { Shear wall panels } \\
\text { description }\end{array}$} & \multirow{2}{*}{$\begin{array}{l}\text { Sheathing } \\
\text { material and } \\
\text { thickness }\end{array}$} & \multirow{2}{*}{$\begin{array}{l}\text { Edge screw } \\
\text { Spacing } \\
(\mathrm{mm})\end{array}$} & \multicolumn{3}{|c|}{$\begin{array}{l}\text { Lateral } \\
\text { strength }(\mathrm{kN})\end{array}$} & \multicolumn{3}{|c|}{$\begin{array}{l}\text { Ultimate lateral } \\
\text { displacement (mm) }\end{array}$} \\
\hline & & & Test & FEM & $\begin{array}{l}\text { Ratio } \\
\text { FEM/ } \\
\text { Test }\end{array}$ & Test & FEM & $\begin{array}{l}\text { Ratio } \\
\text { FEM/ } \\
\text { Test }\end{array}$ \\
\hline $\begin{array}{l}\text { Steel stud: } 89 \mathrm{~S} 41-1.37 \mathrm{~mm} \text {. } \\
\text { Walls length and height: } \\
2438 \mathrm{~mm}, 2438 \mathrm{~mm} \text {. }\end{array}$ & $\begin{array}{l}\text { OSB } 11 \mathrm{~mm} \\
\text { One side }\end{array}$ & 51 & 83.81 & 64.75 & 0.77 & - & 75.0 & - \\
\hline $\begin{array}{l}\text { Sheathing length and height: } \\
\text { (2) } 1219 \mathrm{~mm}, 2438 \mathrm{~mm},[2] .\end{array}$ & $\begin{array}{l}\text { OSB } 11 \mathrm{~mm} \\
\text { Both side }\end{array}$ & 51 & 148.62 & 125.98 & 0.85 & - & 75.2 & - \\
\hline $\begin{array}{l}\text { Steel stud: } 150 \mathrm{~S} 41-1.5 \mathrm{~mm} \text {. } \\
\text { Wall length and height: } \\
3600 \mathrm{~mm}, 2440 \mathrm{~mm} \text {. } \\
\text { Sheathing length and height: } \\
\text { (3) } 1200 \mathrm{~mm}, 2440 \mathrm{~mm},[5] .\end{array}$ & $\begin{array}{l}\text { OSB } 10 \mathrm{~mm} \\
\text { One side }\end{array}$ & 102 & 78.76 & 74.93 & 0.95 & 2.9 & 45.3 & 1.06 \\
\hline $\begin{array}{l}\text { Steel stud: } 150 \text { S32- } 0.88 \mathrm{~mm} \text {. } \\
\text { Wall length and height: } \\
2438 \mathrm{~mm}, 2438 \mathrm{~mm} \text {. } \\
\text { Sheathing length and height: } \\
\text { (2) } 1219 \mathrm{~mm}, 2438 \mathrm{~mm} \text {, [1]. }\end{array}$ & $\begin{array}{l}\text { GWB } 12.7 \mathrm{~mm} \\
\text { Both side }\end{array}$ & 152 & 26.64 & 25.8 & 0.97 & 40.0 & 45.0 & 1.13 \\
\hline
\end{tabular}

It should be mentioned that the difference between the experimental and FEM results can be attributed to some factors such as accuracy of measuring tools and experimental errors including, imperfection of shear wall panels, cracking of wood and gypsum panels, etc. On the other hand, it seems difficult to construct a model which is completely compatible with several experimental results. Thus, the current model constructed by the finite element method is reasonably accurate.

\section{PARAMETRIC STUDY OF SHEAR WALL PANELS}

Using the above mentioned FE model, the effects of several parameters such as the thickness of framing members, details of track to stud connections, screw spacing and yield properties of steel on the lateral response of the frames (in particular the $\mathrm{R}$ factor) are examined. After plotting the load-displacement curve for each of the frames, the ductility and lateral strength can be determined. In order to idealize the envelope of load-displacement curve, the presented method in the FEMA 356 [13] is employed (Figure 8). A sample of idealized force-displacement curve is shown in Figure 9. This curve has been plotted for specimen No.3 of Table 5 .

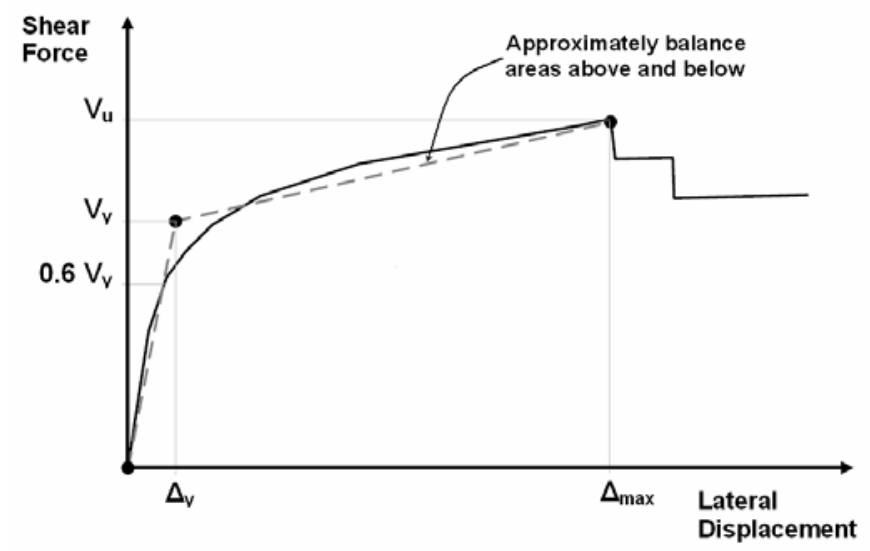

Figure 8. Idealizing Force-Displacement Curve [13] 


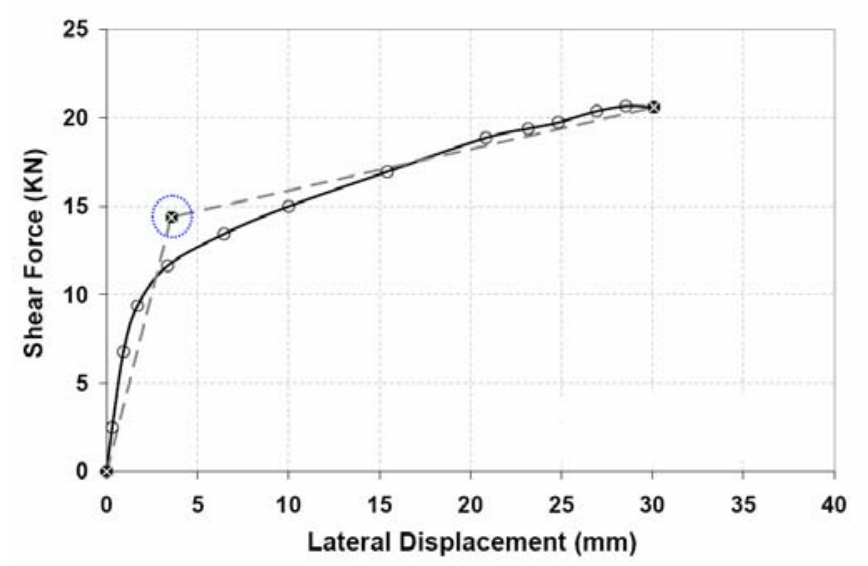

Figure 9. A Sample of Idealized Force-Displacement Curve of a Shear Wall Panel

In order to calculate the ductility reduction factor $\left(R_{\mu}\right)$, Eq. (5) is used. Because, a range between 0.1 and $0.5 \mathrm{sec}$ for period $T$, in one and two story cold-formed steel frames with plaster panels is logical [14]. After computing $\Omega$ and $R_{\mu}$, force reduction factors of each frame can be determined.

In general, three factors may contribute to the over strength factor; these are the design overstrength $\left(\Omega_{D}\right)$, the material Over-strength $\left(\Omega_{M}\right)$ and the system over-strength $\left(\Omega_{S}\right)$. In those structures where the lateral strength is dominant, e.g. structures with bracing or shear walls similar to the cold formed structures of this study, the design over-strength is small and its factor can be considered as 1.0. Material over-strength is a strength that structural materials may possess beyond the design material strength. Design regulations normally work based on the nominal strengths which are reduced by the strength reduction factors $(\Phi)$. The strength of a structure made of these materials is significantly higher than that considered in the design. $\Phi$ in AISI Lateral Design [3] is assumed to be 0.6 , so $\Omega_{M}$ can be considered equal to 1.67 . System Over-strength mainly depends on the indeterminacy of structure. For instance in the moment resisting frame, the sequence of plastic hinge leads to increase in the structure strength. In this paper, by ignoring the shear strength of the plaster boards in the lateral design of light steel structures, the system over-strength is conservatively considered 1.0. Therefore, by the multiplication of $\Omega_{D}, \Omega_{M}$ and $\Omega_{S}$, over strength factor, $\Omega$, will be equal to 1.67 .

In this section, unless specified differently for individual cases, the length and height of the shear wall panels are $1219 \mathrm{~mm}(4 \mathrm{ft})$ and $2438 \mathrm{~mm}(8 \mathrm{ft})$, respectively. The designation of cold-formed steel studs is $92 \mathrm{~S} 41-1.12 \mathrm{~mm}$. OSB sheathing (with $11 \mathrm{~mm}$ thickness) is fastened on one side of the panels. The screw spacing at the edge and within the sheathing is $102 \mathrm{~mm}$ (4 in) and $305 \mathrm{~mm}$ (12 in), respectively. The yield strength, Young's modulus and Poisson's ratio of steel are considered to be $230 \mathrm{MPa}, 203 \mathrm{GPa}$ and 0.3 respectively.

\subsection{Thickness of Frame Members}

The thickness of the frame members is an important parameter in the performance of shear wall panels. In order to examine the effects of thickness on the lateral strength and displacement, four shear wall panels with stud and track thickness of $0.838,1.092,1.372,1.727 \mathrm{~mm}$ are considered. The framing members are $89 \mathrm{~S} 41 \mathrm{~mm}$. The screws spacing at the edge and within the sheathing are $51 \mathrm{~mm}$ (2 in) and $305 \mathrm{~mm}$ (12 in), respectively. The load-displacement curves of the shear walls are illustrated in Figure 10 and the values of ductility and force reduction factors of the frames for different frame members' thickness are presented in Table 5. As the thicknesses of frame members increase, the ultimate load of studs increases which in turn results in increase of lateral strength of the frame. 


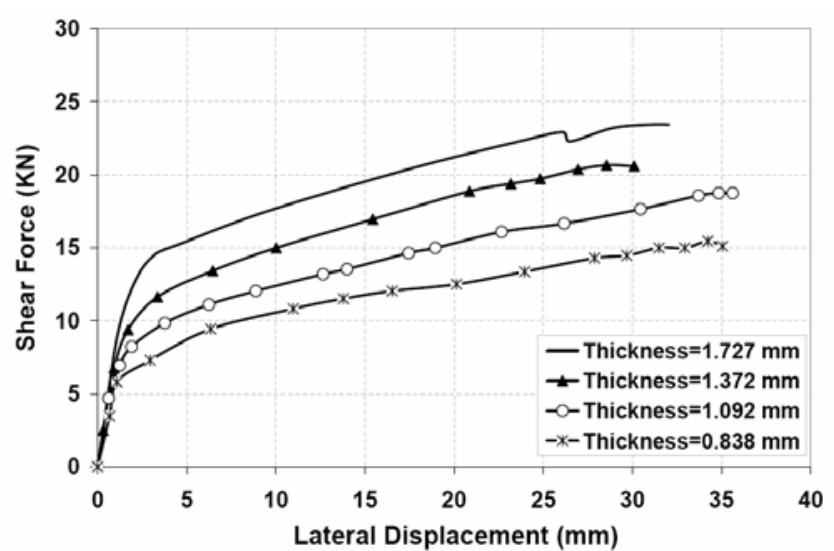

Figure 10. Effect of Frame Members' Thickness on the Racking Performance of Shear Wall Panel with OSB Sheathing and Dimension of $1.2 \times 2.4 \mathrm{~m}$

Table 5. Values of Ductility and R-factor of Shear Wall Panel with Different Thickness of Frame Members

\begin{tabular}{llllllll}
\hline No & $\begin{array}{l}\text { Thickness } \\
(\mathrm{mm})\end{array}$ & $\Delta_{\mathrm{y}}(\mathrm{mm})$ & $\begin{array}{l}\Delta_{\max } \\
(\mathrm{mm})\end{array}$ & $\mu$ & $\mathrm{R}_{\mu}$ & $\mathrm{R}$ & $\begin{array}{l}\mathrm{Vu} \\
(\mathrm{kN})\end{array}$ \\
\hline 1 & 0.838 & 3.82 & 35.04 & 9.17 & 4.16 & 6.95 & 15.10 \\
2 & 1.092 & 4.38 & 35.61 & 8.11 & 3.90 & 6.51 & 18.75 \\
3 & 1.372 & 3.56 & 30.09 & 8.44 & 3.98 & 6.65 & 20.60 \\
4 & 1.727 & 3.62 & 32.05 & 8.83 & 4.08 & 6.80 & 23.43 \\
\hline
\end{tabular}

\subsection{Wall Height}

To examine the effect of wall heights, seven specimens with heights of 2, 2.4, 2.7 and $3 \mathrm{~m}$ and lengths of 1.2 and $2.4 \mathrm{~m}$ are investigated (Figure 11). One DFP sheathing (with thickness and length of 12.5 and $1219 \mathrm{~mm}$ respectively) was fastened on one side of the panels with length of $1219 \mathrm{~mm}$ and two CSP sheathing (with thickness and length of 12.5 and $1219 \mathrm{~mm}$ respectively) were fastened on one side of the panels with length of $2438 \mathrm{~mm}$. The values of ductility and force reduction factor for different frame heights are presented in Table 6.

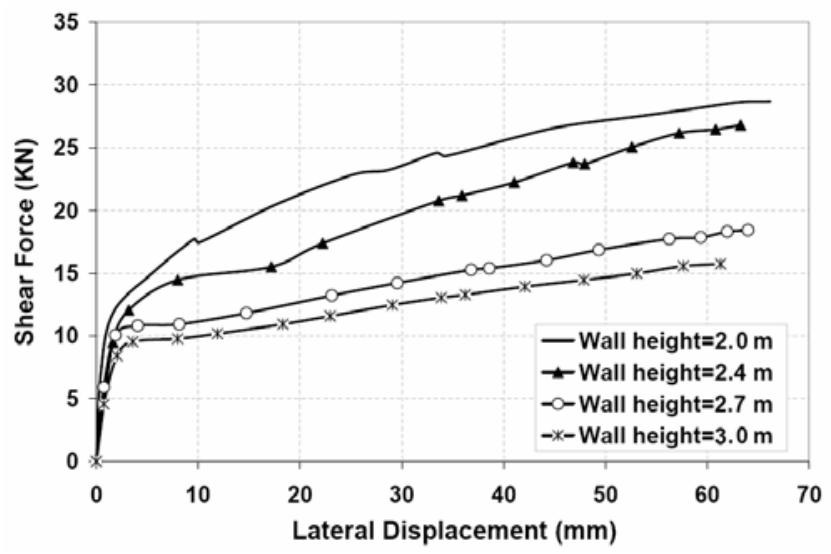

(a) 


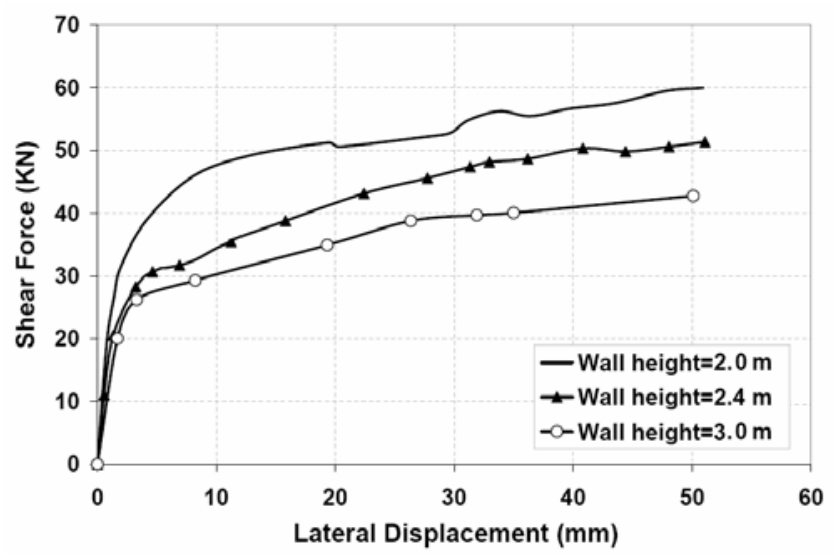

(b)

Figure 11. Effect of Frame Height on the Racking Resistance of Shear Wall Panels with Length of; a) $1.2 \mathrm{~m}$, b) $2.4 \mathrm{~m}$

Table 6. Values of Ductility and R-factor of Shear wall Panels with Different Wall Height

\begin{tabular}{lllcccccc}
\hline No & $\begin{array}{l}\text { Frame width } \\
(\mathrm{m})\end{array}$ & $\begin{array}{l}\text { Frame height } \\
(\mathrm{m})\end{array}$ & $\begin{array}{l}\Delta_{\mathrm{y}} \\
(\mathrm{mm})\end{array}$ & $\begin{array}{l}\Delta_{\max } \\
(\mathrm{mm})\end{array}$ & $\mu$ & $\mathrm{R}_{\mu}$ & $\mathrm{R}$ & $\begin{array}{l}\mathrm{Vu} \\
(\mathrm{kN})\end{array}$ \\
\hline 1 & 1.2 & 3.0 & .33 & 60.95 & 14.04 & 5.20 & 8.68 & 15.74 \\
2 & & 2.7 & 4.01 & 60.95 & 15.16 & 5.41 & 9.03 & 18.43 \\
3 & & 2.4 & 5.32 & 60.95 & 11.43 & 4.67 & 7.80 & 26.80 \\
4 & & 2.0 & 7.83 & 60.95 & 7.77 & 3.81 & 6.36 & 28.67 \\
& & & & & & & & \\
5 & 2.4 & 3.0 & 5.61 & 50.09 & 8.92 & 4.10 & 6.85 & 42.77 \\
6 & & 2.4 & 6.44 & 51.07 & 7.93 & 3.85 & 6.43 & 51.37 \\
7 & 2.0 & 4.86 & 50.93 & 10.47 & 4.46 & 7.45 & 59.98 \\
\hline
\end{tabular}

In general, lateral strength decreases as frame height increases. This is due to the increase in the inplane flexural moment of shear panels, and studs respectively and the local displacement at the place of screws. The average decrease of both frames was 29 percent as the frame height increased from 2438 to $3000 \mathrm{~mm}$. The ductility, however, normally increases with the increase in the height of the braced span and this is mainly due to the increase in the flexural deformation of shear panel.

\subsection{Spacing of Field and Edge Screws}

It is evident that stud strength can be significantly increased by using sufficient number of connection screws which essentially decreases the effective length coefficient. Screws connecting the frame and the shear panels play a valuable role in laterally supporting the studs. Hence, to evaluate the effect of connection screws, twelve shear wall panels with lengths of 1219 and 2438 $\mathrm{mm}$ and height of $2438 \mathrm{~mm}$ are investigated. DFP and CSP sheathings with thickness of 12.5 were fastened on one side of the panels with length of $1219 \mathrm{~mm}$ and two $2438 \mathrm{~mm}$, respectively. Figure 12 shows load-displacement curves of the walls for three edge screw spaces and Figure 13 illustrate these curves for three field screw spaces. The values of ductility and force reduction factor of the walls are presented in Tables 7 and 8. 


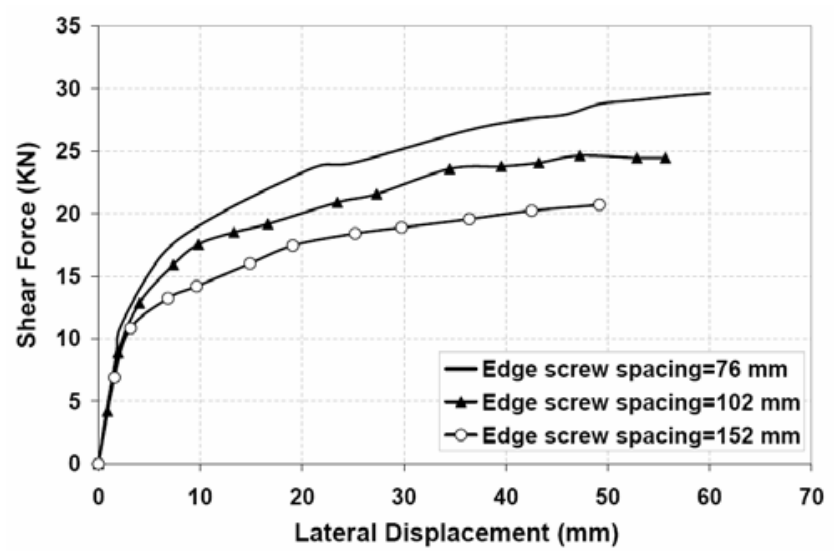

(a)

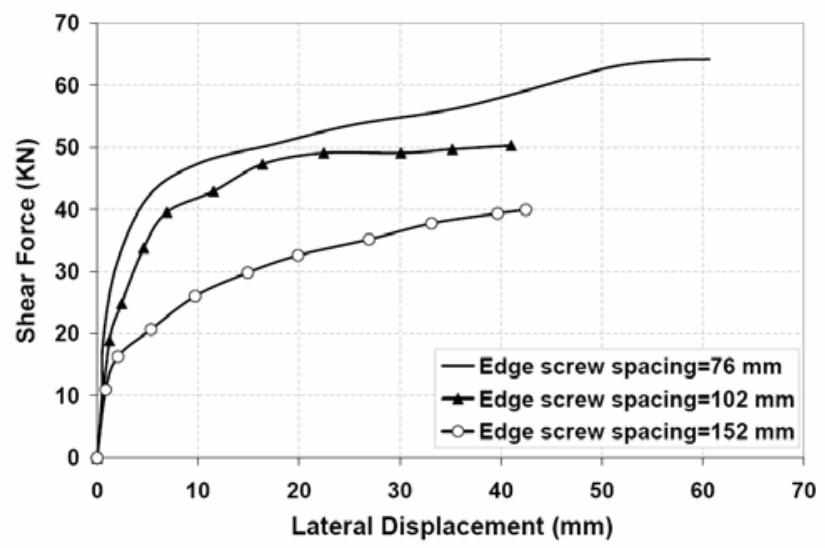

(b)

Figure 12. Effect of Edge Screw Spacing on the Racking Resistance of Shear Wall Panels with Dimensions of; a) $1.2 \mathrm{~m} \times 2.4 \mathrm{~m}$, b) $2.4 \mathrm{~m} \times 2.4 \mathrm{~m}$

Table 7. Values of Ductility and R-factor of Shear Wall Panels with Different Spacing of Edge Screws

\begin{tabular}{|c|c|c|c|c|c|c|c|c|c|}
\hline No & $\begin{array}{l}\text { Frame } \\
\text { dimensions } \\
(\mathrm{m})\end{array}$ & $\begin{array}{l}\text { Field } \\
\text { screw } \\
\text { spacing } \\
(\mathrm{mm})\end{array}$ & $\begin{array}{l}\text { Edge screw } \\
\text { spacing } \\
(\mathrm{mm})\end{array}$ & $\begin{array}{l}\Delta_{\mathrm{y}} \\
(\mathrm{mm})\end{array}$ & $\begin{array}{l}\Delta_{\max } \\
(\mathrm{mm})\end{array}$ & $\mu$ & $\mathrm{R}_{\mu}$ & $\mathrm{R}$ & $\begin{array}{l}\mathrm{Vu} \\
(\mathrm{kN})\end{array}$ \\
\hline 1 & $1.2 \times 2.4$ & 305 & 152 & 4.37 & 49.17 & 11.23 & 4.63 & 7.73 & 20.71 \\
\hline 2 & & & 102 & 8.18 & 55.65 & 6.79 & 3.54 & 5.91 & 24.45 \\
\hline 3 & & & 76 & 7.83 & 60.02 & 7.65 & 3.78 & 6.31 & 29.63 \\
\hline 4 & $2.4 \times 2.4$ & 305 & 152 & 5.59 & 42.46 & 7.59 & 3.76 & 6.28 & 39.97 \\
\hline 5 & & & 102 & 6.66 & 41.00 & 6.1 & 3.36 & 5.61 & 50.31 \\
\hline 6 & & & 76 & 5.76 & 60.65 & 10.52 & 4.47 & 7.46 & 64.23 \\
\hline
\end{tabular}

As can be seen from Table 7, decreasing the spacing of edge screws from 152 to 102 and $76 \mathrm{~mm}$ in the frame with length of $1219 \mathrm{~mm}$ is accompanied by $18.1 \%$ and $43.1 \%$ increase in the lateral strength, respectively. The corresponding increase in the frame with length of $2438 \mathrm{~mm}$ is $25.8 \%$ and $60.7 \%$. This means that the average increase in the lateral strength of both frames was $22 \%$ and $52 \%$ when the edge screw spacing decreases from 152 to 102 and $76 \mathrm{~mm}$, respectively. By a decrease in the spacing of edge screws, shear forces and axial forces can be distributed more uniformly on the panel members and edge members, respectively. As a consequence, the chances of the occurrence of any local failure decreases which leads to an increase in the lateral strength of the frame. In addition, screw connections provide supports for studs and tracks which help with the buckling issues. 


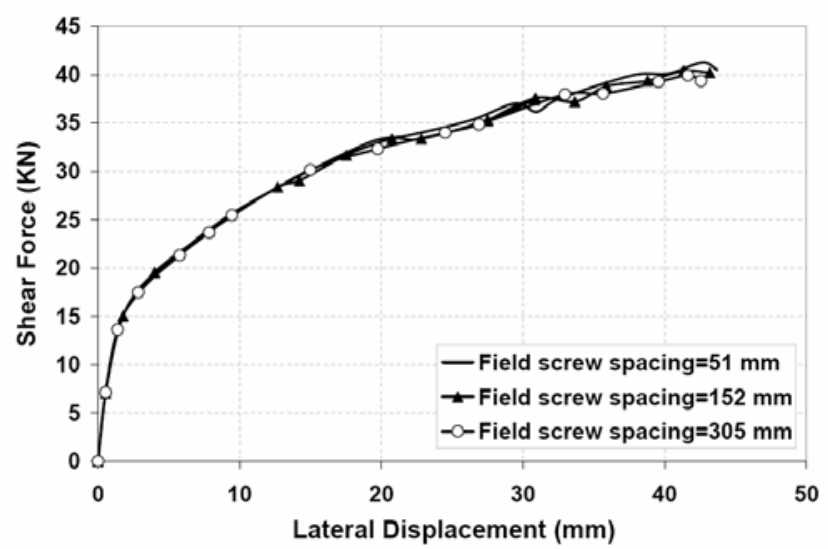

(a)

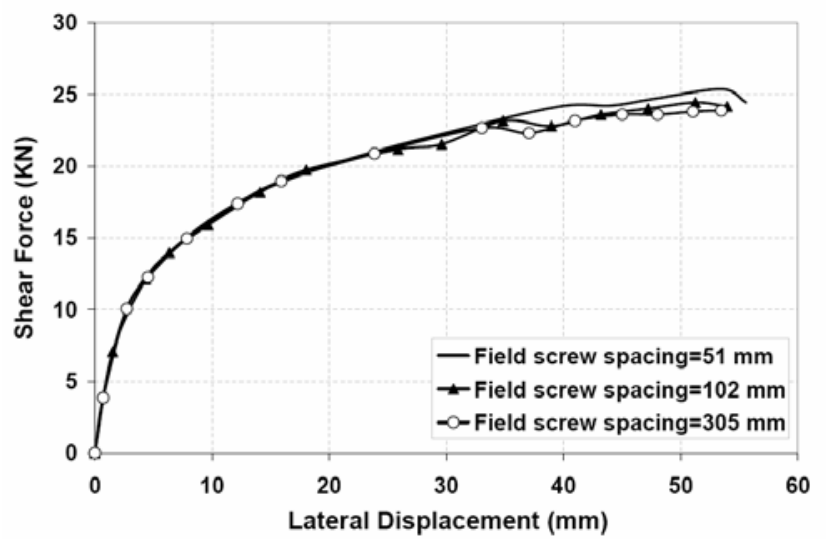

(b)

Figure 13. Effect of Field Screw Spacing on the Racking Resistance of Shear Wall Panels with Dimensions of; a) $1.2 \mathrm{~m} \times 2.4 \mathrm{~m}$, b) $2.4 \mathrm{~m} \times 2.4 \mathrm{~m}$

Table 8. Values of Ductility and R-factor of Shear Wall Panels with Different Spacing of Field Screws

\begin{tabular}{llllllllll}
\hline No & $\begin{array}{l}\text { Frame } \\
\text { dimension } \\
(\mathrm{m})\end{array}$ & $\begin{array}{l}\text { Edge screw } \\
\text { spacing } \\
(\mathrm{mm})\end{array}$ & $\begin{array}{l}\text { Field screw } \\
\text { spacing } \\
(\mathrm{mm})\end{array}$ & $\Delta_{\mathrm{y}}(\mathrm{mm})$ & $\begin{array}{l}\Delta_{\max } \\
(\mathrm{mm})\end{array}$ & $\mu$ & $\mathrm{R}_{\mu}$ & $\mathrm{R}$ & $\begin{array}{l}\mathrm{Vu} \\
(\mathrm{kN})\end{array}$ \\
\hline 1 & $1.2 \times 2.4$ & 152 & 305 & 5.92 & 42.54 & 7.18 & 3.65 & 6.10 & 23.87 \\
2 & & & 102 & 6.15 & 43.16 & 7.00 & 3.60 & 6.01 & 24.15 \\
3 & & & 51 & 5.79 & 43.70 & 7.53 & 3.75 & 6.26 & 24.44 \\
& & & & & & & & & \\
4 & $2.4 \times 2.4$ & 102 & 305 & 8.26 & 53.45 & 6.46 & 3.45 & 5.76 & 39.36 \\
5 & & & 152 & 8.35 & 53.95 & 6.45 & 3.45 & 5.76 & 40.20 \\
6 & & & 51 & 8.50 & 55.57 & 6.53 & 3.47 & 5.79 & 40.49 \\
\hline
\end{tabular}

Since field screws do not have a notable contribution in the transfer of lateral loads, the effect of spacing of these screws is minor. Decrease in the spacing of field screws from 305 to $51 \mathrm{~mm}$ will result in an increase equal to $2.4 \%$ and $2.9 \%$ in the lateral strength of frames with the length of 1219 and $2438 \mathrm{~mm}$, respectively. Accordingly, the number of field screws shall be limited to a minimum to reduce construction costs. 


\subsection{Yielding Stress of Frame Members}

Mechanical properties of cold-formed sections are different to those prior to cold forming of the sections. This usually shows with an increase in the yielding point and tensile strength and a decrease in the ductility. The average yielding point of cold-formed steel sections is normally 10-15 percent and at maximum 20 percent larger than that prior to cold forming. Accordingly, models with yielding stress of 230 and $300 \mathrm{MPa}$ have been constructed and studied. As it is shown in Figure 14, 30 percent increase in the yielding stress of frame members has a minor effect on the initial stiffness and racking resistance.

To examine the effect of the yielding stress on the frame members, four shear wall panels with dimensions of $1.2 \mathrm{~m} \times 2.4 \mathrm{~m}$ and $3.6 \mathrm{~m} \times 2.4 \mathrm{~m}$ are investigated (Figure 14). The framing steel studs used in the experiment were 92S41-1.12mm (362S162-44 mils) for panels with length of $1219 \mathrm{~mm}$ and 150S41-1.5mm (590S162-59 mils) for panels with length of $3600 \mathrm{~mm}$. The values of ductility and force reduction factor of the shear walls are presented in Table 9.

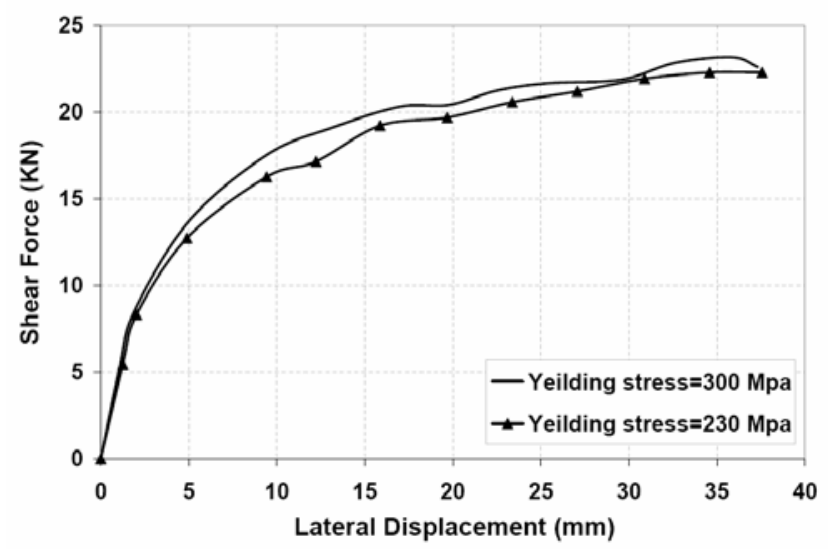

(a)

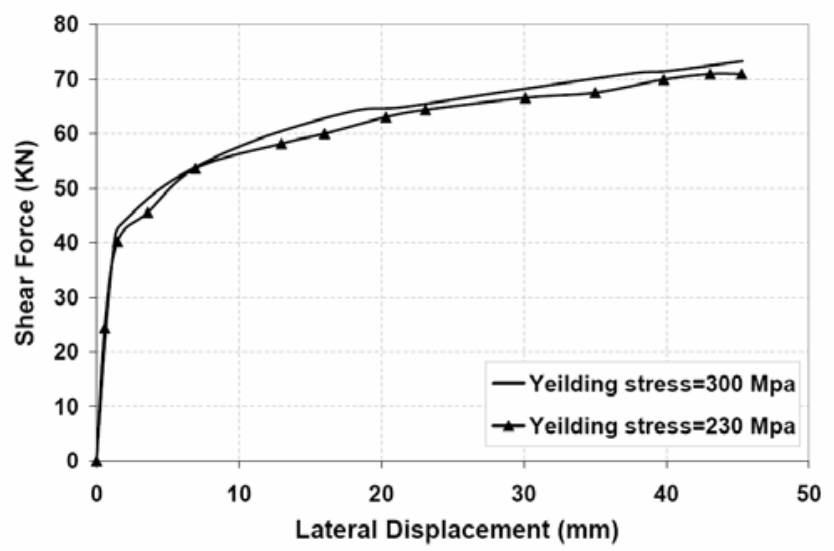

(b)

Figure 14. Effect of Yielding Point on the Stiffness and Racking Resistance of Shear Wall Panels with Dimensions of; a) $1.2 \mathrm{~m} \times 2.4 \mathrm{~m}, \mathrm{~b}) 3.6 \mathrm{~m} \times 2.4 \mathrm{~m}$

Since the sections are thin and lateral load bearing members do not experience yield even at the ultimate displacement, therefore, in these specimens, the steel type may not have a large effect on the lateral strength and ductility of the frame. For example, by increase in the yielding stress of frame members from 230 to $300 \mathrm{Mpa}$, lateral strength of frames with the length of 1219 and $3600 \mathrm{~mm}$ increases $1.4 \%$ and $3.3 \%$, respectively. 
Table 9. Values of Ductility and R-factor of Shear Wall Panels with Different Yielding Stress of Frame Members

\begin{tabular}{lllllllll}
\hline No & $\begin{array}{l}\text { Frame dimension } \\
(\mathrm{m})\end{array}$ & $\begin{array}{l}\text { Yielding stress } \\
(\mathrm{MPa})\end{array}$ & $\begin{array}{l}\Delta_{\mathrm{y}} \\
(\mathrm{mm})\end{array}$ & $\begin{array}{l}\Delta_{\max } \\
(\mathrm{mm})\end{array}$ & $\mu$ & $\mathrm{R}_{\mu}$ & $\mathrm{R}$ & $\begin{array}{l}\mathrm{Vu} \\
(\mathrm{kN})\end{array}$ \\
\hline 1 & $1.2 \times 2.4$ & 230 & 6.15 & 37.55 & 6.09 & 3.34 & 5.58 & 22.29 \\
2 & & 300 & 6.15 & 37.31 & 6.06 & 3.33 & 5.56 & 22.60 \\
& & & & & & & \\
3 & $3.6 \times 2.4$ & 230 & 4.34 & 45.26 & 10.41 & 4.45 & 7.43 & 70.92 \\
4 & & 300 & 3.59 & 45.35 & 12.61 & 4.92 & 8.22 & 73.27 \\
\hline
\end{tabular}

\section{FAILURE MODES}

In the current study, the behavior of shear wall panels subjected to in-plane lateral loading is considered. The failure of shear wall panel at ultimate strength state occurs when the panel has no further strength to resist lateral loads. According to the results obtained from experiments, the predominant failure mode of shear wall panels is associated with the sheathing failure $[2,4,15]$. As observed in the experimental studies, for most of the common sheathing materials such as plywood, OSB, and GWB, failure is often initiated by rupture of the sheathing at the location of screws, and in some cases the sheathing is separated completely from the frame. However, in cases in which the thickness of the steel studs is relatively small, the failure of the shear wall panels may be initiated by buckling of steel studs even though the studs are braced by the sheathing. Moreover, the buckling of steel studs occurs when sheathing is employed on the both sides of the frame. By applying the sheathing on both sides of the frame, or doubling the sheathing thickness, the panel lateral strength can be increased. This, in turn, increases the compressive force on the studs and may lead to overall buckling of the studs.

All failure mechanisms of shear wall panels that occur in laboratory can not be observed using finite element modeling. Two types of failure mechanisms that can be observed in these modeling are as follows:

Local buckling of the cold-formed steel section at the bottom of the compression stud is a common event in practice. Figure 15a shows this failure mode in the experimental tests of Lange and Naujoks [16] and Figure 15b indicate the similar failure in the finite element model.

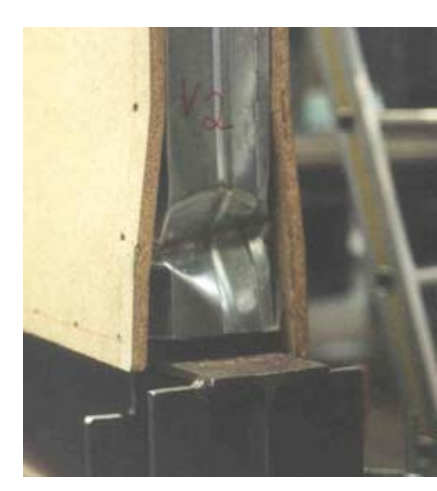

(a)

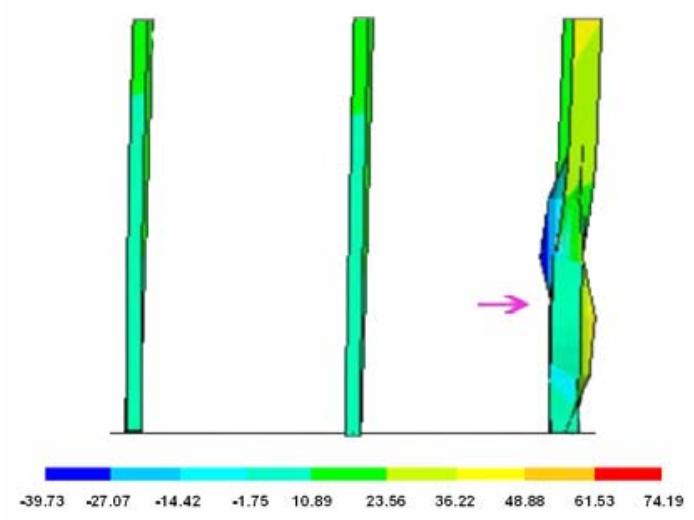

(b)

Figure 15. Local Buckling at Bottom of Stud; a) Experiment [16], b) The Present Finite Element Model 
Another failure mode is the overall buckling of studs under compression loads created from the racking force. This phenomenon is shown in Figure 16. Indeed, the maximum compression load is applied to the end studs of a frame due to their distance from the center of frame. Hence, some types of buckling are primarily observed in the end studs before the middle studs, as the local buckling is seen at the bottom of end stud in Figure 15. Nevertheless, when the double studs is used at the ends of frame and single stud at the middle, overall buckling may occur in one of middle studs before end studs, as observed in Figure 16.

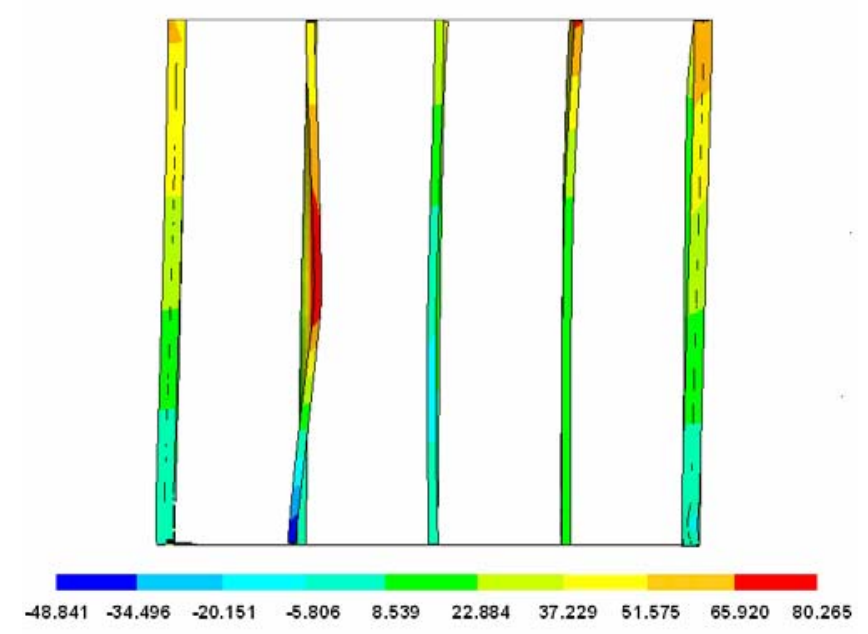

Figure 16. Overall Buckling of Stud

As shown in Figure 17a, in the test [16] tensile stress at the corner of the wall panel cause diagonal cracking within the sheathing. This will be followed by the collapse of shear wall sheathings. The extreme tensile stress can be observed at the corner of sheathing in the finite element model, as well. (Figure 17b)

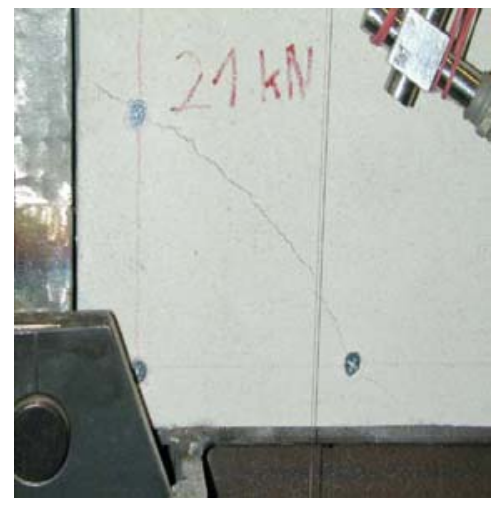

(a)

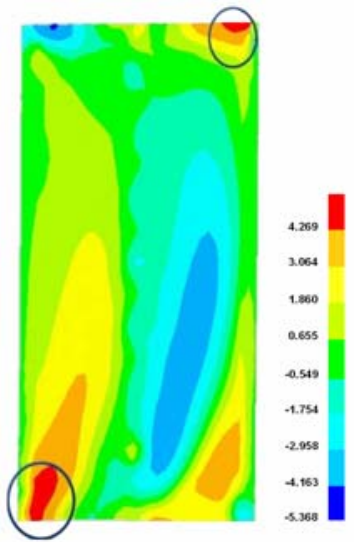

(b)

Figure 17. Tensile Fracture of Sheathing at the Corner of Frame;

a) Experiment [16], b) The Present Finite Element Model 


\section{CONCLUSION}

Using finite element model, this paper investigates the lateral performance of shear walls panels in cold formed steel frames. In order to validate the model, the finite element results, compared with the results of 28 specimens from some experimental studies. After validation, the FE model was used to perform a parametric study on the racking behavior of sheathed light steel frames.

The following conclusions are drawn from the results of the parametric study on 34 walls:

1. The stiffness and the racking resistance decreased as the frame height increased. This is due to the increase in the in-plane flexural moment of shear panels. In a similar manner, the ductility increased with the increase in the height of the braced span and this was mainly due to the increase in the flexural deformation of shear panel.

2. It was found that the field screws do not have a notable contribution in the transfer of lateral loads. Contrary to field screws, a decrease in the spacing of edge screws created a significant change in the stiffness and lateral strength. Average increases in the lateral strength of frames was $22 \%$ and $52 \%$ when edge screw spacing decrease from 152 to 102 and $76 \mathrm{~mm}$, respectively

3. As expected thickness of the frame members is important in the racking performance of system. The predominant failure mode in walls made with thick members is failure in the sheathing materials or the connections, while in walls with thin member, buckling of studs can dominates. By increasing the frame members' thickness, the ultimate load of studs increases which consequently results in an increase in the lateral strength of the frame.

4. Varying the yielding stress of steel members had a low effect on the initial stiffness and racking resistance of the system.

5. Ductility reduction factor, $R_{\mu}$, has varied from 3.3 to 5.5 with the average of 4.0 in the specimens of the present study. Choosing a value of 1.67 for over-strength factor, $\Omega$, in cold-formed steel shear walls, force reduction factor ( $R$-factor) vary between 5.5 and 9.1 with the average of 6.8 .

\section{REFERENCES}

[1] Serrette, R.L. and Ogunfunmi, K., "Shear Resistance of Gypsum-sheathed Light-gauge Steel Stud Walls", Journal of Structural Engineering, ASCE, 1996, Vol. 122, No. 4, pp. 383-399.

[2] Serrette, R.L., Morgan, K.A., and Sorhouet M.A., "Performance of Cold Formed SteelFramed Shear Walls: Alternative Configurations", Final report LGSRG-06-02 Santa Clara University, 2002.

[3] AISI, "Standard for Cold-formed Steel Framing-lateral Design", Washington, DC: American Iron and Steel Institute, 2004.

[4] Rogers, C.A., Branston, A.E., Boudreault, F.A., and Chen, C.Y., "Steel Frame Wood Panel Shear Walls: Preliminary Design Information for Use with the 2005 NBCC", In: Proceedings of the 13th World Conference on Earthquake Engineering, Vancouver, BC, 2004.

[5] Fulop, L. and Dubina, D., "Performance of Wall-stud Cold-formed Shear Panels under Monotonic and Cyclic Loading Part I: Experimental Research", Thin-Walled Structures, 2004, Vol. 42, No. 2, pp. 321-338. 
[6] Fulop, L. and Dubina, D., "Performance of Wall-stud Cold-formed Shear Panels under Monotonic and Cyclic Loading Part II: Numerical Modeling and Performance Analysis", Thin-Walled Structures, 2004, Vol. 42, No. 2, pp. 339-349.

[7] Xu, L. and Martinez, J., "Strength and Stiffness Determination of Shear Wall Panels in Cold Formed Steel Framing”, Thin-Walled Structures, 2006, Vol. 44, No. 10, pp. 10841095.

[8] Pan, C.L. and Shan, M.Y., "Monotonic Shear Tests of Cold-formed Steel Wall Frames with Sheathing", Thin-Walled Structures, 2011, Vol. 49, No. 2, pp. 363-370.

[9] Newmark, N.M. and Hall, W.J., "Earthquake Spectra and Design", Engineering Monograph, Earthquake Engineering Research Institute, Berkeley, California, 1982.

[10] OSB Design Manual, "Design Rated Oriented Strand Board", Willowdale, ON: Structural Board Association, 1995.

[11] CANPLY, "Plywood Design Fundamentals", Vancouver, BC: Canadian Plywood Association, 2003.

[12] Gypsum, "Association Gypsum Board Typical Mechanical and Physical Properties", Report GA-235-01, Washington, DC, 2002.

[13] FEMA 356, "Prestandard and Commentary for the Seismic Rehabilitation of Buildings, 2000 edition", Washington (DC, USA): Building Seismic Safety Council, National Institute of Building Science, 2000.

[14] Gad, E.F., Chandler, A.M., Duffield, C.F., and Hutchinson, G.L., "Earthquake Ductility and Over Strength in Residential Structures", Structural Engineering and Mechanics, 1999, Vol. 8, No. 4, pp. 361-382.

[15] Gad, E.F., Chandler, A.M., Duffield, C.F., and Stark, G., "Lateral Behaviour of Plasterboard-Clad Residential Steel Frames", Journal of Structural Engineering, ASCE, January 1999, Vol. 125, No. 1, pp. 32-39.

[16] Lange, J. and Naujoks, B., "Behaviour of Cold-formed Steel Shear Walls under Horizontal and Vertical Loads", Thin-Walled Structures, 2006, Vol. 44, No. 12, pp. 1214-1222. 


\title{
EXPERIMENTAL STUDY ON FIRE RESISTANCE OF SQUARE HOLLOW SECTION (SHS) TUBULAR T-JOINT UNDER AXIAL COMPRESSION
}

\author{
J. Yang ${ }^{1}$, Y.B. Shao ${ }^{2, *}$ and C. Chen ${ }^{1}$ \\ ${ }^{I}$ Graduate student, School of Civil Engineering, Yantai University, PR China \\ ${ }^{2}$ Professor, School of Civil Engineering, Yantai University, PR China \\ *(Corresponding author: E-mail: cybshao@ytu.edu.cn)
}

Received: 8 November 2012; Revised: 1 January 2013; Accepted: 3 January 2013

\begin{abstract}
The main purpose of this paper is to study the fire resistance and failure mode of the square hollow section (SHS) T-joint at elevated temperatures under axial compression. Experimental tests on two full-scale square tubular T-joints with different geometries are carried out. The specimens are set to sustain constant compressive loading at brace end during the heating process. The environmental temperature around the specimens is in accordance with ISO 834 heating curve. The temperature on the tube surface and the deforming process of the two T-joints are both measured till the failure of the specimens. The experimental results show that the failure process of both specimens includes three stages. The final failure mode of both specimens is local buckling on the chord surface near the brace/chord intersection while there is no clear global deformation on the T-joint surfaces. In comparison, the T-joint specimen with smaller brace-to-chord diameter ratio has a more gradual and longer time of deforming process before final failure, which shows the geometry of the tubular joint has an effect on the failure mechanism.
\end{abstract}

Keywords: SHS tubular T-joint, fire resistance, experimental study, axial compression, failure mode

\section{INTRODUCTION}

Tubular structures can be found easily in industry buildings, long-span bridges, railway stations and towers for their characteristics of light weight, high strength and easy fabrication. In these structures, tubular joints are the critical parts due to high stress concentration at the weld toe caused by discontinuous stiffness and residual stress produced by welding process. A typical tubular joint is consisted of a chord member and several brace members. For hollow section joints, failure often occurs on the chord surface near the brace/chord intersection as the radial stiffness of the chord is much weaker than the axial stiffness of the brace. In addition, the material properties of steel are quite sensitive to high temperature. In general, the elastic modulus and the yield stress of steel both reduce extremely at an elevated temperature which makes the joints fail easier. Therefore, it is considerably important and necessary to study the mechanical behavior of tubular joints under fire condition.

Considerable work has been carried out on the fire resistance of beams, columns and beam-column joints in building structures [1-9]. However, there is relatively less research work on tubular joints. For tubular T-joints, the mechanical behavior under various loading conditions at room temperature has been studied experimentally and numerically in the literature, and such work can be found in Refs [10-14]. Studies on mechanical performance of tubular joints under fire condition mostly focus on the phases of loading at constant-high temperature and post-fire loading to failure. Among these studies, Liu et al. [15-16] studied the ultimate bearing capacity of circular tubular T-joints with and without stiffened rings at elevated temperatures using finite element method. It was found that the bearing capacity of the joint decreased as the temperature increased and that the static strength has been improved obviously after reinforcing the joint with several rings. In addition, the number of reinforced ring in design is recommended to be 1 or 3. Nguyen et al. [17-18] carried out both experimental and parametric studies on the static strength of several CHS T-joints subjected to 
brace axial compression at different elevated temperatures. It was found that the ultimate bearing capacity of the joint decreased obviously as the temperature increased and parameters $\beta$ and $\gamma$ have more significant effects on the static strength of the joints. An experimental and parametric study on the post-fire behavior of circular hollow section T-joints was conducted by Jin et al [19]. Residual strengths of the joints after fire exposure and the influence of geometric parameters were studied. The results indicated that the failure of the joints is due to local buckling of the chord member near the brace/chord intersection, and parameter $\beta$ has more significant effect on load-bearing capacity of the T-joint than $\gamma$ when the joint endures same elevated temperature. Very scarce research work on tubular joints under heating state of fire has been conducted in recent years. $\mathrm{Yu}$ et al. [20] carried out an experimental investigation to study the mechanical behavior of an impacted steel tubular T-joint under fire condition. The joint specimen was impacted first and then heated up under constant loading. The experimental results showed that local buckling failure occured on the chord wall and that the critical temperature of the impacted joint is higher than the one without impact loading. However, all above research work is only focused on circular tubular T-joints and there is considerably less research work on fire resistance of square hollow section T-joints. Thus, it is necessary to conduct further investigation on the mechanical behavior of SHS tubular joints under fire condition. This study is thus carried out to analyze the fire resistance of SHS tubular joints through experimental tests.

\section{2.}

\section{EXPERIMENTAL TEST ARRANGEMENTS}

\section{$2.1 \quad$ Test Specimens}

Two square hollow section T-joints named SP-T 1 and SP-T $\mathrm{T}_{2}$ respectively are tested. Figure 1 shows the appearance of a T-joint specimen. The brace member is directly welded onto the upper surface of the chord member by using penetration weld, and the brace is profiled around the intersection before welding to ensure the welding quality. For convenience to apply axial load at brace end, an end plate, $300 \mathrm{~mm} \times 300 \mathrm{~mm} \times 20 \mathrm{~mm}$ (length by width by thickness), is welded on the brace end. Two end plates with four bolt holes, $450 \mathrm{~mm} \times 400 \mathrm{~mm} \times 20 \mathrm{~mm}$ (length by width by thickness), are welded on two chord ends to connect the specimen to supports. Figure 2 shows the schematic view and definitions of some symbols for T-joint specimen. The geometric dimensions of the specimens are listed in Table 1. As is shown in Table 1, the two T-joints have same geometrical dimensionless parameters except for the ratio of brace diameter to chord diameter of the specimen, $\beta$. The values of this parameter are 0.4 and 0.8 for the two specimens respectively. This design is then to investigate the effect of parameter $\beta$ on fire performance of the T-joints directly through experimental results. In addition, the outer length $\left(b_{0}\right)$ of the two specimens is constant which means the heating height of the braces in furnace is equivalent. As the critical part of the joint is the area near the brace/chord intersection, the two T-joint specimens are heated locally around this region. The heating lengths of brace and chord in electric heating furnace are $400 \mathrm{~mm}$ and $895 \mathrm{~mm}$ respectively. All the square steel tubes and end plates are fabricated with Q235B steel which is commonly used in Chinese construction industry. The tensile coupon specimens are designed and tested according to China code of metallic material--tensile testing at ambient temperature (GBT 228-2002). The tensile test rig is shown in Figure 3. The measured steel material properties are listed in Table 2, and they are the fundamentals in future numerical study. In Table 2, the yield stress and the ultimate tensile stress are defined as $f_{\mathrm{y}}$ and $f_{\mathrm{u}}$ respectively, and $E$ denotes the elastic modulus. 


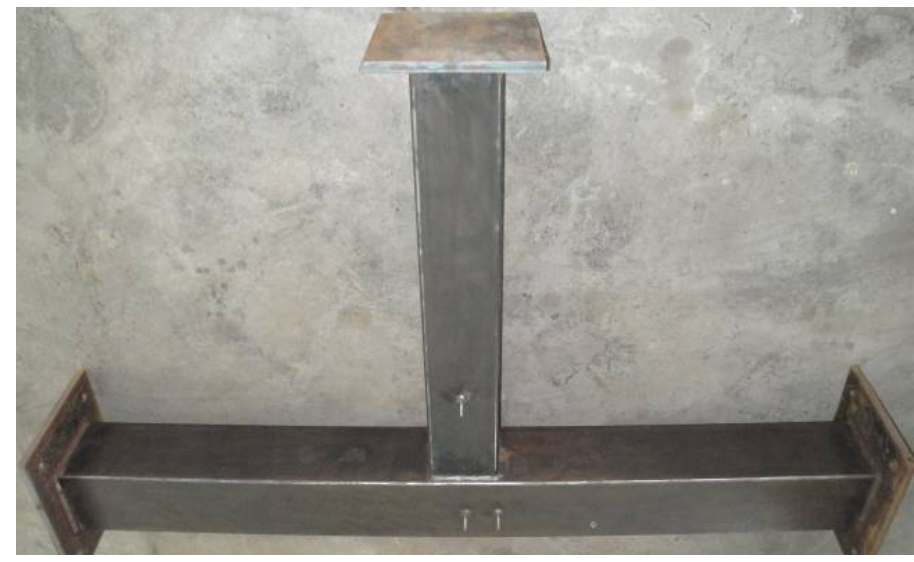

Figure 1. Appearance of a T-joint Specimen

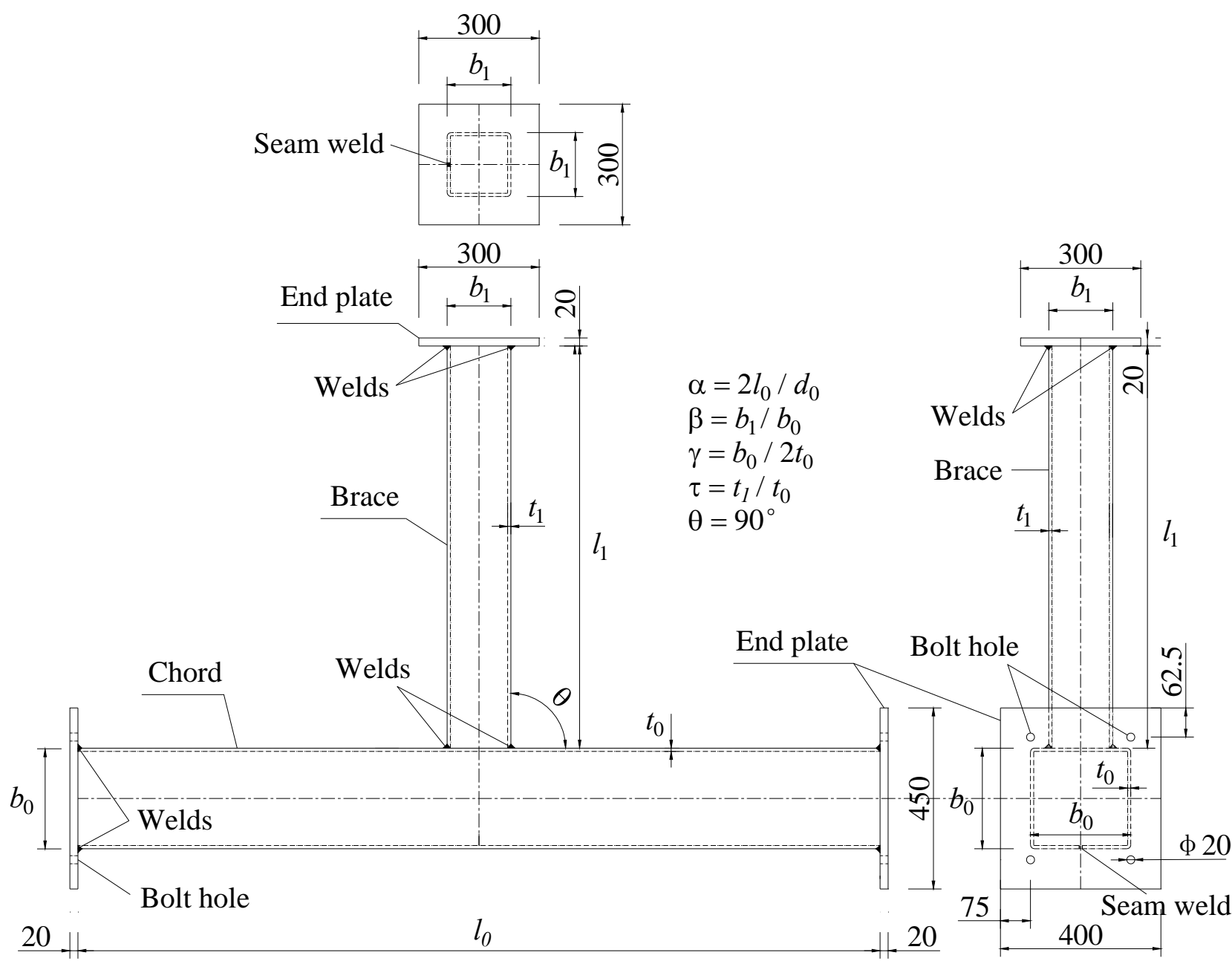

Figure 2. Schematic View and Definition of Symbols for T-joint Specimen 
Table 1. Geometrical Dimensions of T-joint Specimens

\begin{tabular}{|c|c|c|c|c|c|c|c|c|c|c|}
\hline Specimen & $b_{0}(\mathrm{~mm})$ & $b_{1}(\mathrm{~mm})$ & $t_{0}(\mathrm{~mm})$ & $t_{1}(\mathrm{~mm})$ & $l_{0}(\mathrm{~mm})$ & $l_{1}(\mathrm{~mm})$ & $\alpha$ & $\beta$ & $\gamma$ & $\tau$ \\
\hline $\mathrm{SP}_{1} \mathrm{~T}_{1}$ & 200 & 80 & 5 & 5 & 2000 & 1000 & 20 & 0.4 & 20 & 1.0 \\
\hline $\mathrm{SP}_{1} \mathrm{~T}_{2}$ & 200 & 160 & 5 & 5 & 2000 & 1000 & 20 & 0.8 & 20 & 1.0 \\
\hline
\end{tabular}

Table 2. Results of Material Tensile Tests

\begin{tabular}{|c|c|c|c|}
\hline Tube diameter $(\mathrm{mm})$ & $f_{\mathrm{v}}(\mathrm{MPa})$ & $f_{\mathrm{u}}(\mathrm{MPa})$ & $E(\mathrm{MPa})$ \\
\hline 80 & 399.5 & 463.9 & 187432 \\
\hline 160 & 364.5 & 518.8 & 183834 \\
\hline 200 & 320.7 & 442.8 & 202607 \\
\hline
\end{tabular}

\section{$2.2 \quad$ Test Rig}

The experimental tests of T-joints are carried out in a specially designed electric heating furnace. To heat specimens uniformly, the resistance coils, which are placed on the inner wall of the furnace and are used to produce heat when electric current is flowing in them, are arranged evenly in the furnace. The air temperature in a space of $900 \mathrm{~mm} \times 600 \mathrm{~mm} \times 700 \mathrm{~mm}$ (length by width by height) can be heated up to $1200{ }^{\circ} \mathrm{C}$. Compared with gas/oil furnace, electric heating furnace has several advantages. Firstly, the air temperature in heating process can be controlled accurately by $1{ }^{\circ} \mathrm{C}$. Secondly, the test cost is much lower. During the experimental tests, the air temperatures near the surfaces of square tubular T-joint is necessary to agree with ISO 834 standard heating curve. Before experiments, the furnace is tested several times, and the final temperature versus time curve obtained from testing is compared with ISO 834 standard heating curve, and the comparison is shown in Figure 4. As shown in Figure 4, the air temperatures around T-joint surfaces in furnace agree with the standard curve reasonably well except for the beginning stage. However, the temperatures near resistance coils are higher than air temperatures. In order to satisfy the standard fire condition, convection and radiation should be taken into consideration separately for electric heating furnace. In future finite element modelling, the air temperature in furnace will be used for convection and the resistance coils temperature will be used for radiation.

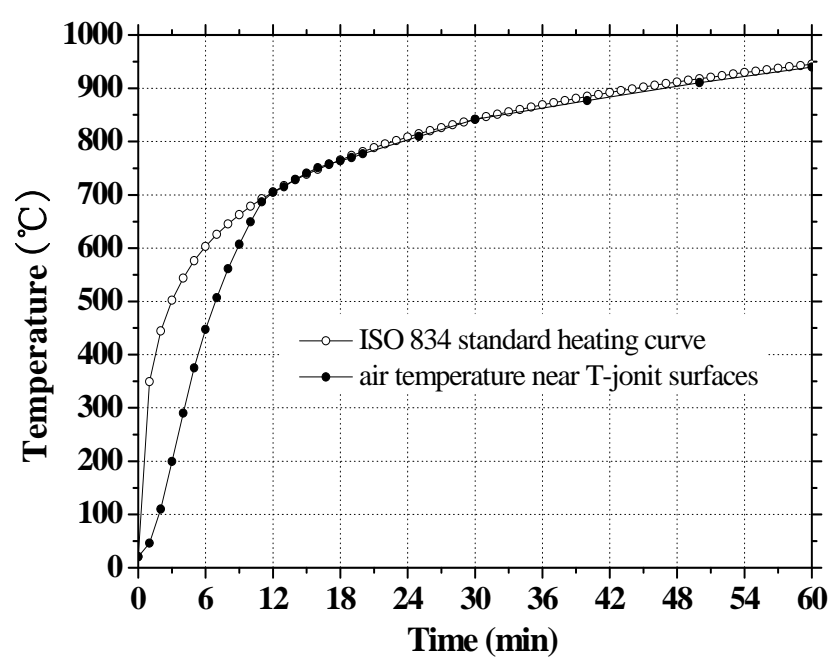

Figure 4. Comparison of Temperature Versus Time Curves 
Besides electric heating furnace, the test rig includes support and loading devices. The whole test rig is shown in Figure 5. Each support is consisted of two I-section beams, two end plates and several slats. The end plates of the chord are connected to the support by four bolts. Actually, the support can not supply enough stiffness to constrain axial expansion and rotation of chord during the heating process. Therefore, the boundary condition can not be regarded as fixed constraint in finite element modelling. The main part of the loading device is a jack. The maximum compressive force provided by the jack is $300 \mathrm{kN}$. Before heating the square tubular T-joint, an axial compressive load is applied by the jack at the brace end while the freedoms in other directions of brace end are free.

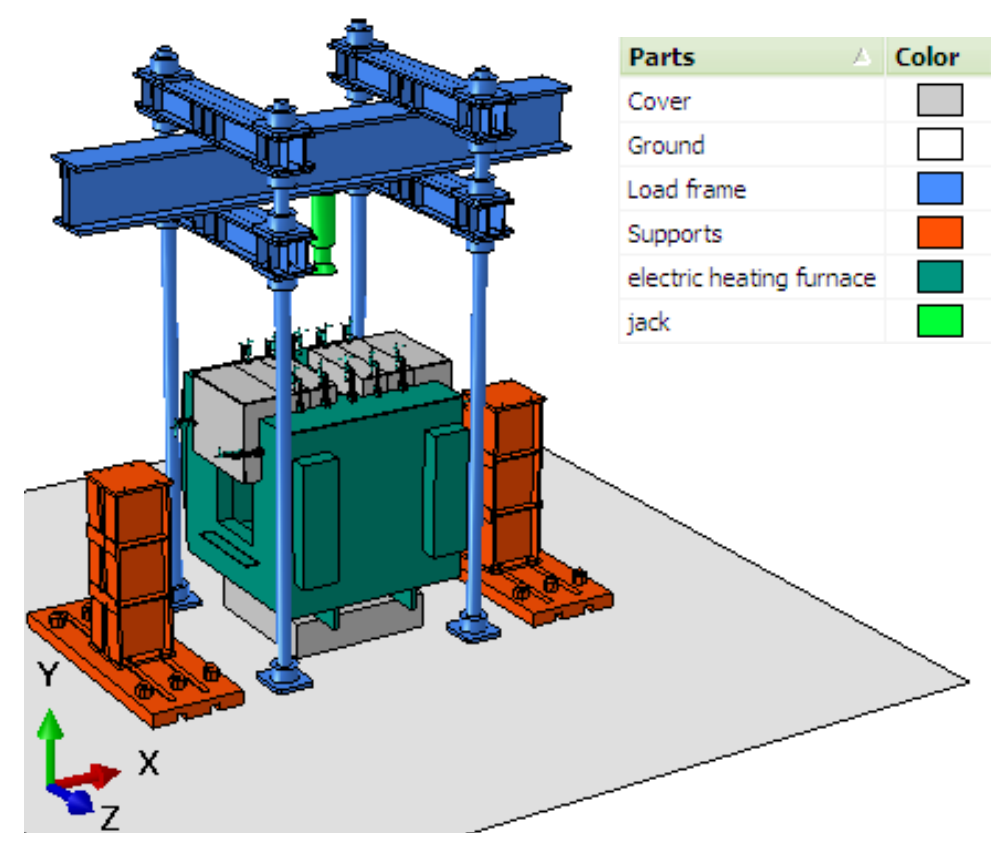

Figure 5. 3D View of Test Devices

\subsection{Measuring Method and Instruments}

For each SHS T-joint specimen, the displacements at three points are measured during the tests including two on chord and one at brace end. The positions of the two points on the chord are shown in Figure 6. The brace end displacement is measured by LVDT directly while the displacements of points Dc- 1 and Dc-2 can not be measured directly because of the high temperature in furnace. Therefore, an indirect method to obtain the displacement is adopted by using two fixed pulleys and a piece of molybdenum wire. The schematic is shown in Figure 7. One end of the wire is fixed on the iron rod which is welded at the measure point and the other end of the wire is connected with a LVDT. The two pulleys are used to arrange the LVDT conveniently by changing the direction of the molybdenum wire. A weight of $250 \mathrm{~g}$ is tied at the end of LVDT to keep molybdenum straight during the experimental tests. The axial applied load is measured by force sensor which is connected with a computer. As shown in Figure 8, the temperatures at three points on each T-joint specimen are tested by using K-type nickle-chromium thermocouples. The measure point on brace wall is $200 \mathrm{~mm}$ away from the chord upper surface. In addition, the temperatures of air and resistance coils are also measured during the tests. All the temperatures can be shown on screen of control box of the heating furnace. The control box is shown in Figure 9. 


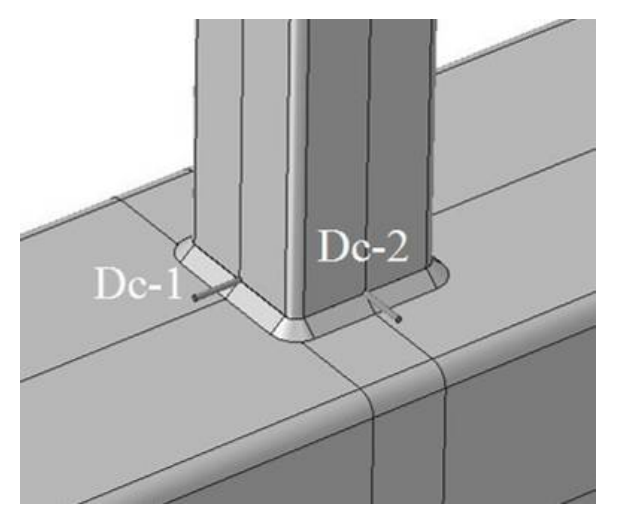

Figure 6. Arrangement of Displacement Measure Points

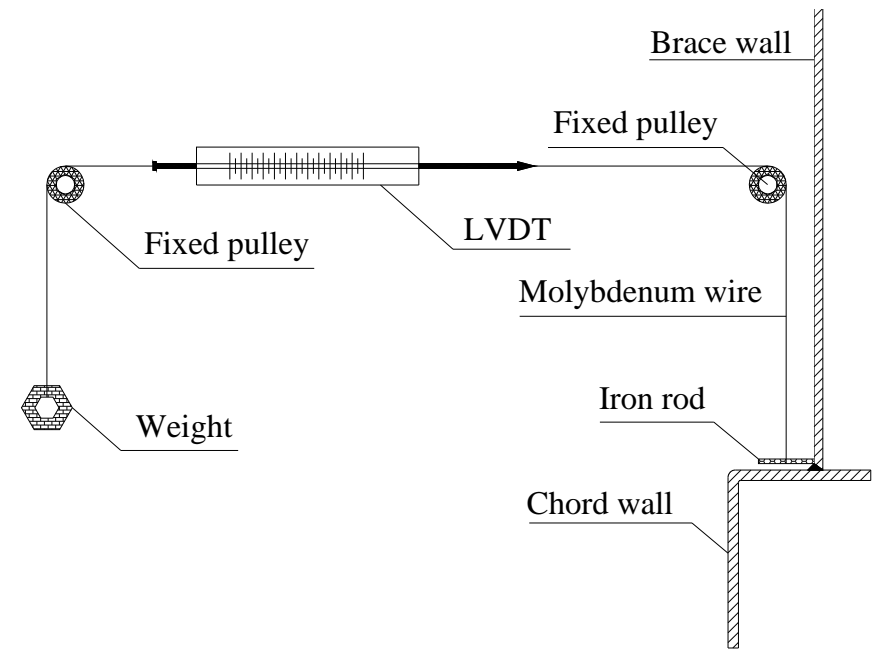

Figure 7. Schematic of Indirect Measure Method

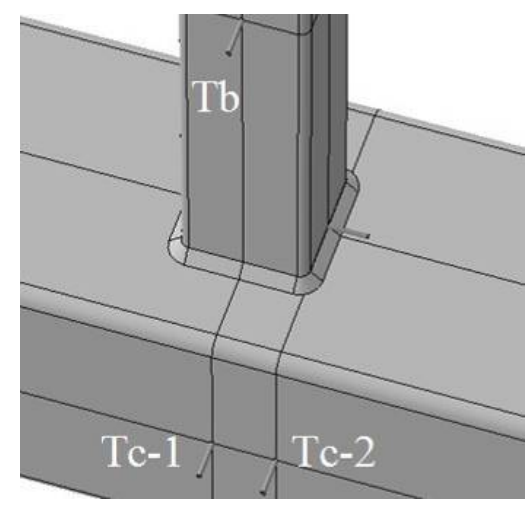

Figure 8. Arrangement of Temperature Measure Points

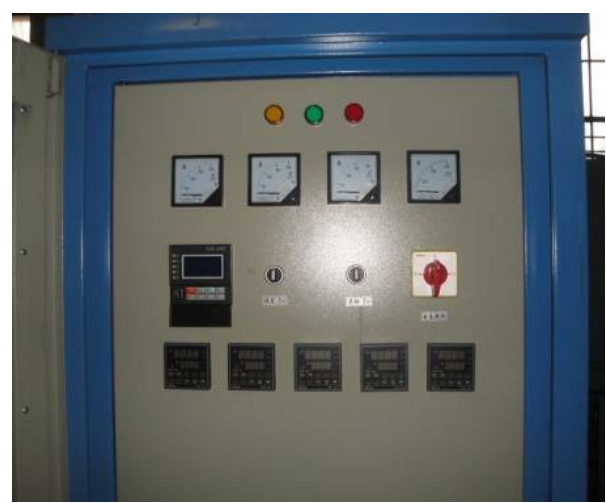

Figure 9. View of Control Box of Heating Furnace

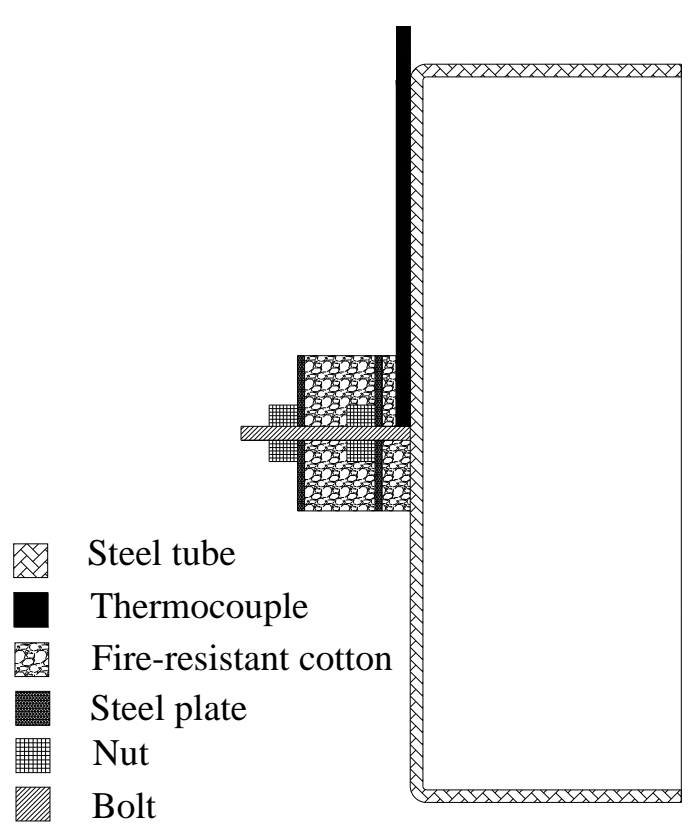

Figure 10. View of the Fixed Thermocouple 
To measure tube surface temperature accurately, thermocouple should not expose to air and be affected by temperature of air in the furnace. Hence, the end of the thermocouple should be packed with fire-resistant cotton which is shown in Figure 10. Before fixing thermocouple, a bolt is welded on the measure point. A thermocouple is firstly placed near the bolt and covered by a layer of fire-resistant cotton. A thin steel plate and a nut are then used to fix thermocouple. Afterwards, the above two steps are repeated to ensure the thickness of the cotton.

\section{$2.4 \quad$ Test Procedure}

Figure 11 shows a specimen in heating furnace. The fire resistance tests of SHS T-joint specimens include two main steps: loading stage and heating stage. Before heating the joint, a constant axial load was applied at the brace end. The axial load ratio $n$ is about 0.5 , which means the pre-load is half of the ultimate bearing capacity of corresponding SHS T-joint at ambient temperature. The ultimate strengths of SP- $\mathrm{T}_{1}$ and $\mathrm{SP}-\mathrm{T}_{2}$ obtained from finite element analyses by using ABAQUS are $46 \mathrm{kN}$ and $154 \mathrm{kN}$ respectively. The static strengths are determined by deformation limit provided by Zhao [21]. The pre-loads at brace end are then determined to be $23 \mathrm{kN}$ and $77 \mathrm{kN}$ respectively. The finite element models are built using solid elements to generate the meshes of the two joints. Geometrical and material nonlinearity are both taken into consideration in the models. The mechanical properties of steel material can be found in Table 2, and the stress-strain relationship is defined as ideal elastic-plastic model. As it is very mature for calculating the ultimate strength of tubular joints by using finite element method, this technique is not described in details in this study. The pre-load is kept for several minutes before heating stage to ensure the specimen is in a stable state. Thereafter, the SHS T-joint is heated locally according to a predefined heating curve. During the heating process, the temperatures of the air in the furnace and of the heating wires are plotted together as shown in Figure 12. It can be seen that the temperature of the air is lower because there is a heat transfer process between the air and the heating wires. However, the temperature increase is regular for both the air and the heating wires.

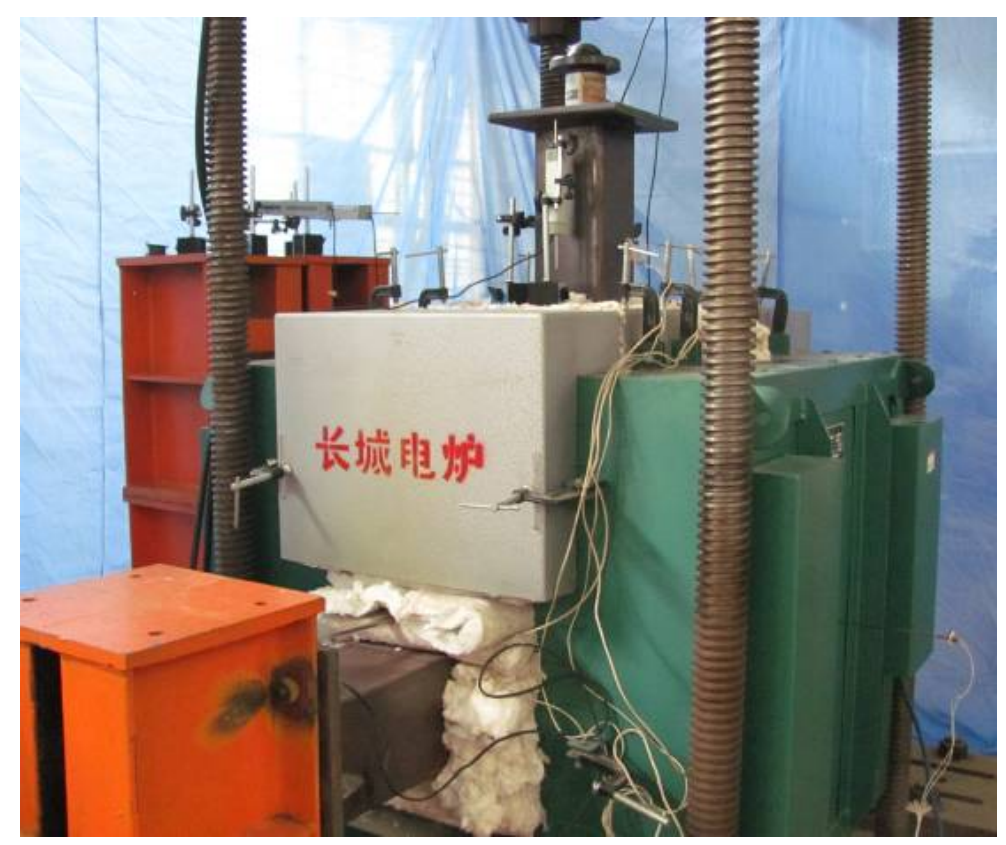

Figure 11. View of a Specimen in Heating Furnace 


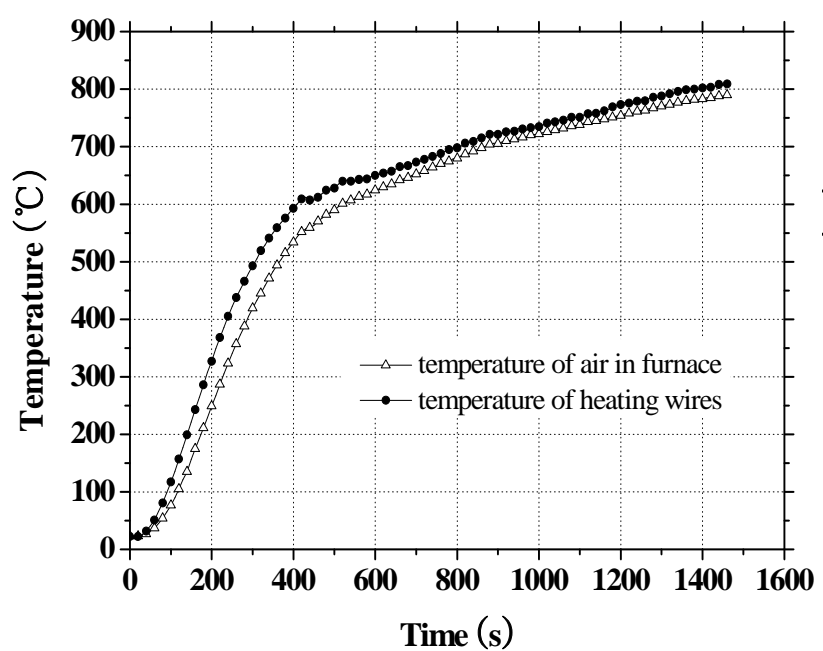

(a) $\mathrm{SP}-\mathrm{T}_{1}$

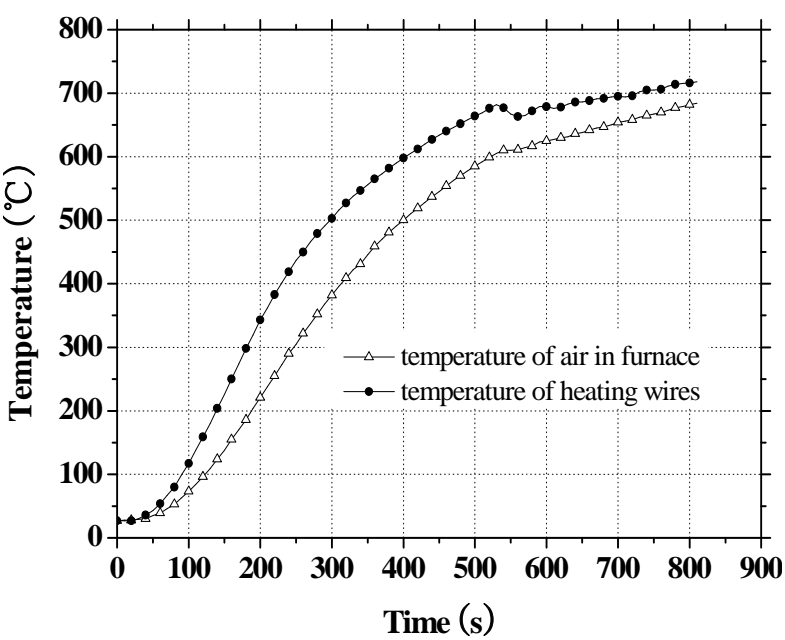

(b) $\mathrm{SP}-\mathrm{T}_{2}$

Figure 12. Heating Curves of T-joint Specimens

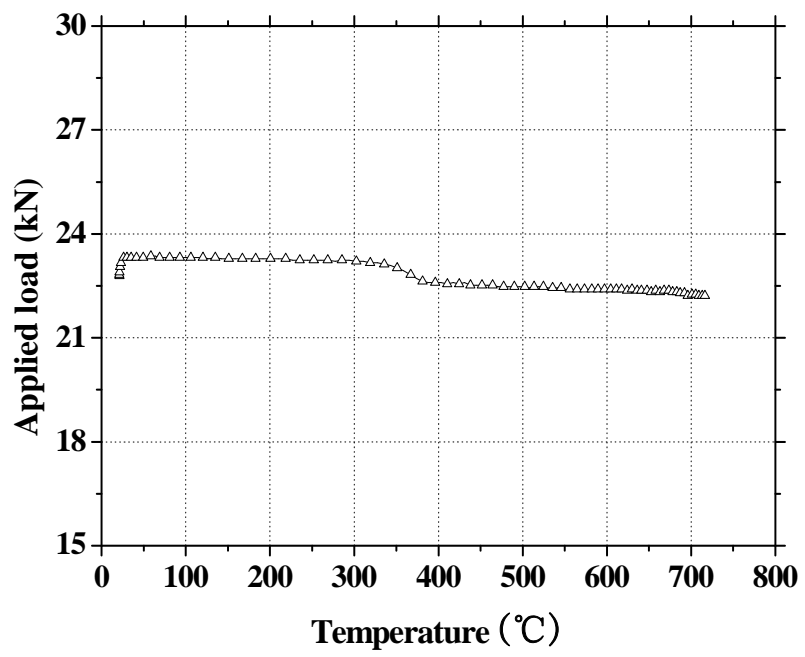

(a) $\mathrm{SP}-\mathrm{T}_{1}$

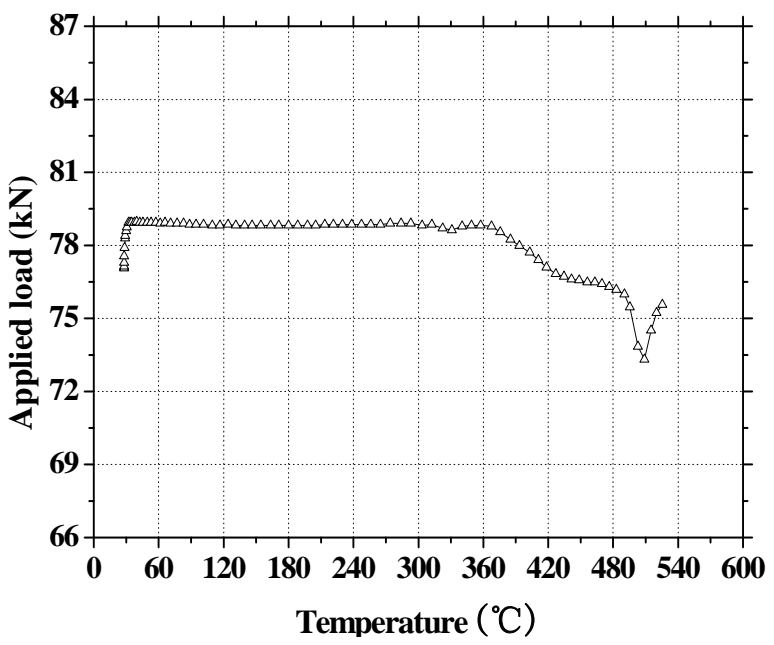

(b) $\mathrm{SP}-\mathrm{T}_{2}$

Figure 13. Applied Load Versus Temperature Curves

Figure 13 shows the actual applied load versus chord average temperature curve. The applied load is steady in most heating time. However, there is also smaller change of the loading value during the experimental tests. The reason is that the hydraulic device is not sensitive to tiny changes of pressure, and hence it can not react unless the change value of load is big or small enough. In addition, as the brace end is not constrained, the brace can move up firstly due to expansion of steel and then move down due to the compressive displacement of the chord surface.

3.

RESULTS AND ANALYSES

\subsection{Failure Mode}

In general, local buckling failure of chord is observed for both specimens SP-T $\mathrm{T}_{1}$ and $\mathrm{SP}-\mathrm{T}_{2}$, which is shown in Figure 14. The main reason is that the transverse stiffness of chord is much lower than the axial stiffness of brace when the specimen is subjected to axial external load at brace end. For the first specimen $S P-T_{1}$, there is no obvious deformation on the brace wall. Additionally, the bottom surface of the chord has clear bulge deformation. The reason may be that residual deformation caused by welding exists. In this case, the bottom surface of the chord is not flat, and 
such deformation may occur if the bottom surface has an initial convex deflection. Hence, initial deformation should be taken into consideration in future finite element modelling. For the second specimen SP-T $\mathrm{T}_{2}$, minor deformation occurred on the brace wall near the weld toe while there is no clear deformation on the bottom surface of the chord.

As the elastic modulus is deteriorated severely at elevated temperature, the flexural stiffness of the top surface of the chord reduces greatly. The existence of high stress concentration around the weld on the chord surface causes failure to occur in local region near the weld toe. In high temperature, such failure is especially easier because the deterioration of the flexural stiffness of top surface of the chord. Figure 14 shows local failure around the weld toe is much dominant for the T-joints at elevated temperature. The chord, however, has very minor global flexural deformation during the heating process.
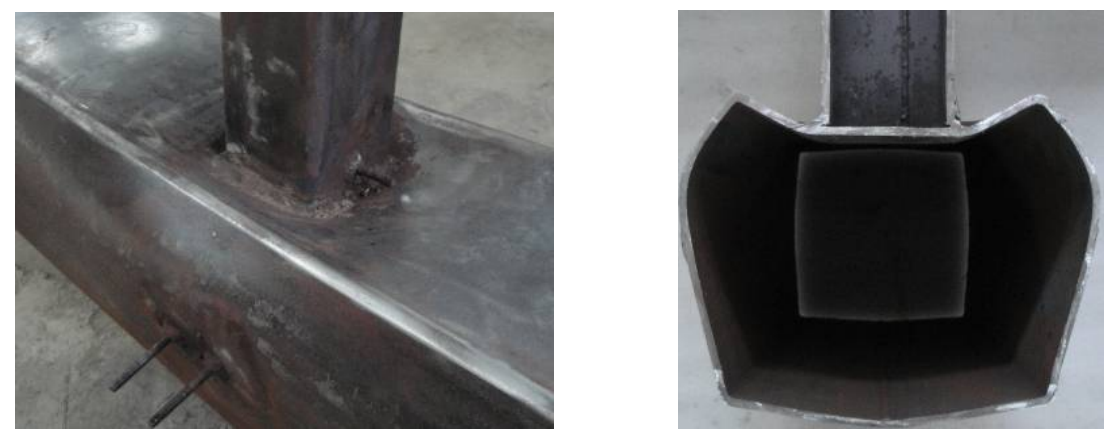

(a) $\mathrm{SP}-\mathrm{T}_{1}$
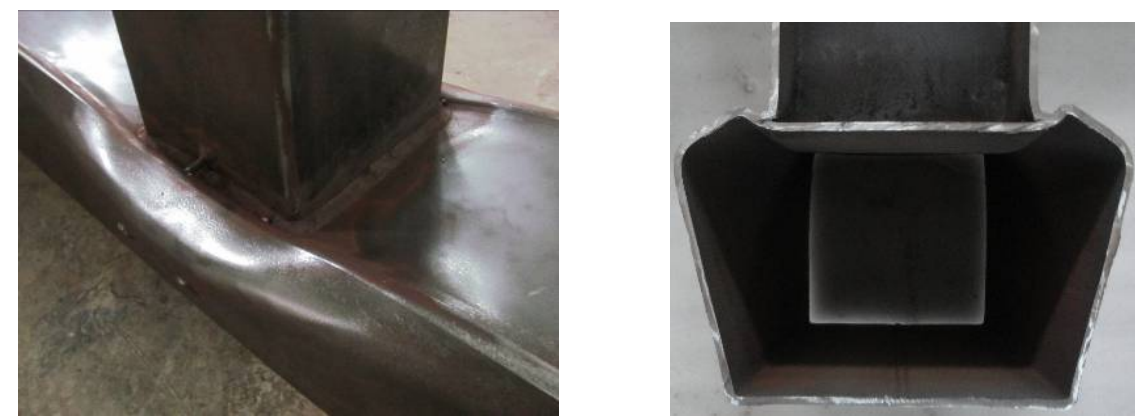

(b) $\mathrm{SP}-\mathrm{T}_{2}$

Figure 14. Failure Mode of the Specimens

\subsection{Displacement Versus Temperature Curves}

To reduce measurement error caused by expansion of molybdenum wire during heating the T-joint, the elongation of a molybdenum wire with a $250 \mathrm{~g}$ weight in fire condition is tested before the experimental tests. The heated length of the wire is $900 \mathrm{~mm}$. The results obtained from testing are shown in Figure 15. It is clear that a total displacement of approximate $1.7 \mathrm{~mm}$ occurs in the molybdenum wire. This displacement should be extracted from the total displacement of the specimen. 


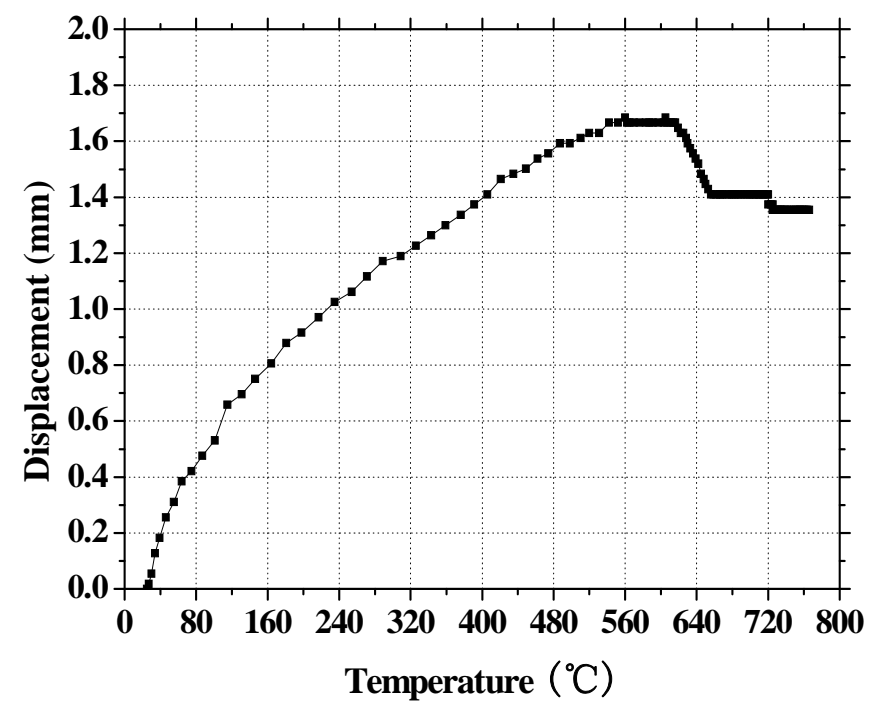

Figure 15. Displacement Versus Temperature Curve of Molybdenum Wire

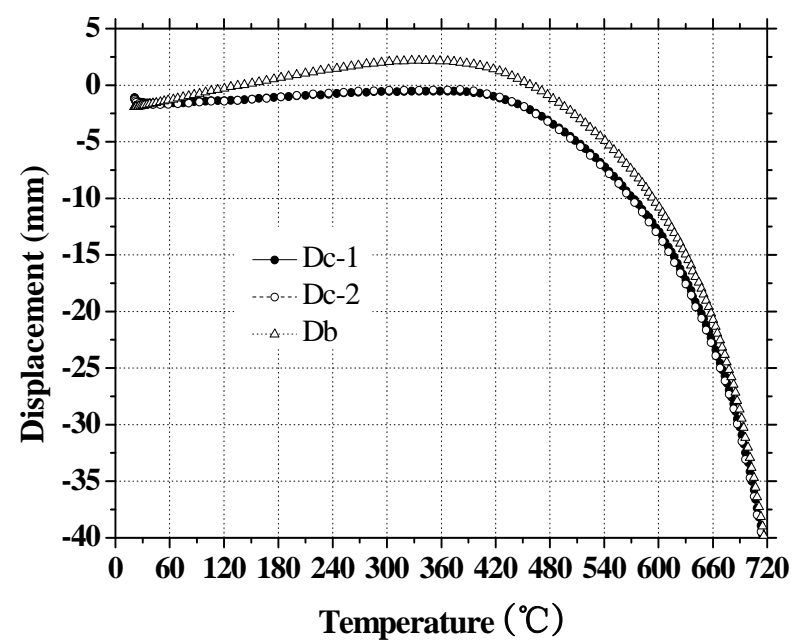

(a) $\mathrm{SP}-\mathrm{T}_{1}$

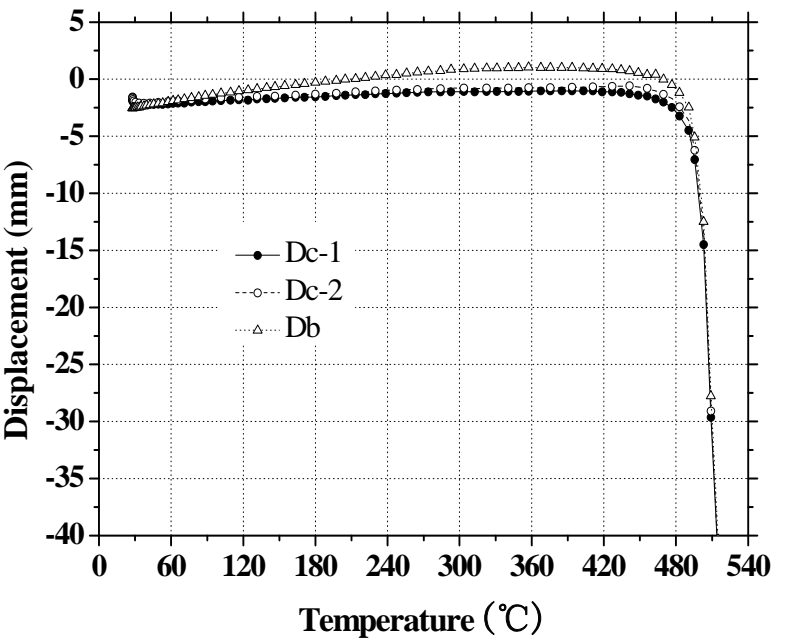

(b) $\mathrm{SP}-\mathrm{T}_{2}$

Figure 16. Corrected Displacement Versus Temperature Curves of T-joint Specimens

After eliminating the influence of the molybdenum wire, the curves of displacement versus temperature for both specimens obtained from experimental tests are plotted in Figure 16. A negative displacement denotes a compressive deformation. It can be seen from the curves that there are three stages in failure process of T-joint specimen in fire condition. In the first stage, the initial displacement caused by pre-load decreases slightly as the temperature increases. In this stage, expansion of the specimen in heating process is dominant, and such expansion will definitely reduce the compressive deformation. As the brace end is not fixed in its axial direction, the brace has a tensile deformation due to expansion, which can reduce the compressive displacement of the brace. It can also be seen that the decrease of the compressive displacement of the brace has an approximately linear relationship with the increase of the temperature in this stage.

In the second stage, the displacements begin to increase gradually after the temperature exceeds certain value. In this stage, the expansion of the steel can not compensate for the deterioration of the steel stiffness and steel strength, and hence expansion is not still dominant. The deterioration of steel mechanical properties becomes a key factor to cause the specimens to deform gradually. In the last stage, the displacements increase abruptly and drastically which means the failure of T-joint specimens. 
However, there are some differences between the two specimens. For the first specimen, it can be seen that a larger expansion displacement occurs in the first stage. Additionally, the failure process of the first specimen seems to be more gradual. Figure 16(b) shows the displacement of the second specimen increases suddenly in a much faster way after temperature exceeds $500^{\circ} \mathrm{C}$. This means the failure occurs in a much shorter time for $S P-T_{2}$. Further study is necessary to be conducted for studying the effect of joint geometry on the failure mode.

\subsection{Displacement Versus Time Curves}

The displacement versus time curves for specimen $\mathrm{SP}-\mathrm{T}_{1}$ and $\mathrm{SP}-\mathrm{T}_{2}$ obtained from experimental tests are plotted in Figure 17. As shown in Figure 17, the curves can also be divided into three stages. In the first stage (time less than 200 seconds), the displacement is almost unchanged because the material property of the steel in this time has minor change. In the second stage (200 seconds 600 seconds for the first specimen, and 200 seconds 700 seconds for the second specimen), a positive displacement occurs and its value increases with the increase of temperature. This positive displacement is due to the expansion of the chord tube in transverse direction in higher temperature. In the third stage (after 600 seconds for the first specimen, and after 700 seconds for the second specimen), the compressive displacement for both specimens increases. However, the displacement of the first specimen increases quite gradually while it increases sharply for the second specimen. It can be seen from Figure 17(b) that the displacement increases to $40 \mathrm{~mm}$ in the third stage within 100 seconds for the second specimen. For the first specimen, however, such time increases to be more than 800 seconds, which means the deformation of this specimen has an accumulating process.

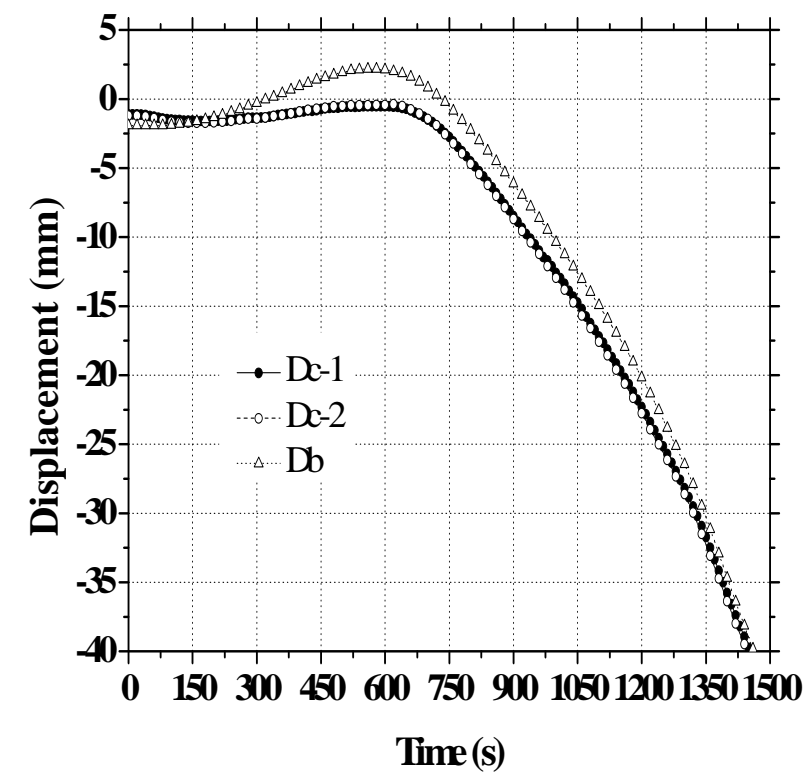

(a) $\mathrm{SP}_{1}$

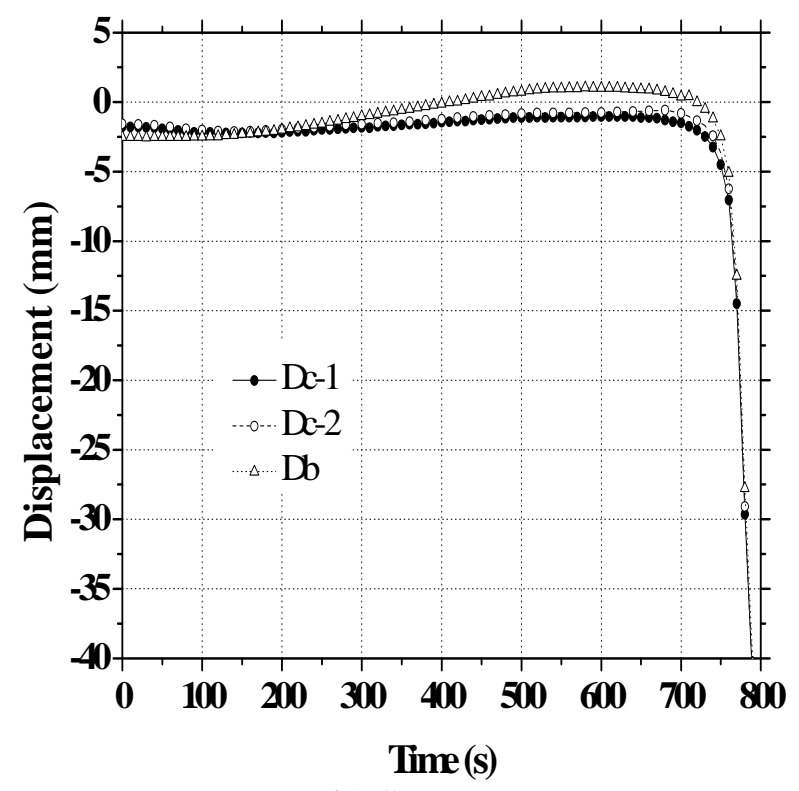

(b) $\mathrm{SP}-\mathrm{T}_{2}$

Figure 17. Displacement Versus Time Curves of T-joint Specimens

The relationship between the displacement and the heating time can be explained from Figure 14 . As seen from the final failure mode of the specimens after heating process, most deformation is caused by the top surface of the chord around the brace/chord intersection. From the view of the cross section of the specimens after tests, the top surface of the chord can be simplified to be a plate supported by the two side walls of the chord tube. The top surface of the chord inside the brace tube can not deform due to the constraints of the brace member. The remaining top surface of the chord, however, has a bending deformation when the joint is subjected to compressive loading at brace end. For the first specimen, the value of $\beta$ is smaller than that of the second specimen, which means 
a larger region of the top surface of the chord behaves as a bending plate, as shown in Figure 14(a). The two side walls of the chord tube provide elastic support for the top surface, and they deforms cooperatively. As the bending deformation of the top surface of the chord is an accumulating process, the displacement increases gradually. However, for the second specimen, as seen from Figure 14(b), a much bigger value of $\beta$ causes most top surface of the chord to be inside the brace tube. Therefore, the deformation of the top surface is restricted by the brace. There is much minor bending deformation of the top surface of the chord. The two side walls of the chord tube can be still considered as supports to the top surface although the top surface can not bend easily. When the temperature increases to certain value, the deterioration of the steel material causes the stiffness of the tube wall to reduce greatly, and the two side walls of the chord fail suddenly. This is why the displacement of the second specimen increases sharply after the heating time exceeds certain value.

\section{CONCLUSIONS}

Experimental study for fire resistance of square hollow section T-joints has been provided in this paper. The failure process and the failure mode for the tested specimens have been studied. From experimental observation, it is found that local buckling failure occurred on the chord surface near the brace/chord intersection for both specimens. The failure process of the joints includes initial expansion of the steel material, a deforming process caused by severe deterioration of the steel materials and a quick failure of the specimen after temperature exceeds certain value. However, the geometry of the tubular joint has a remarkable effect on the failure process.

\section{REFERENCES}

[1] Tan, Q.H., Han, L.H. and Yu, H.X., "Fire Performance of Concrete Filled Steel Tubular (CFST) Column to RC Beam Joints”, Fire Safety Journal, 2012, Vol. 51, pp. 68-84.

[2] Chen, J. and Young, B., "Design of High Strength Steel Columns at Elevated Temperatures”, Journal of Constructional Steel Research, 2008, Vol. 64, pp. 689-703.

[3] Ding, J. and Wang, Y.C., "Experimental Study of Structural Fire Behavior of Steel Beam to Concrete Filled Tubular Column Assemblies with Different Types of Joints”, Engineering Structures, 2007, Vol. 29, pp. 3458-3502.

[4] Qian, Z.H., Tan, K.H. and Burgess, I.W., "Numerical and Analytical Investigations of Steel Beam-to-column Joints at Elevated Temperatures”, Journal of Constructional Steel Research, 2009, Vol. 65, No. 5, pp. 1043-1054.

[5] Han, L.H. and Xu, L., "Tests on the Fire Resistance Concrete Filled Steel Square Tubular Columns with Protections”, China Civil Engineering Journal, 2000, Vol. 33, No. 6, pp. 63-69. (in Chinese).

[6] Dharma, R.B. and Tan, K.H., "Rotational Capacity of Steel I-beams under Fire Conditions Part I: Experimental Study”, Engineering Structures, 2007, Vol. 29, No. 9, pp. 2391-2402.

[7] Tan, K.H., Toh, W.S., Huang, Z.F. and Phng, G.H., "Structural Responses of Restrained Steel Columns at Elevated Temperatures. Part 1: Experiments”, Engineering Structures, 2007, Vol. 29, No. 8, pp. 1641-1652.

[8] Han, L.H., Wang, W.H. and Yu, H.X., "Experimental Behaviour of Reinforced Concrete (RC) Beam to Concrete-filled Steel Tubular (CFST) Column Frames Subjected to ISO-834 Standard Fire”, Engineering Structures, 2010, Vol. 32, No. 10, pp. 3130-3144.

[9] Li, G.Q. and Guo, S.X., "Experiment on Restrained Steel Beams Subjected to Heating and Cooling”, Journal of Constructional Steel Research, 2008, Vol. 64, No. 3, pp. 268-274. 
[10] Shao, Y.B., Li, T., Seng, T.L. and Chiew, S.P., "Hysteretic Behaviour of Square Tubular T-joint with Chord Reinforcement under Axial Cyclic Loading”, Journal of Constructional Steel Research, 2011, Vol. 67, No. 1, pp. 140-149.

[11] Feng, R. and Young, B., “Tests of Concrete-filled Stainless Steel Tubular T-joints”, Journal of Constructional Steel Research, 2008, Vol. 64, No. 11, pp. 1283-1293.

[12] Feng, R. and Young, B., "Experimental Investigation of Cold-formed Stainless Steel Tubular T-joints”, Thin-Walled Structures, 2008, Vol. 46, No. 10, pp. 1129-1142.

[13] Lee, M.M.K., and Llewelyn-Parry, A., "Offshore Tubular T-joints Reinforced with Internal Plain Annular Ring Stiffeners”, Journal of Structural Engineering, ASCE, 2004, Vol. 130, No. 6, pp. 942-951.

[14] Shao, Y.B., "Study on Reinforcing Methods for Welded Tubular Joints Structures”, Journal of Yantai University (Natural science and engineering edition), 2009, Vol. 22, No. 4, pp. 312-320.

[15] Liu, M.L., Zhao, J.C. and Yang, X.Y., "Study on Mechanical Performance of Tubular T-joints of Offshore Platform under Fire”, The Ocean Engineering, 2009, Vol. 27, No. 3, pp. 6-13. (in Chinese).

[16] Liu, M.L., Zhao, J.C. and Jin, M., "Study on Load Capacity and Deformation of T-joints with Reinforced Ring at Elevated Temperatures”, China Offshore Platform, 2009, Vol. 24, No. 5, pp. 17-23. (in Chinese).

[17] Nguyen, M.P., Fung, T.C. and Tan, K.H., "An Experimental Study of Structural Behaviours of CHS T-joints Subjected to Brace axial Compression in Fire Condition", Tubular Structures X III, Hong Kong, 2010, pp. 725-732.

[18] Nguyen, M.P., Tan, K.H. and Fung, T.C., "Numerical Models and Parametric Study on Ultimate Strength of CHS T-joints Subjected to Brace Axial Compression under Fire Condition”, Tubular Structures X III, Hong Kong, 2010, pp. 733-740.

[19] Jin, M., Zhao, J.C., Chang, J. and Zhang, D.X., "Experimental Study and Parametric Study on the Post-fire Behavior of Tubular T-joint”, Journal of Constructional Steel Research, 2012, Vol. 70, pp. 93-100.

[20] Yu, W.J., Zhao, J.C., Luo, H.X., Shi, J.Y. and Zhang, D.X., "Experimental Study on Mechanical Behavior of an Impacted Steel Tubular T-joint in Fire”, Journal of Constructional Steel Research, 2011, Vol. 67, No. 9, pp. 1376-1385.

[21] Zhao, X.L., "Deformation Limit and Ultimate Strength of Welded T-joints in Cold-formed RHS Sections”, Journal of Constructional Steel Research, 2000, Vol. 53, No. 2, pp. 149-165. 


\title{
SEISMIC RESPONSE OF STRAIGHT LINE TYPE AND BROKEN LINE TYPE TRANSMISSION LINES SUBJECTED TO NON-UNIFORM SEISMIC EXCITATIONS
}

\author{
L. Tian ${ }^{1, *}$, R.S. Ma ${ }^{1}$, H.N. $\mathrm{Li}^{2}$ and P. Zhang ${ }^{3}$ \\ ${ }^{1}$ School of Civil and Hydraulic Engineering, Shandong University, Jinan, PR China \\ ${ }^{2}$ Professor, Faculty of Infrastructure Engineering, Dalian University of Technology, Dalian, PR China \\ ${ }^{3}$ Faculty of Infrastructure Engineering, Dalian University of Technology, Dalian, PR China \\ *(Corresponding author: E-mail: tianli@sdu.edu.cn)
}

Received: 15 November 2012; Revised: 12 October 2012; Accepted: 18 October 2012

\begin{abstract}
Seismic responses of straight line type and broken line type transmission tower-line systems subjected to non-uniform seismic excitations are studied in this paper. Three-dimensional finite element models of the straight line type and broken line type transmission tower-line coupled systems are established, respectively. Based on power spectral density function, coherency loss function and code for design of seismic of electrical installations, spatial variation of seismic ground motions are synthesized. Using nonlinear time history analysis method, the influence of wave passage effect, coherency loss effect and different local site effect on the seismic response of two type transmission tower-line systems are investigated, respectively. The results show that the assumption of uniform ground motion could not provide accurate responses of the two type transmission tower-line systems. Non-uniform seismic excitations increase the axial force of transmission tower, and the vertical displacement and tension force of transmission lines. Neglecting these effects will underestimate the response of the two type transmission tower-line systems. The effect of non-uniform ground motions should be considered in seismic design for the straight line type and broken line type transmission lines practical engineering.
\end{abstract}

Keywords: non-uniform seismic excitations, transmission tower-line system, nonlinear time history, wave passage effect, coherency loss effect, local site effect

\section{INTRODUCTION}

Due to the influence of buildings and other important regions, or to prevent the collapse of straight line type, transmission lines are often arranged as a broken line type in practical engineering. Because of the importance of an angle tower, it is necessary to study the seismic response of the broken line type transmission line (Yin et al. [1]). With the voltage and capacity of transmission line improving, the height of transmission tower and the span of transmission line increase, and the spans of most transmission lines are larger than $100 \mathrm{~m}$. The ground motions at the bottom of all towers are different because of the difference in arrival times of seismic waves at different supports, the coherency loss effect owing to reflections and refractions of the waves in the heterogeneous media of the ground, and the local site effect due to different local soil properties (Zerva and Harada [2]).

In recent decades, the transmission tower-line systems were often destroyed during earthquake, and many studies about the seismic responses of transmission lines have been conducted. Ghobarah et al. (Ghobarah et al. [3]) investigated the effect of multi-support excitations on the lateral responses of overhead power transmission lines, and transmission towers were modeled by space truss elements and the cables were modeled by straight two node elements. Li et al. [4, 5, 6] have completed a number of investigations on seismic problems of coupled system of long-span transmission towers. Tian et al. [7] synthesized multi-support time histories of earthquake ground motion and analyzed the power transmission tower-line system under multi-support excitations considering traveling-wave and coherency loss effect, and the results showed that it was necessary to consider multiple support excitations in transmission tower-line system analysis. In all these studies, the transmission tower-line systems were assumed to the straight line type structure. There 
is no study about the seismic response of the broken line type structure, not to mention the seismic analysis of this type structure under non-uniform seismic excitations.

Based on the above research, seismic response of the broken line type transmission tower-line system subjected to non-uniform seismic excitations is performed using nonlinear time history analytical method. In order to compare with the seismic response of the broken line type structure, the response of the straight line type system is also analyzed. According to a practical engineering, the finite element models of two types are established, respectively. The transmission towers are modeled by beam elements, while the transmission lines are modeled by cable elements that account for the geometric nonlinear of cable structures. Non-uniform seismic ground motions are simulated considering power spectral density function, coherency loss function and code for design of seismic of electrical installations. The influence of wave passage effect, coherency loss effect and different local site effect on seismic response of the straight line type and broken line type transmission tower-line systems are investigated, respectively.

\section{STRUCTURAL MODEL}

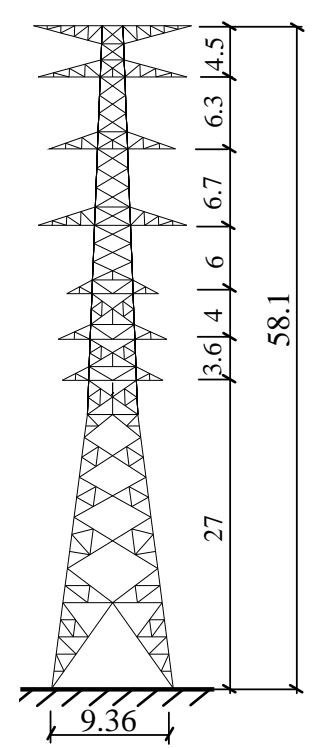

Figure 1. Tower Size (m)

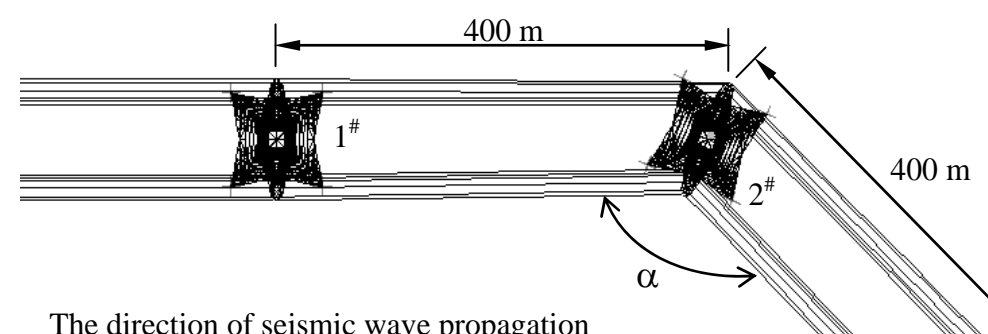

The direction of seismic wave propagation

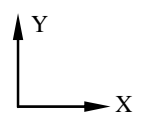

Figure 2. Schematic Diagram of Transmission Line

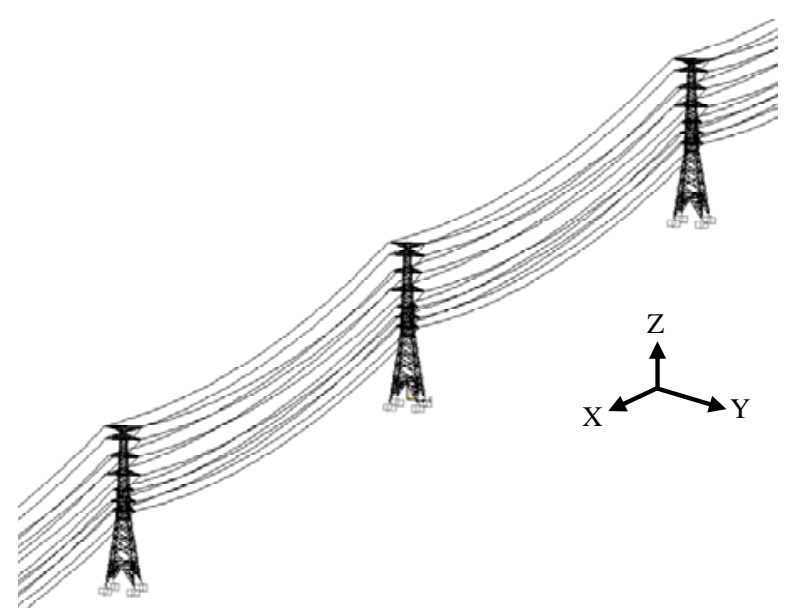

(a) Straight Line Type

(b) Broken Line Type

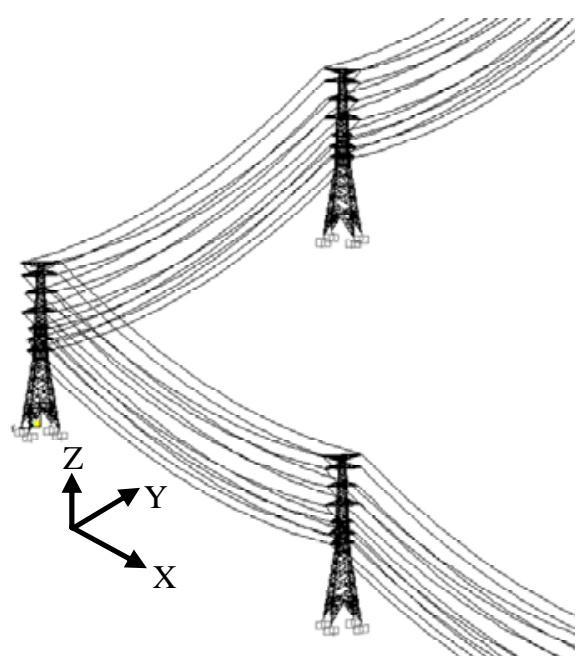

Figure 3. Three-dimensional Finite Element Model of Three Towers and Four-span Lines Coupled System

Figure 1 shows the tower size. The tower is $58.1 \mathrm{~m}$ high, and its weight is approximately $30 \mathrm{t}$. The 
structural members of the tower are made of angle steel with the elastic modulus of $206 \mathrm{GPa}$. The schematic diagram of transmission line is shown in Figure 2. It can be seen from the Figure 2 that the angle $\alpha$ of the broken line type and straight line type transmission tower line systems are $150^{\circ}$ and $180^{\circ}$, respectively. The direction of seismic wave propagation can be seen in Figure 2. Using SAP2000 software, three-dimensional finite element tower-line system is established according to a practical project. Figure 3 shows the three-dimensional finite element model of three towers and four-span lines coupled system, and the straight line type and broken line type of transmission tower line system are established, respectively. The tower is modeled by 1883 space beam members and 727 nodes, and the connections of members are rigid. It has been approved that the numerical results of transmission tower according to beam element are close to the test results (Deng et al. [8]), so the beam element are selected for the simulation of transmission tower. The types of transmission ground line and conductor are JLB40-150, LGJ-400/35 and LGJ-240/30, respectively. The upper 8 cables are ground lines and lower 48 cables are two bundled conductor. The spans to adjacent towers are all $400 \mathrm{~m}$. The base points of the transmission tower are fixed to the ground and the connections between transmission towers and lines are hinged by insulators. The transmission lines from upper to down are numbered (1), (2), (3), (4), (5), (6) and (7), respectively.

The initial axial force and large deformation effect of cable are taken into consideration. Under self weight, the cable spatial configuration is a catenary. Based on the coordinate system illustrated in Figure 4, the mathematical expression used to define the initial geometry of the cable profile is given in the following form (Shen et al. [9])

$$
z=\frac{H}{q}|\cosh (\alpha)-\cosh | \frac{2 \beta x}{l}-\alpha||
$$

where, $\alpha=\sinh ^{-1}\left|\frac{\beta(c / l)}{\sin (\beta)}\right|+\beta, \quad \beta=\frac{q l}{2 H}$, in which $H$ represents initial horizontal tension which can be obtained from a preliminary static analysis, and $q$ denotes uniformly distributed gravity loads along the transmission line.

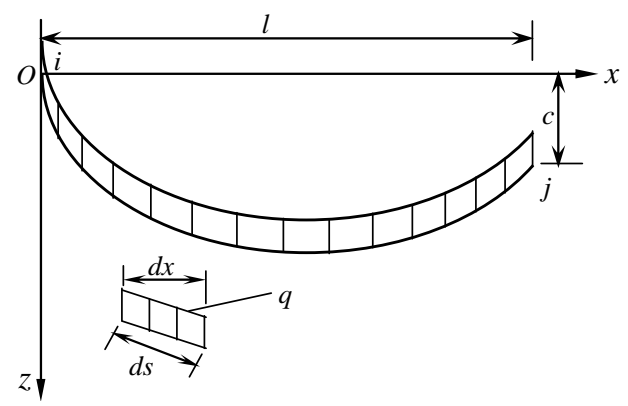

Figure 4. Coordinates of a Single Cable under Self-weight

\section{SIMULATION OF SPATIALLY VARYING GROUND MOTIONS}

The ground motion cross power spectral density function of spatial ground motions at point $i$ and $j$ on the ground surface can be written as

$S_{i j}(\omega)=S_{g}(\omega) \gamma_{i j}\left(\omega, d_{i j}\right)$

where, $S_{g}(\omega)$ is a power spectral density function. $\gamma_{i j}\left(\omega, d_{i j}\right)$ is an empirical coherency 
function.

\subsection{Power Spectrum Density Function}

Clough-Penzien model is selected (Clough and Penzien [10]), and its power spectral density function can be expressed as

$$
S_{g}(\omega)=\frac{\omega_{g}{ }^{4}+4 \xi_{g}{ }^{2} \omega_{g}{ }^{2} \omega^{2}}{\left(\omega_{g}{ }^{2}-\omega^{2}\right)^{2}+4 \xi_{g}{ }^{2} \omega_{g}{ }^{2} \omega^{2}} \cdot \frac{\omega^{4}}{\left(\omega_{f}{ }^{2}-\omega^{2}\right)^{2}+4 \xi_{f}{ }^{2} \omega_{f}{ }^{2} \omega^{2}} S_{0}
$$

in which $S_{0}$ is a scale factor depending on the ground motion intensity, $\omega_{g}$ and $\xi_{g}$ are the predominant frequency and damping ratio of the first filter, $\omega_{f}$ and $\xi_{f}$ are those of the second filter. Reference (Tian and $\mathrm{Li}$ [11]) gives the parameters of Clough-Penzien model according to the Code for Design of Seismic of Electrical Installations (GB 50260-96 [12]).

\subsection{Coherency Loss Function}

In this paper, the coherency loss function is derived from recorded strong ground motions at SMART-1 array by Hao et al. (Hao et al. [13]; Hao [14]). The coherency loss function between ground motions at two points $i$ and $j$ on ground surface is

$\gamma_{i j}\left(\omega, d_{i j}\right)=\left|\gamma_{i j}\left(\omega, d_{i j}\right)\right| e^{-i o d_{i j} / v_{a p p}}$

where, $v_{a p p}$ is the apparent wave propagation velocity and the exponential function represents the influence of the wave passage effect. $\left|\gamma_{i j}\left(\omega, d_{i j}\right)\right|$ can be expressed as

$\left|\gamma_{i j}\left(\omega, d_{i j}^{l}, d_{i j}^{t}\right)\right|=\exp \left[-\left(\beta_{1}\left|d_{i j}^{l}\right|+\beta_{2}\left|d_{i j}^{t}\right|\right)\right] \cdot \exp \left\{-\left[a_{1}(\omega) \sqrt{\left|d_{i j}^{l}\right|}+a_{2}(\omega) \sqrt{\left|d_{i j}^{t}\right|}\right]\left(\frac{\omega}{2 \pi}\right)^{2}\right\}$

in which $d_{i j}^{l}$ and $d_{i j}^{t}$ are the projected and vertical distance in the wave propagation direction between points $i$ and $j$ on ground surface, respectively. $\alpha_{1}(\omega)$ and $\alpha_{2}(\omega)$ are functions with the form

$$
\begin{aligned}
& a_{1}(\omega)=\left\{\begin{array}{lc}
2 \pi \mathrm{a} / \omega+b \omega / 2 \pi+c, & 0.314 \mathrm{rad} / \mathrm{s} \leq \omega \leq 62.83 \mathrm{rad} / \mathrm{s} \\
0.1 a+10 b+c, & \omega \geq 62.83 \mathrm{rad} / \mathrm{s}
\end{array}\right. \\
& a_{2}(\omega)=\left\{\begin{array}{lc}
2 \pi \mathrm{d} / \omega+e \omega / 2 \pi+g, & 0.314 \mathrm{rad} / \mathrm{s} \leq \omega \leq 62.83 \mathrm{rad} / \mathrm{s} \\
0.1 d+10 e+g, & \omega \geq 62.83 \mathrm{rad} / \mathrm{s}
\end{array}\right.
\end{aligned}
$$

where, the constant $a, b, c, d, e, g, \beta_{1}$ and $\beta_{2}$ can be obtained by least-squares fitting the coherency function of recorded motions. The constants in coherency function are $a=3.583 \times 10^{-3}$, $b=-1.811 \times 10^{-5}, \quad c=1.177 \times 10^{-4} d=5.163 \times 10^{-3}, e=-7.583 \times 10^{-6}, g=-1.905 \times 10^{-4}, \beta_{1}=1.109 \times 10^{-4}$, and $\beta_{2}=6.730 \times 10^{-5}$, which were obtained by processing recorded motions during event 45 at the SMART-1 array. In order to compare the change of the coherency loss, different degrees of 
coherency loss are selected according to the previous study (Bi et al. [15]).

\subsection{Simulation of Non-uniform Ground Motions}

A stochastic approach based on random vibration analysis is used, and the simulated ground motion time history is iterated to be compatible with the response spectrum defined in Code for Design of Seismic of Electrical Installations. The transmission tower-line system is assumed to be located in the medium firm soil with peak longitudinal ground acceleration $0.4 \mathrm{~g}$. The intensity of the transverse component and vertical component, as stated in the code, are 0.85 and 0.65 times of the longitudinal component, respectively. According to Penzien and Watable's research (Penzien and Watabe [16]), the three components of ground motions along a set of principal axes are uncorrelated. In this study, the three components of the ground motion are assumed to be directed along the principal axes. Based on the above method, multi-support and multi-component ground motions time histories are generated. Figure 5 gives acceleration time histories of all base points of transmission tower in the three-dimensional direction.
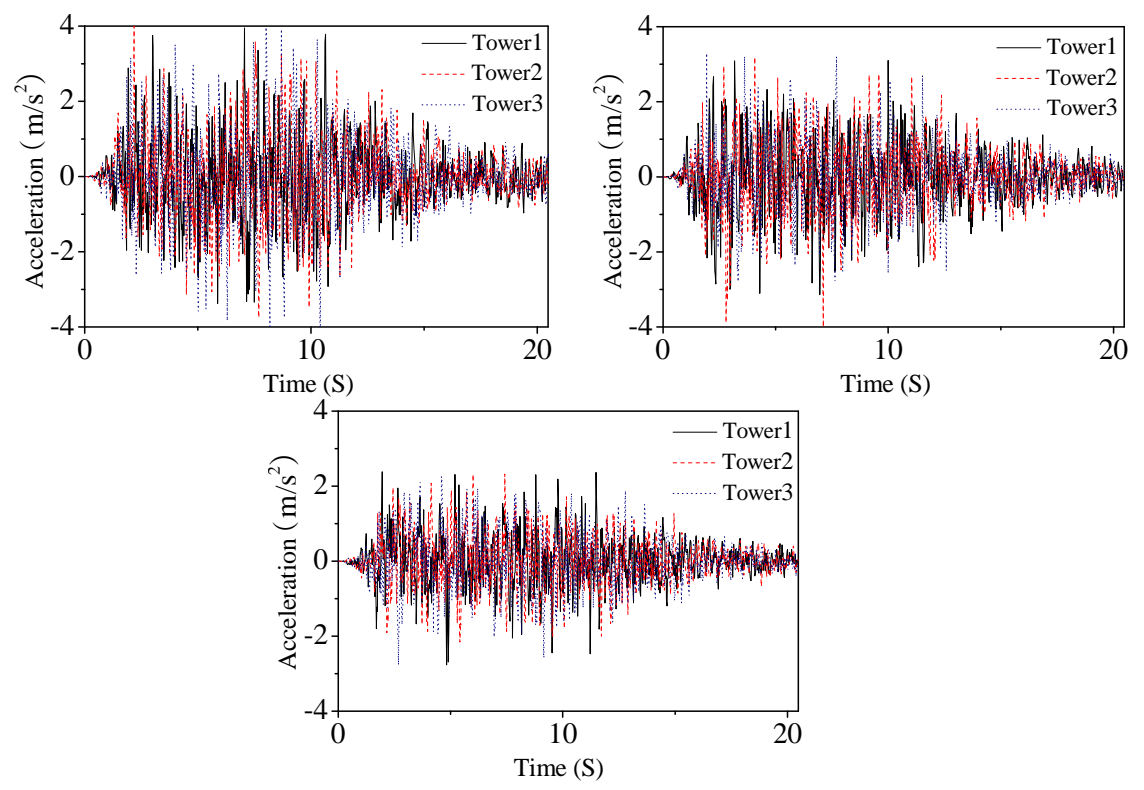

(a) Longitudinal direction

(b) Transverse direction

(c) Vertical direction

Figure 5. Acceleration Time Histories of All Base Points of

Transmission Tower in Three-dimensional Direction

\section{NUMERICAL ANALYSIS AND DISCUSSION}

Seismic responses of the straight line type and broken line type transmission tower-line systems subjected to spatially varying ground motions are analyzed using nonlinear time history analysis method. The geometric nonlinearity is taken into account due to large deformation, and the effect of $P-\Delta$ is also considered. The damping ratios of the tower and line are assumed to be 0.02 and 0.01 , respectively. The HHT method is applied in the numerical integration. In order to obtain reliable calculation results, three independent numerical calculations are carried out using the three sets of independently simulated spatial ground motions as input. Mean value are obtained from the three numerical calculation results.

\subsection{Analysis Case}


A total of 17 cases, seismic excitations of spatially varying ground motions are shown in Table 1. Firm, medium firm, medium soft and soft sites are denoted by F, MF, MS, S, respectively. Case 1 is the uniform excitation, because apparent velocity, coherency and soil condition are infinite, completely correlated and medium firm site, respectively. In order to investigate the effect of wave passage influence on the structural response, the coherency and soil condition of case 2 10 are highly correlated and medium firm site, respectively. To research the effect of coherency loss influence on the structural response, the apparent wave and soil condition of case 6, 11 14 are $1000 \mathrm{~m} / \mathrm{s}$ and medium firm site, respectively. To study the effect of local soil condition influence on the structural response, the apparent wave and coherency of case $6,15 \sim 17$ are $1000 \mathrm{~m} / \mathrm{s}$ and highly correlated, respectively.

Table 1. Analysis Cases of Non-uniform Seismic Excitations

\begin{tabular}{|c|c|c|c|c|c|}
\hline \multirow{2}{*}{ Case } & \multirow{2}{*}{$\begin{array}{c}\text { Apparent } \\
\text { velocity }\end{array}$} & \multirow{2}{*}{ Coherency } & \multicolumn{3}{|c|}{ Soil condition } \\
\cline { 4 - 6 } & infinite & Perfectly & MF & MF & MF \\
\hline Case 1 & $200 \mathrm{~m} / \mathrm{s}$ & Highly & MF & MF & MF \\
\hline Case 2 & $400 \mathrm{~m} / \mathrm{s}$ & Highly & MF & MF & MF \\
\hline Case 3 & Highly & MF & MF & MF \\
\hline Case 4 & $600 \mathrm{~m} / \mathrm{s}$ & Highly & MF & MF & MF \\
\hline Case 5 & $800 \mathrm{~m} / \mathrm{s}$ & Highly & MF & MF & MF \\
\hline Case 6 & $1000 \mathrm{~m} / \mathrm{s}$ & Highly & MF & MF & MF \\
\hline Case 7 & $1200 \mathrm{~m} / \mathrm{s}$ & Highly & MF & MF & MF \\
\hline Case 8 & $1600 \mathrm{~m} / \mathrm{s}$ & Highly & MF & MF & MF \\
\hline Case 9 & $2000 \mathrm{~m} / \mathrm{s}$ & Highly & MF & MF & MF \\
\hline Case 10 & $3000 \mathrm{~m} / \mathrm{s}$ & Uncorrelated & MF & MF & MF \\
\hline Case 11 & $1000 \mathrm{~m} / \mathrm{s}$ & Weakly & MF & MF & MF \\
\hline Case 12 & $1000 \mathrm{~m} / \mathrm{s}$ & Intermediately & MF & MF & MF \\
\hline Case 13 & $1000 \mathrm{~m} / \mathrm{s}$ & Completely & MF & MF & MF \\
\hline Case 14 & $1000 \mathrm{~m} / \mathrm{s}$ & Highly & F & MF & F \\
\hline Case 15 & $1000 \mathrm{~m} / \mathrm{s}$ & Highly & MS & MF & MS \\
\hline Case 16 & $1000 \mathrm{~m} / \mathrm{s}$ & Highly & S & MF & S \\
\hline Case 17 & $1000 \mathrm{~m} / \mathrm{s}$ & & & & \\
\hline
\end{tabular}

\subsection{Effect of Wave Passage}

To study the effect of apparent velocity, nine different velocities of wave propagation are considered in the analysis, $200 \mathrm{~m} / \mathrm{s}$ (Case 2), $400 \mathrm{~m} / \mathrm{s}$ (Case 3), $600 \mathrm{~m} / \mathrm{s}$ (Case 4), $800 \mathrm{~m} / \mathrm{s}$ (Case 5), $1000 \mathrm{~m} / \mathrm{s}$ (Case 6), $1200 \mathrm{~m} / \mathrm{s}$ (Case 7), $1600 \mathrm{~m} / \mathrm{s}$ (Case 8), $2000 \mathrm{~m} / \mathrm{s}$ (Case 9) and $3000 \mathrm{~m} / \mathrm{s}$ (Case 10 ), to cover the range of practical propagation velocities in the engineering. In all these cases, the coherency loss and soil condition of ground motion are assumed to be highly correlated and the medium firm site, respectively. 
Table 2. Comparison of Displacements at the Top of Tower under Different Traveling Wave Velocities

\begin{tabular}{|c|c|c|c|c|}
\hline \multirow{2}{*}{ Case } & \multicolumn{2}{|c|}{ Straight line type } & \multicolumn{2}{c|}{ Broken line type } \\
\cline { 2 - 5 } & Longitudinal & Transverse & Longitudinal & Transverse \\
\hline Case 1 & 1.00 & 1.00 & 1.00 & 1.00 \\
\hline Case 2 & 6.56 & 1.10 & 4.20 & 1.37 \\
\hline Case 3 & 6.18 & 1.06 & 3.26 & 1.31 \\
\hline Case 4 & 3.68 & 1.11 & 2.65 & 1.34 \\
\hline Case 5 & 2.53 & 1.37 & 2.03 & 1.37 \\
\hline Case 6 & 1.68 & 1.03 & 1.61 & 1.48 \\
\hline Case 7 & 1.37 & 1.04 & 1.58 & 1.22 \\
\hline Case 8 & 1.44 & 1.05 & 1.42 & 1.11 \\
\hline Case 9 & 1.36 & 1.05 & 1.33 & 1.13 \\
\hline Case 10 & 1.46 & 1.10 & 1.30 & 1.05 \\
\hline
\end{tabular}

The response of the structure under uniform excitation is normalized. The normalized displacements at the top of $2^{\#}$ tower under different traveling wave velocities are given in Table 2 . It can be seen from the table that the longitudinal displacements of the straight line type and broken line type have a decreasing tendency with the increasing wave velocity, but those all larger than that under uniform excitation, and the amplification of the straight line type is larger than that of the broken line type. For the transverse displacement, the difference between the straight line type and the broken line type is very large, and the amplification of the broken line type is greatly larger than that of the straight line type.

The maximum values of the axial force of $2^{\#}$ transmission tower under different traveling wave velocities are shown in Figure 6. It can be seen from the figure 6 that the variations of the two type models are similar. The axial forces increase gradually with the decrease of the traveling wave velocities. The maximum axial forces of two type models appear when the velocity is $200 \mathrm{~m} / \mathrm{s}$, and the axial forces are 3.7 and 2.2 times as the cases under uniform excitation, respectively. The axial forces considering wave passage effect are larger than those under uniform excitation. The change of the axial force of the straight line type system is very little when the velocity exceeds $1000 \mathrm{~m} / \mathrm{s}$, but the axial forces of the broken line type system decrease gradually with the increasing velocity.

Figure 7 shows the maximum value curves of the vertical displacements of transmission lines under different traveling wave velocities. Owing to the effect of the broken line, the shapes of the vertical displacements have changed. The variations of the two type models considering wave passage effect are similar. With the decrease of traveling wave velocities, the vertical displacements of transmission lines increase and are amplified strongly. The vertical displacements of transmission lines decrease with the increasing wave velocity. When the velocity exceeds $1000 \mathrm{~m} / \mathrm{s}$, the variations of the displacements of two type models are very little but all displacements are larger than those under uniform excitation.

As shown in Figure 8, the maximum value curves of tension forces of transmission lines under different traveling wave velocities are given. It can be seen from the figure 8 that the tension forces of two type models considering wave passage effect are larger than those under uniform excitation. The maximum tension forces of transmission lines of the two type models can be obtained when 
the velocity is $400 \mathrm{~m} / \mathrm{s}$, and the others velocities have different influence on the two type models. With the increasing velocity, the tension forces decrease gradually and are close to the response of structure under uniform excitation. Neglecting the wave passage effect of ground motion, the tension forces of transmission lines of the two type models could be underestimated by more than $160 \%$.

According to the variations of the displacement and internal force responses of transmission tower and transmission lines considering the change of traveling wave velocity, the wave passage effect has a significant influence on the straight line type and broken line type structures. The responses of the two type models are very large when the wave velocities are low, and the responses of the two type models decrease gradually with the increasing wave velocity and are close to the cases under uniform excitation. Different traveling wave velocities have different influence on the responses of the two type models. Therefore, the traveling wave velocity can not be ignored for the straight line type and broken line type systems.

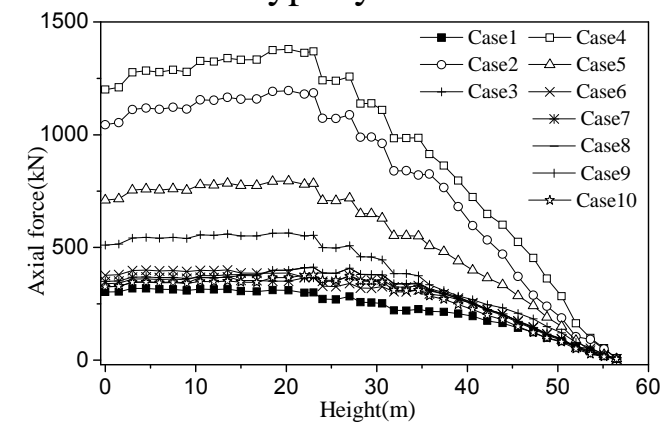

(a) Straight line type

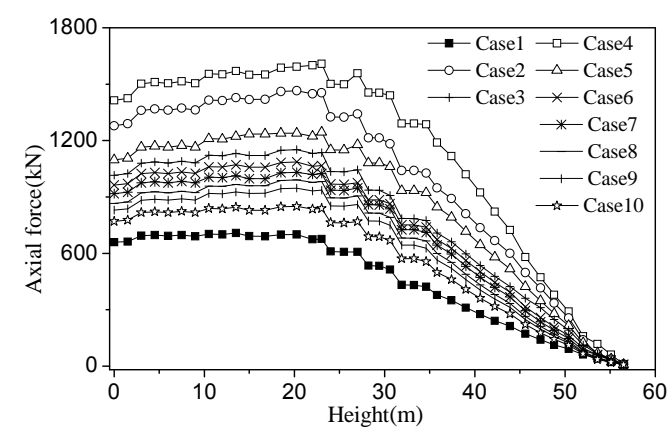

(b) Broken line type

Figure 6. Axial Forces of Tower under Different Traveling Wave Velocities

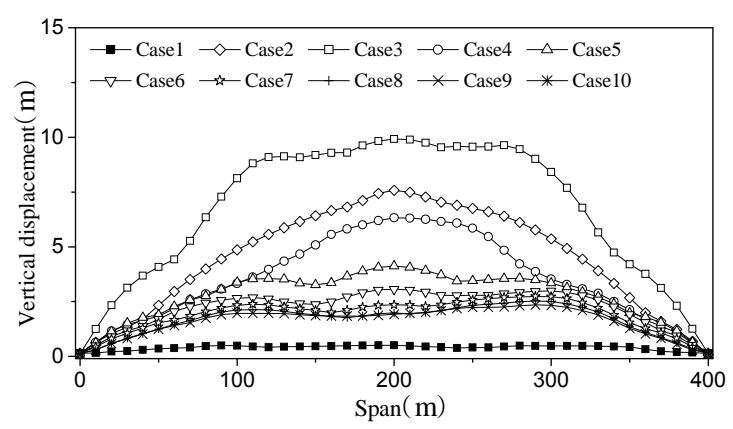

(a) Straight line type

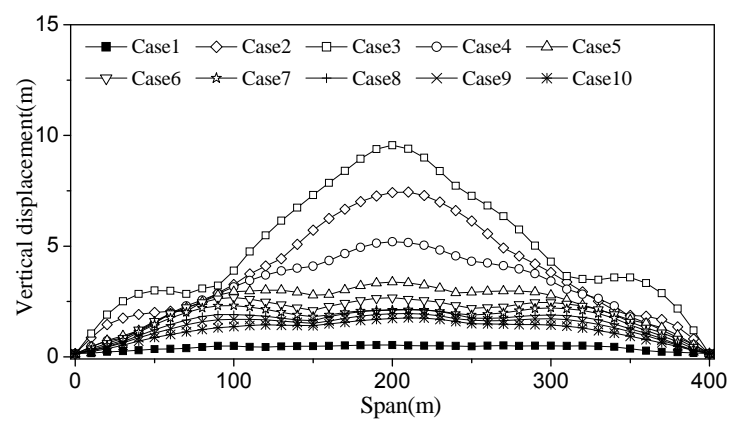

(b) Broken line type

Figure 7. Vertical Displacements of Transmission Lines under Different Traveling Wave Velocities

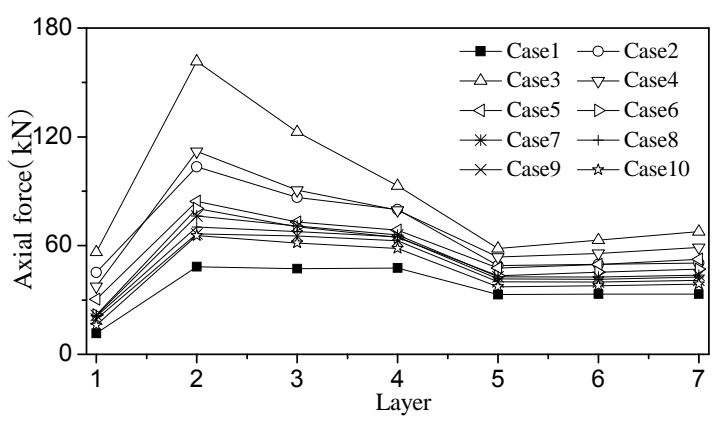

(a) Straight line type

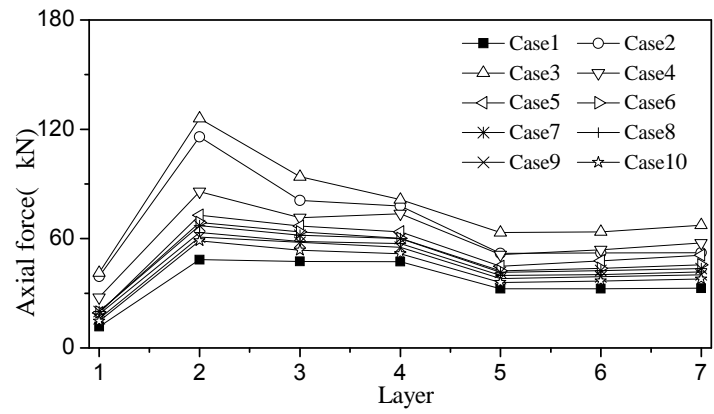

(b) Broken line type

Figure 8. Tension Forces of Transmission Lines under Different Traveling Wave Velocities 


\subsection{Effect of Coherency Loss}

To investigate the effect of coherency loss, uncorrelated (Case 11), weakly (Case 12), intermediately (Case 13), highly (Case 6), and completely correlated (Case 14) ground motions are considered, respectively. It should be noted that the correlation as low as uncorrelated does not usually occur at short distances, unless there are considerable changes in the local geology from one support to the other. In all these cases, the apparent velocity and soil condition of ground motion are assumed to be $1000 \mathrm{~m} / \mathrm{s}$ and the medium firm site, respectively.

The response of the structure under uniform excitation is normalized. Table 3 shows the normalized displacements at the top of $2^{\#}$ tower under different degrees of coherency loss. The longitudinal displacement of the straight line type system increases with the decrease of the degree of coherency loss, but the variation of the broken line type system's displacement is little with the change of the degree of coherency loss. The transverse displacement of the straight line type has an increasing tendency with the decrease of the degree of coherency loss, and its amplification varies significantly. The transverse displacement of the broken line type system has changed indistinctively with the degree of coherency loss varying.

Table 3. Comparison of Displacements at the Top of Tower under Different Degrees of Coherency Loss

\begin{tabular}{|c|c|c|c|c|}
\hline \multirow{2}{*}{ Case } & \multicolumn{2}{|c|}{ Straight line type } & \multicolumn{2}{c|}{ Broken line type } \\
\cline { 2 - 5 } & Longitudinal & Transverse & Longitudinal & Transverse \\
\hline Case 1 & 1.00 & 1.00 & 1.00 & 1.00 \\
\hline Case 11 & 1.61 & 0.97 & 1.38 & 1.28 \\
\hline Case 12 & 1.68 & 1.03 & 1.61 & 1.48 \\
\hline Case 13 & 2.40 & 1.30 & 2.20 & 1.35 \\
\hline Case 6 & 3.16 & 1.51 & 2.38 & 1.39 \\
\hline Case 14 & 5.03 & 1.54 & 3.04 & 1.36 \\
\hline
\end{tabular}

Figure 9 shows the maximum values of axial force of $2^{\#}$ transmission tower under different degrees of coherency loss. It can be seen from the figure that the responses of two type models have an increasing tendency with the decrease of the degree of coherency loss. The maximum axial forces appear when the coherency loss is uncorrelated, and the axial forces of two type models are 3.7 and 2.2 times as the cases under uniform excitation, respectively. The degree of coherency loss has a significant influence on the variation of transmission tower's axial forces, and the axial forces have a decreasing tendency with the degree of coherency loss increasing.

As shown in Figure 10, the maximum value curves of the vertical displacements of transmission lines under different degrees of coherency loss. Two type models have an increasing tendency with the decrease of the degree of coherency loss. The change of coherency loss has a great influence on the vertical displacement of transmission lines for the straight line type system, but the vertical displacements of transmission lines are affected insignificantly by the change of coherency loss except for uncorrelated and weakly correlated.

The maximum value curves of tension forces of transmission lines under different degrees of coherency loss are shown in Figure 11. The change of coherency loss has little influence on the tension force of transmission line for the straight line type system, so the change of coherency loss can be ignored. The tension forces of transmission lines are affected slightly by the change of 
coherency loss except for uncorrelated and weakly correlated for the broken line type system. Neglecting the coherency loss effect of ground motion, the tension forces of transmission lines of two type models could be underestimated by more than $80 \%$ and $120 \%$, respectively.

The variations of the displacement and internal force responses of transmission tower and transmission lines considering the change of coherency loss can be obtained from the above analysis. The change of the degree of coherency loss has a great influence on the responses of the two type models except for the tension forces of transmission lines for the straight line type. The responses of structures are affected insignificantly by the change of coherency loss except for uncorrelated and weakly correlated for the broken line type system, but the correlation as low as uncorrelated and weakly occur at long distances, so the change of coherency loss could not be considered at short distances. Neglecting the coherency loss effect of ground motion could underestimate the responses of the straight line type and broken line type systems.

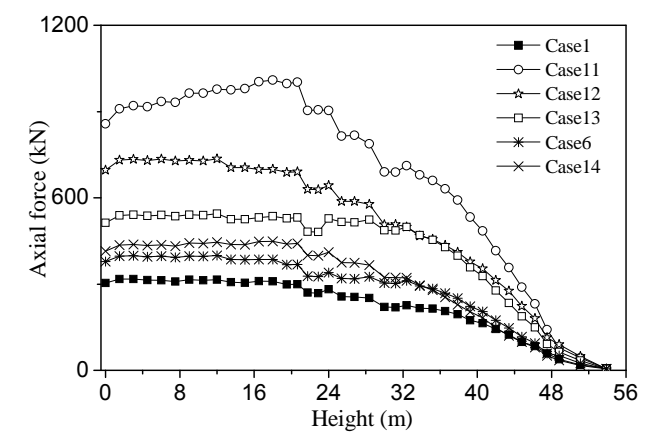

(a) Straight line type

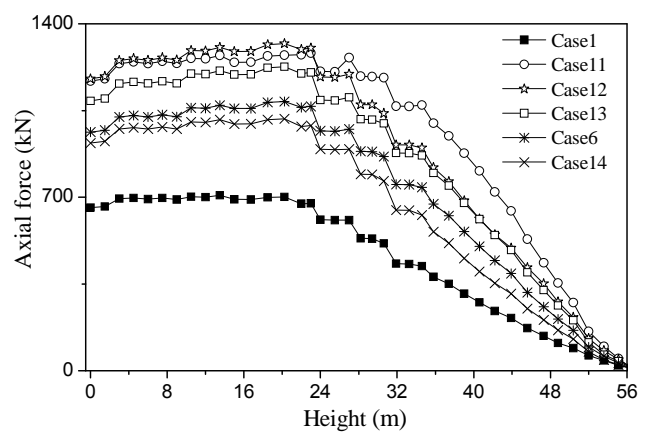

(b) Broken line type

Figure 9. Axial Forces of Tower under Different Degrees of Coherency Loss

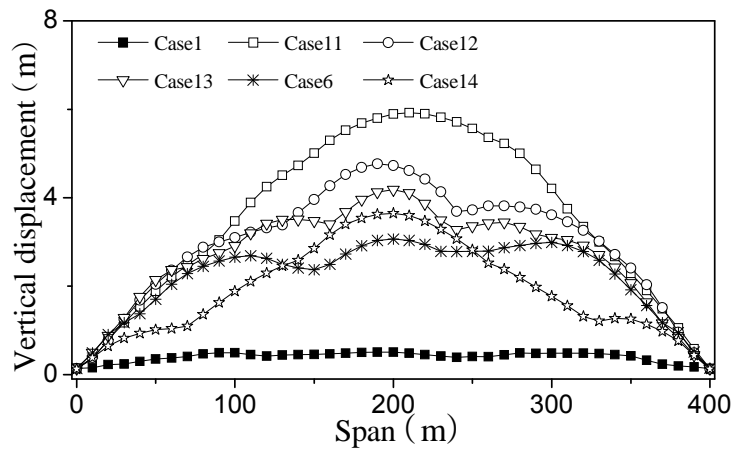

(a) Straight line type

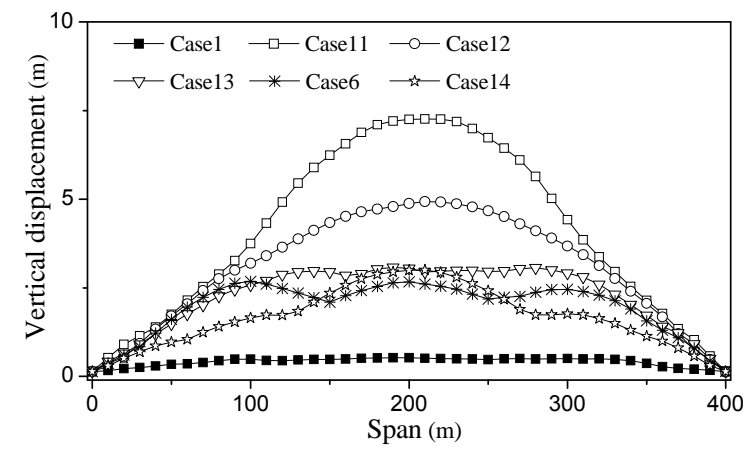

(b) Broken line type

Figure 10. Vertical Displacements of Transmission Lines under Different Degrees of Coherency Loss

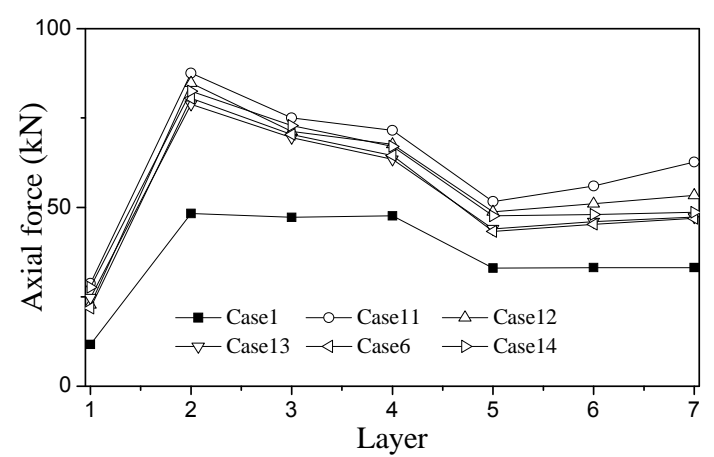

(a) Straight line type

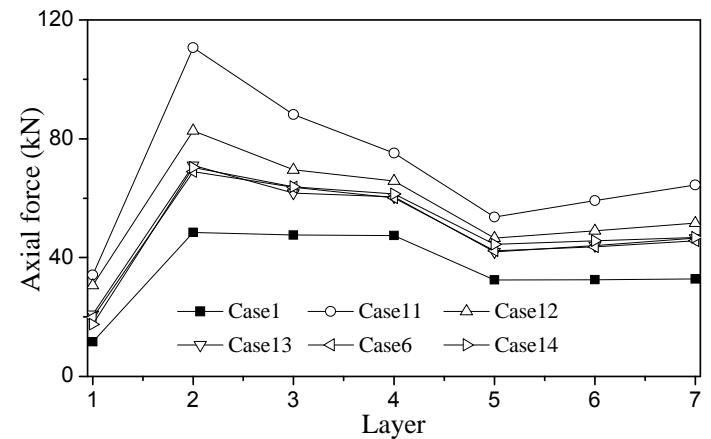

(b) Broken line type

Figure 11. Tension Forces of Transmission Lines under Different Degrees of Coherency Loss 


\subsection{Effect of Local Site}

In order to research the effect of local site, MF-MF-MF (Case 6), F-MF-F (Case 15), MS-MF-MS (Case 16) and S-MF-S (Case 17) are considered. In all these cases, the apparent velocity and coherency of ground motion are assumed to be $1000 \mathrm{~m} / \mathrm{s}$ and highly correlated, respectively.

The response of the structure under uniform excitation is normalized. Table 4 shows the normalized displacements at the top of $2^{\#}$ tower under different site conditions. The longitudinal displacements of the straight line type and broken line type structures increase with the degree of the difference of the site condition increasing. The change of site condition has little influence on the transverse displacement of two type models, but the amplification of the broken line type system is larger than that of the straight line type system.

Table 4. Comparison of Displacements at the Top of Tower under Different Site Conditions

\begin{tabular}{|c|c|c|c|c|}
\hline \multirow{2}{*}{ Case } & \multicolumn{2}{|c|}{ Straight line type } & \multicolumn{2}{c|}{ Broken line type } \\
\cline { 2 - 5 } & Longitudinal & Transverse & Longitudinal & Transverse \\
\hline Case 1 & 1.00 & 1.00 & 1.00 & 1.00 \\
\hline Case 6 & 1.68 & 1.03 & 1.61 & 1.48 \\
\hline Case 15 & 2.20 & 1.03 & 1.77 & 1.39 \\
\hline Case 16 & 1.62 & 1.04 & 1.62 & 1.36 \\
\hline Case 17 & 2.32 & 1.07 & 1.94 & 1.54 \\
\hline
\end{tabular}

Figure 12 shows the maximum values of axial force of $2^{\#}$ transmission tower under different site conditions. The site condition has obvious influence on the response of the straight line type system, and the axial force of the tower in the different sites is larger than that in the same site. The site condition has a significant influence on the response of the broken line type system, and the response increases with the degree of the difference of the site condition increasing.

As shown in Figure 13, the maximum value curves of the vertical displacements of transmission lines under different site conditions are given. The great differences of site conditions magnify strongly the vertical displacement of transmission line for the straight line type system, but the change of vertical displacement is little when the difference of site conditions is small. The vertical displacement increases gradually with the degree of the difference of site condition increasing for the broken line type system.

The maximum value curves of tension forces of transmission lines under different site conditions are shown in Figure 14. The tension forces of the two type models increase gradually with the degree of the difference of site condition increasing, but the amplification of the straight line type system is larger than that of the broken line type system. Neglecting the local site effect of ground motion, the tension forces of transmission lines of two type models could be underestimated by more than $100 \%$ and $70 \%$, respectively.

The variations of the displacement and internal force responses of transmission tower and transmission lines considering different site conditions can be obtained from the above observations. The two type models have an increasing tendency with the degree of the difference of site conditions increasing. The change of the site conditions has a greater influence on the response of the straight line type system than that of the broken line type system. Therefore, it is necessary to consider the local site effect of ground motion, especially for the straight line type system. 


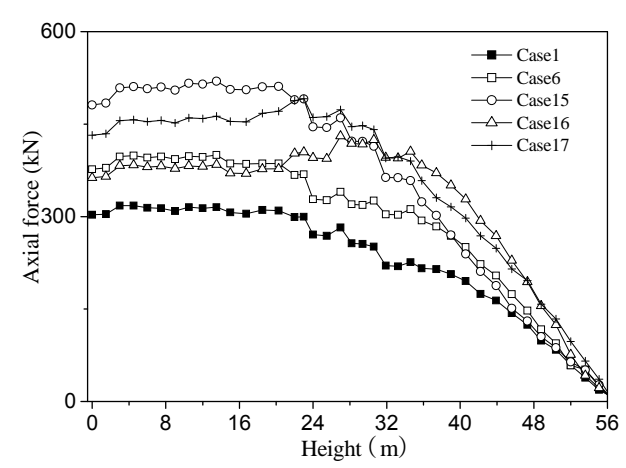

(a) Straight line type

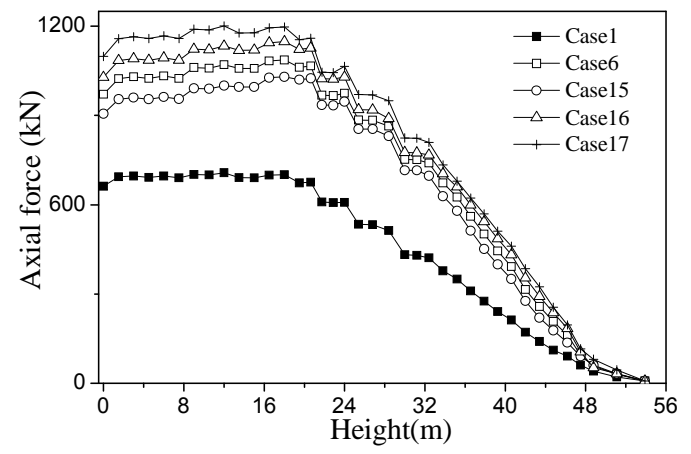

(b) Broken line type

Figure 12. Axial Forces of Tower under Different Site Conditions

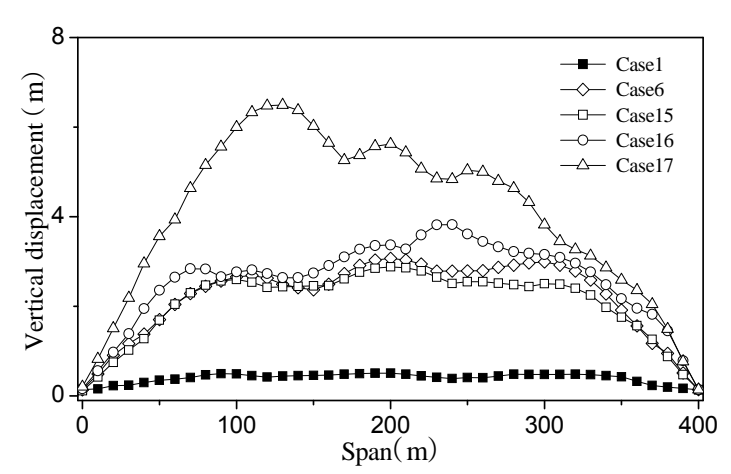

(a) Straight line type

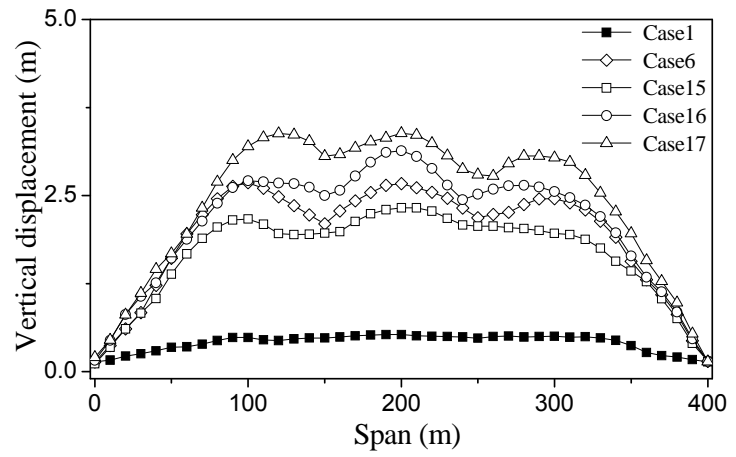

(b) Broken line type

Figure 13. Vertical Displacements of Transmission Lines under Different Site Conditions

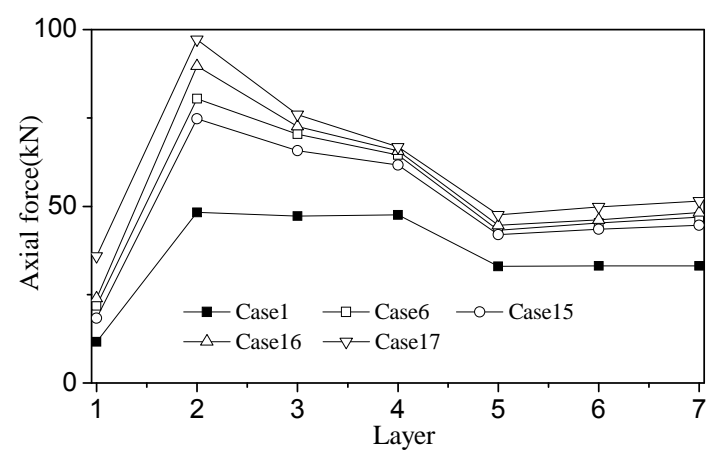

(a) Straight line type

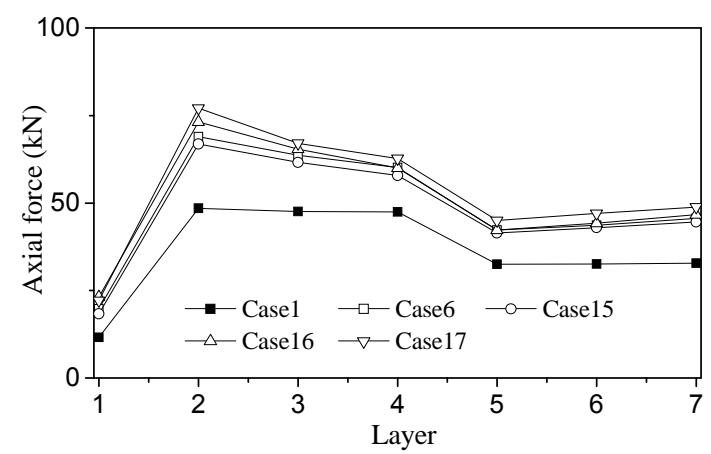

(b) Broken line type

Figure 14. Tension Forces of Transmission Lines under Different Site Conditions

\section{CONCLUSIONS}

The effect of non-uniform ground motions on the response of the straight line type and broken line type transmission tower-line systems have been investigated in this paper. The influence of wave passage effect, coherency loss effect and different local site effect on the system are considered, respectively. Based on the numerical results and analysis, the following conclusions are drawn:

(1) The wave passage effect has a significant influence on both the straight line type and broken line type models. Neglecting the wave passage effect in analysis, the structural responses would be underestimated. The traveling wave velocity can not be ignored for the straight line type and broken line type systems. 
(2) The change of the degree of coherency loss has a great influence on the response of structures except for the tension forces of transmission lines for the straight line type system. The responses of structures are affected insignificantly by the change of coherency loss except for uncorrelated and weakly correlated for the broken line type system. Neglecting the coherency loss effect of ground motion, the responses of the straight line type and broken line type systems would be underestimated.

(3) The two type models have an increasing tendency with the degree of the difference of site conditions increasing. It is necessary to consider the local site effect of ground motion, especially for the straight type system.

This study demonstrates that the non-uniform seismic excitations are very important to not only the straight line type transmission tower-line system but also the broken line type transmission tower-line system. In order to obtain a general conclusion, more studies should be investigated about broken line type transmission tower-line system.

\section{ACKNOWLEDGEMENTS}

This research work was jointly supported by the National Natural Science Foundation of China (Grant No. 51208285), China Postdoctoral Science Foundation funded project (Grant No. 2012M521338), Shandong Province Natural Science Foundation of China (Grant No. ZR2012EEQ005) and Independent Innovation Foundation of Shandong University of China (Grant No. 2011GN051)

\section{REFERENCES}

[1] Yin, R.H., Li, D.L. Liu, G.L. and Zhai, T., "Seismic Damage and Analysis of Power Transmission Towers”, World Earthquake Engineering, 2005, Vol. 21, No. 1, pp. 51-54.

[2] Zerva, A. and Harada, T., "Response of a Rigid Foundation to a Spatially Random Ground Motion”, Earthquake Engineering and Structural Dynamics, 1992, Vol. 21, No. 8, pp. 713-740.

[3] Ghobarah, A., Aziz, T.S., and El-Attar, M., "Response of Transmission Lines to Multiple Support Excitation”, Engineering Structure, 1996, Vol. 18, No. 12, pp. 936-946.

[4] Li, H.N., Shi, W.L. and Jia, L.G., "Simplified Aseicmic Calculation Method Considering Effects of Line on Transmission Tower", Journal of Vibration Engineering, 2003, Vol. 16, No. 2, pp. 233-237.

[5] Li, H.N., Shi, W.L. and Jia, L.G., "Limitations of Effects of Lines on In-plane Vibration of Transmission Towers and Simplified Seismic Calculation Method”, Vibration and Impact, 2004, Vol. 23, No. 2, pp. 1-7.

[6] Li, H.N., Shi, W.L., Wang, G.X. and Jia, L.G., "Simplified Models and Experimental Verification for Coupled Transmission Tower-line System to Seismic Excitations”, Journal of Sound and Vibration, 2005, Vol. 286, No. 3, pp. 565-585.

[7] Tian, L., Li, H.N. and Huang, L. Zh., "Lateral Response of Transmission Tower-line System under Multiple Support Excitations”, Proceeding of the Chinese Society for Electrical Engineering, 2008, Vol. 28, No. 16, pp. 108-114.

[8] Deng, H. Zh., Chen, X.M., Tu, H.M., Ma, X. and Wang, Zh. M., “Experimental Study on Model of Jiangyin Long Span Transmission Tower”, Journal of Building Structures, 2001, Vol. 22, No. 6, pp. 31-35. 
[9] Shen, Sh. Zh., Xu, Ch. B. and Zhao, Ch., "Design of Suspension Structure”, China Architecture and Building Press, 1997.

[10] Clough, R.W. and Penzien, J., “Dynamics of structures”, McGraw-Hill Education, 1975.

[11] Tian, L. and Li, H.N., "Parameter Study on Seismic Random Model Based on Code for Design of Seismic of Electrical Installations”, Journal of Disaster Prevention and Mitigation Engineering, 2010, Vol. 30, No. 1, pp. 17-22.

[12] GB 50260-96, “Code for Seismic Design of Electrical Facilities”, China Plan Press, 1996.

[13] Hao, H., Oliveira, C.S. and Penzien, J., "Multiple-station Ground Motion Processing and Simulation based on SMART-1 Array Data”, Nuclear Engineering and Design, 1989, Vol. 111, pp. 1325-1345.

[14] Hao, H., "Effects of Spatial Variation of Ground Motions on Large Multiply-supported Structures”, Report No. UCB/EERC-89/06, 1989.

[15] Bi, K.M., Hao, H. and Chou, W.N., "Required Separation Distance between Decks and at Abutments of a Bridge Crossing a Canyon Site to Avoid Seismic Pounding”, Earthquake Engineering and Structural Dynamics, 2009, Vol. 39, No. 3, pp. 303-323.

[16] Penzien, J. and Watabe, M., "Characteristics of 3-dimensional Earthquake Ground Motions”, Earthquake Engineering and Structural Dynamics, 1975, Vol. 4, pp. 365-373. 


\title{
EXPERIMENTAL STUDY OF CONCRETE-FILLED STEEL TUBULAR ARCHES WITH CORRUGATED STEEL WEBS
}

\author{
Jing $\mathrm{Gao}^{1}$, Jiazhan $\mathrm{Su}^{2}$, Yong $\mathrm{Xia}^{3, *}$ and Baochun $\mathrm{Chen}^{4}$ \\ ${ }^{1}$ Associate professor, Department of Civil Engineering, Xiamen University, China \\ ${ }^{2}$ Research student, Department of Civil and Environmental Engineering, \\ The Hong Kong Polytechnic University, Hong Kong \\ ${ }^{3}$ Associate professor, Department of Civil and Environmental Engineering, \\ The Hong Kong Polytechnic University, Hong Kong \\ ${ }^{4}$ Professor, College of Civil Engineering, Fuzhou University, China \\ *(Corresponding author: E-mail: ceyxia@polyu.edu.hk)
}

Received: 20 March 2013; Revised: 12 June 2013; Accepted: 17 October 2013

\begin{abstract}
Concrete-filled steel tubular (CFST) arches with corrugated steel web (CSW) are a new developing type of arches, which combine the high strength of CFST and good shearing resistance of CSW. This paper studies the behaviour of CFST arches with CSW (or CFST-CSW arches) under in-plane and out-of-plane loading conditions. A series of experiments was conducted. The displacement and strain of CFST-CSW arch models under different loading schemes were measured. These experiments enabled the direct assessment of the load-deflection and failure mode of the CFST-CSW arches. The effectiveness of this new arch type verified by comparison of a reinforced concrete arch model with CSW in terms of the ultimate load and failure mode.
\end{abstract}

Keywords: Concrete-filled steel tube (CFST), Corrugated steel web (CSW), Arch, Load-carrying capacity, Failure mode

\section{INTRODUCTION}

A concrete-filled steel tube (CFST), which consists of a thin-walled steel tube and a concrete core, fully utilizes the geometric efficiency and mechanical characteristics of both components. The concrete infill is confined by the steel tube, resulting in a triaxial state of compression and increasing the strength and ductility of the concrete. On the other hand, the concrete core improves the local and global buckling capacity of the steel tube (Zhao et al. [1]). Given these merits, CFST has been widely used in columns, piers, and arches where compression is dominant (Zhong [2], Bradford et al. [3], Roeder et al. [4], Pi et al. [5]).

To enhance the bending stiffness and stability, laced CFST structures (named as truss rib in CFST arches), which utilize two or more CFST members tied together by either laced steel hollow tubular members or battened members, are used as columns or arches (Bode [6], Chen and Wang [7]). More than 200 CFST arch bridges have been constructed in China because of their low fabrication costs and fast erection. Among them, 33 bridges with spans greater than $200 \mathrm{~m}$ adopt CFST truss ribs (Chen and Wang [7]). One example is the $460 \mathrm{~m}$ span Wuxia Yangtze River Bridge, which is the longest CFST arch bridge in the world (Mu et al. [8]). However, for most of the long span CFST arches with quite slender ribs, buckling is one of the major concerns in the design. Moreover, there is no prescriptive code or guidance available for the strength design of CFST arches. Research of laced CFST structures is also limited. Ou et al. [9] performed an experimental study of the ultimate load of the laced CFST column. They found that the shear effect resulting from laced members or battened members reduced the ultimate load when the column is slender. Experimental investigation by Chen and Huang [10] showed that when the CFST truss girder was subjected to bending, the failure of joints considerably reduces the ultimate load. Furthermore, the welding intersection between the laced tube (or tubular web) and chords generally governs the fatigue life, which is also critical in construction and quality control. 
In recent years, the corrugated steel web $(\mathrm{CSW})$ has been commonly employed in steel girders and prestressed concrete girders because CSW not only enhances shear stability, but also reduces the self-weight (dead load) (Elgaaly et al. [11], Johnson and Cafolla [12], Chan et al. [13], Li et al. [14]). The CFST structure with CSW was proposed, motivated by the Val de Maupre Viaduct, in which the steel tubular web members in a truss system were substituted for CSW without tube-to-tube welding intersection (Brozzetti [15], Chen and Wang [16], Wei et al. [17]).

The combination of the CFST and CSW forms a new structure component (briefly referred to as CFST-CSW), whereas some new issues such as buckling of the CSW, ultimate load-carrying capacity, and failure modes under different loading conditions have not been sufficiently studied. Gao and Chen [18] carried out experiments on a CFST-CSW beam under bending. The results indicated that the flexural rigidity and ultimate load-carrying capacity of the CFST-CSW beam considerably improved compared with the CFST truss beam. Furthermore, Gao and Chen [19] conducted experiments on a CFST-CSW column. The results demonstrated that the mechanical behavior of the CFST-CSW column is similar to the CFST laced columns. Compared with CFST, CFST-CSW columns have a small shear deformation, indicating that CSWs have good shear resistance.

This paper extends the previous studies on CFST-CSW structures and applies it to arches. Three CFST-CSW arch models were tested in the laboratory, in which in-plane and out-of-plane loadings were applied. The structural responses, including displacement and strain under different loading conditions, were measured and analyzed. The ultimate load-carrying capacity and the failure mode of the CFST-CSW arches were investigated, as well.

\section{EXPERIMENTAL INVESTIGATION}

\subsection{Physical Models}

Three CFST-CSW arches with identical geometric dimensions but under different loading schemes were designed and tested. The first two models, ACSW-1 and ACSW-2, were tested under in-plane loading with different vertical loading schemes. The former was loaded symmetrically at $5 / 12$ and $7 / 12$ of the span, whereas the latter was loaded at $2 / 3$ and $5 / 6$ of the span, as shown in Figure 1(a) and Figure 1(b), respectively. During the test of the third arch model, ACSW-3, five in-plane vertical loads were applied simultaneously with a lateral load at the arch crown. The magnitude of the lateral load $(P / 10)$ was $2 \%$ of the total vertical loads $(5 P)$, as shown in Figure 1(c).

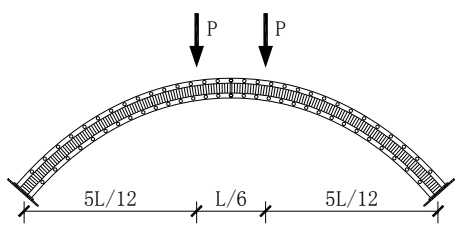

(a) ACSW-1

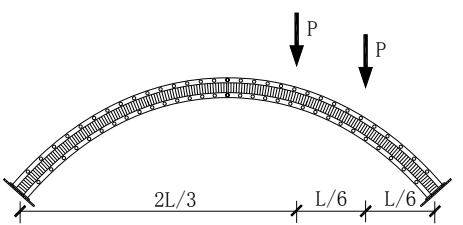

(b) ACSW-2

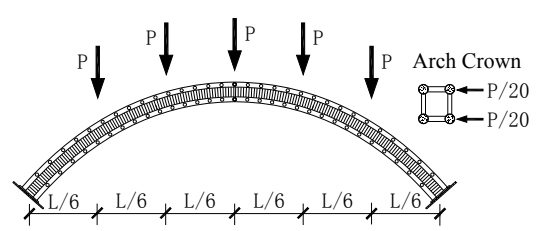

(c) ACSW-3

Figure 1. Arch Models and Loading

One typical arch model is shown in Figure 2. The arch has a parabolic profile. It has a rise of 1.556 $\mathrm{m}$ and a span of $6.223 \mathrm{~m}$ (measured from the center of both springings), giving a rise to span ratio of 1/4. Its uniform cross section is $300 \mathrm{~mm}$ deep and $275 \mathrm{~mm}$ wide. The arch consists of four CFSTs connected by two continuous vertical CSWs and two series of transverse bracings. Each tubular chord is $75 \mathrm{~mm}$ in diameter with a thickness of $1.8 \mathrm{~mm}$. The $2 \mathrm{~mm}$ thick CSW was welded continuously to the top sides of the bottom tubular chords and bottom sides of the upper tubular 
chords along the arch axis. The geometrical size of the CSW is shown in Figure 2(c). The transverse bracings are steel tubes with $40 \mathrm{~mm}$ in diameter and $2 \mathrm{~mm}$ in thickness, and welded at a uniform spacing of $195 \mathrm{~mm}$ in both top and bottom chords. The average yield stress of the steel was tested to be $335 \mathrm{MPa}$, and the average ultimate strength was $417 \mathrm{MPa}$. The Young's elastic modulus of steel was $210 \mathrm{GPa}$. The average ultimate strength of concrete was $44 \mathrm{MPa}$ with the Young's modulus of $34.7 \mathrm{GPa}$.

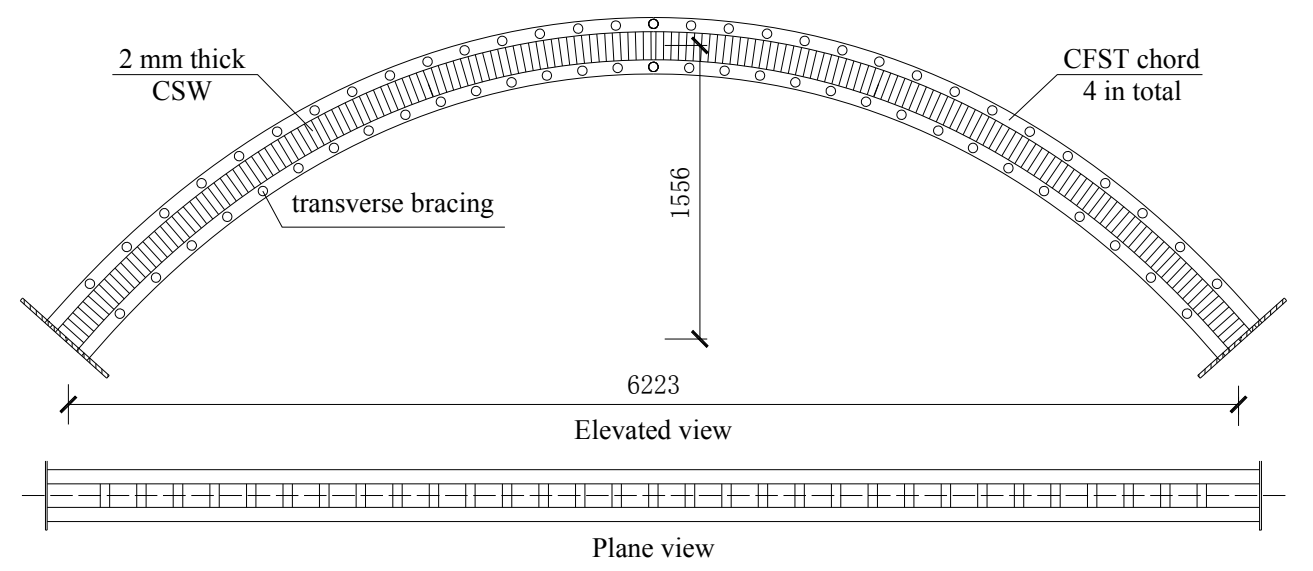

(a) Elevation

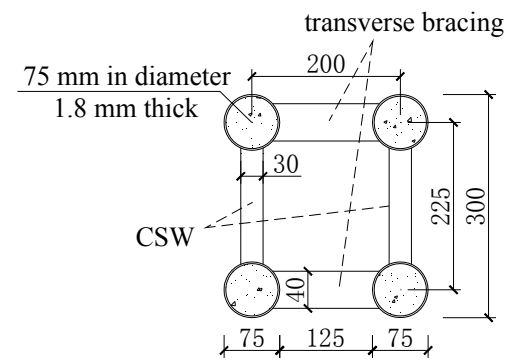

(b) Cross-section

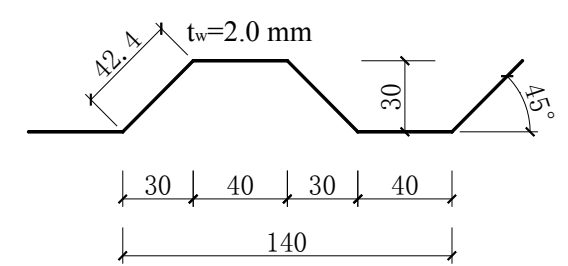

(c) CSW

Figure 2. Configuration of the Arch Model (unit: mm)

The arch models were fixed on two stiffened steel pedestals at ends. Supports were made up of triangular steel plates placed on a reinforced concrete block anchored to the ground. The supports restricted the horizontal displacement and rotation of the arch springing, simulating the fixed support conditions.

The load step was designed according to the preliminary analysis of the arch. At each load step, the loading was kept constant for at least three minutes to stabilize the response. The load $\mathrm{P}$ was applied gradually using hydraulic jacks on loading frames. The load jacks were driven by several oil-pumps that were mechanically coupled to ensure synchronization. The operating capacity of each jack was approximately $600 \mathrm{kN}$. Two overhead braced steel frames provided the required support for the jacks. Load cells, one at each jack location, were used to measure the applied loads. The magnitude of the applied loads was determined from the predefined nominal strains. The minimum load per jack was $5 \mathrm{kN}$, which corresponds to a minimum nominal strain of approximately $30 \mu \varepsilon$. Additionally, at the end of each jack, a ball-and-socket joint was provided to allow for unrestrained longitudinal displacement at the loading point. 


\subsection{Instrumentation}

The positioning of strain gauges and linear voltage displacement transducers (LVDT's) for the models is illustrated in Figure 3. A total number of 234 or 13 sets of electronic resistance strain gauges were positioned at L/12 intervals along the arch (sections $a$ to $g$ and $a$ ' to $f^{\prime}$ ). Three types of strain gauges were used. Uniaxial strain gauges were used in the longitudinal direction for the connection of the CSWs and chords (points 5, 6, 5', and 6'), biaxial strain gauges were used on the chord to record longitudinal strains and circumferential strain (points 1 to 4 and 1' to 4'), and strain gauge rosettes were installed on the CSWs to measure the shear (points 7 to 9 and 7' to 9'). For ACSW-1, seven LVDT's were attached to the bottom chord of the arch at positions L/12, L/4, 5L/12 and the crown (i.e., points $A, C, E, F$ and their symmetric locations), to measure the in-plane deflections of the arch. For ACSW-2, the LVDT's were installed at points $A, B, D, F$ and their symmetric locations of the bottom chord. For ACSW-3, five LVDT's were attached to the bottom chord of the arch at points $B, D, F$ and their symmetric locations to measure the vertical deflections, and five more LVDT's were attached to the same positions to measure the lateral deflections. A commercial data acquisition system DH3816 was used to record the readings of the strain gauges, LVDT's, and load cells.
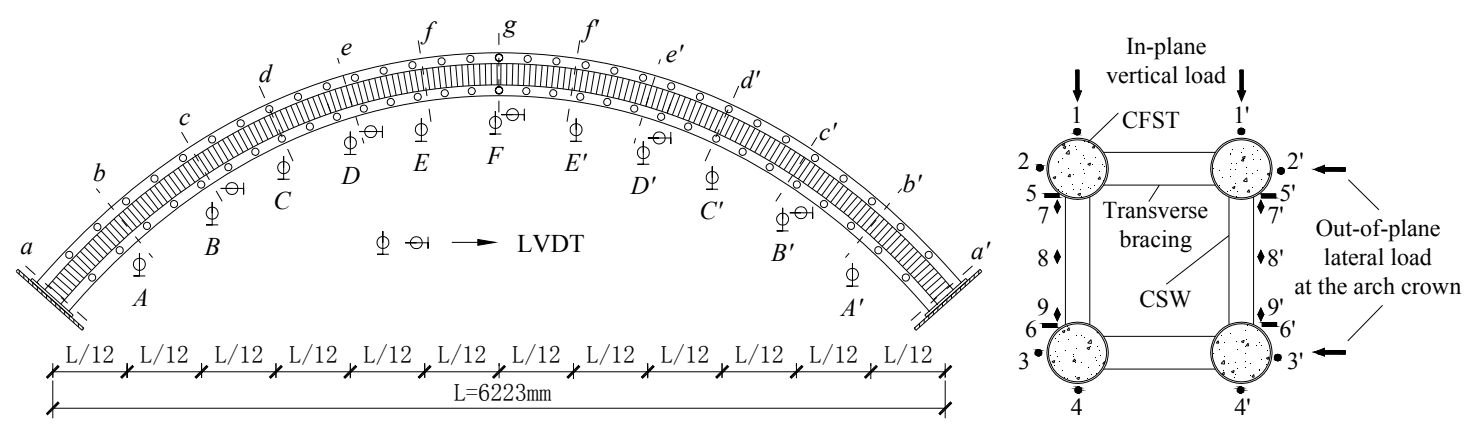

Figure 3. Positions of Strain Gauges and LVDT's in One Model

\subsection{Testing Procedure and Observations}

All three models were loaded to about $20 \%$ of the ultimate load to check the setup and instrumentation before the formal test began. In the formal test, the arch was loaded progressively in load increments of $10 \mathrm{kN}$ until failure in the elastic phase, and $5 \mathrm{kN}$ after entering the elastic-plastic phase.

Figure 4(a) shows the deformed shapes of ACSW-1 under the ultimate load. The local web buckling occurred near the quarter span (Region A in the Figure) involving at least several folds in the webs. As a result, the plastic deformation was distributed along the arch. Particularly, the buckling waves, extending over parts of the inclined folds as well as the longitudinal folds, had similar sizes and angles of inclination with respect to the arch axis. The buckled web after the load drop is shown in Figure 4(b). As ACSW-1 was loaded further, more folds in CSWs buckled near the quarter span, and the tubes of the chords near the arch springings wrinkled. 


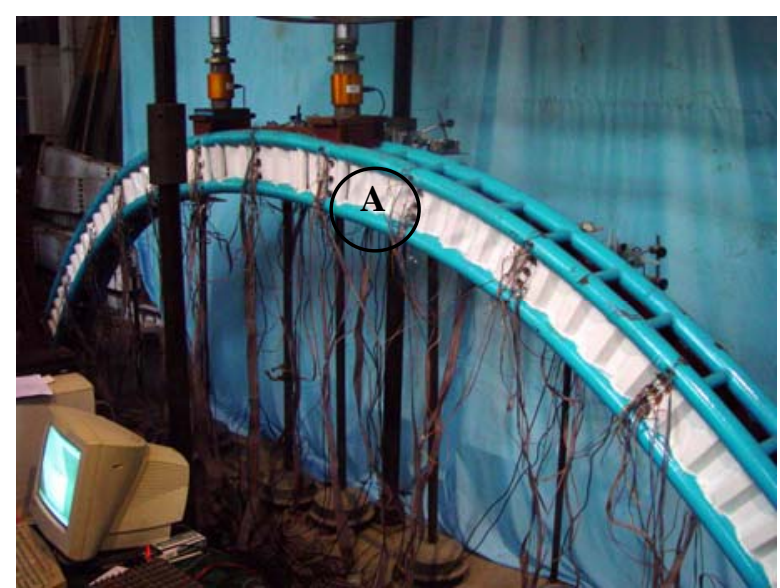

(a) Overall failure mode

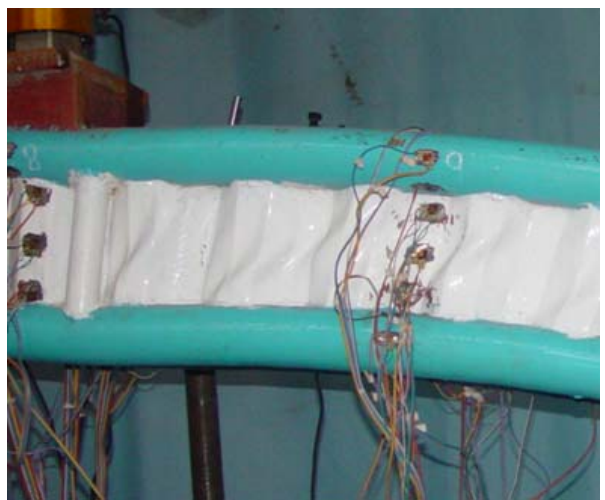

(b) Local buckling in region $\mathrm{A}$

Figure 4. View of ACSW-1 after Buckling Failure

The loading in the arch model ACSW-2 was applied at spans 2L/3 and 5L/6 simultaneously. No crack and wrinkle along the arch tube or buckling of the web was observed before the yielding of the chord steel tube. Failure in the arch was due to yielding of the tension chord, which started around loading positions and the arch springings. Figure 5 shows the deformed shape of ACSW-2 at the end of the test. As seen from the Figure, the global buckling and plastic deformation were concentrated at three positions due to the large bending moment in these regions, namely, $\mathrm{A}$ - between the left springing and $\mathrm{L} / 6, \mathrm{~B}$ - near the arch crown, and $\mathrm{C}$ - near the right springing. As a result, the stiffness and strength at the regions were significantly reduced. The buckling of CSWs became severe after the peak load.

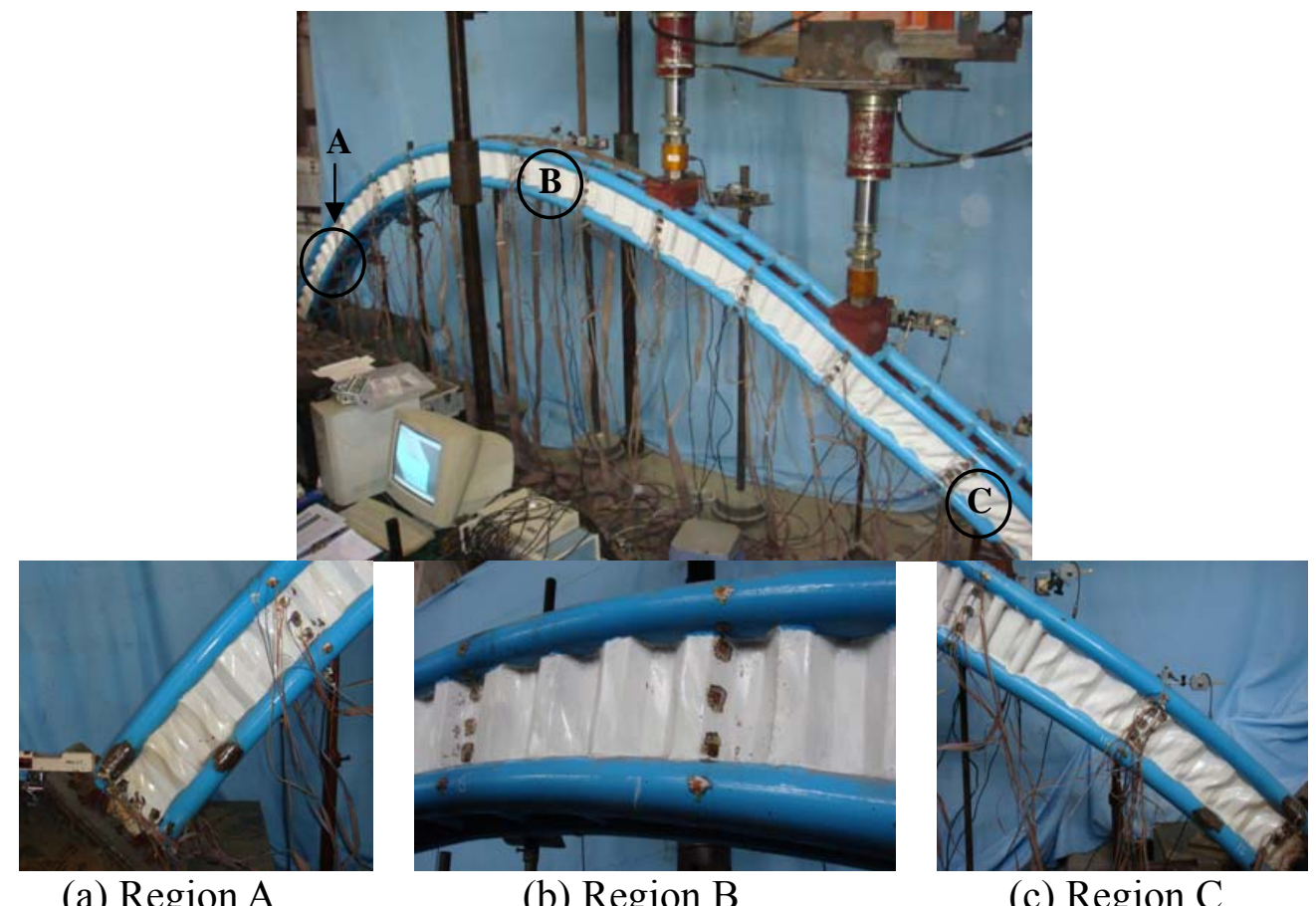

(a) Region A

(b) Region B

(c) Region C

Figure 5. View of ACSW-2 after Failure

For ACSW-3, the vertical load was applied simultaneously with the lateral load at the arch crown as shown in Figure 6. Both vertical deflections and the lateral deflections were symmetrical, and the maximum value occurred at the arch crown. In the later stage of the test, the lateral displacement 
developed rapidly, which shows that the stiffness of the arch nearly reached zero at this instance. Local buckling appeared at both springings only, and no obvious buckling could be observed at other sections.

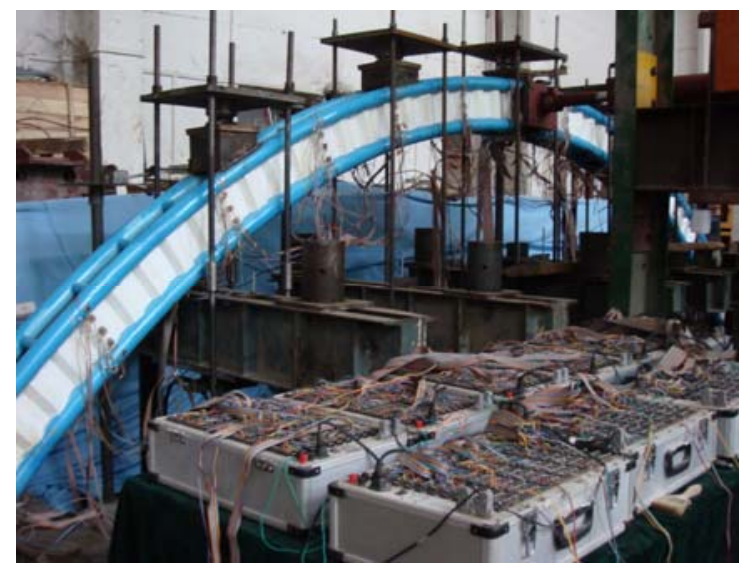

Figure 6. View of ACSW-3 in the Test

\section{$2.4 \quad$ Load-deflection Curves}

The vertical deflections of ACSW-1 at various testing stages are shown in Figure 7(a). Hereinafter, the loading magnitude refers to one single load $P$. The total vertical loads are $2 P, 2 P$, and $5 P$ for ACSW-1, ACSW-2, ACSW-3, respectively. As demonstrated in the Figure, the arch deflected symmetrically and the largest deflection occurred at the midspan. Two contraflexure points appeared near quarter spans. Figure 7(b) shows the load versus deflection response of the arch. Under the small load, the arch behaved elastically and linearly. After the load exceeded $200 \mathrm{kN}$, the deflection increased nonlinearly. The maximum deflection at the midspan was $45.3 \mathrm{~mm}$ under the failure load of $315 \mathrm{kN}$. During the test, the deflections from the contraflexure points to the arch springings were quite small even under the ultimate load.

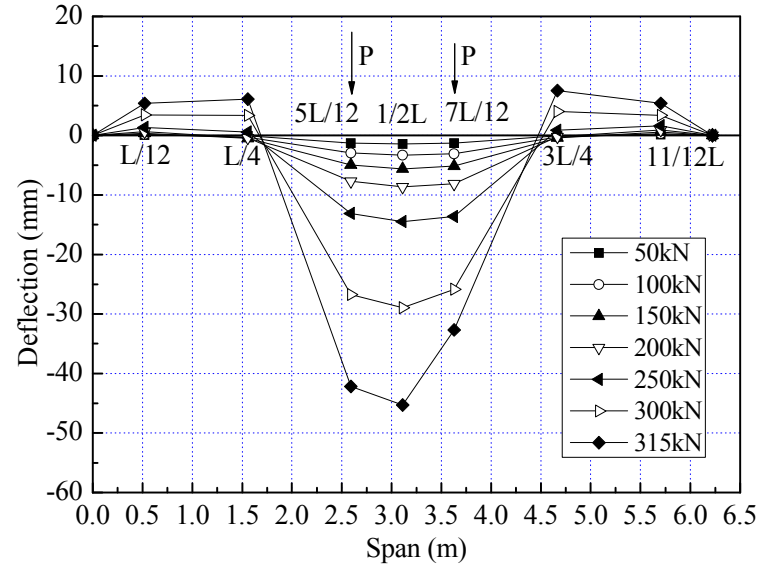

(a) Deflection of the arch

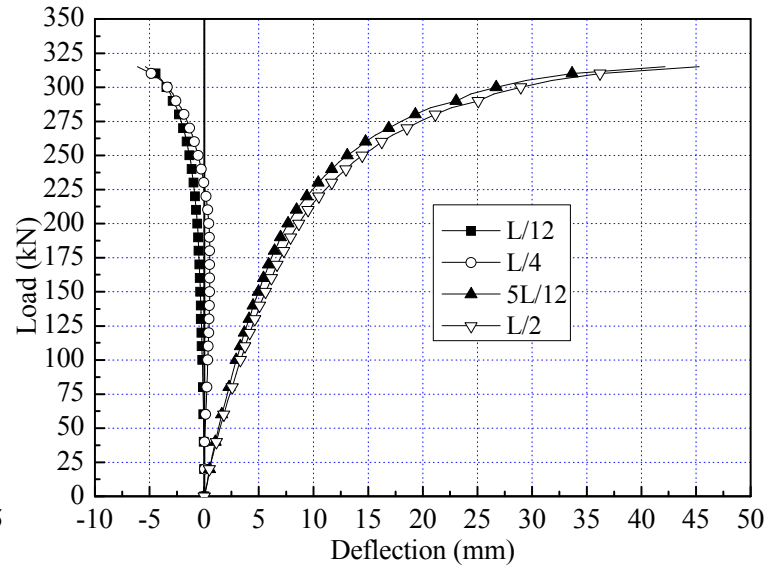

(b) Load-deflection curves

Figure 7. Load-deflection Curves of ACSW-1

The deflections along the arch ACSW-2 at different load levels are plotted in Figure 8(a), which shows that the deflection of the arch is generally asymmetric under the loading. Figure 8(b) shows the load versus deflection response. The deflection increases nonlinearly after the load is over 200 $\mathrm{kN}$. The maximum deflection occurred at $2 / 3$ of the span and amounted to $52.3 \mathrm{~mm}$ at the ultimate load of $280 \mathrm{kN}$. Comparison between Figures 7 and 8 shows that the ultimate load-carrying capacity of ACSW-1 is higher than that of ACSW-2. 


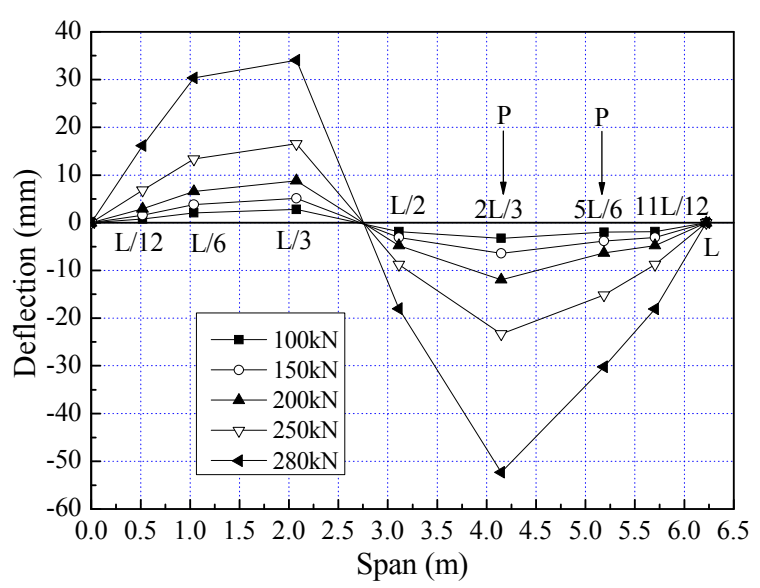

(a) Deflection along the arch

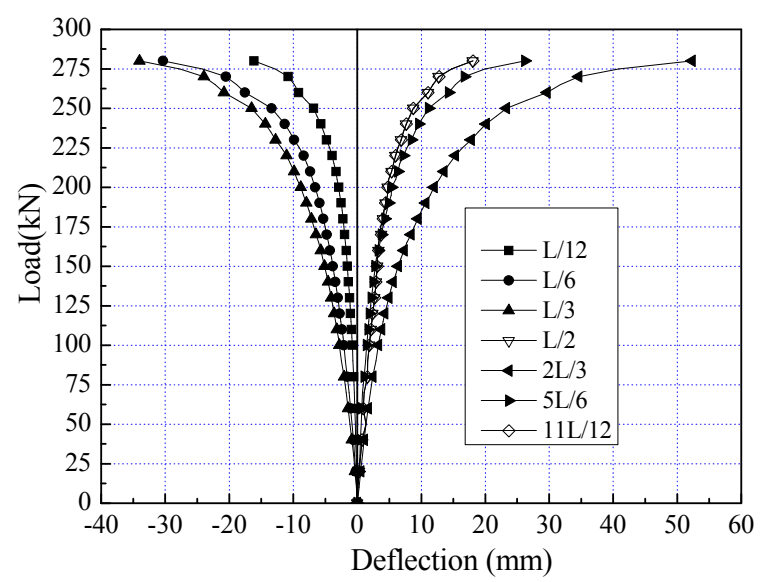

(b) Load-deflection curves

Figure 8. Load-deflection Curves of ACSW-2

Figure 9 shows the deflection distribution of ACSW-3 at specified loading steps. From the beginning, the lateral deflection is much larger than the vertical deflection although the total vertical load $(5 P)$ is 50 times of the lateral load $(P / 10)$, indicating that the in-plane stiffness of the arch is significantly larger than the out-of-plane one.

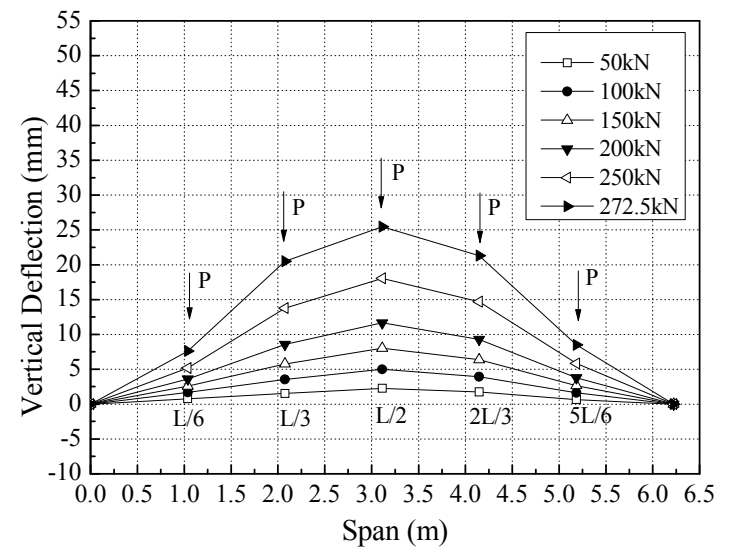

(a) Vertical deflection

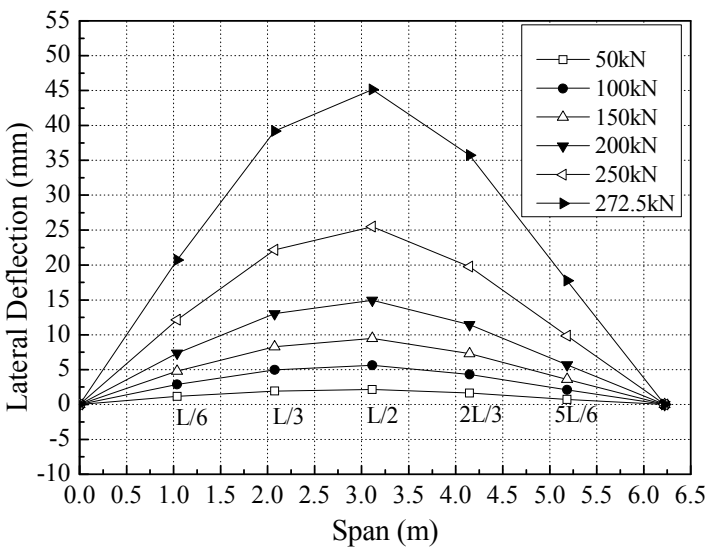

(b) Lateral deflection

Figure 9. Vertical and Lateral Deflection Curves of ACSW-3

The load-deflection relationship of ACSW-3 is shown in Figure 10. The slope of the curve in Figure 10 (a) is much larger than the curve in Figure 10(b). Loads refer to the vertical load $P$. The lateral deflection has little effect on the vertical one because the interaction between the out-of-plane and in-plane deflections is not obvious at the beginning. When the lateral load increases to some extent (about $P=170 \mathrm{kN}$ ), the increment of the in-plane and out-of-plane deflections develop rapidly, mostly at the midspan section. The lateral deflection is larger than the vertical deflection in the subsequent loading steps. Therefore, the failure mode of the arch is controlled by the lateral deformation. After $P=250 \mathrm{kN}$, the load vs. vertical deflection enters the nonlinear stage and reaches the ultimate load at $P=272.5 \mathrm{kN}$. Both the out-of-plane and in-plane deflections show a tendency to become fairly large as the vertical load increases and the collapse exhibits a complicated spatial behavior. 


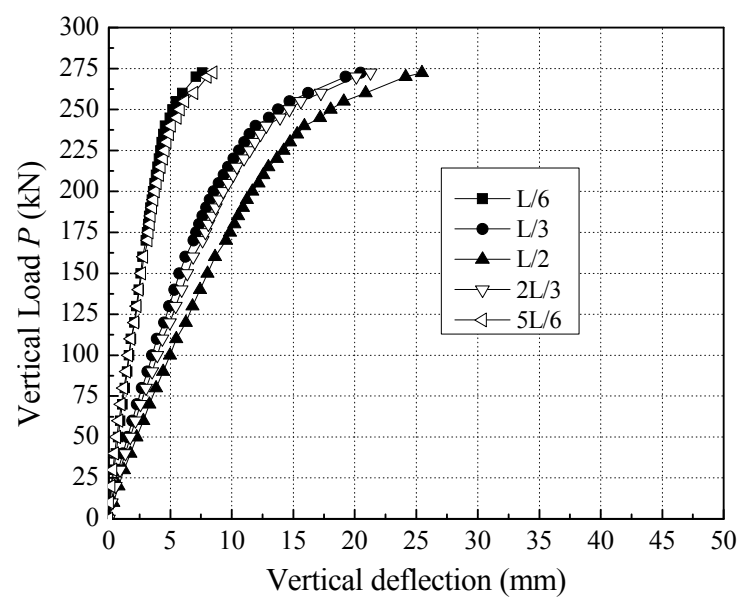

(a) Vertical deflection

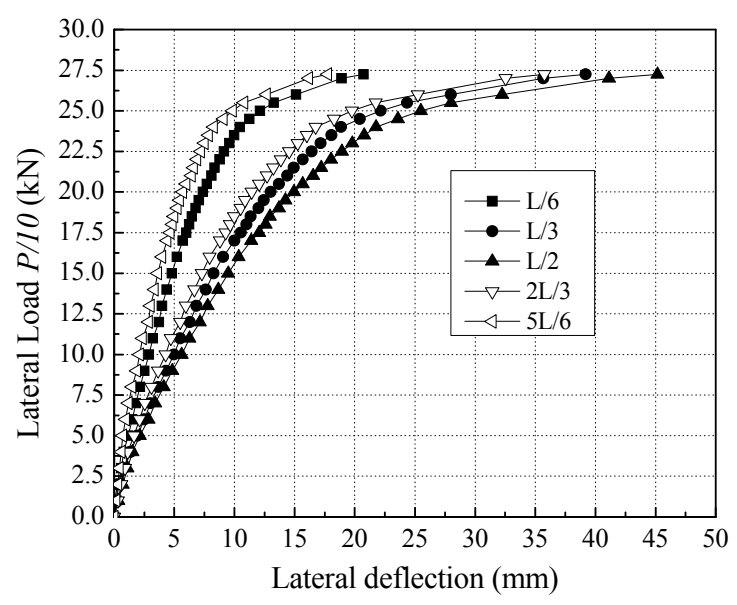

(b) Lateral deflection

Figure 10. Load-deflection Curves of ACSW-3

\subsection{Strain Responses}

\subsubsection{Strain in Chords}

The longitudinal strain distribution of the chords was measured by strain gauges (points 1 and 4 in Figure 3) on the top and bottom chords of ACSW-1 and ACSW-2. The results of ACSW-1 at various testing stages are plotted in Figure 11, in which the positive value denotes tension, negative value denotes compression, and the dotted line refers to the yield strain of steel $(1626 \mu \varepsilon)$. The strain distribution in the arch is nearly symmetric about the midspan, which confirms that the arch is essentially loaded symmetrically at each step with little eccentricity. At the top chord, the strains at the quarter span and springings increase rapidly after the load reaches $200 \mathrm{kN}$, and then exceed the yield strain when failure occurs, whereas other portions remain below the yield strain for all cases. The strain of the bottom chord is larger than that of the top chord, and the bottom chord yields over a large range after the loading reaches $250 \mathrm{kN}$, as shown in Figure 11(b). The strain of the chords develops quickly after the yielding occurs at the quarter spans, which indicates that the yielding of the tube members is the primary cause of the failure of the CFST-CSW arch.

The longitudinal strains of the arch chords for ACSW-2 are illustrated in Figure 12. Strains of many cross-sections of the tubes have reached the yield strain under the ultimate loading. The strain of the top chord develops rapidly after load of $200 \mathrm{kN}$, with the maximum values in tension and compression located at spans $\mathrm{L} / 4$ and $3 \mathrm{~L} / 4$, respectively. The maximum values in compression and tension of the bottom chord are located at spans $\mathrm{L} / 3$ and $2 \mathrm{~L} / 3$, respectively. For both top and bottom chords, the largest strains occur at the springings. 


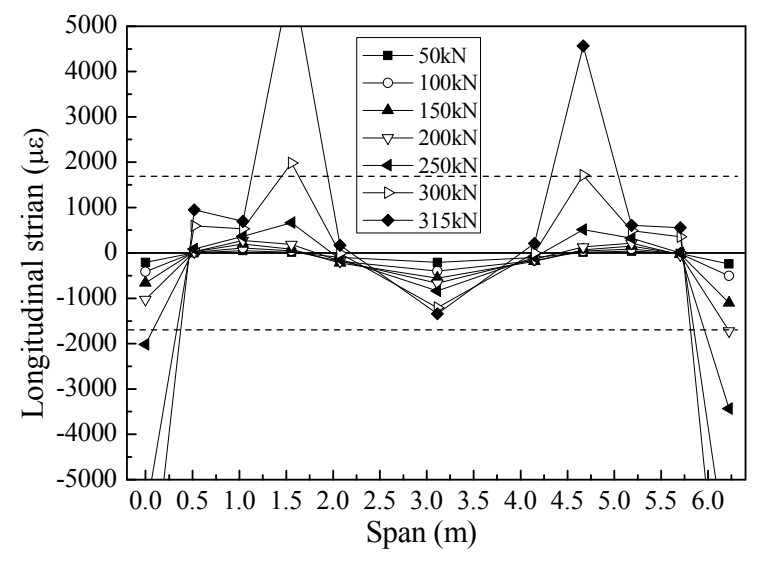

(a) Top chord (point 1)

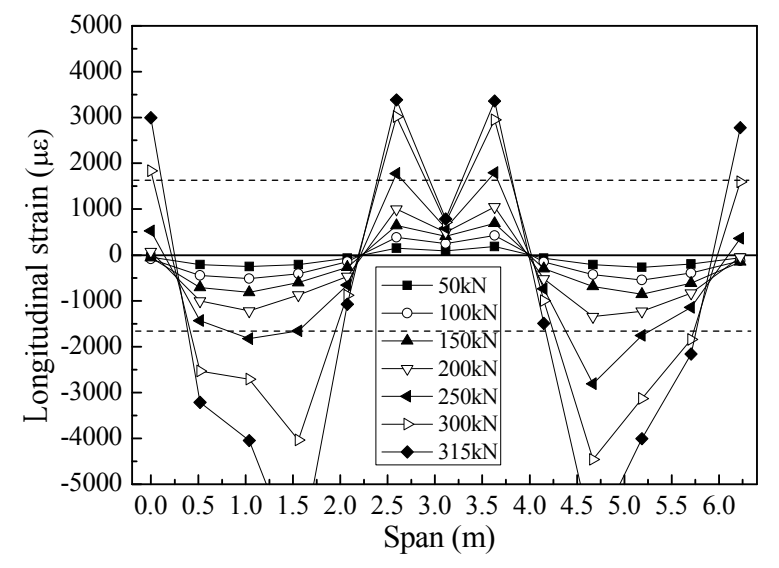

(b) Bottom chord (point 4)

Figure 11. Distribution of Strain in Chords of ACSW-1

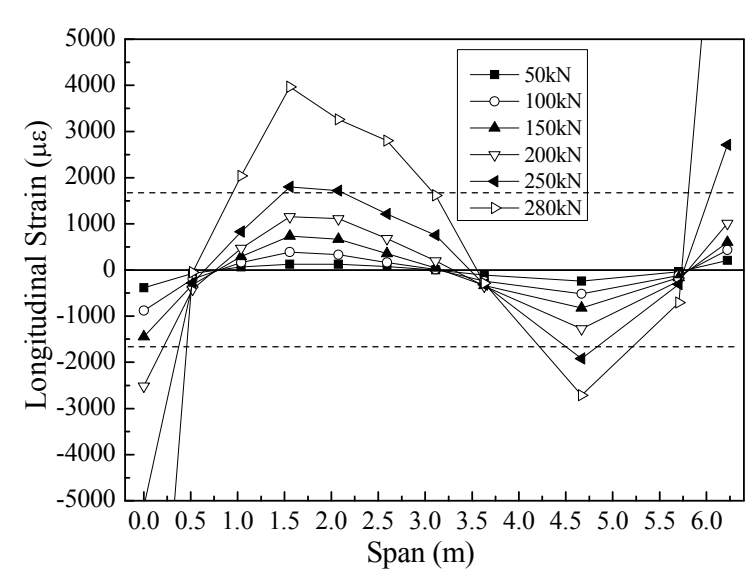

(a) Top chord (point 1)

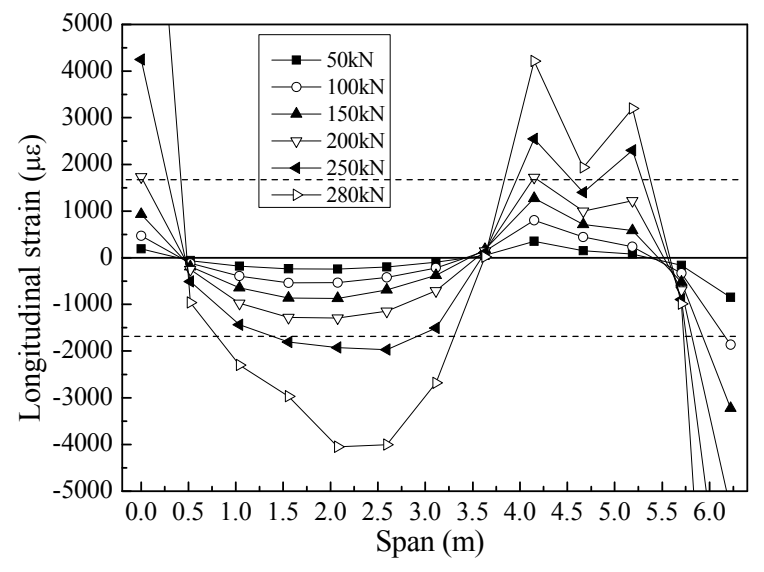

(b) Bottom chord (point 4)

Figure 12. Distribution of Strain in Chords of ACSW-2

For ACSW-3, the longitudinal strain distribution of the chords are illustrated in Figures 13 and 14. The strain distribution of the arch is almost symmetrical for most loading steps before reaching the failure load. During the test, most sections of the arch are in compression, except at the mid-span of the bottom chord (point 4).

The relationship between the longitudinal strain and applied load is plotted in Figure 15. The curves experience linear and nonlinear phases nearly in the same way. When the load increases to $250 \mathrm{kN}$, the strain in the bottom chord reverses direction, indicating the occurrence of stress redistribution. 


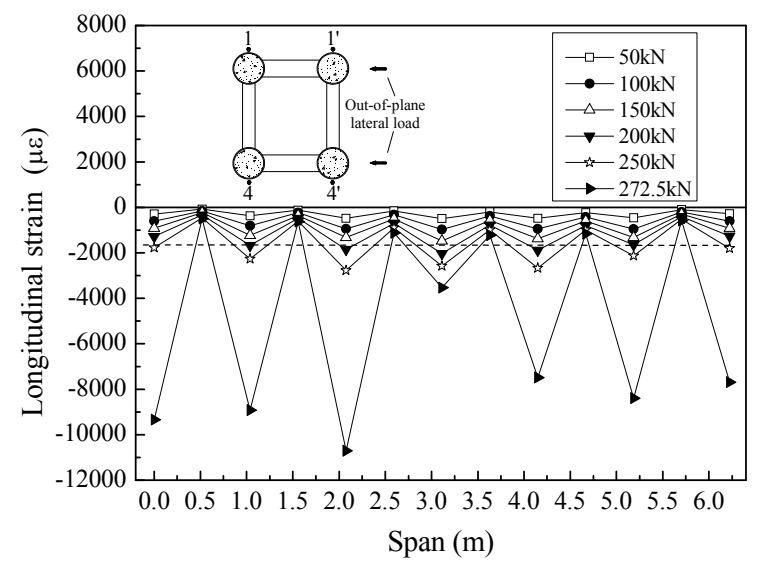

(a) Top chord (point 1)

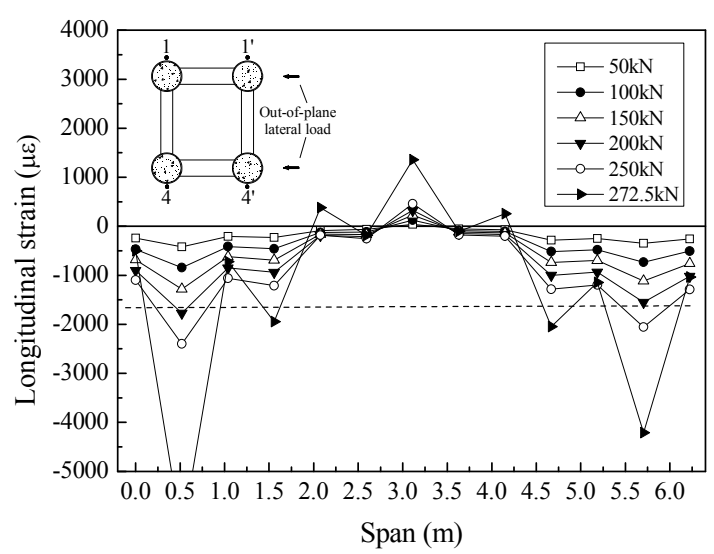

(b) Bottom chord (point 4)

Figure 13. Distribution of Longitudinal Strain at the Chords (Points 1 and 4)

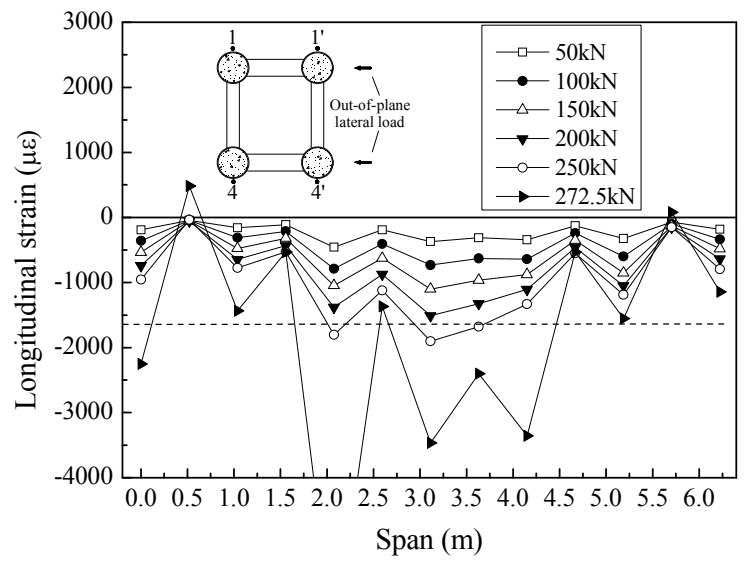

(a) Top chord (point 1')

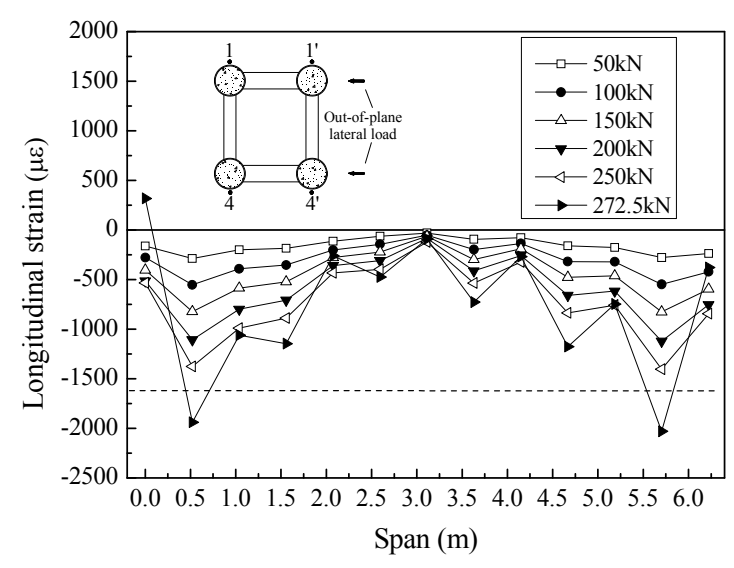

(b) Bottom chord (point 4')

Figure 14. Distribution of Longitudinal Strain at the Chords (Points 1' and 4')

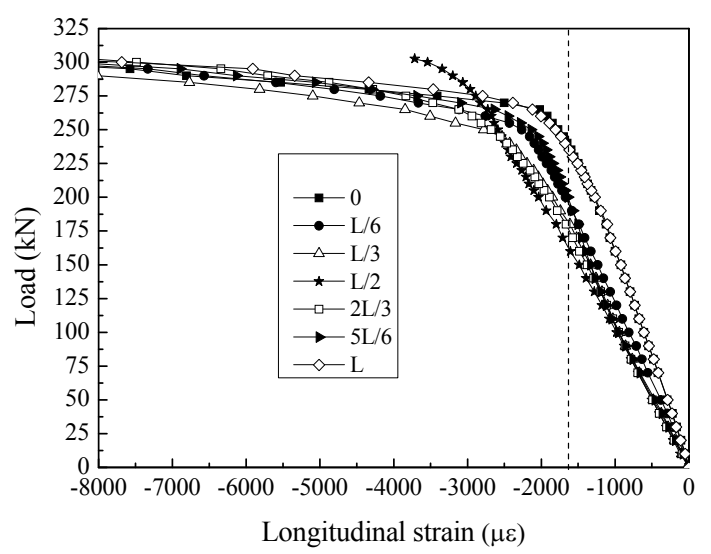

(a) Top chord (point 1)

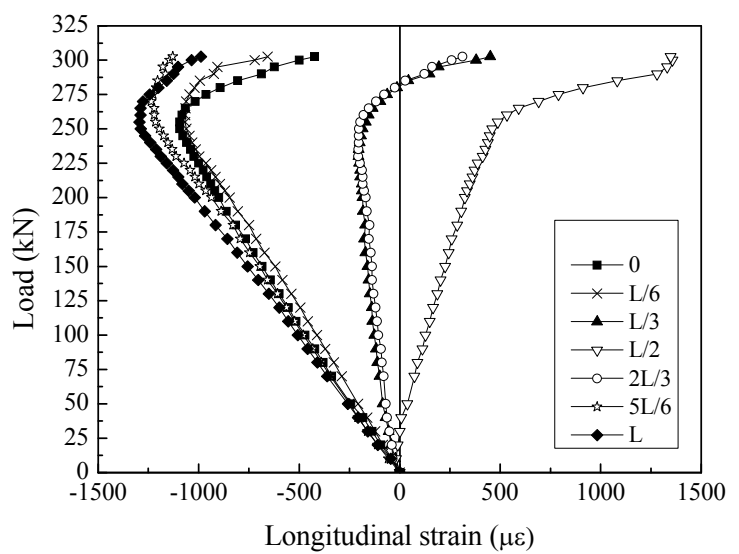

(b) Bottom chord (point 4)

Figure 15. Load-strain Curves of the Chords (Points 1 and 4) 


\subsubsection{Strain in Corrugated Steel Webs}

\section{Longitudinal Strain}

The longitudinal strains along the depth of the cross-sections were measured by strain gauges attached to the CFSTs and CSWs (points $1,2,5,7,8,9,6,3$, and 4 as shown in Figure 3). The results at two critical sections of ACSW-1 and ACSW-2 (i.e., left springing section and L/4 section) are shown in Figures 16 and 17, respectively. The longitudinal strains have an abrupt change at the junction of the CFST chords and CSWs, and the strains of the webs are generally much smaller than those of the chords, which is similar to the strain distribution in CFST-CSW girders [18] and columns [19]. Moreover, the result indicates that the contribution of the corrugated web to the compression and moment carrying capacity of the arch is lower than that of the CFST chord, and the ultimate load heavily depends on the chord yielding.

The longitudinal strains in the web at left springing and L/4 sections increase significantly after the applied load exceeds $250 \mathrm{kN}$, indicating the occurrence of the buckling in the web. This is because the yielding of the chord tubes results in the redistribution of the internal forces.

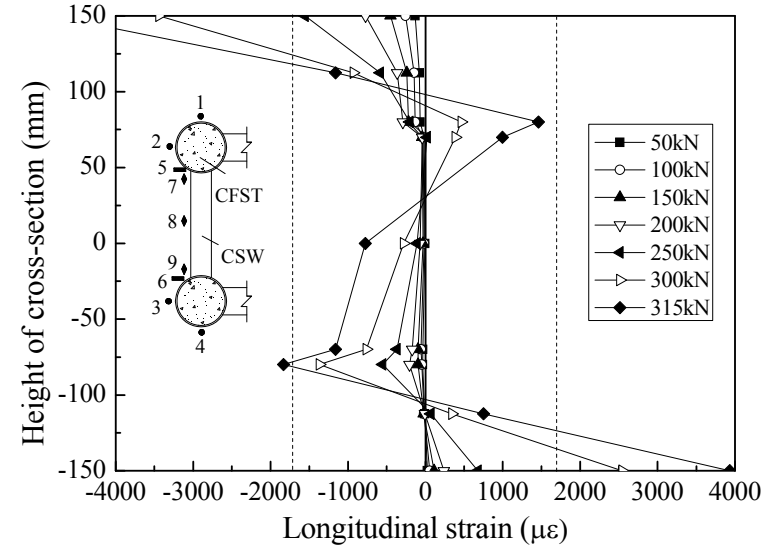

(a) At left springing

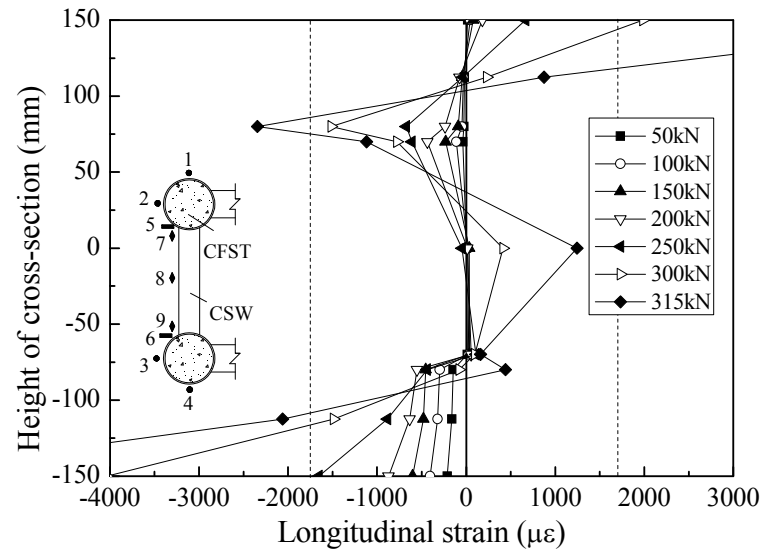

(b) At L/4 section

Figure 16. Distribution of Longitudinal Strain along the Depth of ACSW-1

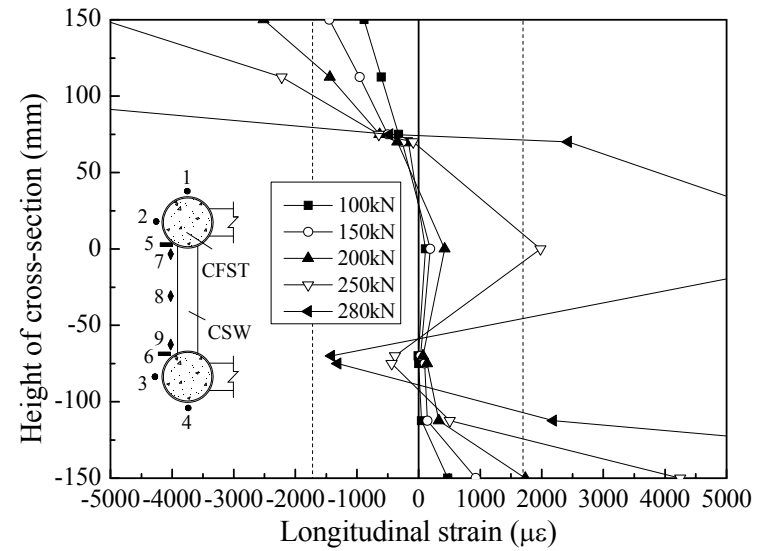

(a) At left springing

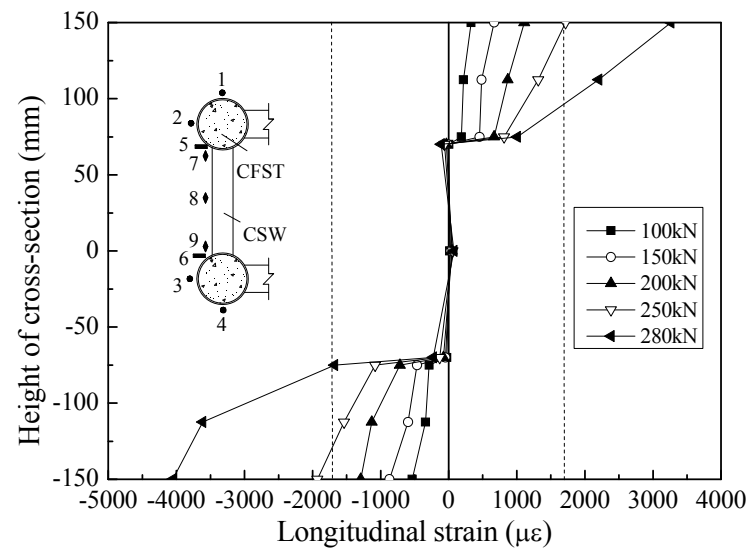

(b) At L/4 section

Figure 17. Distribution of Longitudinal Strain along the Depth of ACSW-2 
Figures 18 and 19 exhibit the longitudinal strain distribution along the depth of the two critical cross-sections (left springing section and L/3 section) of ACSW-3. Similarly, the longitudinal strains of the CSWs are quite small before yielding. The internal forces in the section are redistributed when the steel tubes in the bottom and top chords yield, causing the strains of the CSWs at the springing to increase beyond the yielding strain. However, the strains of the CSWs at other sections are still within their elastic strain even under the failure load, which demonstrates that the contribution of the corrugated web to the ultimate load capacity of the arch under the in-plane and out-of-plane loadings is negligible, and the ultimate load mainly relies on the chord yielding. In addition, Figures 18 and 19 show that the longitudinal strains along the depth of cross sections do not satisfy the plane section assumption.

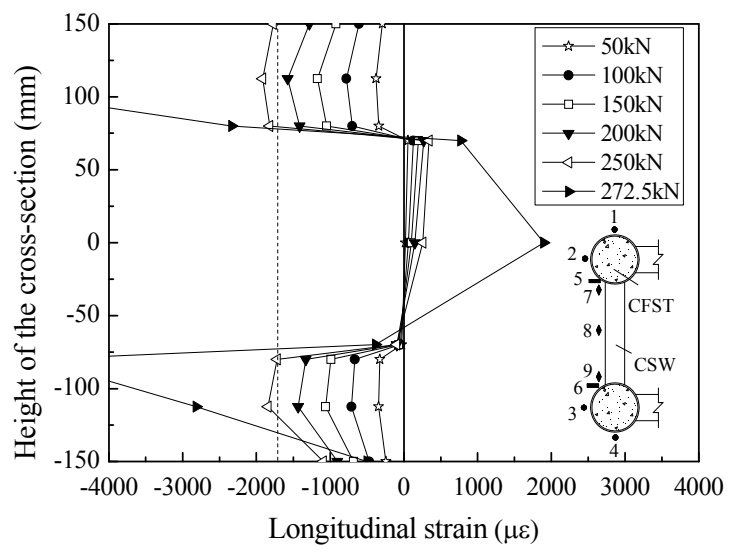

(a) At left springing

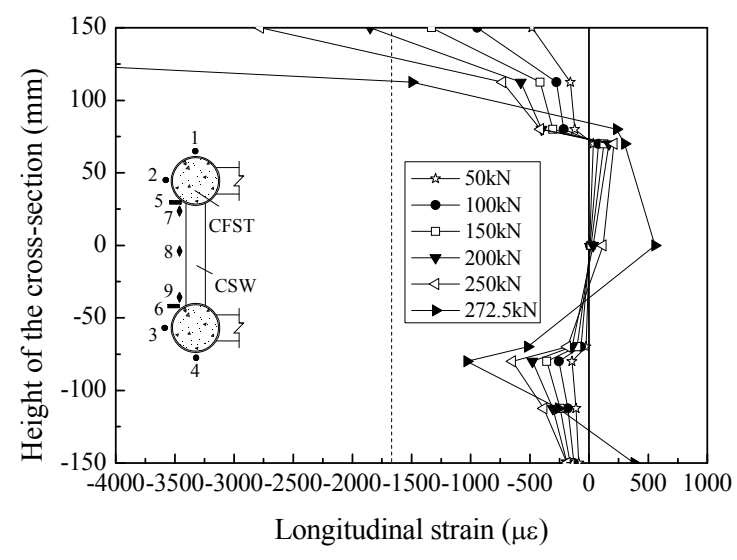

(b) At L/3 section

Figure 18. Distribution of Longitudinal Strain along the Depth of ACSW-3 without the Lateral Load

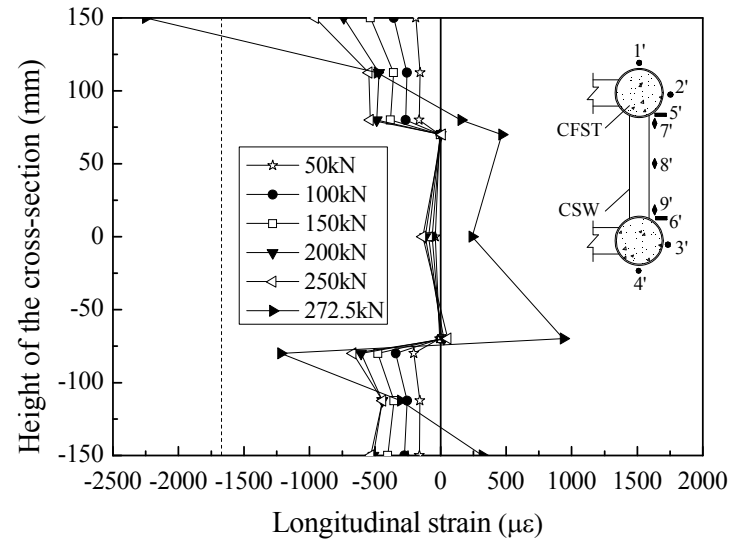

(a) At left springing

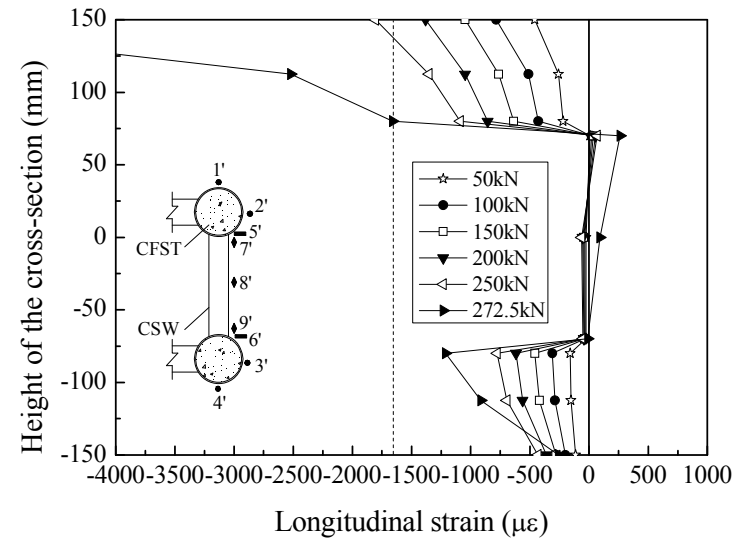

(b) At L/3 section

Figure 19. Distribution of Longitudinal Strain along the Depth of ACSW-3 subjected to the Lateral Load

\section{Shear Strain}

The shear strains in the CSWs were obtained from the measurement of the strain rosettes installed on the webs.

The shear strains at mid-height of the web (point 8 in Figure 3) located at left springing versus the loading applied are plotted in Figure 20. The three arches have similar shear strains at the elastic stage. After chord yielding occurs, the webs experience very large shear strains. 


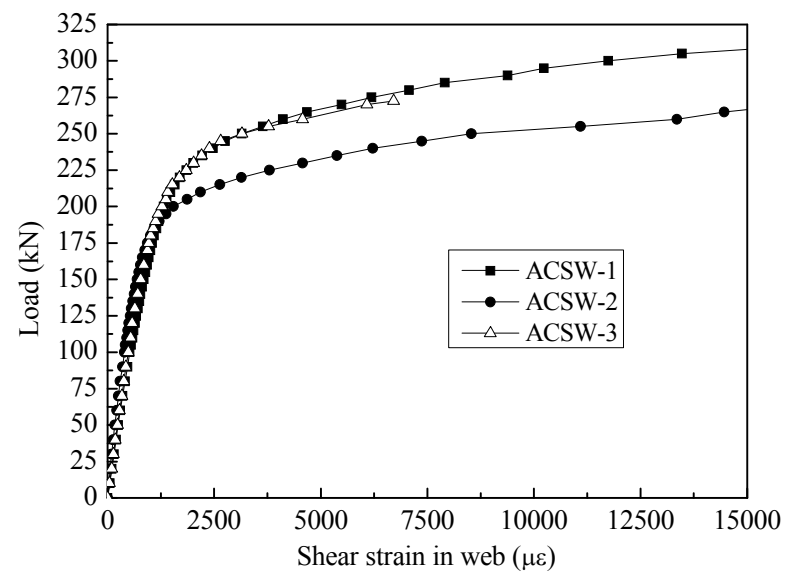

Figure 20. Load-shear Strain Curves at the Left Springing of the Arches (Point 8)

Figure 21 shows the shear strain distribution along the web height of the three arch models. In the elastic range, the shear strains along the height of the web are similar. In the plastic stage, the shear strain at the mid-height of the web increases significantly. Reminding that the webs have low longitudinal strains, one can conclude that the bending moment and compression of the section are mainly resisted by the top and bottom chords, and the shear forces are mainly carried by the CSWs. The top and bottom chords can work together because of the high shear resistance of the CSWs, which is one of main characteristics of the new CSFT-CSW structure.

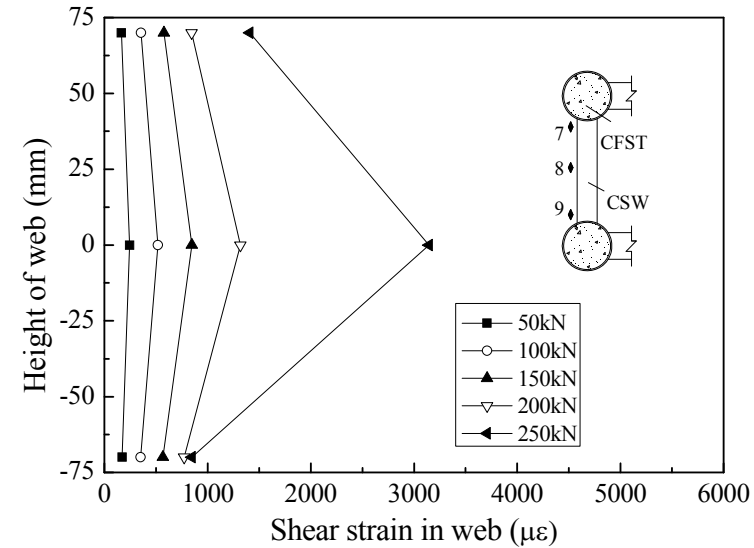

(a) ACSW-1

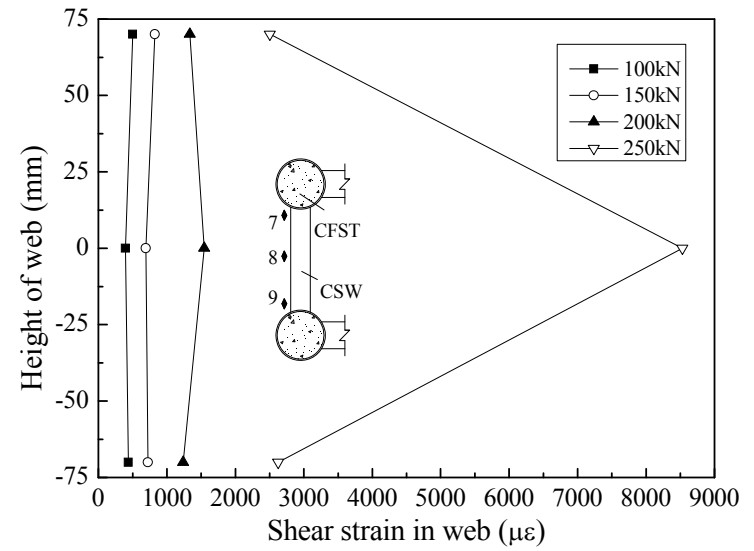

(b) ACSW-2

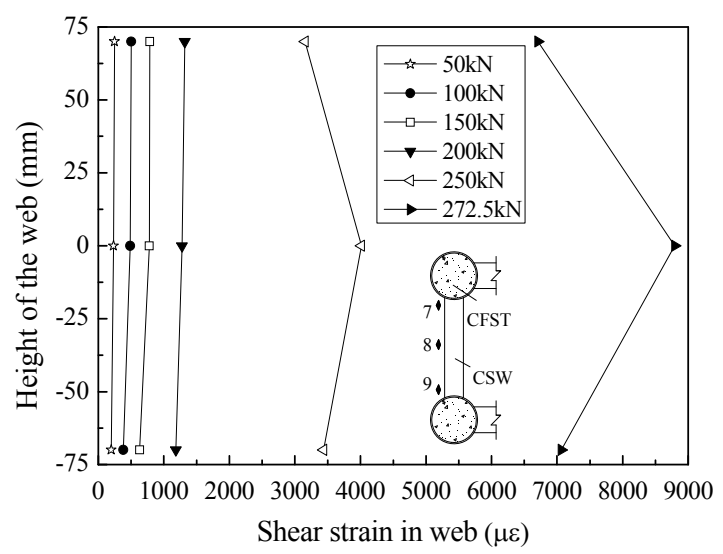

(c) ACSW-3

Figure 21. Distribution of Shear Strain along the Height of Web at Left Springing 


\section{COMPARISON BETWEEN CFST-CSW ARCH AND RC-CSW ARCH}

Most arch bridges employ CFST truss ribs or RC components. The previous analysis shows that the proposed new CFST-CSW arches can fully utilize the merits of the high compression strength of CFST chords and the enhanced shear resistance of CSWs, and consequently develop a significant plastic deformation. Researchers have also investigated the alternatives to heavy-weight concrete arches. For example, Huang [20] carried out tests on a RC arch model with CSW (briefly as $\mathrm{RC}-\mathrm{CSW}$ arch), which aimed to reduce the weight of RC webs. This RC arch model was designed with similar load-carrying capacity and safety margin as the ACSW-2. Therefore, they have similar span, rise, rise-span ratio, cross-section, and material characteristics. The loading steps and sensor installation of the RC-CSW arch are similar to those of ACSW-2. The two arch models are compared in the following sections to further verify the effectiveness of the CFST-CSW arches.

\subsection{Experiment of the RC-CSW Arch [20]}

The RC-CSW arch model [20] is shown in Figure 22. The arch has a span of $6.252 \mathrm{~m}$ and a rise of $1.557 \mathrm{~m}$. The top and bottom flanges were made of reinforced concrete and connected by two 2.8 $\mathrm{mm}$ thick CSWs. The CSWs used in the $\mathrm{RC}$ arch were a little bit thicker than those used in the CFST arch to avoid local buckling of the CSWs as the RC arch was much heavier. The average yield stress of the steel was $380 \mathrm{MPa}$, and the average ultimate strength was $500 \mathrm{MPa}$. The tested Young's elastic modulus of steel was $206 \mathrm{GPa}$. The average ultimate strength of concrete was 41 $\mathrm{MPa}$ with the Young's modulus of $30 \mathrm{GPa}$. The arch model was subjected to asymmetrical loadings at $2 \mathrm{~L} / 3$ and $5 \mathrm{~L} / 6$ sections, the same loading condition as ACSW-2. In order to compare the effectiveness of use of material for the two types of structure, the equivalent areas as steel section according to the principle of composite cross-section equivalent stiffness are compared, as shown in Table 1. For brevity, only the load-deflection and failure mode of the two models are compared.

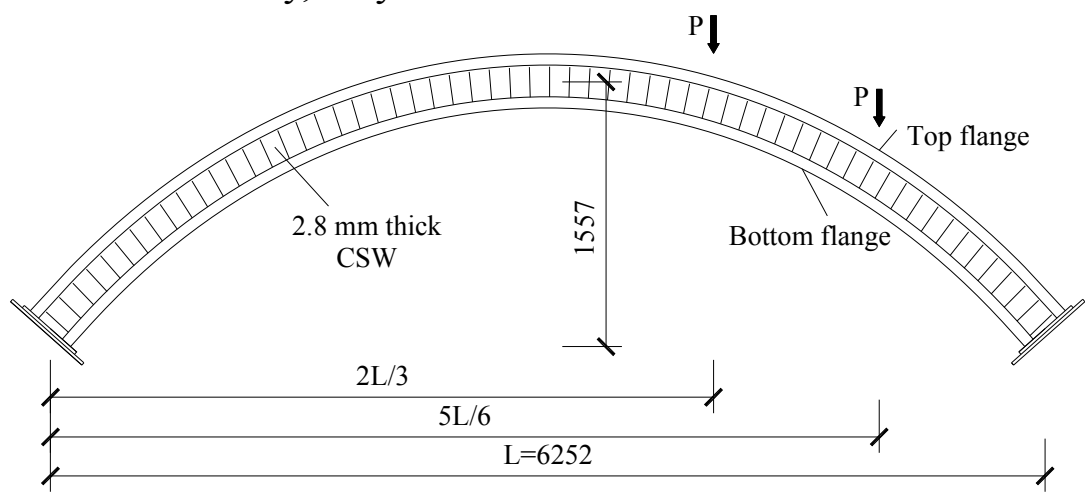

(a) Elevation

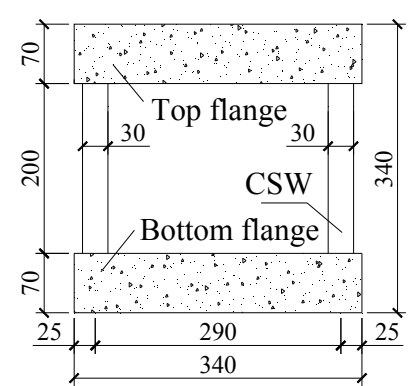

(b) Cross-section

Figure 22. The RC Arch with CSW (Unit: mm)

\subsection{Ultimate Load and Ductility}

The load-deflection curves at the loading position ( $2 \mathrm{~L} / 3$ section) of the two models are compared in Figure 23. The ultimate loads of the two arches are $304 \mathrm{kN}$ for RC-CSW arch and $280 \mathrm{kN}$ for ACSW-2. The RC-CSW arch has the ultimate load capacity 9\% larger than ACSW-2 but its equivalent area as steel section and mass per unit length is more than double. Therefore, it may be concluded that the CFST-CSW arch has a relatively higher ultimate load-carrying capacity because the resistance of the RC-CSW arch is limited by the development of cracking, which results in the formation of plastic hinges. Moreover, the deflection of the RC-CSW arch is only about $70 \%$ of ACSW-2 at the ultimate state, indicating that the CFST-CSW arch has much higher deformation capacity and better ductility than the RC-CSW arch. 


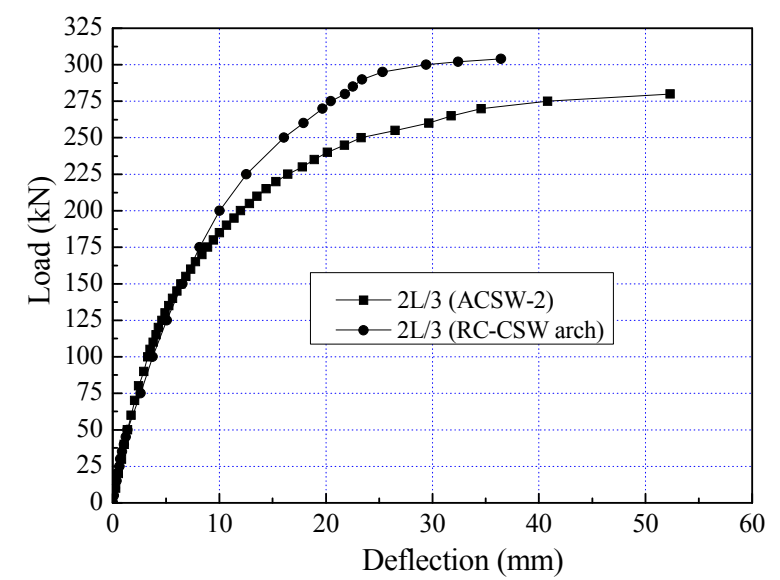

Figure 23. Load-deflection Curves at 2L/3 for Both Arches

Table 1. Comparison of Cross Section Properties and Ultimate Load of ACSW-2 and RC-CSW Arch

\begin{tabular}{ccccc}
\hline Item & $\begin{array}{c}\text { Equivalent area } \\
\text { as steel section } \\
\left(\mathrm{m}^{2}\right)\end{array}$ & $\begin{array}{c}\text { Mass per unit } \\
\text { length } \\
(\mathrm{kg} / \mathrm{m})\end{array}$ & $\begin{array}{c}\text { Maximum } \\
\text { deflection at } \\
2 \mathrm{~L} / 3 \\
(\mathrm{~mm})\end{array}$ & $\begin{array}{c}\text { Ultimate } \\
\text { load } \\
(\mathrm{kN})\end{array}$ \\
\hline RC-CSW arch & $8.79 \times 10^{-3}$ & 123 & 36.4 & 304 \\
\hline ACSW-2 & $4.35 \times 10^{-3}$ & 56 & 52.3 & 280 \\
\hline $\begin{array}{c}\text { Ratio between the two } \\
\text { arches }\end{array}$ & 2.02 & 2.19 & 0.696 & 1.09 \\
\hline
\end{tabular}

\subsection{Cracking and Failure Mode}

For the RC-CSW arch, extensive cracks occurred at the $2 \mathrm{~L} / 3$ section of the bottom flange under ultimate load as shown in Figure 24(a). Cracks also occurred at L/4 section of the top flange as shown in Figure 24(b). Due to the formation of a plastic hinge around this cracked area, the deflection at this area increased about $10 \mathrm{~mm}$ at nearly constant load level. Failure of the arch was characterized by the yielding of steel reinforcement in the maximum moment region, followed by concrete crushing on the top flange near the loading position. Although the internal force tended to close cracks after unloading, some of the cracks did not close completely due to the large plastic deformation.

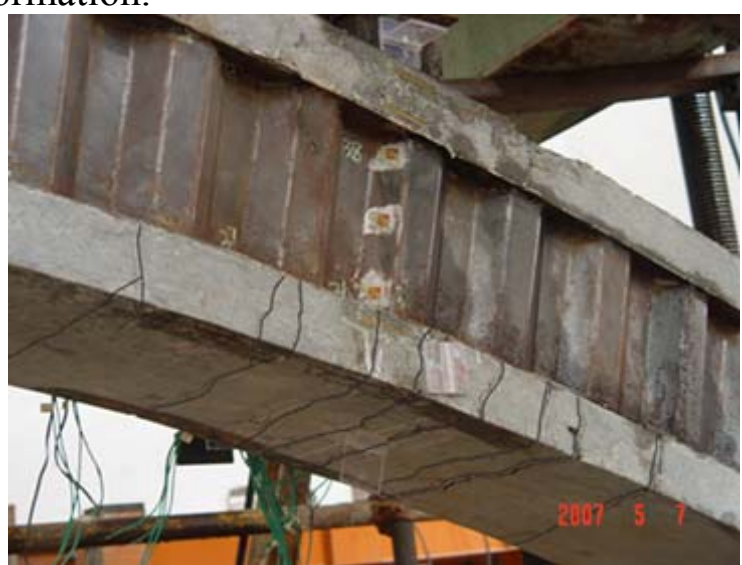

(a) At 2L/3 section (Loading position)

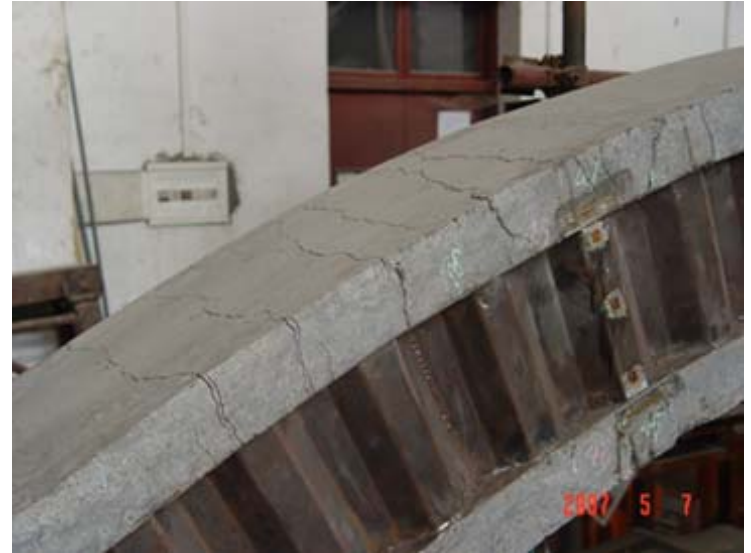

(b) At L/4 section

Figure 24. Failure Mode of the RC-CSW 
Although both arches failed at the $2 \mathrm{~L} / 3$ loading section, no distinct plastic hinges were observed during the experiment of ACSW-2, whereas the RC-CSW arch failed with several plastic hinges. Therefore, the plastic hinge method for calculating ultimate load of RC arch should not be employed in the CFST-CSW arch.

\section{CONCLUSIONS AND DISCUSSIONS}

This paper investigates the ultimate load-carrying capacity of CFST-CSW arches subjected to in-plane and out-of-plane loadings. The deflections and strains under different loadings were measured. The ultimate load and failure mode of the CFST-CSW and RC-CSW arches were compared. Conclusions can be drawn as follows:

1. The ultimate load-carrying capacity of the CFST-CSW arch under the symmetric loading is higher than under the asymmetric one.

2. The arch under in-plane and out-of-plane loadings simultaneously exhibits a larger lateral deflection and lower ultimate load compared with the in-plane loading. The design of such arches needs to give special attention to the out-of-plane stability.

3. Before leading to the buckling of the CSWs, the arches fail after most sections of the chords yield whether or not they are subjected to the symmetric or asymmetric loadings.

4. In CFST-CSW arches, the potential advantages of both the high compression strength of CFST chords and enhanced shear resistance of CSWs are fully utilized.

5. The CFST-CSW arches can sustain large plastic deformation as well as relatively high load carrying capacity. The plastic hinge method for calculating the ultimate load of RC arches may not be suitable for CFST-CSW arches.

In order to develop the design method of CFST-CSW arches, a number of parameters such as cross-section configuration, geometric dimension (including cross-sectional size, span, rise, and so forth), material properties, and loading conditions need to be further studied. Moreover, finite element analysis should be performed to double check the detailed structural behaviours. In addition, simplified methods for the calculation of the ultimate load of CFST-CSW arches should be developed. These merit further investigations.

\section{ACKNOWLEDGMENT}

This research work has been conducted under Grant No. 50778043 of the National Natural Science Foundation of China and Grant No. 2011J05138 of the Natural Science Foundation Project of Fujian Province, China.

\section{REFERENCES}

[1] Zhao, X.L., Han, L.H. and Lu, H., "Concrete-filled Tubular Members and Connections", Taylor \& Francis, UK, 2010.

[2] Zhong, S.T., "The Development of Concrete Filled Steel Tubular Structures in China", Proceeding of 3th International Conference on Concrete Filled Steel Tubular Structures (including Composite Beams) ASCCS, Harbin, China, 1988, pp. 1-7. 
[3] Bradford, M.A., Loh, H.Y. and Uy, B., "Slenderness Limits for Filled Circular Steel Tubes" Journal of Constructional Steel Research, 2002, Vol. 58, No. 2, pp. 243-252.

[4] Roeder, C.W., Lehman, D.E. and Bishop, E., "Strength and Stiffness of Circular Concrete-filled Tubes", Journal of Structural Engineering, ASCE, 2010, Vol. 136, No. 12, pp. 1545-1553.

[5] Pi, Y.L., Liu, C.Y., Bradford, M.A. and Zhang, S.M., "In-plane Strength of Concrete-filled Steel Tubular Circular Arches", Journal of Constructional Steel Research, 2012, Vol. 69, No. 1, pp. 77-94.

[6] Bode, H., "Columns of Steel Tubular Sections Filled with Concrete: Design and Application", Acier-Stahl-Steel, 1976, 11-12, pp. 388-393.

[7] Chen, B.C. and Wang, T.L., "Overview of Concrete Filled Steel Tube Arch Bridges in China", Practice Periodical on Structural Design and Construction, ASCE, 2009, Vol. 14, No. 2, pp. 70-80.

[8] Mu, T.M., Fan, B.K., Zheng, X.F., Zheng, Y.H. and Xie, B.Z., "Wuxia Yangtze-River Bridge in Wushan, China", Proceeding of 5th International Conference on Arch Bridge, Madeira, Portugal, 2007, pp. 911-918.

[9] Ou, Z.J., Chen, B.C., Hsieh, K.H., Halling, M.W. and Barr, P.J., "Experimental and Analytical Investigation of Concrete Filled Steel Tubular Columns", Journal of Structural Engineering, ACSE, 2011, Vol. 137, No. 6, pp. 635-645.

[10] Chen, B.C. and Huang, W.J., "Experimental Research on Ultimate Load Carrying Capacity of Truss Girders Made with Circular Tubes", Journal of Building Structures, 2007, Vol. 28, No. 3, pp. 31-36 (in Chinese).

[11] Elgaaly, M., Hamilton, R.W. and Seshadri, A., "Shear Strength of Beams with Corrugated Webs", Journal of Structural Engineering, ASCE, 1996, Vol. 122, No. 4, pp. 390-398.

[12] Johnson, R.P. and Cafolla, J., "Corrugated Webs in Plate Girders for Bridges", Proceedings of the Institution of Civil Engineers, Structures and buildings, 1997, Vol. 122, No. 2, pp. 157-164.

[13] Chan, C.L., Khalid, Y.A., Sahari, B.B. and Hamouda, A.M.S., "Finite Element Analysis of Corrugated Web Beams under Bending", Journal of Constructional Steel Research, 2002, Vol. 58, pp.1391-1406.

[14] Li, H.J., Ye, J.S., Wan, S., Qian, P.S. and Jiang, Z.G., "Experimental Research on Prestressed Concrete Box Girder with Corrugated Steel Webs", China Journal of Highway and Transport, 2004, Vol. 17, No. 4, pp. 31-36 (in Chinese).

[15] Brozzetti, J., "Design Development of Steel-concrete Composite Bridges in France", Journal of Constructional Steel Research, 2000, Vol. 55, No. 1, pp. 229-243.

[16] Chen, B.C. and Wang, Y.Y., "Concrete Arch with Corrugated Web-A New Approach for Super-long Span Arch Bridge", Proceeding of 5th International Conference on Arch Bridge, Madeira, Portugal, 2007, pp. 807-814.

[17] Wei, J.G., Huang, Q.W. and Chen, B.C., "Trial Design of Arch Bridge of Composite Box Section with Steel Web-concrete Flange", Frontiers of Architecture Civil Engineering in China, 2010, Vol. 4, No. 3, pp. 370-375.

[18] Gao, J. and Chen, B.C., "Experimental Research on Beams with Tubular Chords and Corrugated Steel Web", Proceeding of 12th International Symposium on Tubular Structures, Shanghai, China, 2008, pp. 563-570.

[19] Gao, J., and Chen, B.C., "Experimental Research on Concrete Filled Steel Tubular Columns with Trapezoidally Corrugated Steel Webs", Proceeding of 10th International Symposium on Structural Engineering for Young Experts, Changsha, China, 2008, pp. 611-616.

[20] Huang, Q.W., "Research on In-plane Mechanical Behaviors of Concrete Arch with Steel Webs", PhD Thesis, Fuzhou University, China, 2009. (in Chinese) 